\title{
DRAFT FINAL REPORT
}

FHWA/IN/JTRP-2001/10-I-1

\section{FATIGUE BEHAVIOR OF BEAM DIAPHRAGM CONNECTIONS WITH INTERMITTENT FILLET WELDS (PART I): VOLUME 1 - FIELD EVALUATION}

\author{
By \\ Tammy L. Canna \\ Graduate Research Assistant \\ and \\ Mark D. Bowman \\ Professor of Civil Engineering \\ Purdue University \\ School of Civil Engineering \\ Joint Transportation Research Project \\ Project No: C-36-56KK \\ File No: $7-4-37$ \\ Prepared in Cooperation with the \\ Indiana Department of Transportation and \\ the U.S. Department of Transportation \\ Federal Highway Administration
}

The contents of this report reflect the views of the authors who are responsible for the facts and the accuracy of the data presented herein. The contents do not necessarily reflect the official views or policies of the Federal Highway Administration and the Indiana Department of Transportation. This report does not constitute a standard, specification, or regulation.

\author{
Purdue University \\ West Lafayette, IN 47907 \\ July 2001
}


TECHNICAL REPORT STANDARD TITLE PAGE

\begin{tabular}{|c|c|c|c|c|}
\hline $\begin{array}{l}\text { 1. Report No. } \\
\text { FHWA/IN/JTRP-2001/10- }\end{array}$ & \multicolumn{2}{|c|}{ 2. Government Accession No. } & \multicolumn{2}{|c|}{ 3. Recipient's Catalog No. } \\
\hline \multirow{2}{*}{\multicolumn{3}{|c|}{$\begin{array}{l}\text { 4. Title and Subtitle } \\
\text { Fatigue Behavior of Beam Diaphragm Connections With Intermittent Fille } \\
\text { I, Volume 1, Field Evaluation }\end{array}$}} & \multirow{2}{*}{\multicolumn{2}{|c|}{$\begin{array}{l}\text { 5. Report Date } \\
\text { July } 2001\end{array}$}} \\
\hline & & & & \\
\hline \multicolumn{3}{|c|}{$\begin{array}{l}\text { 7. Author(s) } \\
\text { Tammy L. Canna and Mark D. Bowman }\end{array}$} & \multicolumn{2}{|c|}{$\begin{array}{l}\text { 8. Performing Organization Report No. } \\
\text { FHWA/IN/JTRP-2001/10-I-1 }\end{array}$} \\
\hline \multirow{2}{*}{\multicolumn{2}{|c|}{$\begin{array}{l}\text { 9. Performing Organization Name and Address } \\
\text { Joint Transportation Research Program } \\
1284 \text { Civil Engineering Building } \\
\text { Purdue University } \\
\text { West Lafayette, Indiana } 47907-1284\end{array}$}} & & \multicolumn{2}{|l|}{ 10. Work Unit No. } \\
\hline & & & \multicolumn{2}{|c|}{$\begin{array}{l}\text { 11. Contract or Grant No. } \\
\text { SPR-2113 }\end{array}$} \\
\hline \multirow{2}{*}{\multicolumn{3}{|c|}{$\begin{array}{l}\text { 12. Sponsoring Agency Name and Address } \\
\text { Indiana Department of Transportation } \\
\text { State Office Building } \\
100 \text { North Senate Avenue } \\
\text { Indianapolis. IN } 46204\end{array}$}} & \multicolumn{2}{|c|}{$\begin{array}{l}\text { 13. Type of Report and Period Covered } \\
\text { Draft Final Report }\end{array}$} \\
\hline & & & \multicolumn{2}{|c|}{ 14. Sponsoring Agency Code } \\
\hline \multicolumn{5}{|c|}{$\begin{array}{l}\text { 15. Supplementary Notes } \\
\text { Prepared in cooperation with the Indiana Department of Transportation and Federal Highway Administration. }\end{array}$} \\
\hline \multicolumn{5}{|l|}{$\begin{array}{l}\text { 16. Abstract } \\
\text { This report is the first of a ty } \\
\text { undertaken to evaluate the } b \\
\text { primary beams and girders. } \\
\text { connection. The seriousness } \\
\text { were assessed. Inspection an } \\
\text { part of the research effort. T } \\
\text { connections. The importanc }\end{array}$} \\
\hline \multicolumn{5}{|c|}{ The titles of the three volumes (Report Number in parentheses) are listed below: } \\
\hline \multirow{2}{*}{\multicolumn{5}{|c|}{$\begin{array}{l}\text { Part I, Volume 1: Field Evaluation (FHWA/IN/JTRP-2001/10 - I-1) } \\
\text { Part I, Volume 2: Laboratory Fatigue Evaluation (FHWA/IN/JTRP-2001/10-I-2) } \\
\text { Part II: Evaluation of Blue River Bridge Fracture (FHWA/IN/JTRP-2001/10-II) }\end{array}$}} \\
\hline & & & & \\
\hline \multicolumn{2}{|c|}{$\begin{array}{l}\text { 17. Key Words } \\
\text { bridge, connection, diaphragm, welded connection, fatigue, } \\
\text { cracking, secondary bending, displacement-induced } \\
\text { cracking, load-testing, inspection, retrofit, repair }\end{array}$} & \multicolumn{3}{|c|}{$\begin{array}{l}\text { 18. Distribution Statement } \\
\text { No restrictions. This document is available to the public through the } \\
\text { National Technical Information Service, Springfield, VA } 22161\end{array}$} \\
\hline 19. Security Classif. (of this report) & \multicolumn{2}{|c|}{$\begin{array}{c}\text { 20. Security Classif. (of this page) } \\
\text { Unclassified }\end{array}$} & 21. No. of Pages & 22. Price \\
\hline
\end{tabular}


TABLE OF CONTENTS

Page

LIST OF TABLES $\mathrm{V}$

LIST OF FIGURES $\ldots \ldots \ldots \ldots \ldots \ldots \ldots \ldots \ldots \ldots \ldots \ldots \ldots \ldots \ldots \ldots$ vii

CHAPTER 1 - INTRODUCTION $\ldots \ldots \ldots \ldots \ldots \ldots \ldots \ldots \ldots \ldots \ldots \ldots \ldots \ldots$

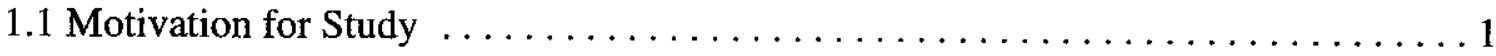

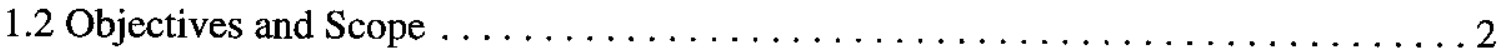

CHAPTER 2 - LITERATURE REVIEW $\ldots \ldots \ldots \ldots \ldots \ldots \ldots \ldots \ldots \ldots \ldots \ldots$

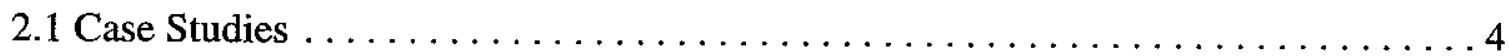

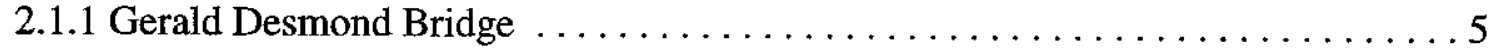

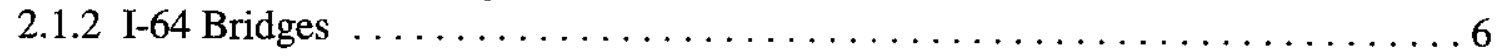

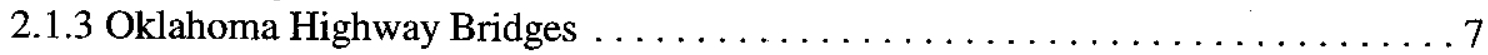

2.1.4 Woodrow Wilson Memorial Bridge $\ldots \ldots \ldots \ldots \ldots \ldots \ldots \ldots \ldots$

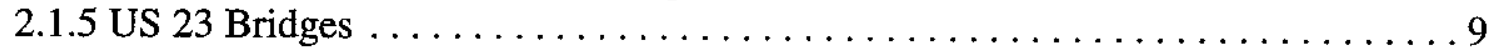

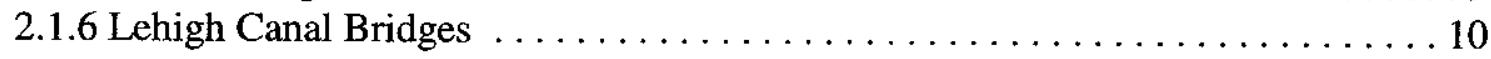

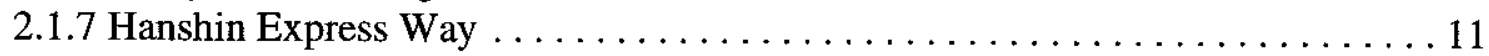

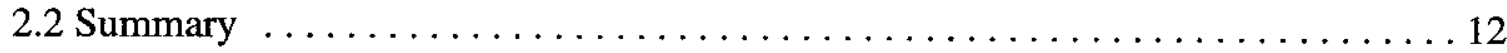

CHAPTER 3 - EXPERIMENTAL PROGRAM $\ldots \ldots \ldots \ldots \ldots \ldots \ldots \ldots \ldots \ldots$

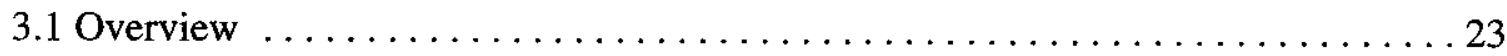

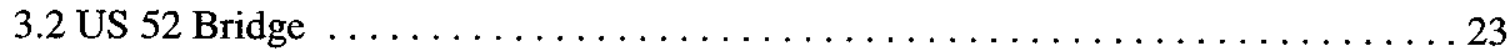

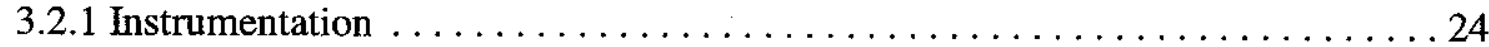

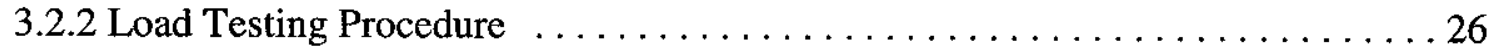

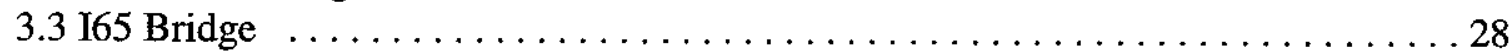

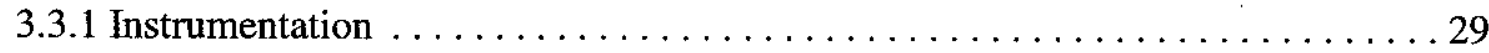

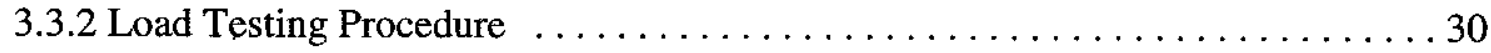

CHAPTER 4 - EXPERIMENTAL RESULTS $\ldots \ldots \ldots \ldots \ldots \ldots \ldots \ldots \ldots \ldots \ldots \ldots \ldots$

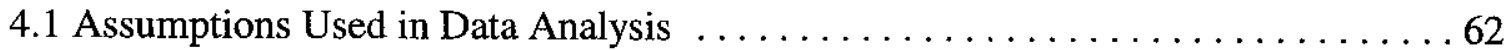

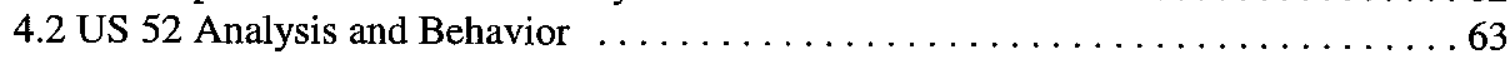

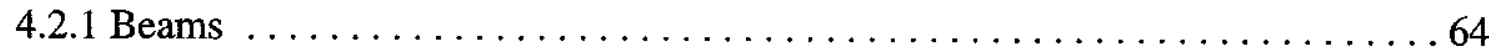

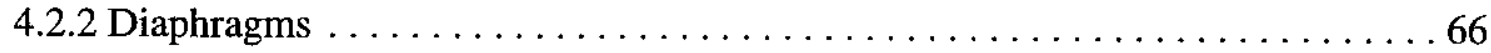




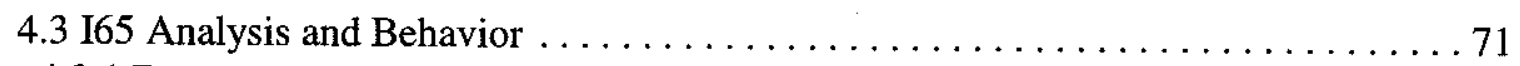

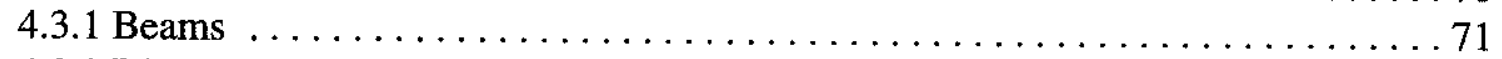

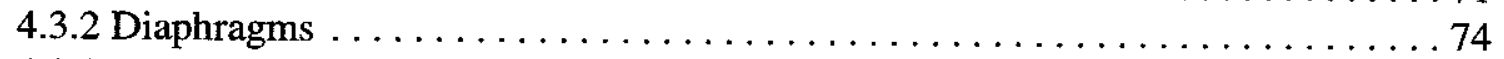

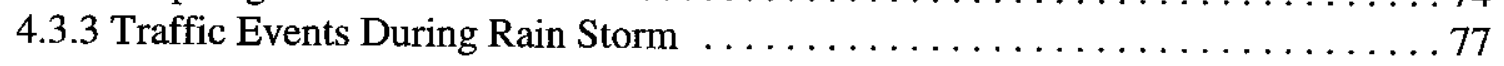

CHAPTER 5 - EXPERIMENTAL COMPARISON BETWEEN BRIDGES . . . . . . . . 140

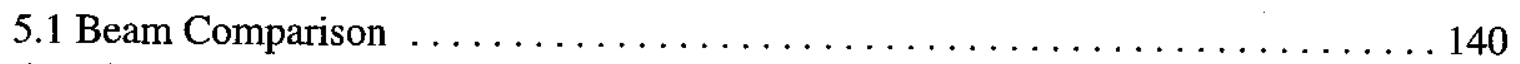

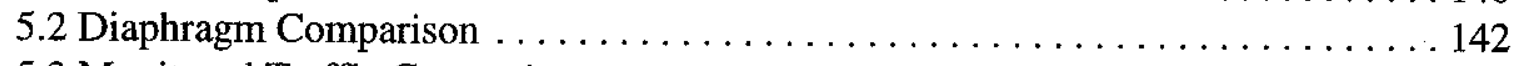

5.3 Monitored Traffic Comparison $\ldots \ldots \ldots \ldots \ldots \ldots \ldots \ldots \ldots \ldots \ldots$

CHAPTER 6 - ANALYTICAL TO EXPERIMENTAL COMPARISON . . . . . . . . . . . 159

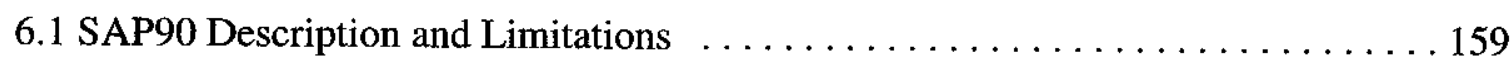

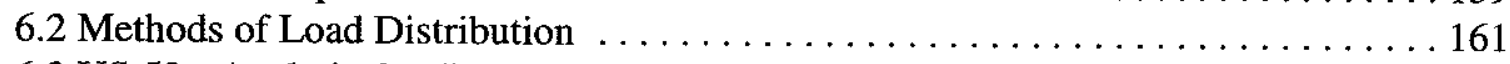

6.3 US 52 - Analytical to Experimental Comparison $\ldots \ldots \ldots \ldots \ldots \ldots \ldots \ldots \ldots \ldots$

6.4 I65 - Analytical to Experimental Comparison $\ldots \ldots \ldots \ldots \ldots \ldots \ldots \ldots \ldots \ldots$

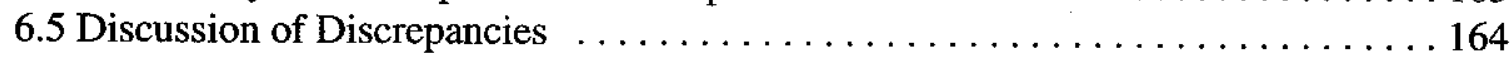

CHAPTER 7 - CONCLUSIONS, RECOMMENDATIONS, IMPLEMENTATION . . . . . 173

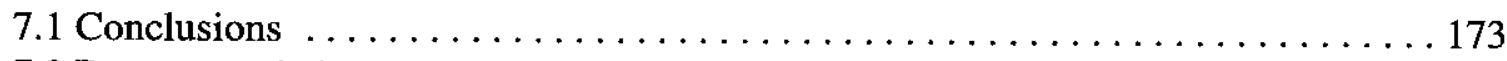

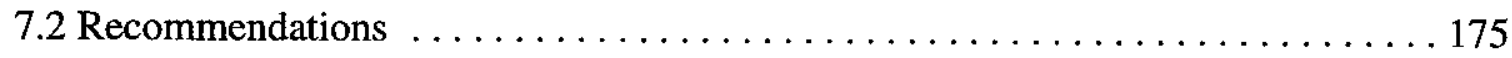

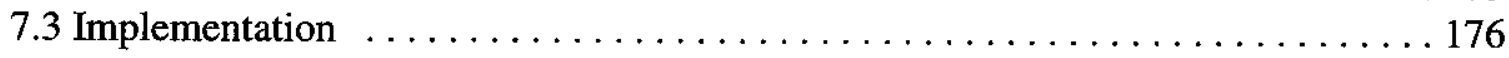

LIST OF REFERENCES $\ldots \ldots \ldots \ldots \ldots \ldots \ldots \ldots \ldots \ldots \ldots \ldots \ldots \ldots \ldots$

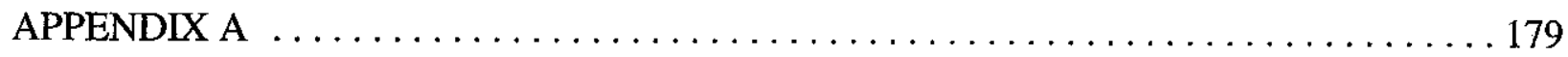

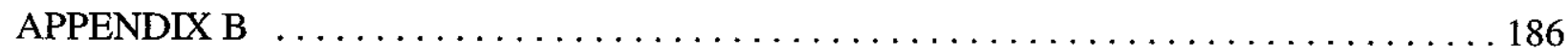

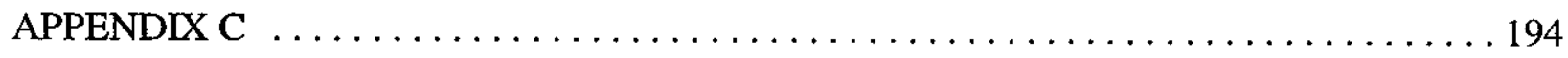




\section{LIST OF TABLES}

Table

Page

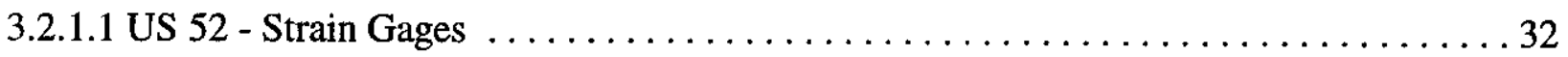

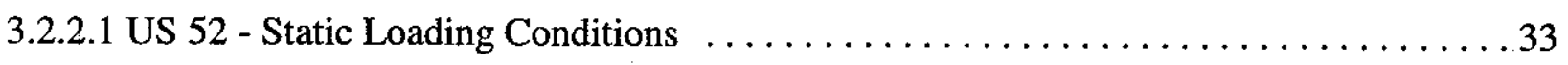

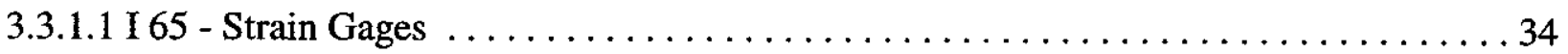

3.3.2.1 I 65 - Static Loading Conditions $\ldots \ldots \ldots \ldots \ldots \ldots \ldots \ldots \ldots \ldots \ldots \ldots \ldots \ldots \ldots \ldots \ldots$

4.2.1.1 US 52 - Maximum Beam Strains and Stresses for Static Loading Conditions . . . . . 78

4.2.1.2 US 52 - Static Loading Conditions - Deflections $\ldots \ldots \ldots \ldots \ldots \ldots$

4.2.1.3 US 52 - Maximum Beam Strains and Strain Ranges for Dynamic Loading

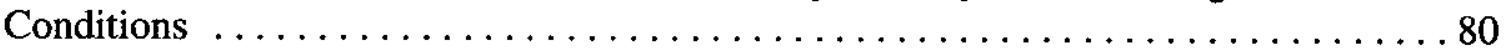

4.2.1.4 US 52 - Average Maximum Beam Strains and Strain Ranges for Regular Traffic . . . . 81

4.2.2.1 US 52 - Maximum Diaphragm Strains and Stresses for Static Loading Conditions . . . 82

4.2.2.2 US 52 - Maximum Diaphragm Forces for Static Loading Conditions $\ldots \ldots \ldots$. . . . 83

4.2.2.3 US 52 - Maximum Diaphragm Strains and Strain Ranges for Dynamic Loading

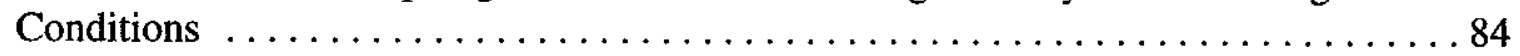

4.2.2.4 US 52 - Maximum Diaphragm Shear Forces and Ranges for Dynamic Loading

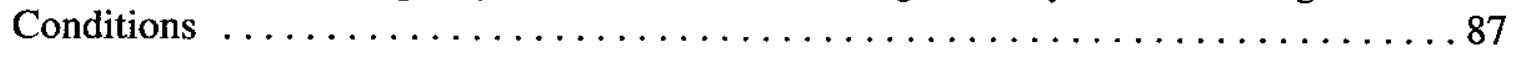

4.2.2.5 US 52 - Average Maximum Diaphragm Strains and Strain Ranges for Regular

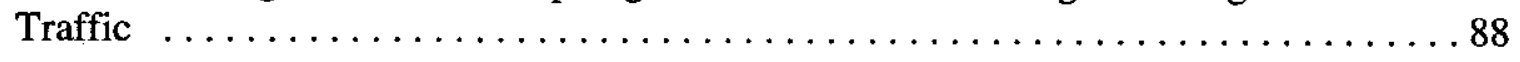

4.2.2.6 US 52 - Average Maximum Diaphragm Shear Forces for Regular Traffic . . . . . . . 92

4.3.1.1 I 65 - Maximum Beam Strains and Stresses for Static Loading Conditions . . . . . . 93

4.3.1.2 I 65 - Static Loading Conditions - Deflections $\ldots \ldots \ldots \ldots \ldots \ldots \ldots$

4.3.1.3 I 65 - Maximum Beam Strains and Strain Ranges for Dynamic Loading

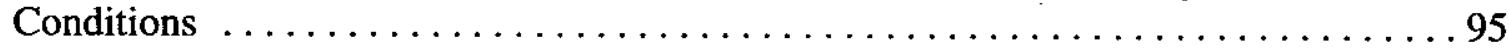


4.3.1.4 I 65 - Average Maximum Beam Strains and Strain Ranges for Regular Traffic . . . . . 99

4.3.2.1 I 65 - Maximum Diaphragm Strains and Stresses for Static Loading Conditions . . . . 97

4.3.2.2 I 65 - Maximum Diaphragm Forces for Static Loading Conditions . . . . . . . . 100

4.3.2.3 I 65 - Maximum Diaphragm Strains and Strain Ranges for Dynamic Loading

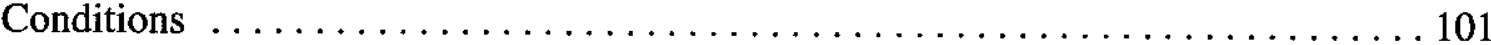

4.3.2.4 I 65 - Maximum Diaphragm Shear Forces and Ranges for Dynamic Loading

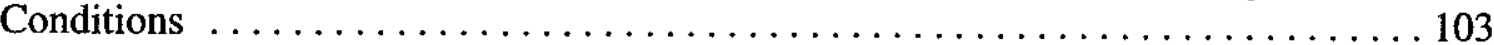

4.3.2.5 I 65 - Average Maximum Diaphragm Strains and Strain Ranges for Regular

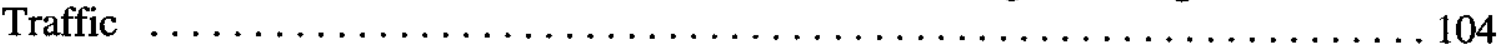

4.3.2.6 US 52 - Average Maximum Diaphragm Shear Forces for Regular Traffic . . . . . . . 106

5.2.1 Bridge Comparison - Maximum Diaphragm Forces for Static Loading Conditions . . 146

5.2.2 Bridge Comparison - Maximum Diaphragm Shear Force Ranges for Dynamic

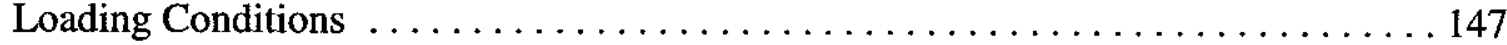

6.2.1 Load Distribution Models for Beam Loadings on US $52 \ldots \ldots \ldots \ldots \ldots$

6.2 .2 Load Distribution Models For Beam Loadings on I $65 \ldots \ldots \ldots \ldots \ldots$

6.3.1 US 52 - Analytical to Experimental Comparison $\ldots \ldots \ldots \ldots \ldots \ldots \ldots$

6.4.1 I 65 - Analytical to Experimental Comparison $\ldots \ldots \ldots \ldots \ldots \ldots$ 


\section{LIST OF FIGURES}

Figure

Page

2.1.1.1 Gerald Desmond Bridge - Strain Gages Installed at Lateral Gusset Plate

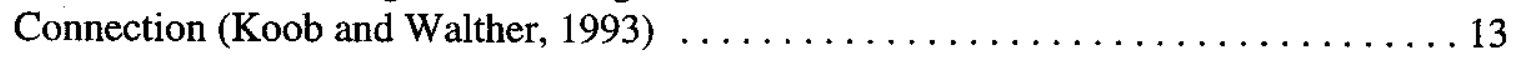

2.1.2.1 I-64 Bridge - Typical Cross Section (Albrecht et al., 1991) . . . . . . . . . . . . 14

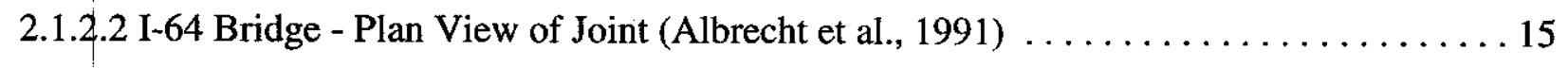

2.1.3.1 Oklahoma Highway Bridge - Example of Cracked Diaphragm

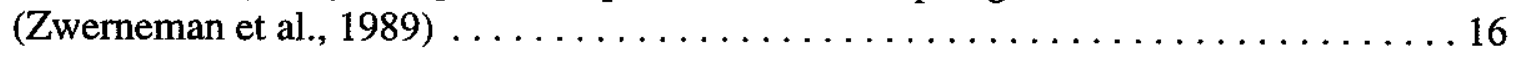

2.1.3.2 Oklahoma Highway Bridge - Strain Gage Locations on Fabricated

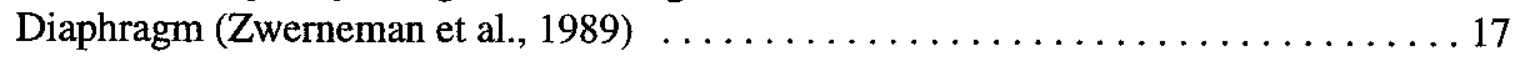

2.1.3.3 Oklahoma Highway Bridge - Strain Gage Locations on Interior

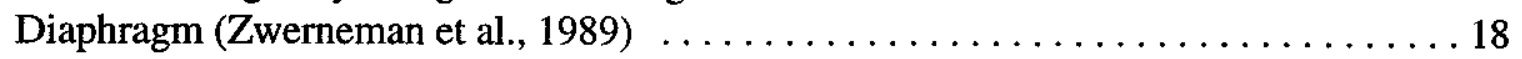

2.1.3.4 Oklahoma Highway Bridge - Strain Gage Locations on Exterior

Diaphragm (Zwerneman et al., 1989) ... . . . . . . . . . . . . . . . . 19

2.1.4.1 Woodrow Wilson Memorial Bridge - Cross Section (Nowak et al., 1993) . . . . . . . 20

2.1.5.1 US 23 Bridge - Cross Section (Laman and Nowak, 1993) . . . . . . . . . . 21

2.1.6.1 Lehigh Canal Bridge - (a) Cross Section of Bridge and (b) Tie Plate Detail at Floor Beam-Bracket Connection to Girder (Fisher et al., 1976) . . . . . . . . . 22

3.1.1 Welded Diaphragm-to-Beam Connection $\ldots \ldots \ldots \ldots \ldots \ldots \ldots \ldots \ldots \ldots \ldots \ldots \ldots \ldots$

3.2.1 US 52 - Plan View of Instrumented $\operatorname{Span} \ldots \ldots \ldots \ldots \ldots \ldots \ldots \ldots \ldots \ldots \ldots$

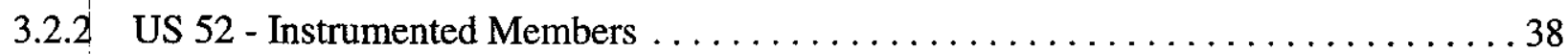

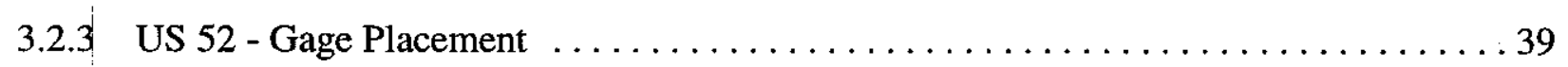

3.2.1.1 US 52 - Strain Gage Placement - Beam $\ldots \ldots \ldots \ldots \ldots \ldots \ldots \ldots \ldots \ldots \ldots \ldots$

3.2.1.2 US 52 - Strain Gage Placement - Diaphragm $\ldots \ldots \ldots \ldots \ldots \ldots \ldots \ldots \ldots \ldots$

3.2.1.3 US 52 - Diaphragm Instrumentation $\ldots \ldots \ldots \ldots \ldots \ldots \ldots \ldots \ldots \ldots \ldots \ldots \ldots$ 
3.2.2.1 US 52 - Tandem Axle Dump Truck ............................. 43

3.2.2.2 US 52 - Static Loading Conditions \#1 (LC\#1) ...................... 44

3.2.2.3 US 52 - Static Loading Conditions $\# 2$ (LC\#2) $\ldots \ldots \ldots \ldots \ldots \ldots \ldots \ldots \ldots \ldots \ldots \ldots \ldots \ldots$

3.2.2.4 US 52 - Static Loading Conditions \#3 (LC\#3) $\ldots \ldots \ldots \ldots \ldots \ldots \ldots \ldots \ldots \ldots \ldots \ldots \ldots$

3.2.2.5 US 52 - Static Loading Conditions \#4 (LC\#4) $\ldots \ldots \ldots \ldots \ldots \ldots \ldots \ldots \ldots$

3.2.2.6 US 52 - Static Loading Condition A $\ldots \ldots \ldots \ldots \ldots \ldots \ldots \ldots \ldots \ldots$

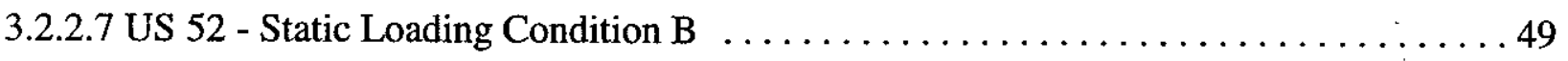

3.2.2.8 US 52 - Dump Truck During a Dynamic Loading Condition $\ldots \ldots \ldots \ldots \ldots \ldots$

3.3.1 I 65 - US 52 - Plan View of Instrumented Span $\ldots \ldots \ldots \ldots \ldots \ldots \ldots \ldots \ldots \ldots \ldots \ldots \ldots \ldots$

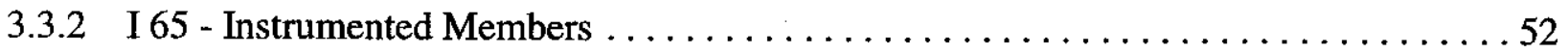

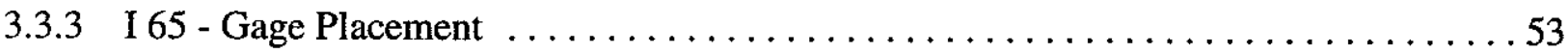

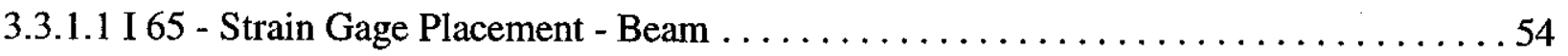

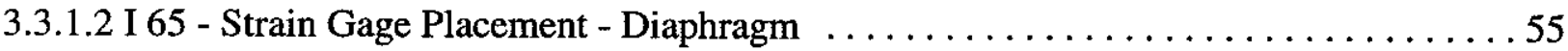

3.3.2.1 I 65 - Tandem Axle Dump Truck ............................. 56

3.3.2.2 I 65 - Static Loading Conditions \#1 (LC\#1) $\ldots \ldots \ldots \ldots \ldots \ldots \ldots \ldots \ldots \ldots \ldots \ldots \ldots \ldots$

3.3.2.3 I 65 - Static Loading Conditions $\# 2$ (LC\#2) $\ldots \ldots \ldots \ldots \ldots \ldots \ldots \ldots \ldots \ldots \ldots \ldots \ldots \ldots \ldots$

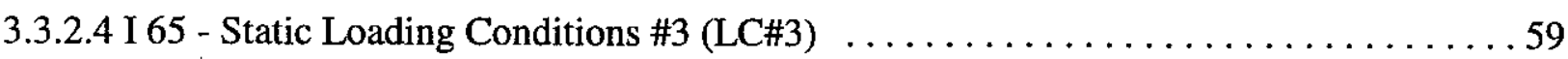

3.3.2.5 US 52 - Static Loading Condition A $\ldots \ldots \ldots \ldots \ldots \ldots \ldots \ldots \ldots \ldots \ldots \ldots \ldots \ldots \ldots \ldots \ldots \ldots$

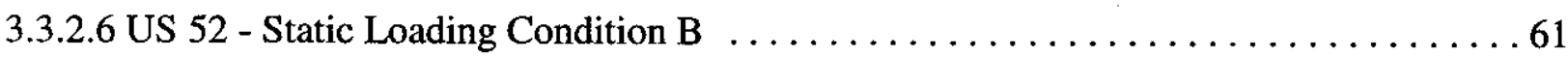

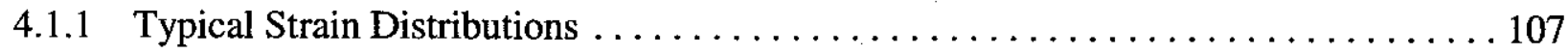

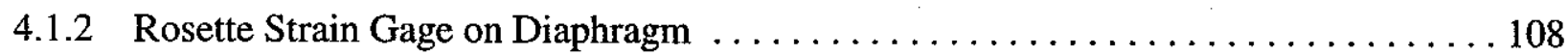

4.2.1.1 US 52 - Strains at Bottom of Beam \#2 - Loading Condition A . . . . . . . . . . . 109 


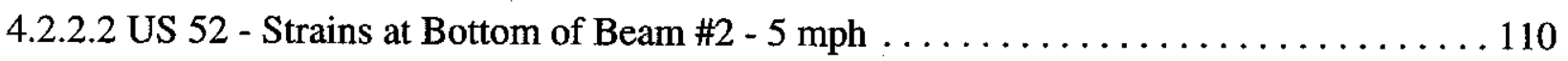

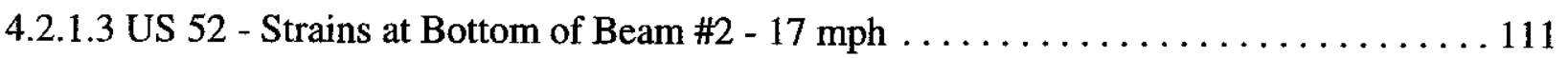

4.2.1.4 US 52 - Strains at Bottom on Beam $\# 2-25 \mathrm{mph} \ldots \ldots \ldots \ldots \ldots \ldots \ldots \ldots \ldots \ldots \ldots \ldots$

4.2.1.5 US 52 - Strains at Bottom of Beams \#2 - Dump Truck and Eighteen-Wheeler . . . . 113

4.2.1.6 US 52 - Strains at Bottom of Beam \#2 - Eighteen-Wheeler ................. 114

4.2.1.7 US 52 - Strains at Bottom of Beam \#2 - Comparison Between Static and

Traffic Loadings ................................... 115

4.2.2.1 US 52 - Strains at Bottom of Diaphragm \#2 - Static Loading Condition A . . . . . 116

4.2.2.2 US 52 - Strains at Bottom of Diaphragm \#2 $-5 \mathrm{mph} \ldots \ldots \ldots \ldots \ldots \ldots \ldots \ldots \ldots$

4.2.2.3 US 52 - Strains at Bottom of Diaphragm $\# 2-17 \mathrm{mph} \ldots \ldots \ldots \ldots \ldots \ldots \ldots \ldots$

4.2.2.4 US 52 - Strains at Bottom on Diaphragm \#2 - $25 \mathrm{mph} \ldots \ldots \ldots \ldots \ldots \ldots \ldots$

4.2.2.5 US 52 - Strains at Bottom of Diaphragm \#2 - Eighteen-Wheeler ........... 120

4.2.2.6 US 52 - Strains at Bottom of Diaphragm \#2 - Dump Truck and Eighteen-Wheeler . . 121

4.2.2.7 US 52 - Strains at Bottom of Diaphragm \#2 - Comparison Between Static and

Traffic Loadings . . . . . . . . . . . . . . . . . . . . . . . . . . . 122

4.2.2.8 US 52 - Shear Force in Diaphragm \#1 - Comparison Between Static and Traffic Loadings . . . . . . . . . . . . . . . . . . . . . . . . . . . . 123

4.2.2.9 US 52 - Shear Force in Diaphragm \#2 - Comparison Between Static and Traffic Loadings . . . . . . . . . . . . . . . . . . . . . . . . . 124

4.2.2.10 US 52 - Shear Force in Diaphragm \#3 - Comparison Between Static and Traffic Loadings . . . . . . . . . . . . . . . . . . . . . . . . 125

4.2.2.11 US 52 - Behavioral Comparison of Beams to Diaphragms $\ldots \ldots \ldots \ldots \ldots \ldots \ldots$

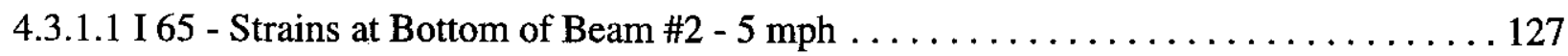

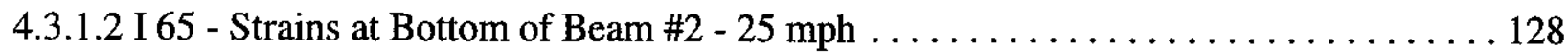


4.3.1.3 I 65 - Strains at Bottom on Beam \#2 - 55 mph .......................... 129

4.3.1.4 I 65 - Strains at Bottom of Beam \#2 - Eighteen-Wheeler ................. 130

4.3.1.5 I 65 - Strains at Bottom of Beam \#2 - Two Eighteen-Wheelers (Side-by-Side) . . . . 131

4.3.1.6 I 65 - Strain Comparison Between Static and Traffic Loadings $\ldots \ldots \ldots \ldots \ldots 132$

4.3.2.1 I 65 - Shear Force in Diaphragm \#1 - Comparison Between Static and

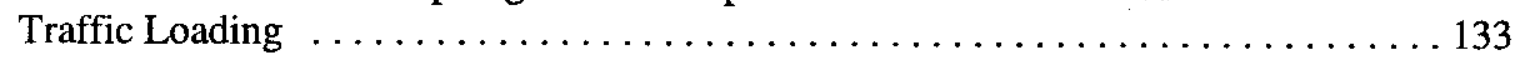

4.3.2.2 I 65 - Shear Force in Diaphragm \#2 - Comparison Between Static and

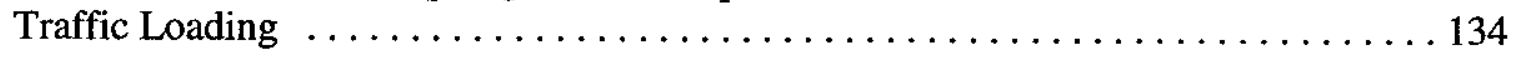

4.3.2.3 I 65 - Behavioral Comparison of Beams to Diaphragms ................. 135

4.3.3.1 I 65 - Traffic Storm Data - Maximum Strains in Top of Beams .............. 136

4.3.3.2 I 65 - Traffic Storm Data - Strain Ranges in Top of Beams $\ldots \ldots \ldots \ldots \ldots \ldots$

4.3.3.3 I 65 - Traffic Storm Data - Axial Strain Ranges in Diaphragms .............. 138

4.3.3.4 I 65 - Strains at Bottom of Beam \#2 - Truck Event During Storm ........... 139

5.1.1 Bridge Comparison - Strains at Bottom of Beams for Static Loading Conditions . . . 148

5.1.2 Bridge Comparison - Strains at Bottom of Beams for Dynamic Loading Conditions . . 149

5.1.3 Bridge Comparison - Beam Web Strains for Static Loading Conditions . . . . . . . 150

5.2.1 Bridge Comparison - Diaphragm Strains for Static Loading Conditions . . . . . . 151

5.2.2 Bridge Comparison - Diaphragm Strains for Dynamic Loading Conditions . . . . . . 152

5.3.1 Bridge Comparison - Strains at Bottom of Beams for a Single Eighteen Wheeler . . . 153

5.3.2 Bridge Comparison - Strains at Bottom of Beams for Two Trucks ............. 154

5.3.3 Bridge Comparison - Diaphragm Strains for a Single Eighteen-Wheeler . . . . . . 155

5.3.4 Bridge Comparison - Diaphragm Strains for Two Trucks ................ 156

5.3.5 Bridge Comparison - Shear Force in Diaphragm \#2 of the US 52 Bridge and 
Diaphragm \#1 of the I 65 Bridge for Traffic Samples ................ 157

5.3.6 Bridge Comparison - Shear Force in Diaphragm \#3 of the US 52 Bridge and Diaphragm \#2 of the I 65 Bridge for Traffic Samples 158

6.1 .1 US 52 - Plan View of Bridge Model $\ldots \ldots \ldots \ldots \ldots \ldots \ldots \ldots \ldots \ldots \ldots \ldots \ldots \ldots \ldots \ldots \ldots \ldots$

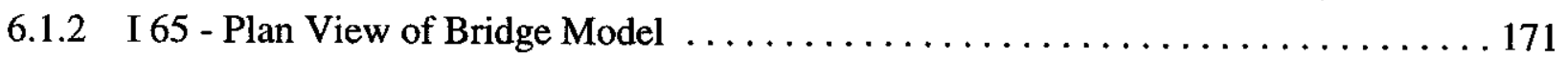

6.2.1 US 52 - Load Distribution \#1 Model ........................ 172

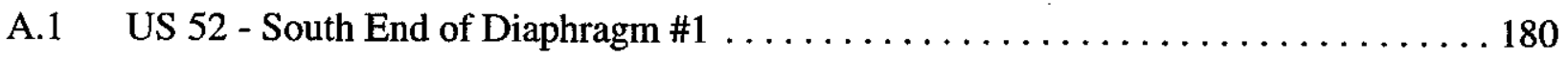

A.2 US 52 - North End of Diaphragm \#2 $\ldots \ldots \ldots \ldots \ldots \ldots \ldots \ldots \ldots \ldots \ldots \ldots \ldots \ldots \ldots \ldots \ldots \ldots$

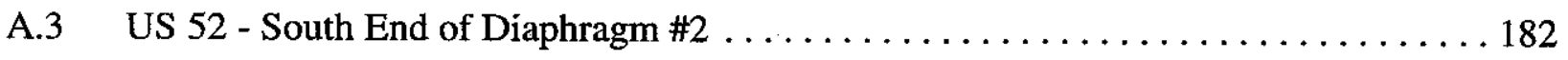

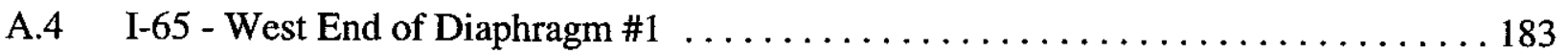

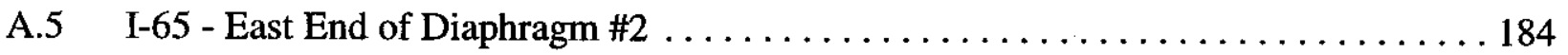

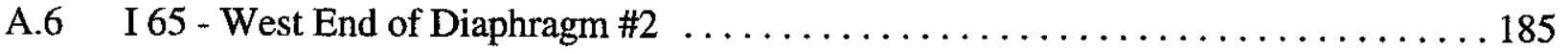

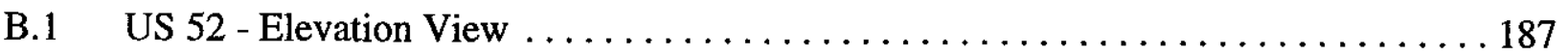

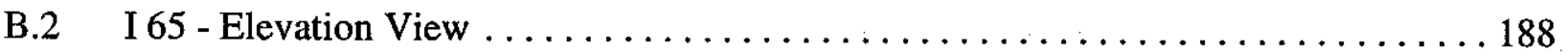

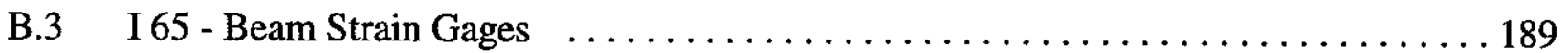

B.4 I 65 - Orientation of Beam Web Gages $\ldots \ldots \ldots \ldots \ldots \ldots \ldots \ldots \ldots \ldots \ldots \ldots \ldots \ldots \ldots \ldots$

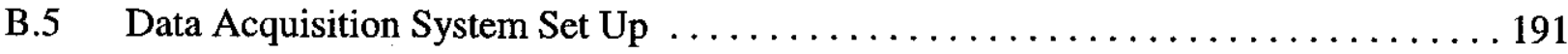

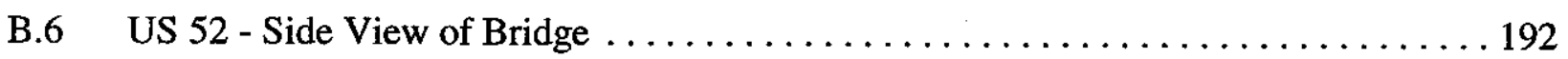

B.7 I 65 - Typical Set Up for a Static Loading Condition $\ldots \ldots \ldots \ldots \ldots \ldots$

C.1 US 52 - Diaphragm Shear Forces for Static Loading Condition A . . . . . . . . . . 195

C.2 US 52 - Diaphragm Shear Forces for Static Loading Condition B ............ 196

C.3 I 65 - Diaphragm Shear Forces for Static Loading Condition A . . . . . . . . . . . . 197 
C.4 I 65 - Diaphragm Shear Forces for Static Loading Condition B . . . . . . . . . . 198 


\section{CHAPTER 1}

\section{INTRODUCTION}

\subsection{Motivation for Study}

In several Indiana steel bridges, cracks have been observed in a frequently used diaphragm-to-beam connection. This detail involves a hot-rolled W-shape which is welded directly to the web of the longitudinal member. Intermittent fillet welds are used to attach the web of the diaphragm to the beam web. Diaphragm flanges are connected to the beam web using fillet welds along the top side of each flange. Cracks have been detected in both the intermittent web welds as well as the bottom flange fillet welds. The possibility of these cracks propagating into the beam web raises serious questions about the structural integrity of these longitudinal members in the future.

As part of a larger study to evaluate the seriousness of this cracking and propose possible methods of correction, a thorough understanding of the loading behavior of the welded diaphragm-to-beam connection must be acquired. Results from the collection of field measurements and development of analytical models will aid in accomplishing this task. 


\subsection{Objectives and Scope}

This experimental study presents an attempt to understand the behavior of a diaphragm-to-beam connection with intermittent fillet welds. The main objectives of this study are the following:

1. To measure and evaluate member strains recorded during the load testing of two steel bridges; one with staggered diaphragms and one with diaphragms situated back-to-back.

2. To reciprocate these load tests using an analysis program.

3. To determine the similarities and differences between the behavior of bridges having staggered diaphragms and those having diaphragms that are not staggered.

A review of literature on the field testing of bridges is presented in Chapter 2. Emphasis is placed on field tests investigating diaphragm behavior and fatigue cracking.

Chapter 3 describes the experimental program used in the field testing of two steel bridges; one bridge with diaphragms situated back-to-back and one bridge with staggered diaphragms. Details concerning the bridge descriptions, instrumentation, and loading conditions are provided in this chapter.

Results of a series of static, dynamic, and traffic loading conditions for each bridge are presented in Chapter 4. An evaluation and comparison of member behavior within each bridge is also described in this chapter.

Chapter 5 presents a comparison of experimental data and observed member behavior between the two bridges. Similarities and differences between staggered and non-staggered diaphragm behavior was stressed. 
The development of the analytical model of each bridge is discussed in Chapter 6 . Results of these analyses are also compared with the experimental data in this chapter.

Chapter 7 presents conclusions drawn from the evaluation of the experimental data and the analytical results. Future work involving bridges employing diaphragm-to-beam connections with intermittent fillet welds is also discussed. 


\section{CHAPTER 2}

\section{LITERATURE REVIEW}

\subsection{Case Studies}

During regular inspection of steel bridges, many cracks have been detected in and near the connection between transverse and longitudinal members. Transverse members, such as diaphragms, lateral bracing, and floor beams, are used to provide lateral stability and to distribute loads laterally. These components are commonly welded or bolted to connection or gusset plates which are in turn bolted or welded directly to the web or stiffener of longitudinal members. Under repetitive loadings, fatigue cracks can form in areas of high stress levels. Some examples of regions of high stress levels are web gap regions between the connection plate and the tension flange or between a gusset plate and the transverse stiffener. Another, less severe, form of cracking can occur vertically along the stiffener-toweb weld; separation of the weld from the web is possible for this type of cracking (Rewerts and Gaudette, 1988).

This section provides information on field testing techniques used to evaluate several different bridges in which fatigue was a concern. Each case study gives a brief description of the bridge, location of instrumentation, type of loading conditions, and pertinent results. 


\subsubsection{Gerald Desmond Bridge}

As part of a fatigue evaluation of the Gerald Desmond Bridge in Long Beach, California, the bridge was instrumented and field tested by Wiss, Janney, Elstner Associates, Inc. to determine the live load stresses and the response of the structure under normal traffic conditions (Koob and Walther, 1993). The approach spans consist of nine plate girders connected by angle cross frames at a spacing of about $6000 \mathrm{~mm}(20 \mathrm{ft}$.) on center. Objectives of field testing were to measure the stress ranges adjacent to fatigue sensitive details and compare stress levels with and verify the structural analysis. To provide information about live load stress ranges at locations of maximum moment, $6 \mathrm{~mm}(1 / 4 \mathrm{in}$.), $350 \mathrm{ohm}$ strain gages were placed on the girder webs and flanges at midspan. Strain gages were also installed at lateral gusset plate connections (Figure 2.1.1.1). Instrumentation was generally positioned beneath the right lane which is used by most truck traffic.

Two dump trucks, weighing approximately $185 \mathrm{kN}(42,000 \mathrm{lb}$.) each, were used in the load testing; one in each lane. The trucks were driven across the span, side-by-side, at $64 \mathrm{~km} / \mathrm{h}(40 \mathrm{mph})$. Strain gage readings were also recorded under normal traffic loadings for about four hours. At the ends of the lateral gusset plates, stress levels ranged from 24.1 $\mathrm{MPa}(3.5 \mathrm{ksi})$ to $29.0 \mathrm{MPa}(4.2 \mathrm{ksi})$ under normal heavy traffic and vehicles of known load. Under these same loading conditions, stresses ranged from $20.7 \mathrm{MPa}(3.0 \mathrm{ksi})$ to $29.0 \mathrm{MPa}$ (4.2 ksi) in the bottom flange of the girders. Normal traffic loadings produced stress levels that were slightly lower than those produced by the two vehicles of known load traveling side-by-side. 


\subsubsection{I-64 Bridges}

During an inspection in 1991, cracks were discovered in the I-64 bridges over Maury River and Kerr's Creek in Virginia (Albrecht et al., 1991). The two bridges are identical. Each is a seven span, continuous bridge consisting of three, $1,829 \mathrm{~mm}(6 \mathrm{ft}$.) deep girders, spaced at 5,029 mm (16 ft. - $6 \mathrm{in}$.) (Figure 2.1.2.1). The girders are joined together by floor beams and diaphragms at a $6,096 \mathrm{~mm}$ ( $20 \mathrm{ft}$.) spacing and lateral bracing every $12,192 \mathrm{~mm}$ (40 ft.). The first crack was found in the exterior girder where the diaphragm and lateral bracing members are connected. Three additional cracks were later discovered in web gaps between connection plates for the diaphragms and gusset plates for the lateral bracing (Figure 2.1.2.2)

A field test of the westbound bridge was performed to prove that out-of-plane bending of the web was the cause of cracking. Four strain gages were placed on the diaphragm and lateral bracing near the connection to measure the forces causing out-of-plane bending. Three gages were mounted longitudinally on the exterior side of the girder web, where the gusset plate and connection plate intersect, to detect out-of-plane bending stresses. An additional strain gage was also located on the girder web to measure in-plane bending stresses.

Strain measurements were recorded as a two-axle dump truck weighing $205 \mathrm{kN}$ $(46,120 \mathrm{lb}$.) drove over the bridge. The in-plane bending stress range was $12.4 \mathrm{MPa}(1.8 \mathrm{ksi})$ and 6.9 $\mathrm{MPa}(1.0) \mathrm{ksi}$ when the truck drove in the right and left lanes respectively. Out-ofplane bending stress in the web and the net force that bends the web gap could not be accurately determined. However, the authors did state that the main cause of the out-of-plane bending in the web gap is due to a large force in the diagonals of the diaphragm resulting 
from the truck axles as they cross the floor beams. These out-of-plane bending stresses caused the observed fatigue cracking. Recommendations suggest to release the restraint by loosening the bolted end connections of both the diaphragm and the lateral bracing members.

A follow-up stress evaluation of the I-64 bridge was performed before and after the retrofit to identify any changes in structural response (Wright et al., 1991). Fourteen strain gages were installed on the girders and floor beams. Dead load readings were recorded before and after the recommended members were removed. A three-axle dump truck weighing $222 \mathrm{kN}(49,920 \mathrm{lb}$.) was then used in a series of live load measurements. With the diaphragm braces removed, the distribution of live load stresses was evened out between the three girders. The stress range in the exterior girder had increased with a corresponding decrease in the interior girder. The safe remaining fatigue life for critical details was also predicted.

\subsubsection{Oklahoma Highway Bridge}

Researchers at Oklahoma State University (Zwerneman et al., 1989) conducted a study on a steel girder bridge to identify the cause of diaphragm cracking. Hot rolled sections were used as diaphragm members, with the diaphragms bolted to a connection plate that is welded to the top flange and web of the girder. Both the top and bottom of the diaphragm are coped at each end. Cracks were found to initiate at the cope in the tension flange and propagate through the member toward the compression flange (Figure 2.1.3.1).

Before load testing began, a diaphragm was fabricated to match existing diaphragms as closely as possible. This new diaphragm, which replaced one that had been cracked, and 
two other uncracked diaphragms were instrumented using $6 \mathrm{~mm} \mathrm{(1/4} \mathrm{in.),} 350 \mathrm{ohm}$ single element and rosette strain gages. Figures 2.1.3.2 through 2.1.3.4 depict strain gage locations on each diaphragm. Strain gages were connected to data acquisition instruments by threeconductor twisted cable with vinyl insulation, braided shield, and vinyl jacket. Differential displacement measurements in longitudinal members were also attempted but were not successful. Most data were taken during static loadings using a tank truck weighing about $114 \mathrm{kN}(25,720 \mathrm{lb}$.$) . Strain readings were also recorded as the tank truck drove across the$ bridge at speeds of 32,48 , and $56 \mathrm{~km} / \mathrm{h}(20,30$, and $35 \mathrm{mph})$ in the inside traffic lane.

Although the girders are continuous, strains recorded while the truck was on uninstrumented spans are negligible. A maximum strain of 150 microstrain was detected in the longitudinal diaphragm web gage near the cope while the rear axle of the truck was directly over the instrumented diaphragms. Characteristically, the peak strain increased slightly as the truck velocity increased.

Results indicate that diaphragms at transverse locations between piers act like continuous beams due to the high degree of restraint at the diaphragm-to-girder connections. These "continuous" diaphragms reach from one side of the bridge to the other and are loaded by the differential deflections of the interior longitudinal members. These differential deflections induce moments in the diaphragms which produce tensile stresses along the bottom of the diaphragms. The presence of a bottom-flange cope at the diaphragm-to-girder connection magnifies these tensile stresses. Removing the bottom two bolts from the connection is the recommended method to prevent further cracking. 


\subsubsection{Woodrow Wilson Memorial Bridge}

As part of the evaluation of fatigue performance of the Woodrow Wilson Memorial Bridge, the western approach spans were instrumented and load tested (Nowak et al., 1993). Each $18,900 \mathrm{~mm}$ ( $62 \mathrm{ft}$.) span consists of four steel plate girders spaced at 7,823 $\mathrm{mm}(25 \mathrm{ft}$. 8 in.) and is connected by W36X150 floor beams (Figure 2.1.4.1). The webs of the main girders are identical; however, interior girders have larger flanges.

Strain gages and strain gage transducers were used in measuring strains at the critical connections between the floor beams and the exterior girders and on main girders to verify the lateral distribution of loads. A three-axle test truck weighing $278 \mathrm{kN}(62,500 \mathrm{lb}$.) was used in determining the bridge response to a known load. Although results were in agreement with those predicted in the analysis, measured values were always significantly lower than the calculated values. This discrepancy is attributed to the uncertainty in calculating the distribution of axle loads to adjacent girders. Floor beam strain gages indicate that the top flange was in compression and the bottom flange in tension as the test truck passed over the floor beam. This behavior is explained by the relative displacement of the floor beam between its supporting girders. Primary stresses at the end of the floor beam are generated by the differential deflection of the girders and not by restraining moments in the connection.

\subsubsection{US 23 Bridges}

As part of the development of a data base for load modeling, the $10,200 \mathrm{~mm}$ ( $33 \mathrm{ft}$. 6 in.) entry span of a bridge located on US 23 in Michigan was instrumented and load tested (Laman and Nowak, 1993). The simply-supported composite span is made up of ten steel 
beams (Figure 2.1.5.1). Exterior beams are W36X150 sections, interior beams are W27X102 sections, and diaphragms are built-up " $\mathrm{C}$ " shapes consisting of $9.5 \mathrm{~mm} \mathrm{(3/8}$ in.) plate riveted to $\mathrm{L} 3 \mathrm{X} 3 \mathrm{X}^{3} / 8$ at the top and bottom flanges.

Using a data acquisition and analysis system from the SoMat Corporation, dynamic strains were simultaneously sampled at a rate of $200 \mathrm{~Hz}$. Weigh-in-motion (WIM) data were also collected. Strains in central diaphragms were measured for a one week period to determine their extent of participation in live load distribution. Diaphragm strain gages were located on the bottom flange, $300 \mathrm{~mm}$ (1 ft.) away from the girder center-line. Results show that interior beams located beneath the lanes of traffic experience higher strains than those located beneath the shoulder. When compared to beam stresses, diaphragm stresses are much smaller. This stress comparison indicates that diaphragm participation in the distribution of live load forces is minimal.

\subsubsection{Lehigh Canal Bridge}

In order to examine the behavior of several steel bridge details under normal traffic conditions, the $43,900 \mathrm{~mm}$ (144 ft.) end span of the eastbound bridge was field tested (Fisher et al., 1976). The bridge is a three-span, continuous, noncomposite structure, and consists of two riveted longitudinal girders with a floor beam-stringer system (Figure 2.1.6.1). During inspection, many cracks in tie plates were detected at or near the exterior edge of the longitudinal girders. All cracks initiated from a tack weld at the edge of the tie plates.

One-quarter inch strain gages were positioned on the tie plates, the flanges of the longitudinal girders, and a stringer. An automatic data acquisition system was utilized in detecting and recording the magnitude and frequency of strain ranges. Recorded events were 
correlated with the type of traffic by visual observation. Strain measurements and traffic observations indicate that each truck passing over the instrumented span produces one primary stress range in all strain gages. Observed live load stresses were substantially higher in the tie plates connecting the outrigger brackets and floor beams than those in longitudinal members. Live load stress distributions in the tie plates show evidence of horizontal, inplane bending. The horizontal bending of the tie plates is the result of differential displacement between the top flange of the girder and the deck-stringer system. Procedures to decrease in-plane bending stresses in the tie plates include unbolting tie plates from the girder and reducing the width of the tie plates.

\subsubsection{Hanshin Express Way}

Fatigue cracks have been observed at the end of vertical stiffeners and connection plates in many plate girder bridges. Load testing of a simple, composite, plate girder bridge on the Hanshin Express Way is part of an investigation to understand the behavior of standard bridges under increasing loads (Kato et al., 1985). The bridge consists of five main girders, one cross beam located at midspan, and four sway bracings at about every $4,500 \mathrm{~mm}$ (15 ft.).

Strain gages were mounted on main girders, the cross beam, sway bracings, and at the ends of stiffeners and connection plates. Displacement of the slab and main girders were also measured. A test truck weighing approximately $196 \mathrm{kN}(44,000 \mathrm{lb}$.) was used in both the static and dynamic loading conditions. Dynamic loading conditions were run at speeds of about 40 and $56 \mathrm{~km} / \mathrm{h}$ (25 and $35 \mathrm{mph}$ ). Field measurements were also recorded during actual traffic loadings. Measured strain distributions suggest that the cross beam is subjected 
to bending moment as well as shear and axial forces. These forces are believed to be the result of the differential deflection of the main girders and the rotation of the top flange of the girders as the concrete slab distorts. Forces detected in the sway bracings are believed to be caused by this same behavior. Results of the known load static and dynamic tests are similar. However, strains measured during normal traffic loadings are 1.7 to 2.7 times greater than those for the other loading conditions. Higher strain readings are believed to be due to increased vehicle weights. A maximum strain range of 650 microstrain was recorded in a gage located at the toe of a weld.

\subsection{Summary}

The current Standard Specifications for Highway Bridges (AASHTO, 1992) requires diaphragms or cross frames to be located over supports and intermediately in all bays at a spacing not to exceed $7,620 \mathrm{~mm}(25 \mathrm{ft}$.). These components are generally welded or bolted to longitudinal members.

Many fatigue cracks have initiated at diaphragm-to-girder connections. Field test results have aided researchers in determining the source of fatigue cracks. As longitudinal members deflect differentially, high stress levels can develop in web gap regions due to outof-plane bending. High stress levels measured in transverse members show evidence of their participation in load distribution. The high stress levels developed at diaphragm connections, when coupled with the use of fatigue sensitive details, can often result in fatigue cracking. 


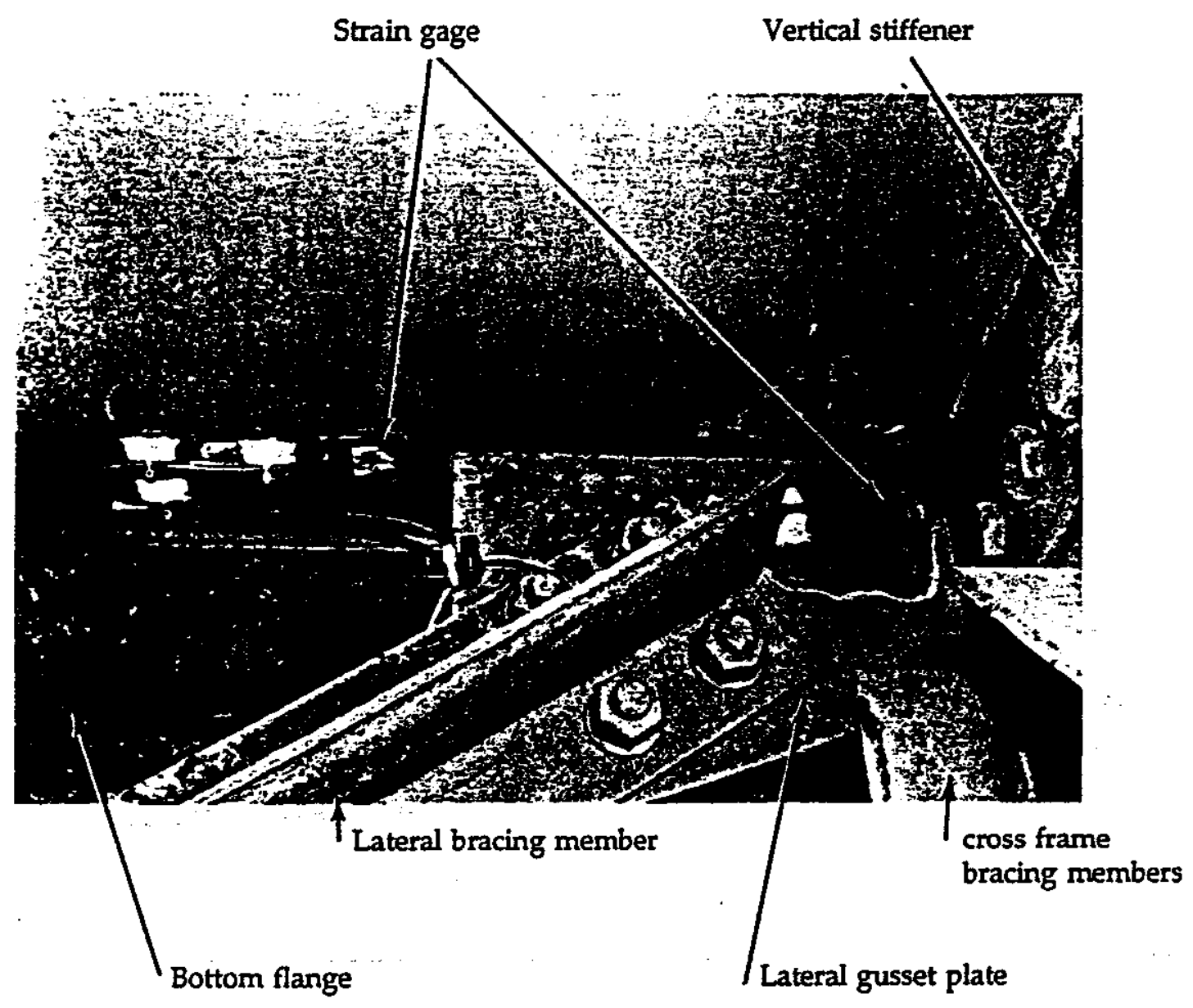

Figure 2.1.1.1 - Gerald Desmond Bridge - Strain Gages Installed at Lateral Gusset Plate Connection (Koob and Walther, 1993) 


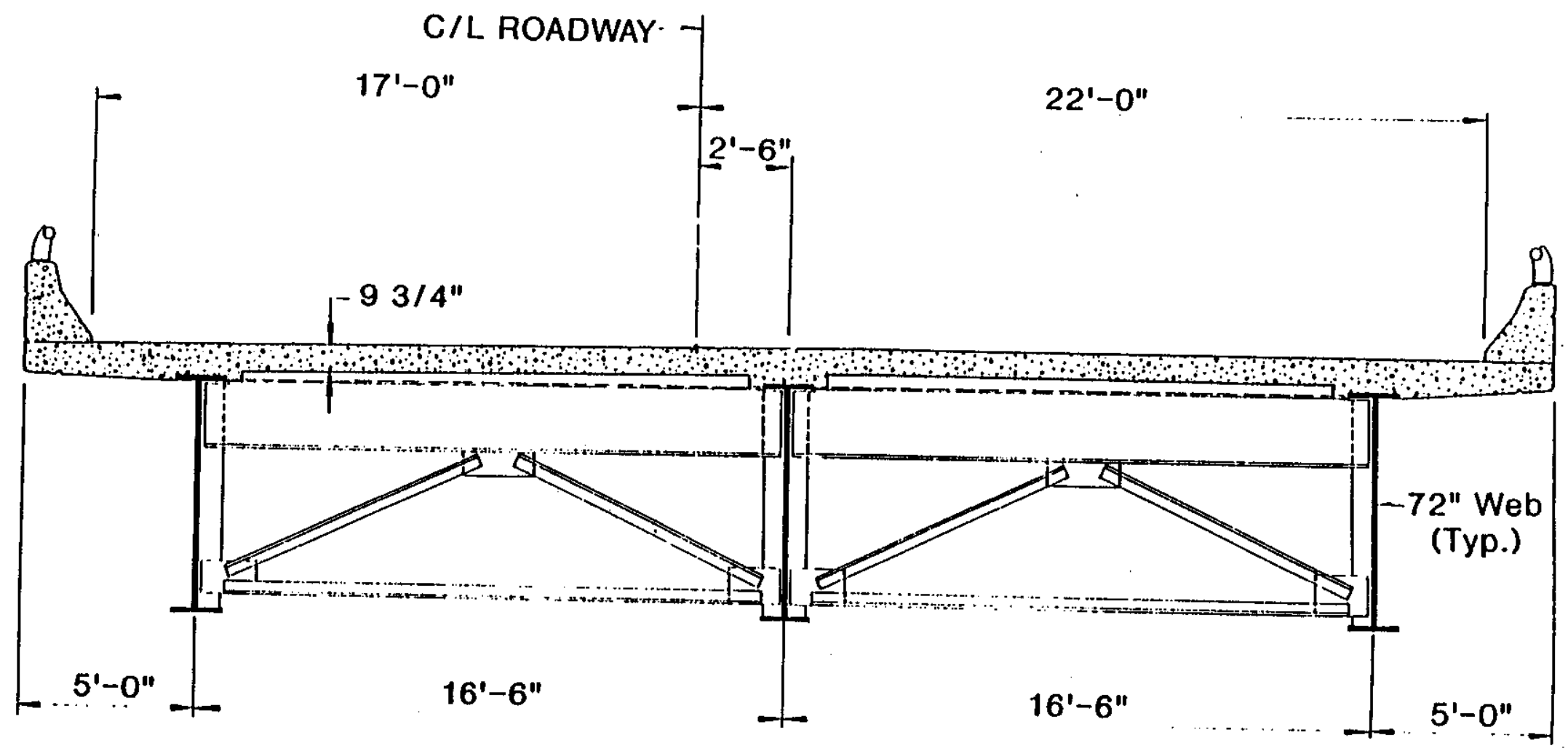

Figure 2.1.2.1 - I-64 Bridge - Typical Cross Section (Albrecht et al., 1991) 


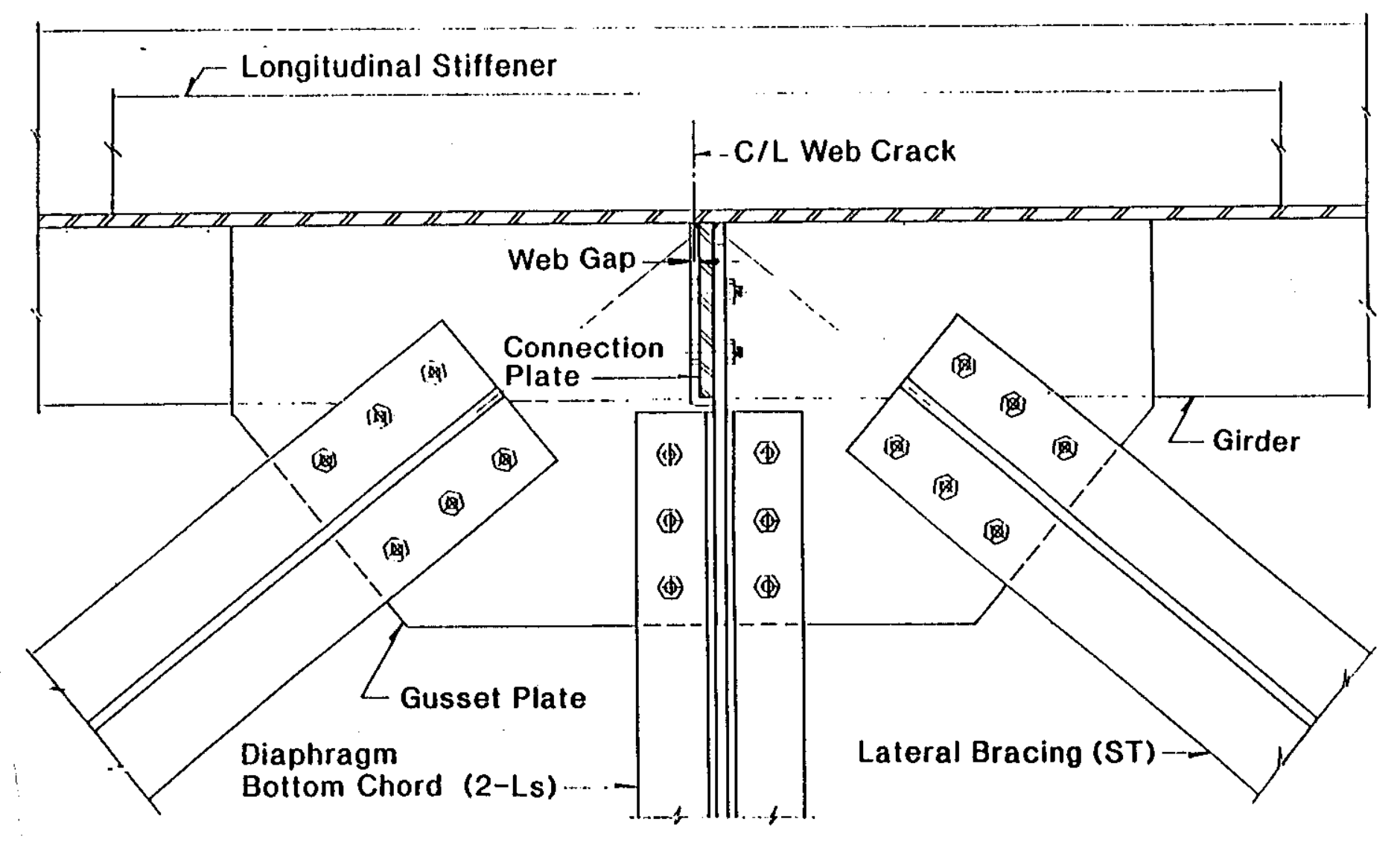

\section{PLAN OF JOINT J1}

Figure 2.1.2.2 - I-64 Bridge - Plan View of Joint (Albrecht et al., 1991) 


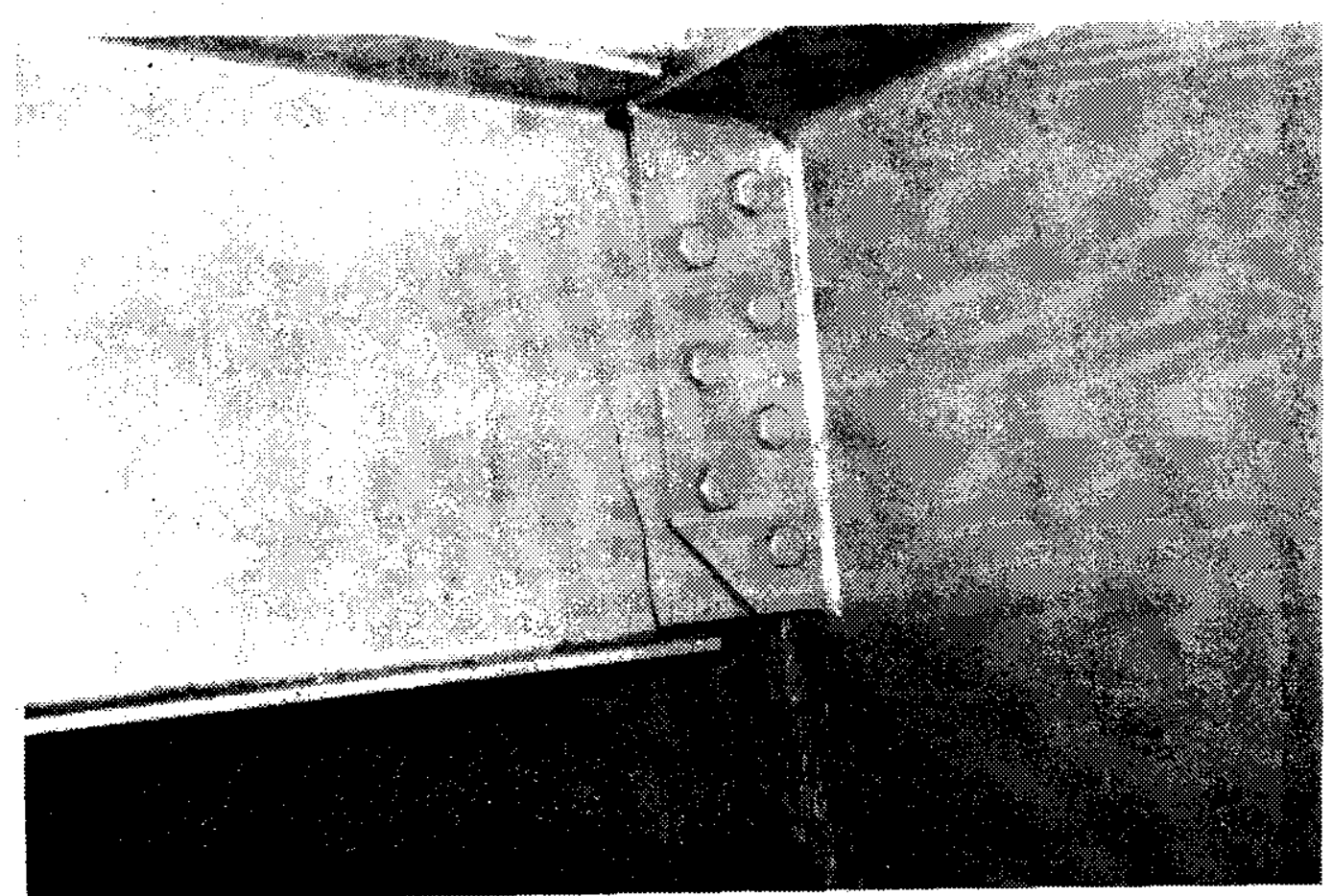

Figure 2.1.3.1 - Oklahoma Highway Bridge - Example of Cracked Diaphragm (Zwerneman et al., 1989) 


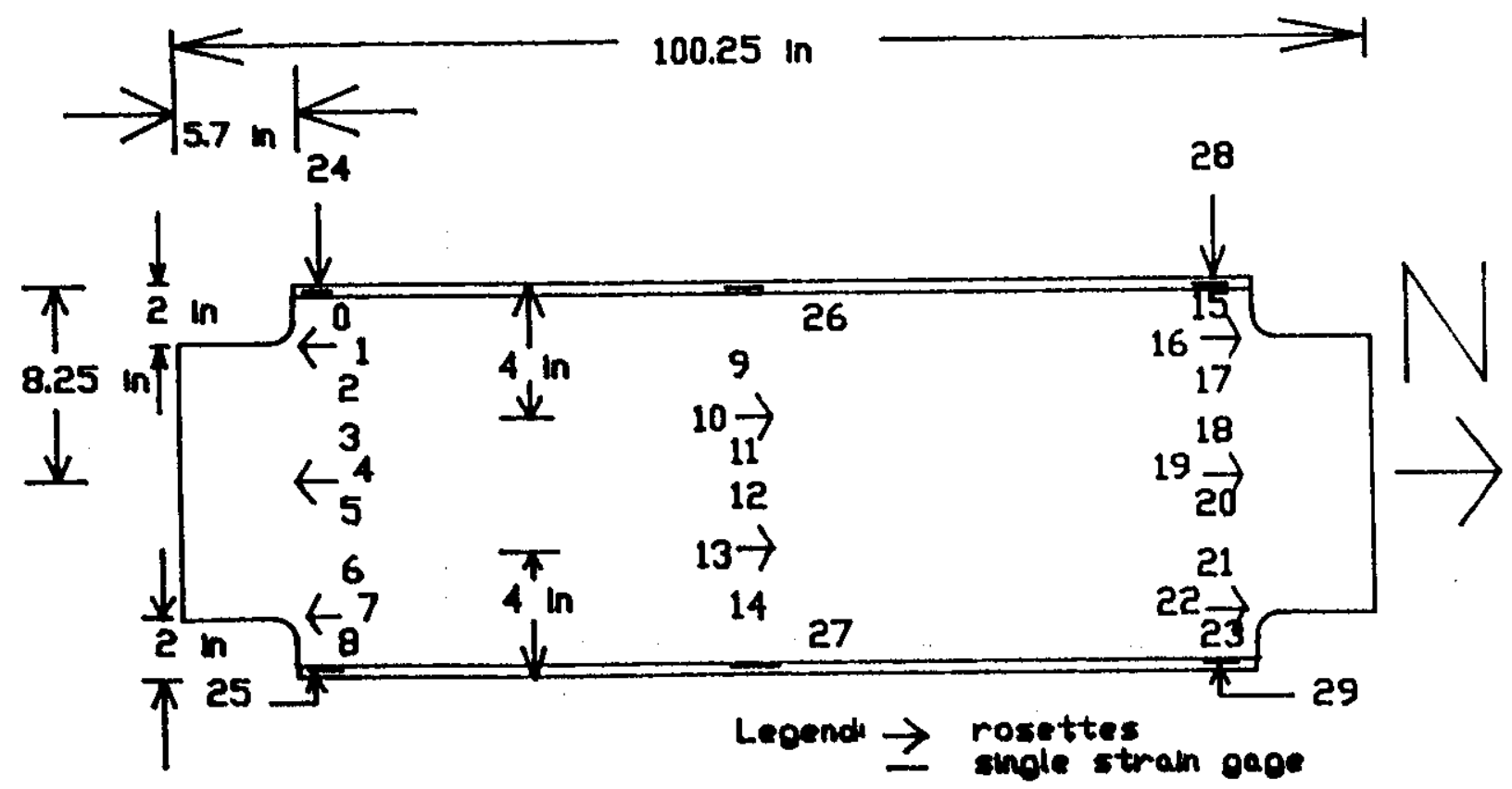

Figure 2.1.3.2 - Oklahoma Highway Bridge - Strain Gage Locations on Fabricated Diaphragm (Zwerneman et al., 1989) 


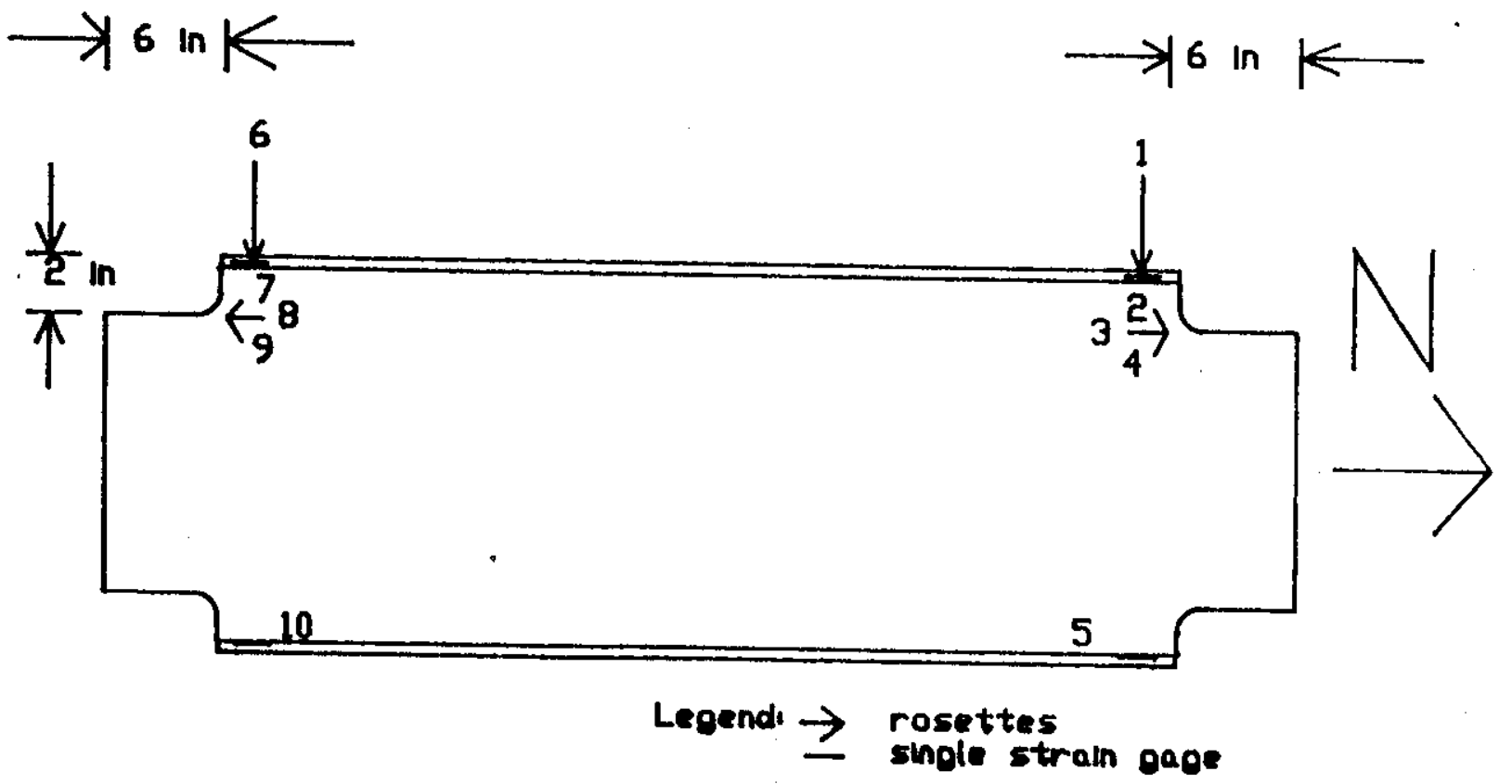

Figure 2.1.3.3 - Oklahoma Highway Bridge - Strain Gage Locations on Interior Diaphragm (Zwerneman et al., 1989) 
$\longrightarrow$ in $K$
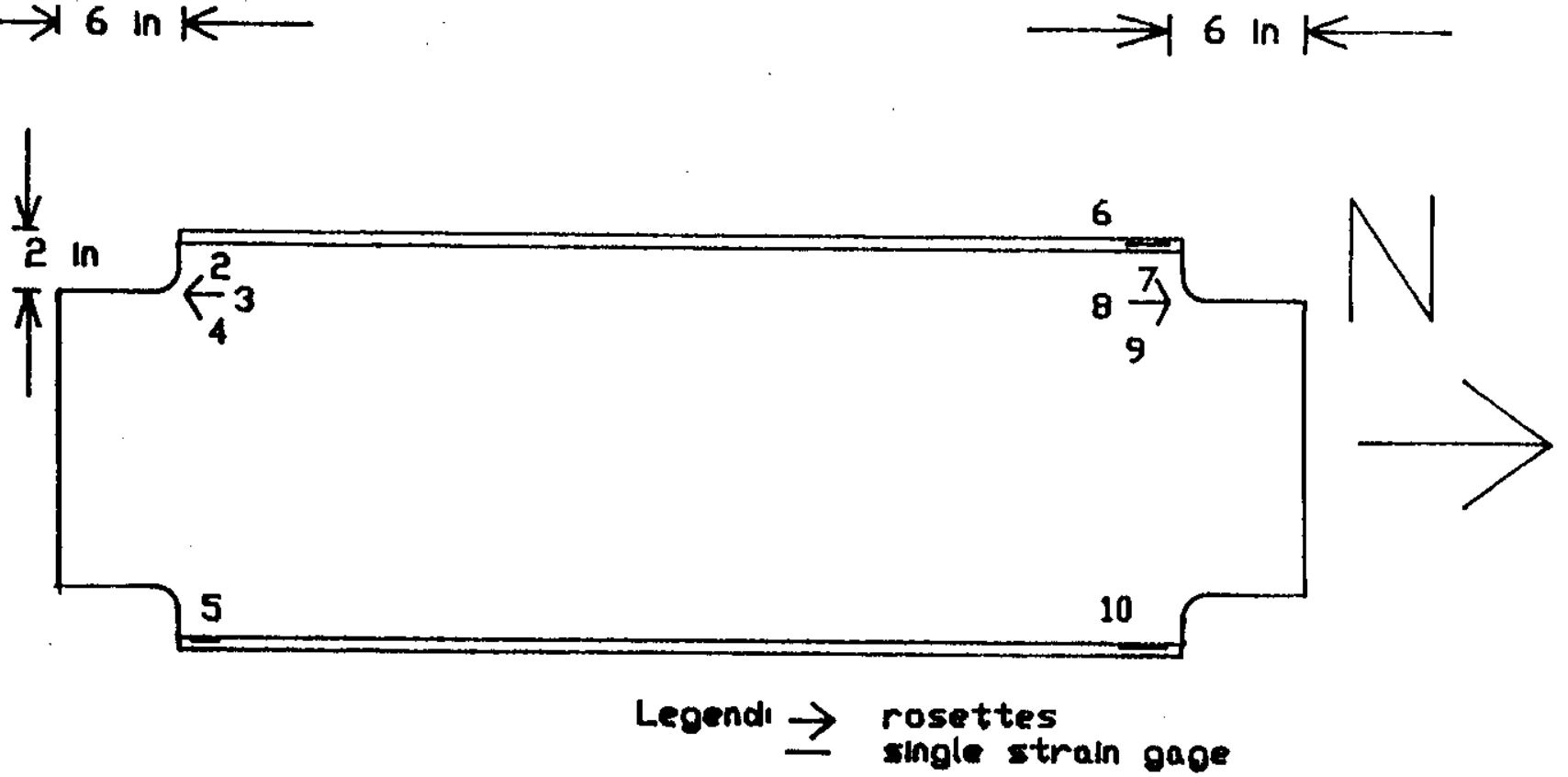

Figure 2.1.3.4 - Oklahoma Highway Bridge - Strain Gage Locations on Exterior Diaphragm (Zwerneman et al., 1989) 


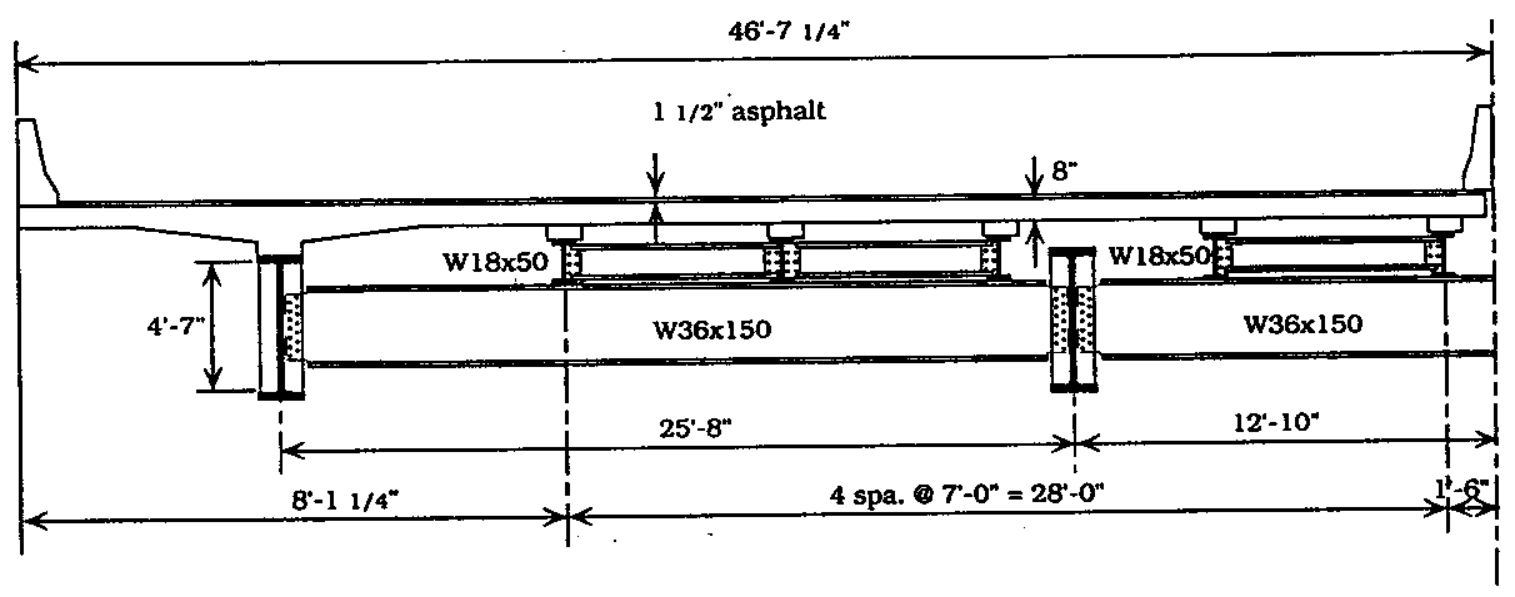

Figure 2.1.4.1 - Woodrow Wilson Memorial Bridge - Cross Section (Nowak et al., 1993) 


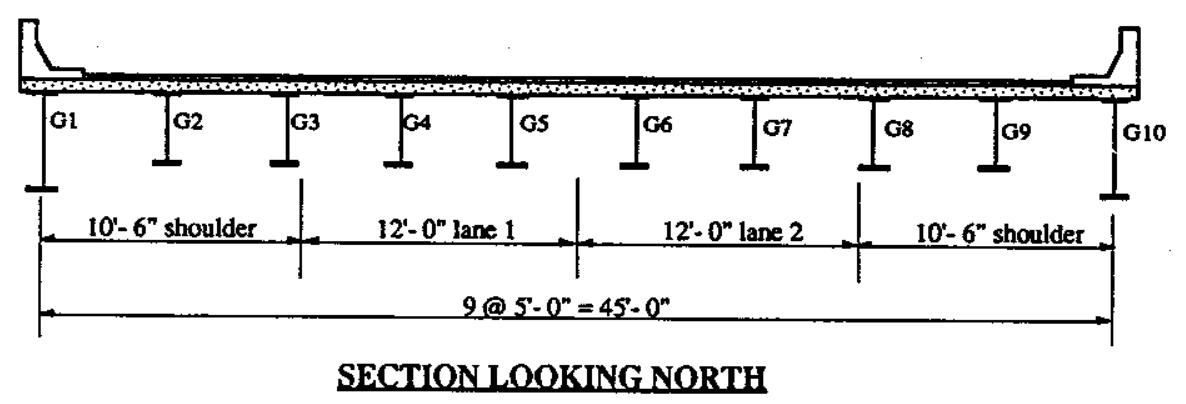

Figure 2.1.5.1 - US 23 Bridge - Cross Section (Laman and Nowak, 1993) 

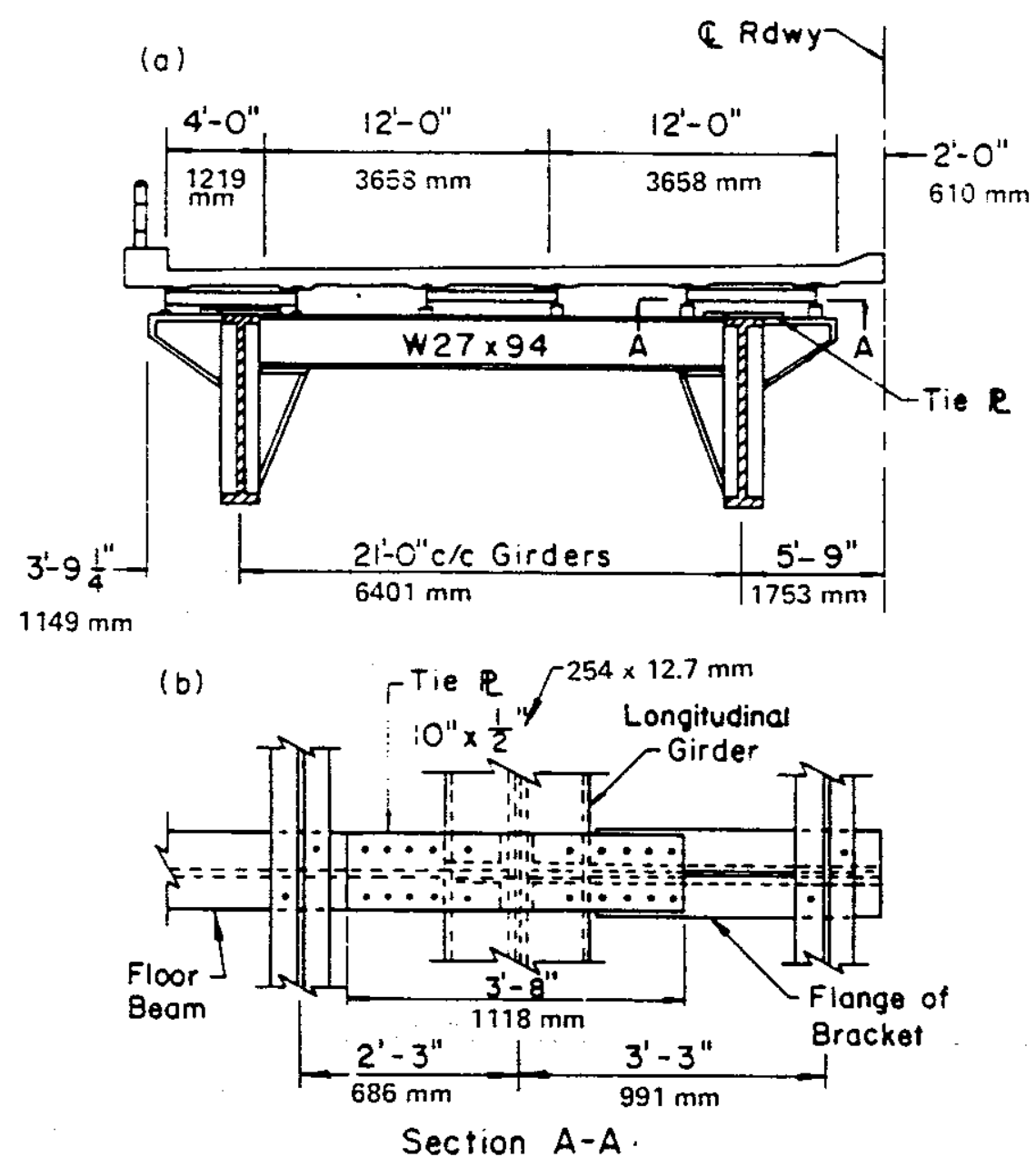

Figure 2.1.6.1 - Lehigh Canal Bridge - (a) Cross Section of Bridge and (b) Tie Plate Detail at Floor Beam-Bracket Connection to Girder (Fisher et al., 1976) 


\section{CHAPTER 3 \\ EXPERIMENTAL PROGRAM}

\subsection{Overview}

For the field testing portion of this study, two bridges incorporating the welded diaphragm-to-beam connection had to be chosen. The detail of interest is described to have the diaphragm welded to the beam web using fillet welds along the top of the diaphragm flanges and intermittent welds along both sides of the diaphragm web (Figure 3.1.1). One bridge was to have a skew so that the diaphragms were staggered, and the other was to have no skew such that the diaphragms lined up back-to-back. After visiting several local bridge sites, two structures were selected for their ease of accessibility and sufficient truck traffic.

\subsection{US 52 Bridge}

Bridge number 052-79-02459AEBL was the first structure used in field testing and will be referred to as the US 52 bridge throughout this report. This bridge was chosen for several reasons. Located in Lafayette, the bridge site is only a short drive from the university. The first steel span was selected to be the instrumented span because of its easy accessibility. Half of the span crosses over a wide shoulder and the other half over 9th Street making instrumentation possible with the help of a bucket truck. Low truck traffic was observed during the initial visit to the site and posed a concern for traffic monitoring.

The US 52 bridge is a six span bridge. The first span is a $9,754 \mathrm{~mm}$ ( $32 \mathrm{ft}$.) concrete simple span, while the remaining spans $[28,042 \mathrm{~mm}-32,919 \mathrm{~mm}-28,652 \mathrm{~mm}-30,785 \mathrm{~mm}$ 
$\left.-28,042 \mathrm{~mm}\left(92^{\prime}-108^{\prime}-94^{\prime}-101^{\prime}-92 '\right)\right]$ are continuous steel spans. The instrumented span over 9th Street is $28,040 \mathrm{~mm}$ (92 ft.) in length and consists of eight beams (W36x150 located before the construction joint and W36x230 after). Interior beams are spaced at $1,829 \mathrm{~mm}$ (6 ft.) and exterior beams at $1524 \mathrm{~mm}(5 \mathrm{ft}$.). To provide lateral stiffness, diaphragms (W18x45) are located perpendicular to the beams at an approximate spacing of 7,160 mm (23 ft.- 6 in.) with no stagger. A plan view of the instrumented span with labeled sections is presented in Figure 3.2.1. Diaphragms are attached to the beams with fillet welds located on top of both flanges of the diaphragms and intermittent welds along both sides of the web. The beams support a $13,100 \mathrm{~mm}$ ( $43 \mathrm{ft}$.) wide concrete deck that is $190 \mathrm{~mm}\left(7^{1} / 2\right.$ in.) thick.

It was decided that three diaphragms and two adjacent beams found near the centerline of the span would be instrumented in order to measure the highest possible strains in the diaphragms and beams (Figure 3.2.2). At this location, strain gages were situated beneath the outside traffic lane to capture the majority of the truck traffic during monitoring. Figure 3.2.3 presents instrumented members and their position.

\subsubsection{Instrumentation}

Strains were measured in the beams and diaphragms by using electrical resistance strain gages. Strain gages were placed on the beams where the diaphragms frame into the beams. In order to obtain the strain distribution across beam sections, strain gages were oriented longitudinally on the bottom of the top and bottom flanges of the beams. Gages were also positioned vertically on the beam web, at a location between the beam and diaphragm flanges to detect out-of-plane bending (Figure 3.2.1.1). On the diaphragms, strain gages were placed at midspan on the top and bottom flanges, and a rosette was mounted to the web at mid-depth (Figure 3.2.1.2). This placement was used to determine the axial, 
shear, and bending forces in the diaphragms. Location of diaphragm strain gages in the field are displayed in Figure 3.2.1.3. Table 3.2.1.1 lists the strain gages, locations, and abbreviations which will be used throughout the text.

After locating and marking the proposed strain gage locations on designated members, each site was ground in a direction parallel to the assumed direction of stress using a $100 \mathrm{~mm}$ (4 in.) disc grinder. The ground area was then "wet sanded" using 400 grit sand paper and applications of Micromeasurements Conditioner A, an acidic solution. Wet sanding was followed by wiping the area clean first with additional Conditioner $\mathrm{A}$ and then with Micromeasurements Neutralizer, a basic solution. Electrical resistance strain gages (Micromeasurements CEA-06-250UN-350) and solder terminals were bonded to the beams and diaphragms using Mbond 200 adhesive. Gage 22, twisted, shielded cable was soldered first to the solder terminals and then connected to the strain gages. When soldering was completed, Micromeasurements Mcoat A, microsilicon wax, and Mcoat J rubber sealant were applied to the strain gages and their wire connection for protection against both moisture and mechanical damage.

$150 \mathrm{~mm}(6 \mathrm{in}$.$) long rulers were mounted on aluminum angles and attached to the$ bottom of the beams using epoxy and C-clamps. Ruler assemblies were attached making sure that they were oriented at an angle such that the level would be able to sight on the markings. The ruler assembly, located where the diaphragms frame into the beams, was used in measuring overall and relative deflections of the instrumented beams. Deflection of the two instrumented beams was measured using a Wild precision level which sighted on rulers attached to the bottom of the beams. Deflection measurements were taken during each static loading condition.

Members were accessed using an INDOT bucket truck. The bucket was spacious and 
allowed two people to prepare locations and mount gages on the members, thereby reducing the amount of time required in the field. Because the area to be gaged and the bucket truck were located on the shoulder side of the span, 9 th Street traffic was not affected. A 5000 Watt portable generator with grounding rod was used to supply the power for soldering, grinding, lighting, and melting the microsilicon wax. Instrumentation was completed after gathering the shielded cable together and running it back along the beams to the west abutment where it was stored on a wooden platform spanning between the instrumented beams.

\subsubsection{Load Testing Procedure}

Load testing consisted of three phases: static load testing with a known load, dynamic load testing with the same known load, and monitoring regular traffic. Known load testing was performed using a loaded tandem axle dump truck weighing $232 \mathrm{kN}(52,200 \mathrm{lb}$.). Truck weights were measured at a nearby weigh station. Initially, only the rear axle was weighed. The middle axle weight was determined by subtracting the rear axle weight from the combined weight of the middle and rear axles. Finally, the front axle weight was able to be calculated by subtracting the weight of the middle and rear axles from the weight of the entire dump truck. Truck axle weights and axle and tire spacings are shown in Figure 3.2.2.1. Normal vehicular traffic was also monitored the day of the load testing. Strains were recorded and stored using 23 channels of a MEGADAC 3008 data acquisition system, an optical disk drive, and a portable personal computer.

A total of eight static loading conditions were performed in order to capture maximum strain readings. Before and after recording the strains and deflections for the static loading conditions, zero readings were taken for calibration purposes. The loaded tandem 
axle dump truck with known axle weights was positioned at two different transverse locations for each of four different longitudinal locations. Starting with the rear axles centered between diaphragm rows 1 and 2 (Figure 3.2.2.2), the truck was next positioned with the front rear axle over the instrumented diaphragms in row 2 (Figure 3.2.2.3). Continuing along the span, the truck was stopped so that the rear axles were centered over the diaphragms in row 2 (Figure 3.2.2.4). Finally, the truck was positioned with the rear axles centered between diaphragm rows 2 and 3 (Figure 3.2.2.5). The first sequence of the longitudinal positions called for the truck to be positioned in the center of the right lane (Figure 3.2.2.6) and the second sequence called for the truck's rear wheels to be lined up along the shoulder line (Figure 3.2.2.7). Making sure that the bridge was clear of truck traffic, strains were recorded using the data acquisition system and deflections were recorded using a Wild level for each of the eight static loading conditions. Table 3.2.2.1 provides a summary of the static loading conditions including descriptions and abbreviations to be used throughout the text.

Five dynamic loading conditions were executed using the same loaded tandem axle dump truck with known axle weights. In order to capture any dynamic effects, a sampling rate of 500 samples per second was utilized for data collection. Zero readings were again recorded before and after the dynamic loading conditions for calibration purposes. The truck made two passes over the span at a crawl speed [ 8 $\mathrm{km} / \mathrm{h}(5 \mathrm{mph})]$ : first along the right side of the right lane and then in the center of the lane. These two transverse positions were then repeated at speeds of approximately $27 \mathrm{~km} / \mathrm{h}(17 \mathrm{mph})$ and $40 \mathrm{~km} / \mathrm{h}(25 \mathrm{mph})$. A higher speed of about $89 \mathrm{~km} / \mathrm{h}(55 \mathrm{mph})$ was originally defined in the procedure but not attainable due to a traffic light and a small hill which preceded the bridge. Figure 3.2.2.8 depicts the dump truck of known load during a dynamic loading condition. 
In order to only record the strains produced by truck traffic, "triggers" were set in the data acquisition system to begin and stop recording at certain strain readings. These "triggers" were determined by taking approximately $50 \%$ and $25 \%$ of the maximum strain readings obtained during the known load testing. Therefore, the system began recording data when the strain gages reading the highest strains read 50 microstrain and stopped recording when they read 25 microstrain. To ensure that the entire signal was captured, the system also recorded one second of data before and after the "triggers" were activated. (The data acquisition system holds all collected data in a buffer. Consequently, a pre-trigger and posttrigger time lag can be stipulated to include data on each side of the trigger strain levels for the recorded signal.) A sampling rate of 500 samples per second was again used while monitoring traffic. Besides the initial balancing of the gages, zero readings were not able to be recorded due to the setting of the "triggers". Thus, the gages were balanced three separate times during monitoring. Many of the truck types corresponding to the recorded events were noted by visual inspection. Scanning continued until data sets had been collected for approximately 45 trucks.

\section{$3.3 \underline{\text { I } 65 \text { Bridge }}$}

Bridge number 165-201-05422ASBL was the second structure used in field testing and will be referred to as the I 65 bridge throughout this report. Located north of Lafayette crossing US 231, the southern span of this bridge was chosen to be instrumented due to its easy accessibility. This span extends over a flat, grassy area making instrumentation possible with an INDOT bucket truck.

The I 65 bridge consists of two, $26,975 \mathrm{~mm}(88 \mathrm{ft} .-6 \mathrm{in}$.) spans with a skew of about 
35 degrees. Each span has six beams (W36x150) spaced at 2,440 mm (8 ft.) that support a $13,056 \mathrm{~mm}$ (42 ft.-10 in.) wide concrete deck that is $210 \mathrm{~mm}\left(8^{1} / 4\right.$ in.) thick. Transverse stiffness is provided by diaphragms (W18x45) spaced at $6,700 \mathrm{~mm}(22 \mathrm{ft}$.) with a stagger of approximately 1,700 $\mathrm{mm}$ (5 ft.-7 in.) (Figure 3.3.1). Diaphragms are connected to the beams by fillet welds located on the top of the flanges and intermittent welds along either side of the web of the diaphragms. Sloped concrete abutments support each end of the bridge making the shielded cable, stored here, easily accessible at the time of testing.

It was decided that two of the diaphragms and their connecting beams located near the centerline of the span would to be instrumented in an attempt to measure the highest possible strains that the diaphragms and beams were enduring. Note in Figure 3.3 .2 that instrumentation is concentrated under the outside lane. Diaphragm orientation and member instrumentation are shown in Figure 3.3.3.

\subsubsection{Instrumentation}

Strains were measured in the beams and diaphragms by using electrical resistance strain gages. Strain gages were placed longitudinally on the bottom of the beam flanges and on the beam web, where the diaphragm frames into the beam, in order to obtain the strain distribution across that section. Gages were also placed vertically on the web in order to detect out-of-plane bending (Figure 3.3.1.1). On the diaphragms, strain gages were placed at midspan on the top and bottom flanges, and a rosette was mounted to the web at mid-depth (Figure 3.3.1.2). This placement was used in order to determine the axial, shear, and bending forces in the diaphragms. Table 3.3.1.1 lists the strain gages, locations, and abbreviations which will be used throughout the text.

Strain gage sites were ground and prepared in a manner similar to that used on the 
US 52 bridge. The wire, gage type, and protective coatings were also the same as for the US 52 bridge. Members were accessed using the same INDOT bucket truck. Because the area to be gaged and the bucket truck were located on the grass under the span, traffic on US 231 was not affected. A 5000 Watt portable generator with grounding rod was used to

supply the power for soldering, grinding, lighting, and melting the microsilicon wax.

Relative deflection of two adjacent beams was measured using a Wild precision level which sighted on a ruler attached to the bottom of the instrumented beams where the instrumented diaphragms frame into the beams. Deflection measurements were again taken at each static loading location. The ruler assembly used in the experimental setup for the I 65 bridge differs only in the use of twelve inch rulers instead of $150 \mathrm{~mm}(6 \mathrm{in}$.). The longer ruler length allowed for the rulers to be sighted more easily with the level. Instrumentation was completed after gathering the shielded cable together and running it back along the beams to the south abutment where it was stored.

\subsubsection{Load Testing Procedure}

Load testing consisted of the same three phases: static load testing with a known load, dynamic load testing with the same known load, and monitoring regular traffic. Load testing was performed using a similarly loaded tandem axle dump truck; this time weighing $239 \mathrm{kN}(53,820 \mathrm{lb}$.). Truck axle weights and axle and tire spacings are shown in Figure 3.3.2.1. Methods used to measure axle weights and wheel spacings are analogous to those used in the testing of the US 52 bridge. Normal vehicular traffic was monitored the day of the load testing as well. Strains were recorded and stored using 24 channels of the same MEGADAC 3008 data acquisition system, optical disk drive, and portable personal 
computer.

Six static loading conditions were performed on the $\mathrm{I} 65$ bridge in order to capture maximum strain readings. Zero readings were again recorded for calibration purposes. The three longitudinal positions are as follows: rear axles centered over Diaphragm \#2 (Figure 3.3.2.2), rear axles centered between the instrumented diaphragms (Figure 3.3.2.3), and rear

axles centered over Diaphragm \#1 (Figure 3.3.2.4). At each of the longitudinal positions, the loaded tandem axle dump truck was placed in the center of the right lane (Figure 3.3.2.5) and the right side of the lane with the rear wheels lined up along the shoulder line (Figure 3.3.2.6). When no truck traffic was on the bridge and the loaded dump truck was in position, strains and deflections were recorded using the MEGADAC and the precision level, respectively. Table 3.3.2.1 summarizes the static known loading conditions and provides descriptions and abbreviations used later in the text.

The five dynamic loading conditions used in the load testing of the $\mathrm{I} 65$ bridge match those used in the load testing of the US 52 bridge. However, the three speeds attained were approximately $8 \mathrm{~km} / \mathrm{h}, 40 \mathrm{~km} / \mathrm{h}$, and $89 \mathrm{~km} / \mathrm{h}$ ( $5 \mathrm{mph}, 25 \mathrm{mph}$, and $55 \mathrm{mph})$. Zero readings were recorded, and a sampling rate of 500 samples per second was used. Before monitoring regular traffic, the dump truck of known load was placed in the right lane over the instrumented diaphragms and two readings were taken as large trucks traversed the span.

The same "triggers" and sampling rate used in monitoring the US 52 bridge were used in monitoring the I 65 bridge. Scanning continued until approximately 87 data sets had accumulated. 
Table 3.2.1.1 US 52 - Strain Gages

\begin{tabular}{|c|c|c|}
\hline Member & Gage & Location \\
\hline \multirow[t]{4}{*}{ Beam \#1 } & $\mathrm{B} 1 \mathrm{~A}$ & Bottom of Top Flange \\
\hline & $\mathrm{B} 1 \mathrm{~B}$ & Top Web Gage \\
\hline & $\mathrm{B} 1 \mathrm{C}$ & Bottom Web Gage \\
\hline & B1D & Bottom of Bottom Flange \\
\hline \multirow[t]{4}{*}{ Beam \#2 } & $\mathrm{B} 2 \mathrm{~A}$ & Bottom of Top Flange \\
\hline & $\mathrm{B} 2 \mathrm{~B}$ & Top Web Gage \\
\hline & $\mathrm{B} 2 \mathrm{C}$ & Bottom Web Gage \\
\hline & $\mathrm{B} 2 \mathrm{D}$ & Bottom of Bottom Flange \\
\hline \multirow[t]{5}{*}{ Diaphragm \#1 } & D1A & Bottom of Top Flange \\
\hline & D1B & Bottom of Bottom Flange \\
\hline & R1A & Top Rosette Gage \\
\hline & R1B & Middle Rosette Gage \\
\hline & R1C & Bottom Rosette Gage \\
\hline \multirow[t]{5}{*}{ Diaphragm \#2 } & D2A & Bottom of Top Flange \\
\hline & $\mathrm{D} 2 \mathrm{~B}$ & Bottom of Bottom Flange \\
\hline & R2A & Top Rosette Gage \\
\hline & R2B & Middle Rosette Gage \\
\hline & $\mathrm{R} 2 \mathrm{C}$ & Bottom Rosette Gage \\
\hline \multirow[t]{5}{*}{ Diaphragm \#3 } & D3A & Top of Top Flange \\
\hline & D3B & Bottom of Bottom Flange \\
\hline & R3A & Top Rosette Gage \\
\hline & $\mathrm{R} 3 \mathrm{~B}$ & Middle Rosette Gage \\
\hline & $\mathrm{R} 3 \mathrm{C}$ & Bottom Rosette Gage \\
\hline
\end{tabular}


Table 3.2.2.1 US 52 - Static Loading Conditions

\begin{tabular}{|c|c|c|}
\hline \multirow{2}{*}{$\begin{array}{c}\text { Loading } \\
\text { Condition }\end{array}$} & Longitudinal Position & Transverse Position \\
\cline { 2 - 3 } LC \#1A & $\begin{array}{c}\text { Rear Axles Centered Between } \\
\text { Diaphragm Rows 1 \& 2 }\end{array}$ & Truck Centered in Right Lane \\
\hline LC \#2A & $\begin{array}{c}\text { Front Rear Axle Over Diaphragm } \\
\text { Row 2 }\end{array}$ & Truck Centered in Right Lane \\
\hline LC \#3A & $\begin{array}{c}\text { Rear Axles Centered Over } \\
\text { Diaphragm Row 2 }\end{array}$ & Truck Centered in Right Lane \\
\hline LC \#4A & $\begin{array}{c}\text { Rear Axles Centered Between } \\
\text { Diaphragm Rows 2 \& 3 }\end{array}$ & Truck Centered in Right Lane \\
\hline LC \#1B & $\begin{array}{c}\text { Rear Axles Centered Between } \\
\text { Diaphragm Rows 1 \& 2 }\end{array}$ & $\begin{array}{c}\text { Right Rear Wheels of Truck } \\
\text { Positioned Along Shoulder Line }\end{array}$ \\
\hline LC \#2B & $\begin{array}{c}\text { Front Rear Axle Over Diaphragm } \\
\text { Row 2 }\end{array}$ & $\begin{array}{c}\text { Right Rear Wheels of Truck } \\
\text { Positioned Along Shoulder Line }\end{array}$ \\
\hline LC \#3B & $\begin{array}{c}\text { Rear Axles Centered Over } \\
\text { Diaphragm Row 2 }\end{array}$ & $\begin{array}{c}\text { Right Rear Wheels of Truck } \\
\text { Positioned Along Shoulder Line }\end{array}$ \\
\hline LC \#4B & $\begin{array}{c}\text { Rear Axles Centered Between } \\
\text { Diaphragm Rows 2 \& 3 }\end{array}$ & $\begin{array}{c}\text { Right Rear Wheels of Truck } \\
\text { Positioned Along Shoulder Line }\end{array}$ \\
\hline
\end{tabular}


Table 3.3.1.1 I 65 - Strain Gages

\begin{tabular}{|c|c|c|}
\hline Member & Gage & Location \\
\hline \multirow[t]{4}{*}{ Beam \#1 } & $\mathrm{B} 1 \mathrm{~A}$ & Bottom of Top Flange \\
\hline & B1B & Top Web Gage \\
\hline & $\mathrm{B} 1 \mathrm{C}$ & Bottom Web Gage \\
\hline & B1D & Bottom of Bottom Flange \\
\hline \multirow[t]{5}{*}{ Beam \#2 } & B2A & Bottom of Top Flange \\
\hline & $\mathrm{B} 2 \mathrm{~B}$ & Top Web Gage \\
\hline & $\mathrm{B} 2 \mathrm{M}$ & Middle (Longitudinal) Web Gage \\
\hline & $\mathrm{B} 2 \mathrm{C}$ & Bottom Web Gage \\
\hline & $\mathrm{B} 2 \mathrm{D}$ & Bottom of Bottom Flange \\
\hline \multirow[t]{5}{*}{ Beam \#3 } & B3A & Bottom of Top Flange \\
\hline & $\mathrm{B} 3 \mathrm{~B}$ & Top Web Gage \\
\hline & $\mathrm{B} 3 \mathrm{M}$ & Middle (Longitudinal) Web Gage \\
\hline & $\mathrm{B} 3 \mathrm{C}$ & Bottom Web Gage \\
\hline & B3D & Bottom of Bottom Flange \\
\hline \multirow[t]{5}{*}{ Diaphragm \#1 } & D1A & Top of Top Flange \\
\hline & D1B & Bottom of Bottom Flange \\
\hline & R1A & Top Rosette Gage \\
\hline & R1B & Middle Rosette Gage \\
\hline & $\mathrm{R} 1 \mathrm{C}$ & Bottom Rosette Gage \\
\hline \multirow[t]{5}{*}{ Diaphragm \#2 } & $\mathrm{D} 2 \mathrm{~A}$ & Top of Top Flange \\
\hline & D2B & Bottom of Bottom Flange \\
\hline & R2A & Top Rosette Gage \\
\hline & R2B & Middle Rosette Gage \\
\hline & $\mathrm{R} 2 \mathrm{C}$ & Bottom Rosette Gage \\
\hline
\end{tabular}


Table 3.3.2.1 I 65 - Static Loading Conditions

\begin{tabular}{|c|c|c|}
\hline \multirow{2}{*}{$\begin{array}{l}\text { Loading } \\
\text { Condition } \\
\end{array}$} & \multicolumn{2}{|c|}{ Description } \\
\hline & Longitudinal Position & Transverse Position \\
\hline LC \#1A & $\begin{array}{c}\text { Rear Axles Centered Over } \\
\text { Diaphragm \#2 }\end{array}$ & Truck Centered in Right Lane \\
\hline $\mathrm{LC} \# 2 \mathrm{~A}$ & $\begin{array}{l}\text { Rear Axles Centered Between } \\
\text { Instrumented Diaphragms }\end{array}$ & Truck Centered in Right Lane \\
\hline LC \#3A & $\begin{array}{c}\text { Rear Axles Centered Over } \\
\text { Diaphragm \#1 }\end{array}$ & Truck Centered in Right Lane \\
\hline LC \#1B & $\begin{array}{c}\text { Rear Axles Centered Over } \\
\text { Diaphragm \#2 }\end{array}$ & $\begin{array}{l}\text { Right Rear Wheels of Truck } \\
\text { Positioned Along Shoulder Line }\end{array}$ \\
\hline $\mathrm{LC} \# 2 \mathrm{~B}$ & $\begin{array}{l}\text { Rear Axles Centered Between } \\
\text { Instrumented Diaphragms }\end{array}$ & $\begin{array}{l}\text { Right Rear Wheels of Truck } \\
\text { Positioned Along Shoulder Line }\end{array}$ \\
\hline LC \#3B & $\begin{array}{c}\text { Rear Axles Centered Over } \\
\text { Diaphragm \#1 }\end{array}$ & $\begin{array}{l}\text { Right Rear Wheels of Truck } \\
\text { Positioned Along Shoulder Line }\end{array}$ \\
\hline
\end{tabular}




\section{Welded Diaphragm-to-Beam Connection}

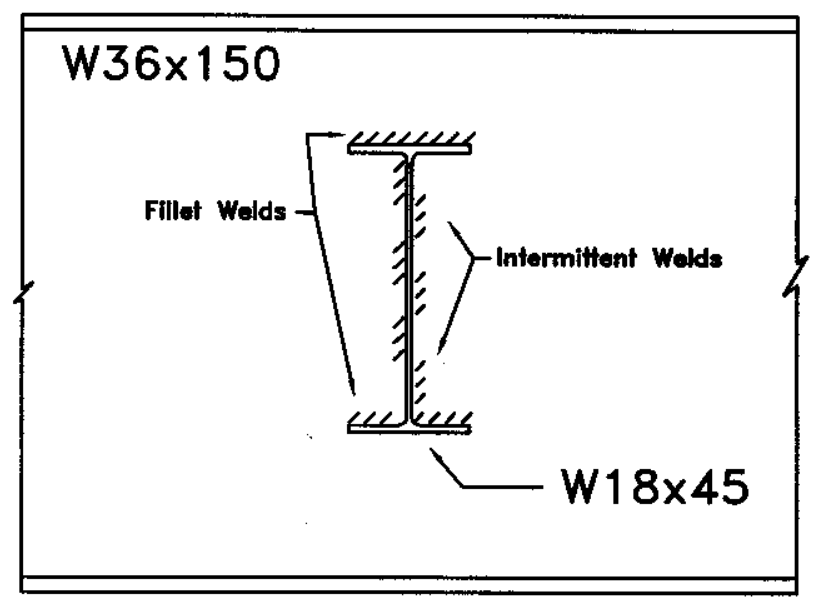

Figure 3.1.1 - Welded Diaphragm-to-Beam Connection 


\section{US 52 Bridge Plan View}

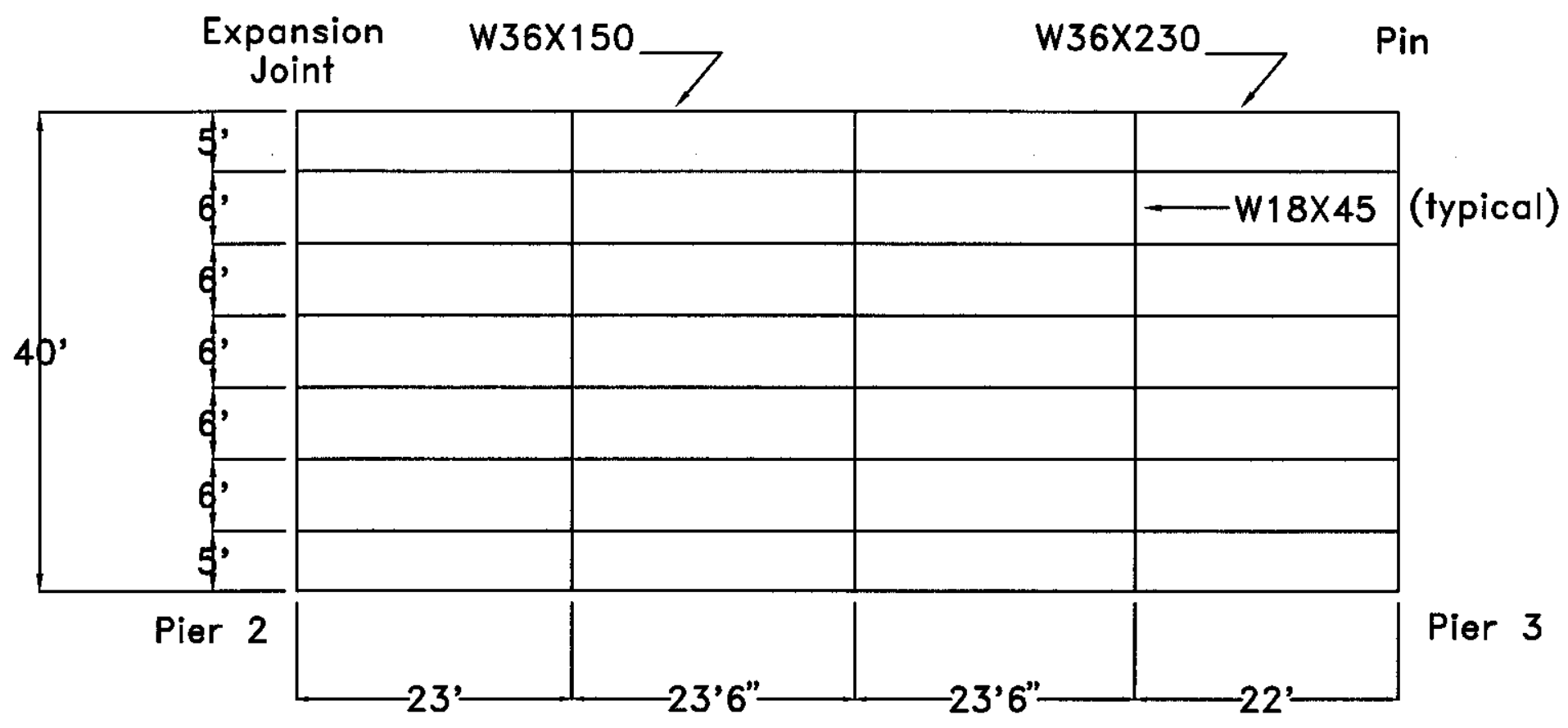

Figure 3.2.1 - US 52 - Plan View of Instrumented Span 


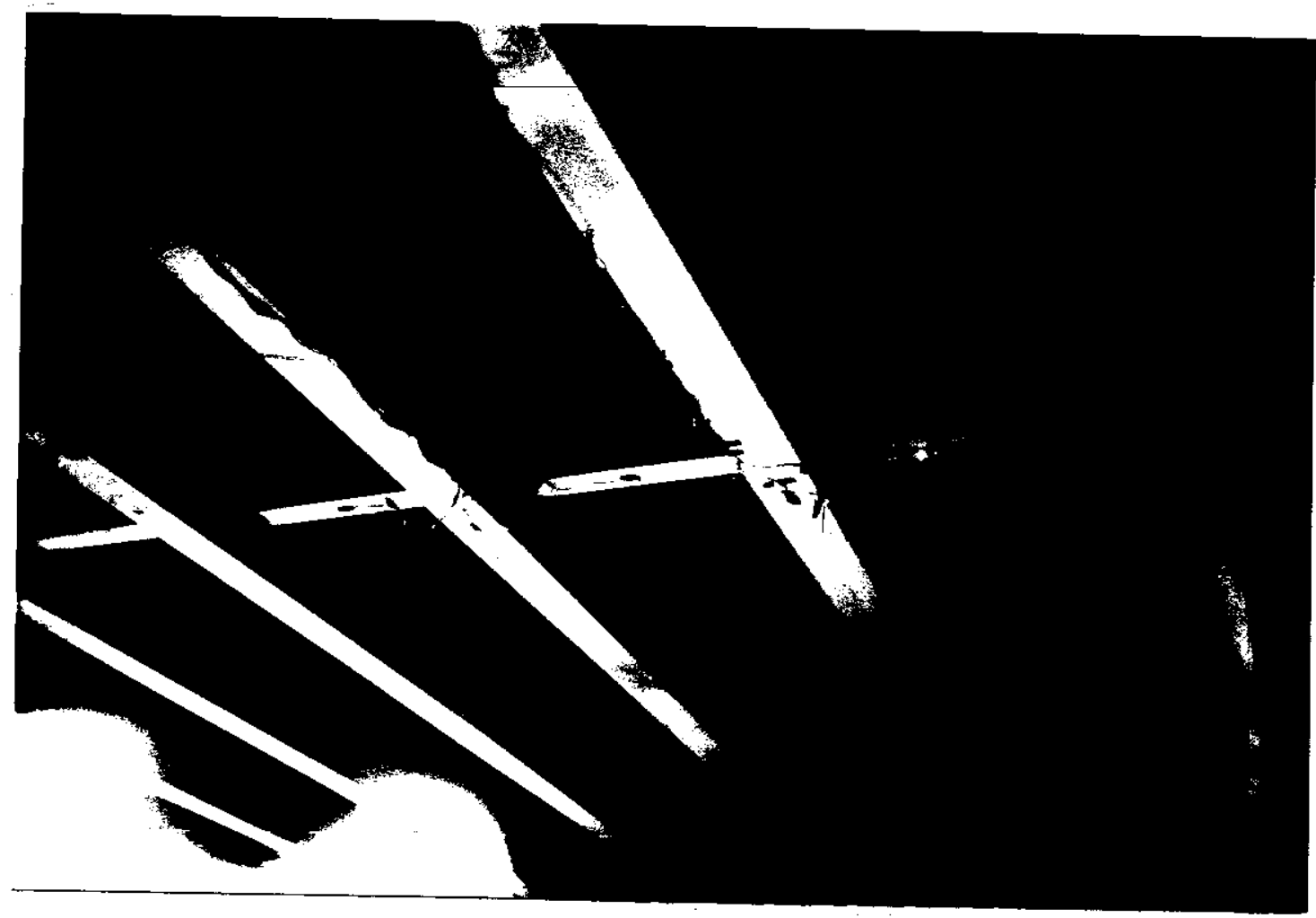

Figure 3.2.2 - US 52 - Instrumented Members 


\section{US 52 Bridge - Gage Placement}

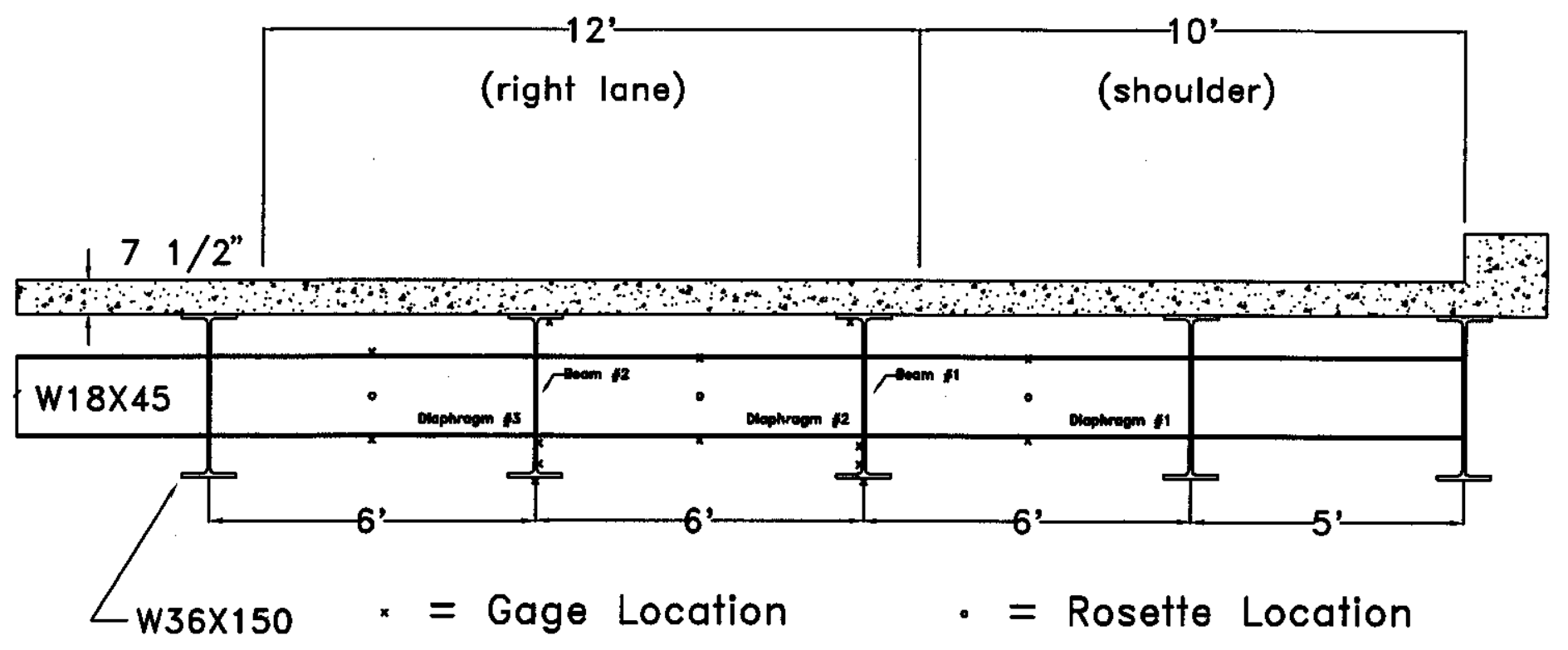

Figure 3.2.3 - US 52 - Gage Placement 


\section{US 52 - Gage Placement Beam \#2}

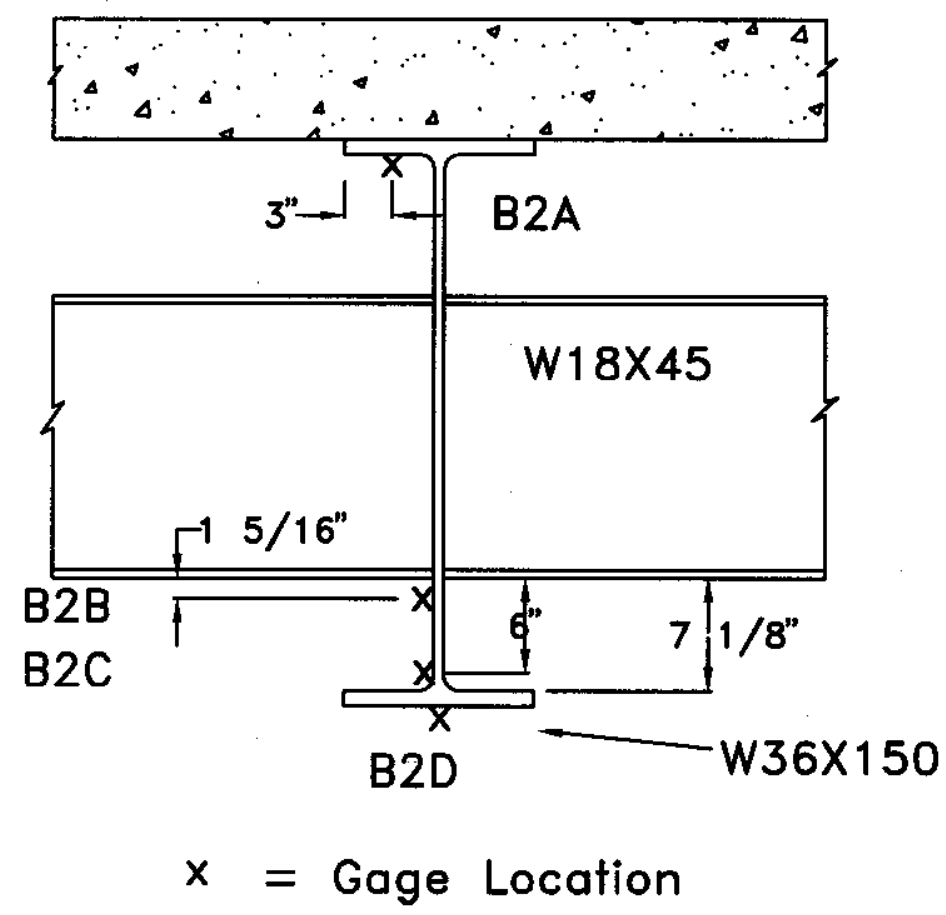

Figure 3.2.1.1 - US 52 - Strain Gage Placement - Beam 


\section{US 52 - Gage Placement Diaphragm \#2 \& Beam \#2}

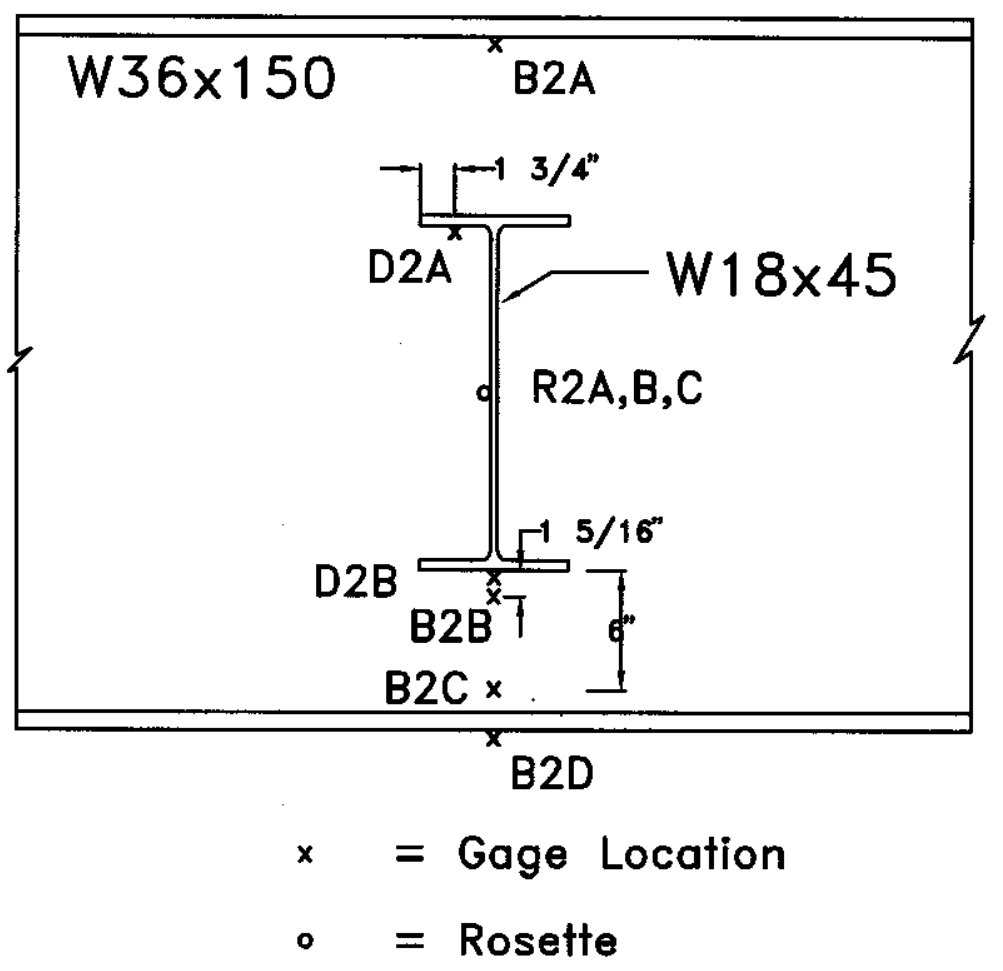

Figure 3.2.1.2 - US 52 - Strain Gage Placement - Diaphragm 


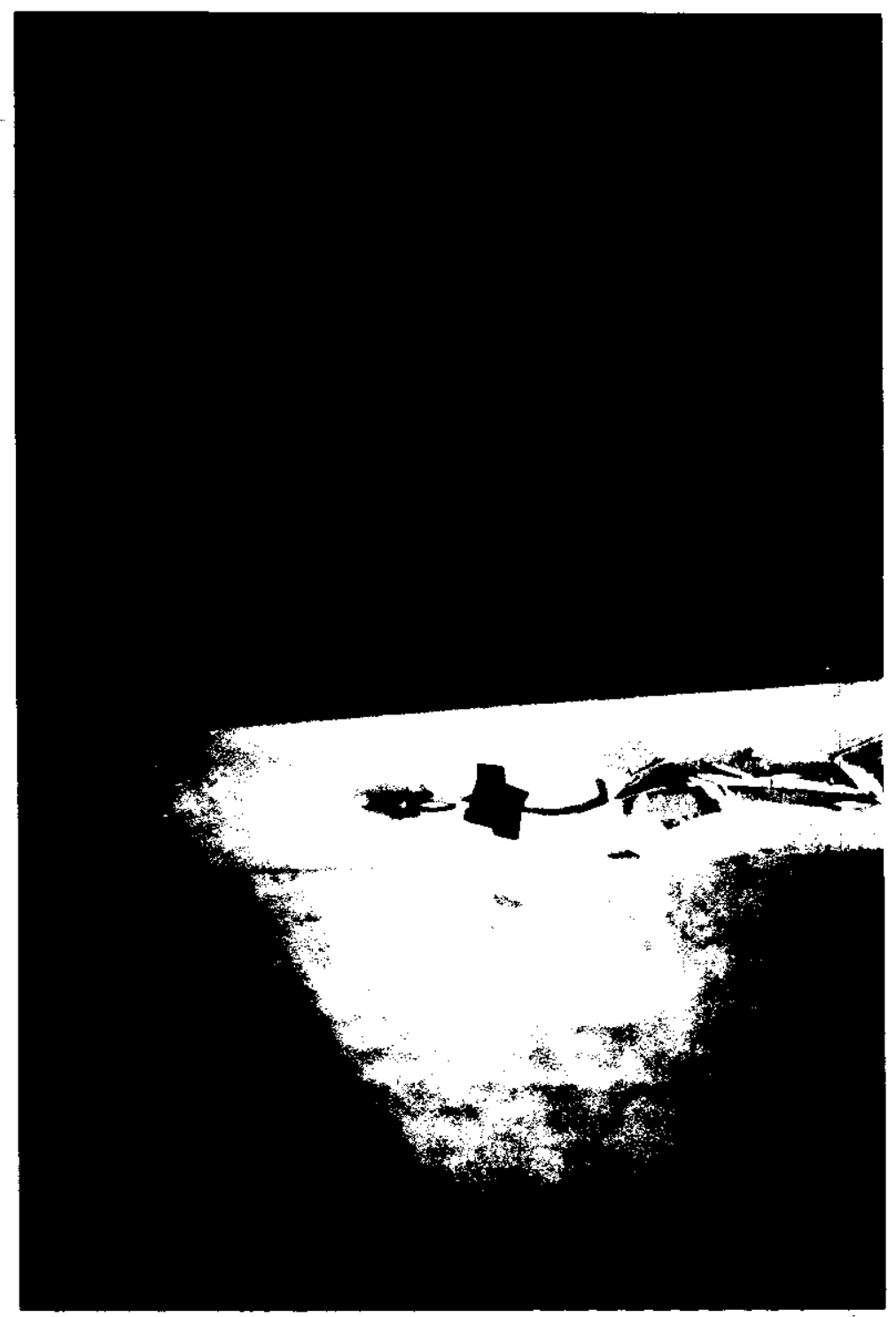

Figure 3.2.1.3 - US 52 - Diaphragm Instrumentation 

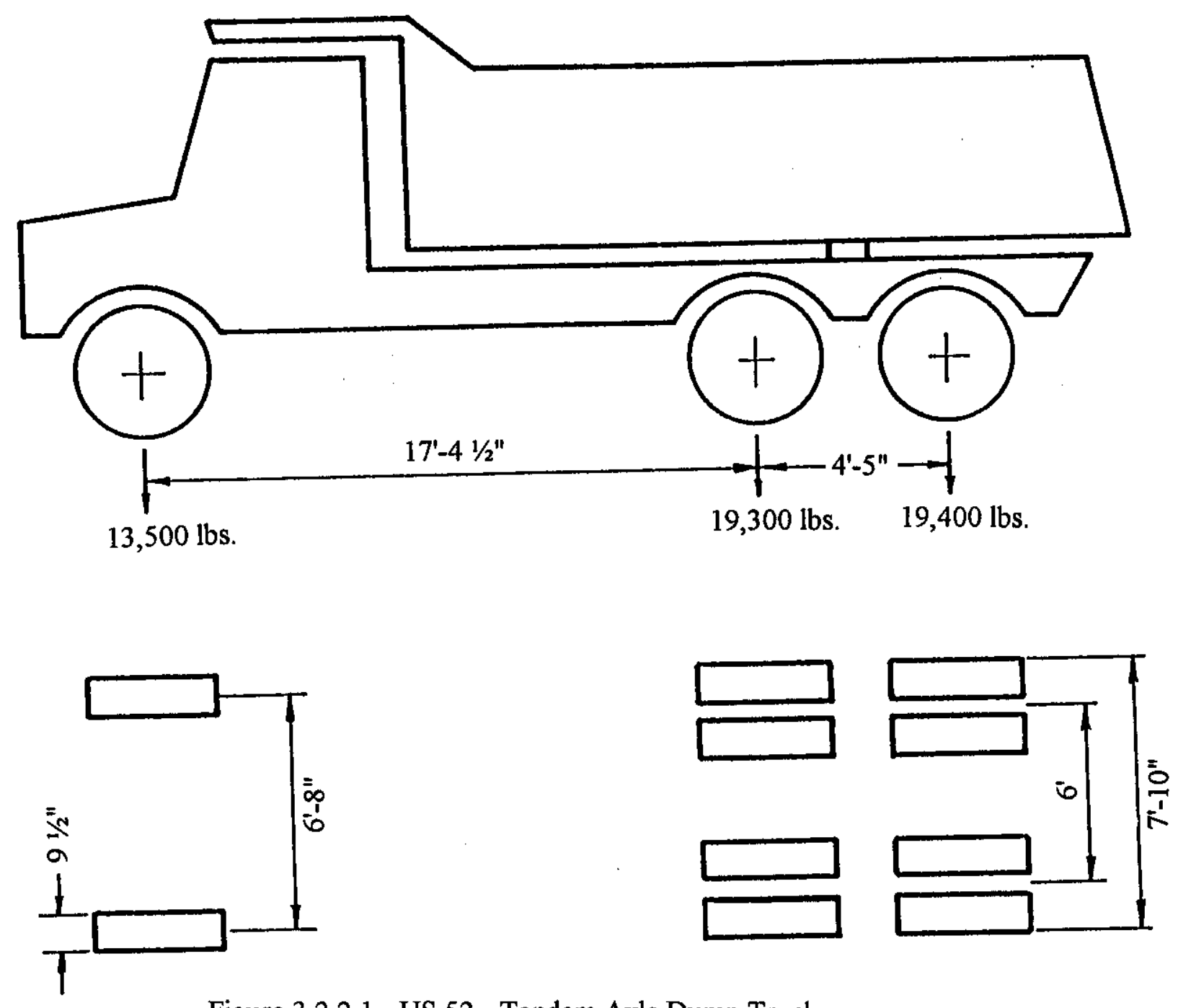

Figure 3.2.2.1 - US 52 - Tandem Axle Dump Truck 


\section{Longitudinal Static Loading \\ Condition \#1}

(Rear Axles Centered Between Diaphragm Rows 1 \& 2)

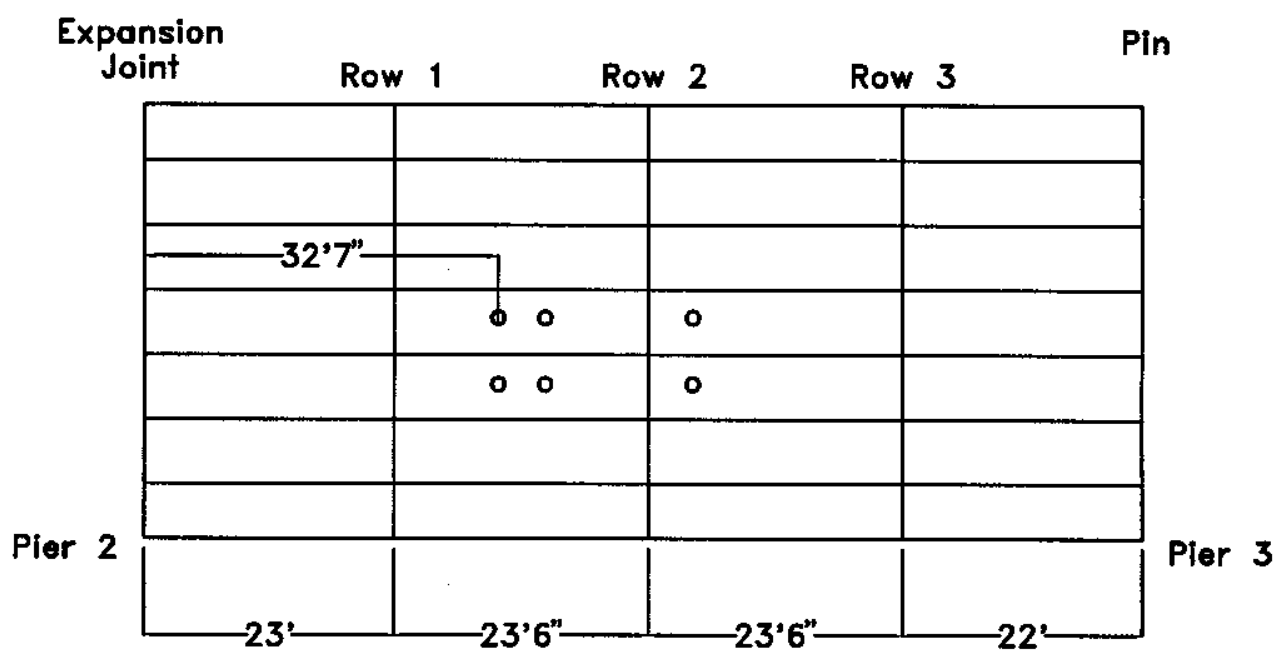

US 52 - Plan View

- = Location of Truck Wheels

Figure 3.2.2.2 - US 52 - Static Loading Condition \#1 (LC \#1) 


\section{Longitudinal Static Loading Condition \#2}

(Front Rear Axle Over Instrumented Diaphragms)

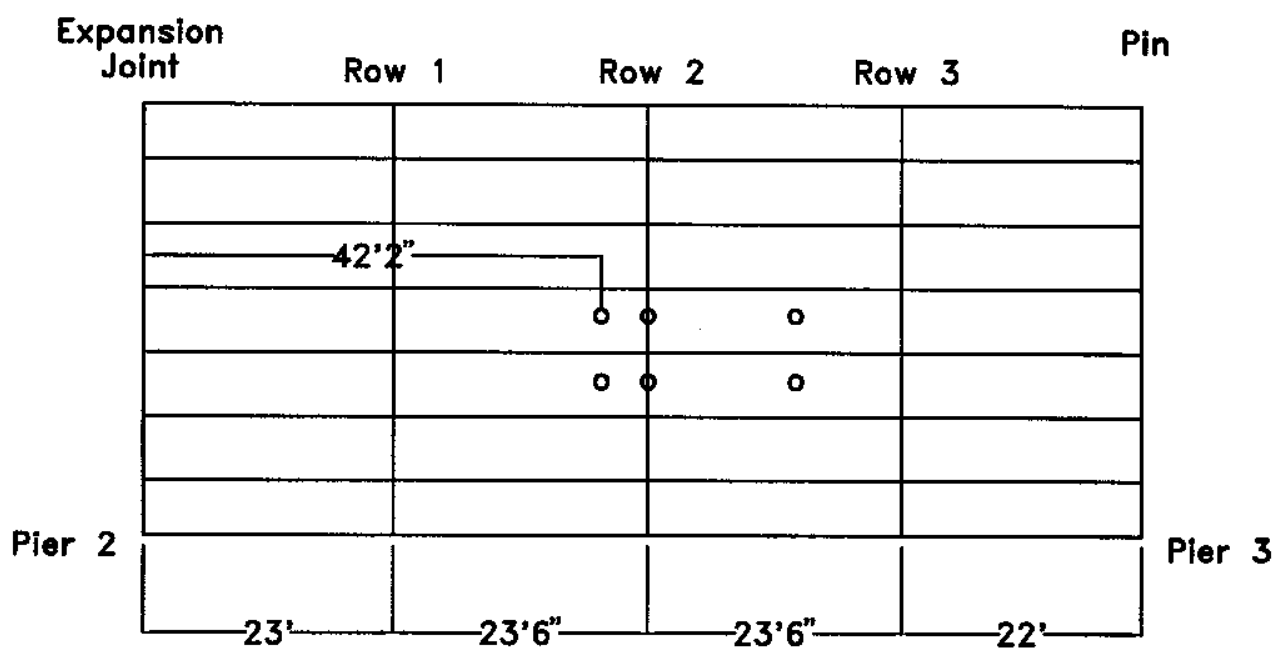

$$
\begin{gathered}
\text { US } 52 \text { - Plan View } \\
\text { - = Location of Truck Wheels }
\end{gathered}
$$

Figure 3.2.2.3 - US 52 - Static Loading Condition \#2 (LC \#2) 


\section{Longitudinal Static Loading Condition \#3}

(Rear Axles Centered Over Instrumented Diaphragms)

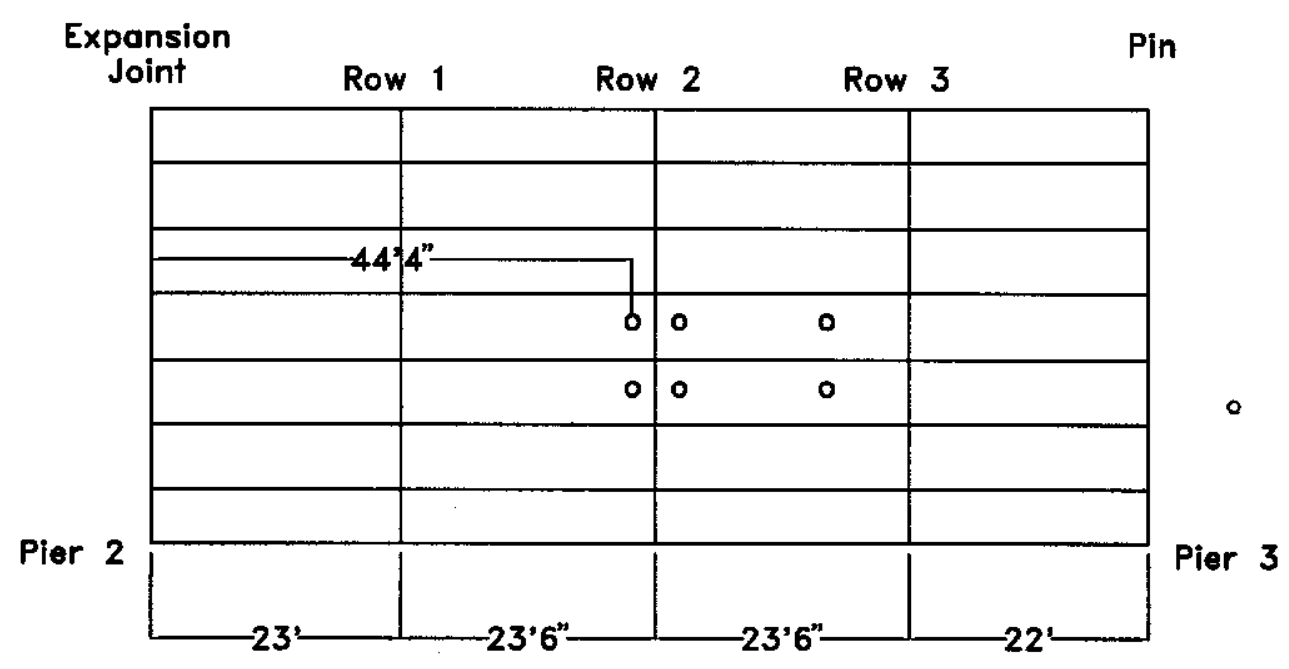

US 52 - Plan View

0 = Location of Truck Wheels

Figure 3.2.2.4 - US 52 - Static Loading Condition \#3 (LC \#3) 


\section{Longitudinal Static Loading Condition \#4}

(Rear Axles Centered Between Diaphragm Rows 2 \& 3)

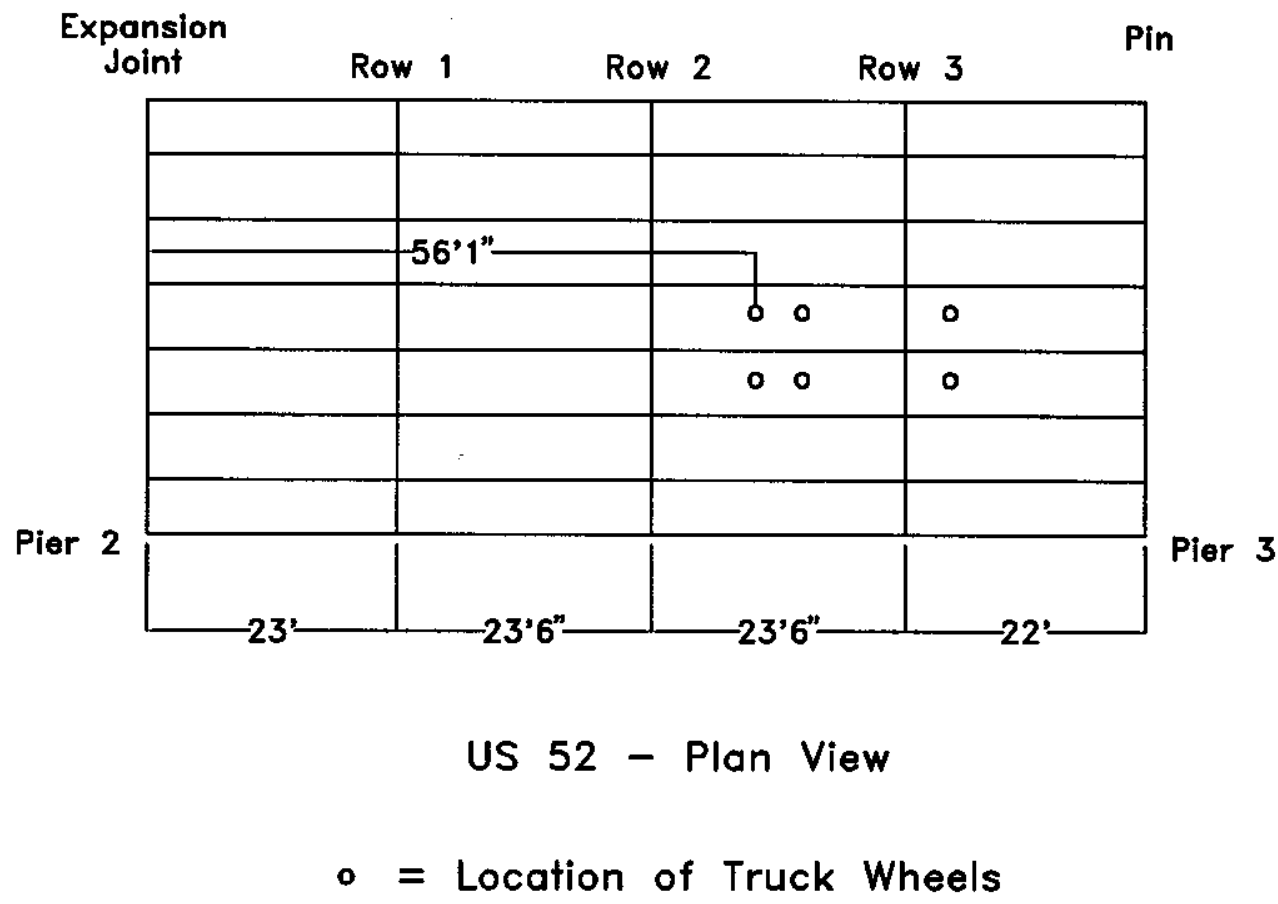

Figure 3.2.2.5 - US 52 - Static Loading Condition \#4 (LC \#4) 


\section{Transverse Static Loading Condition A \\ (Truck Centered in Right Lane) \\ US 52}

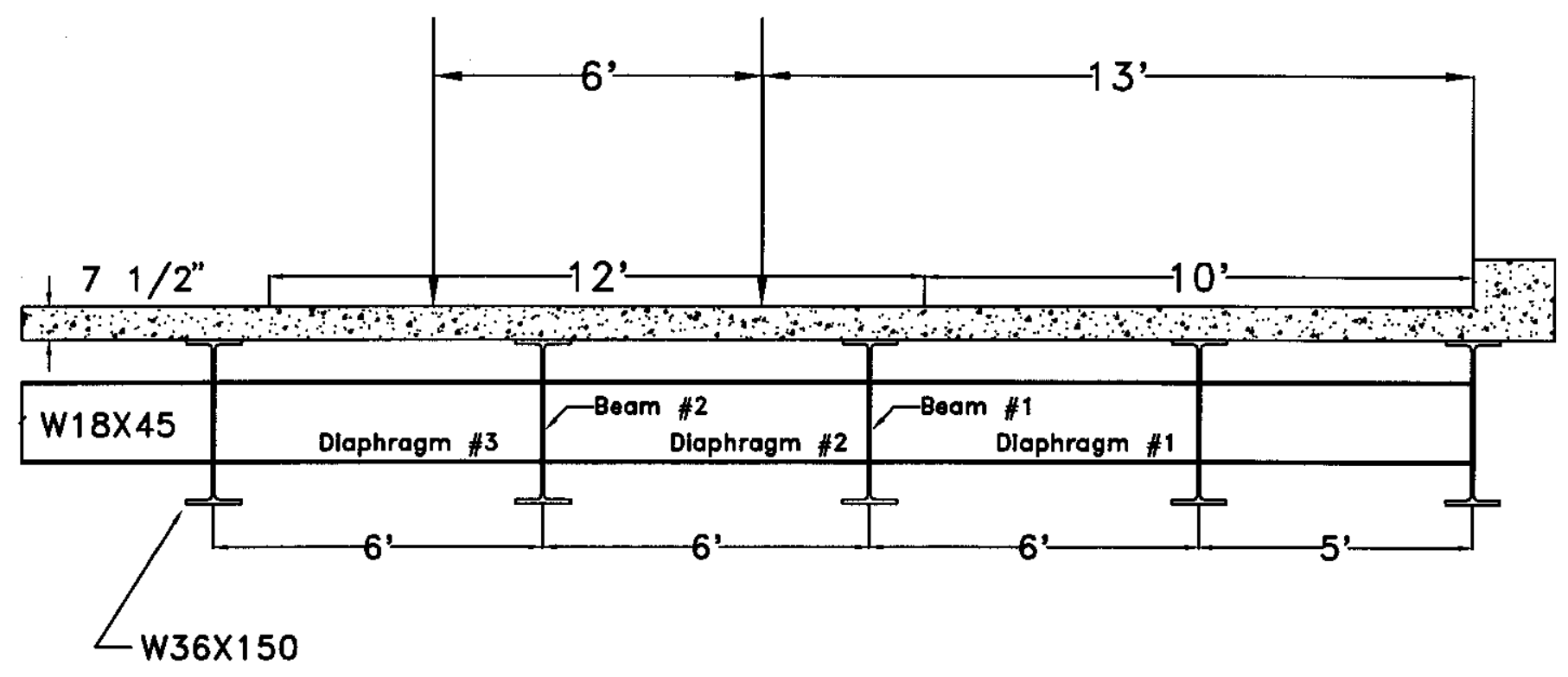

Figure 3.2.2.6 - US 52 - Static Loading Condition A 
Transverse Static Loading Condition B

(Right Rear Wheels Along Shoulder Line)

US 52

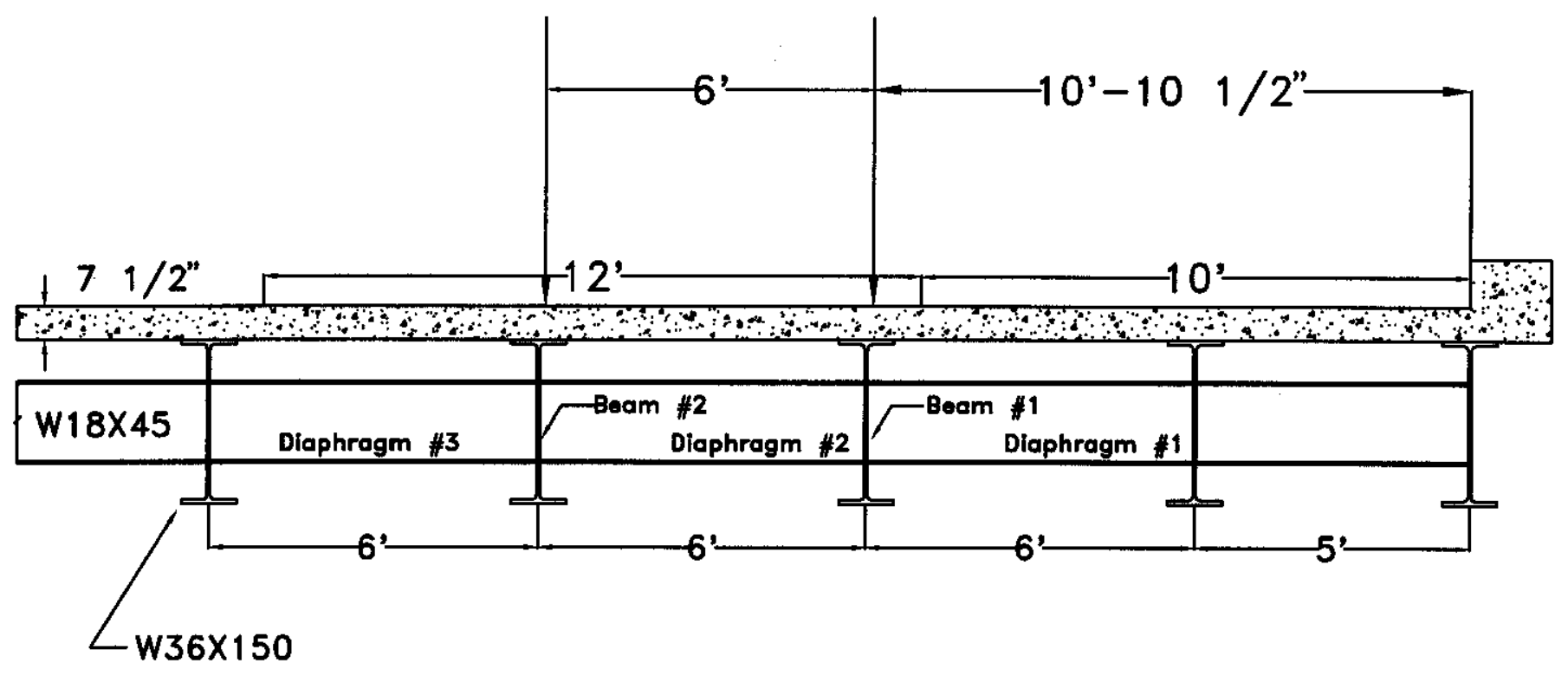

Figure 3.2.2.7 - US 52 - Static Loading Condition B 


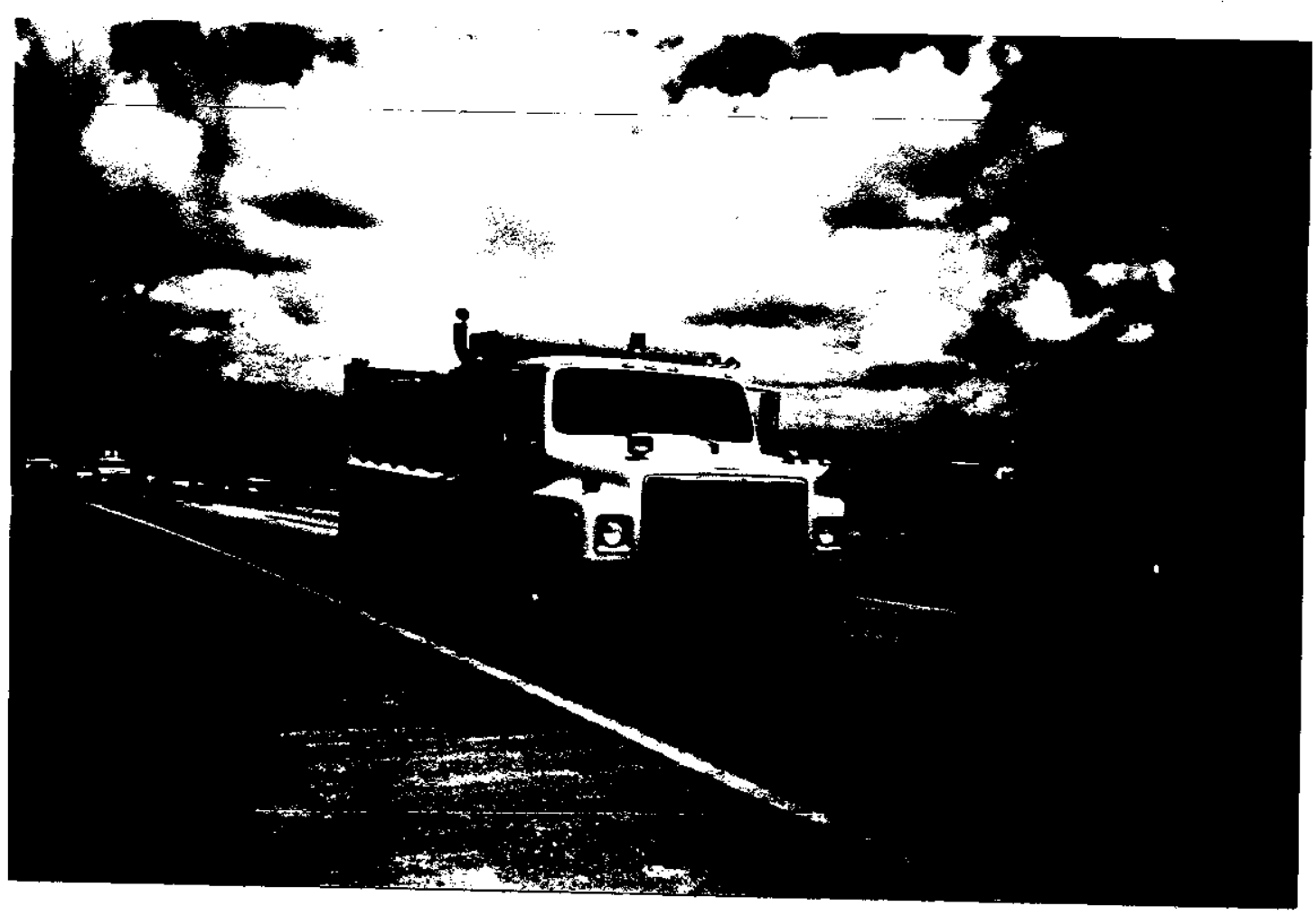

Figure 3.2.2.8 - US 52 - Dump Truck During a Dynamic Loading Condition 


\section{65 Bridge}

\section{Plan View}

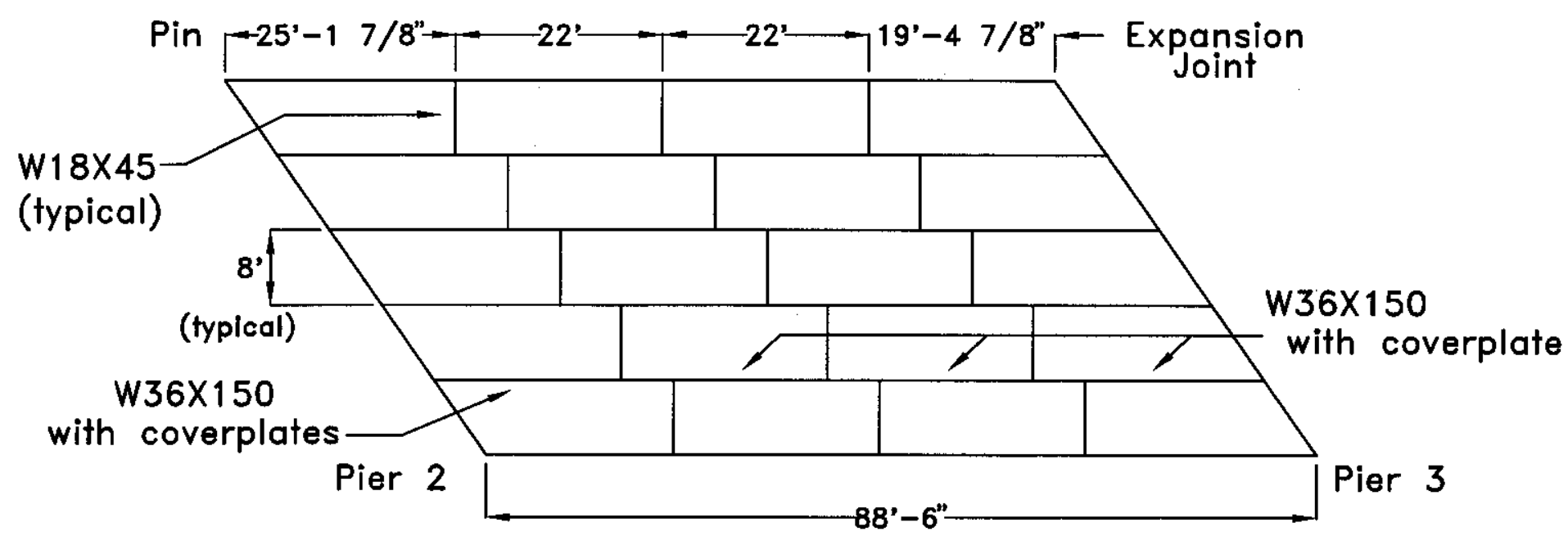

Figure 3.3.1 - I 65 - Plan View of Instrumented Span 


\section{I-65 Bridge Gage Placement}

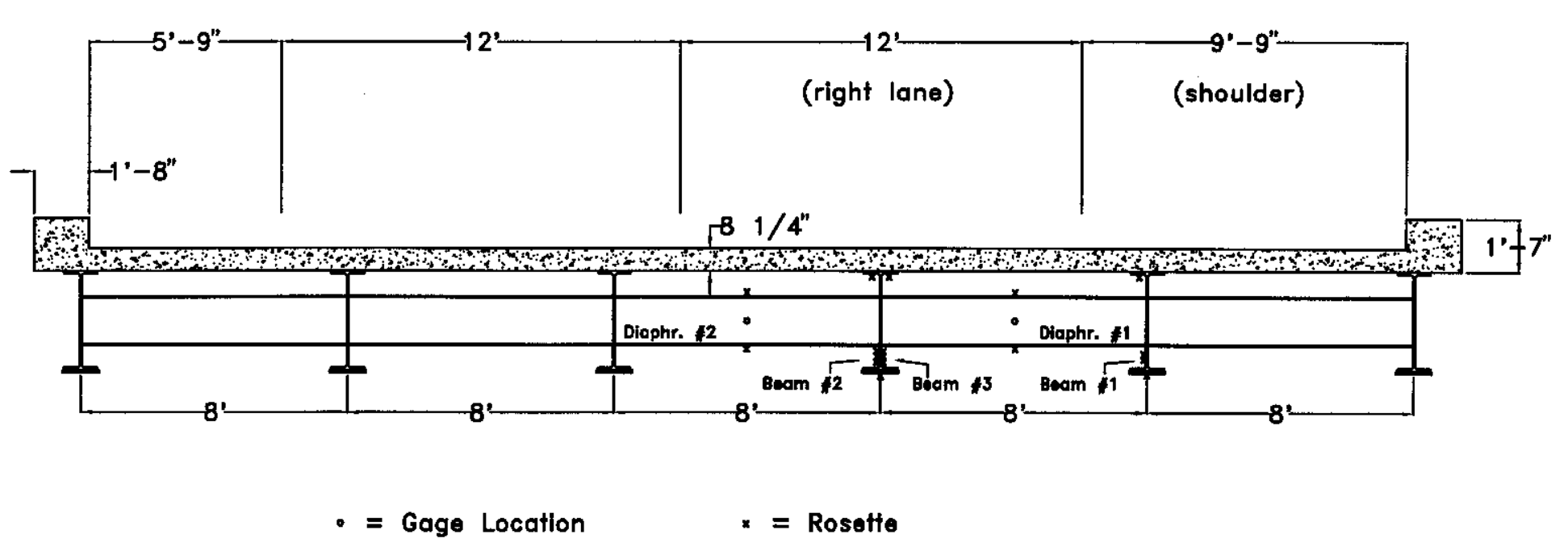

Figure 3.3.2 - I 65 - Gage Placement 


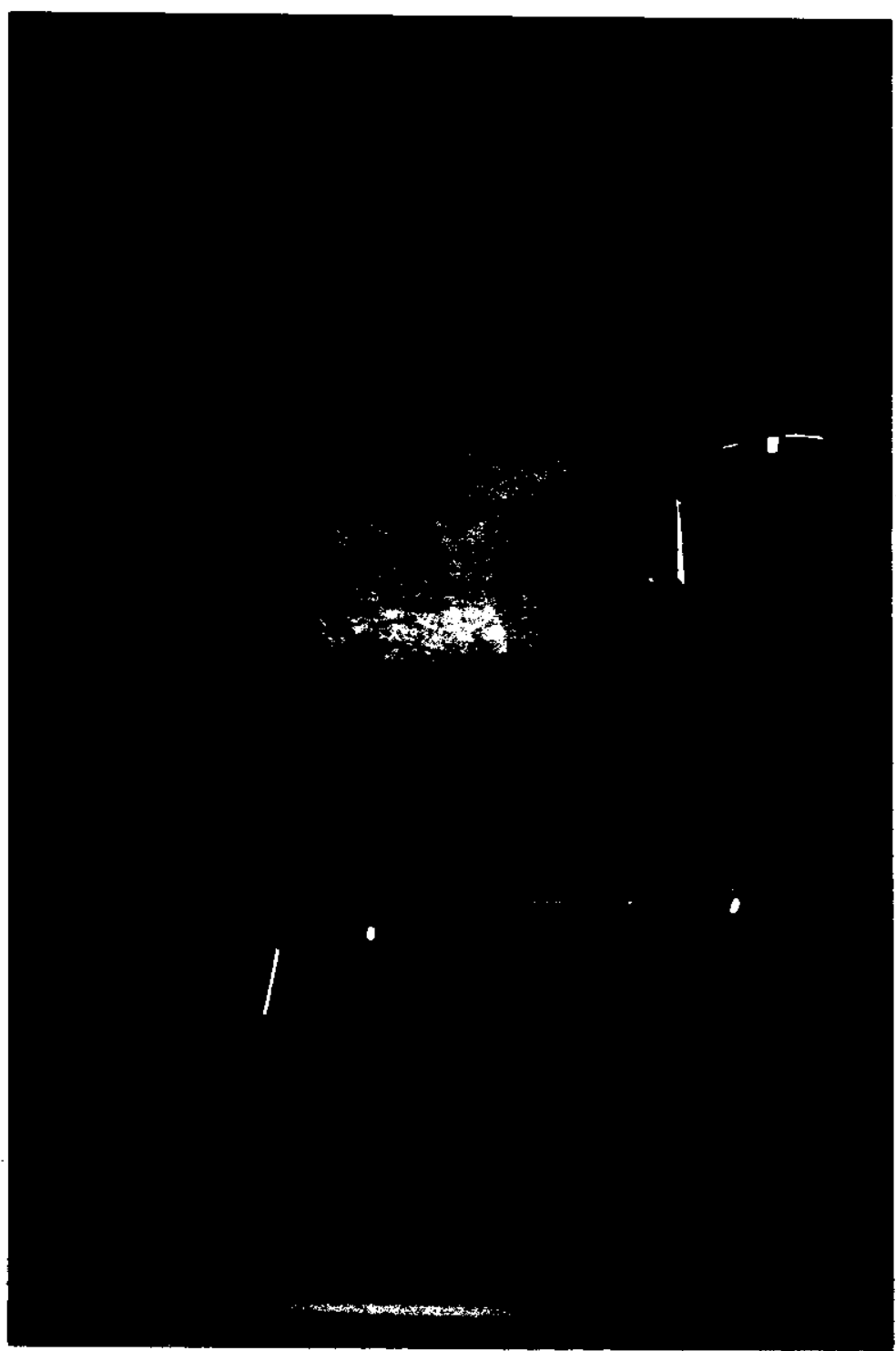

Figure 3.3.3 - I 65 - Instrumented Members 


\section{1-65 Bridge Gage Placement Beam Locations \#2 \& \#3}

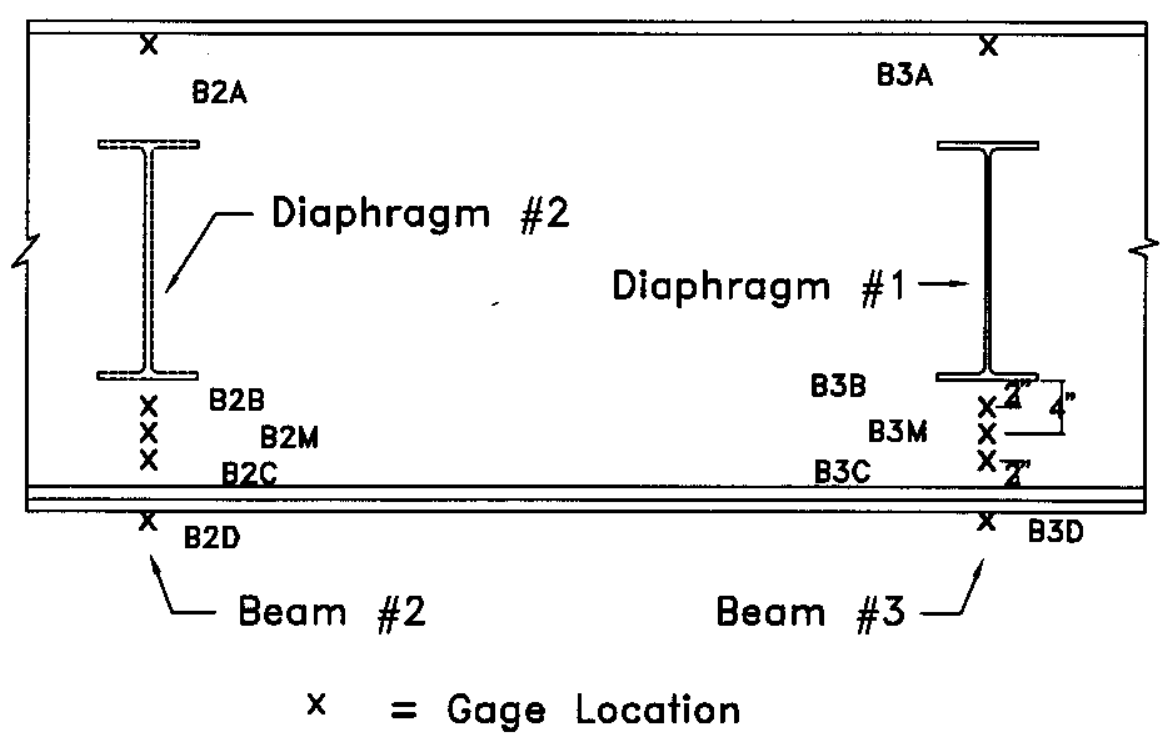

Figure 3.3.1.1 - I 65 - Strain Gage Placement - Beams 


\section{5 - Gage Placement Diaphragm \#2 \& Beam \#2}

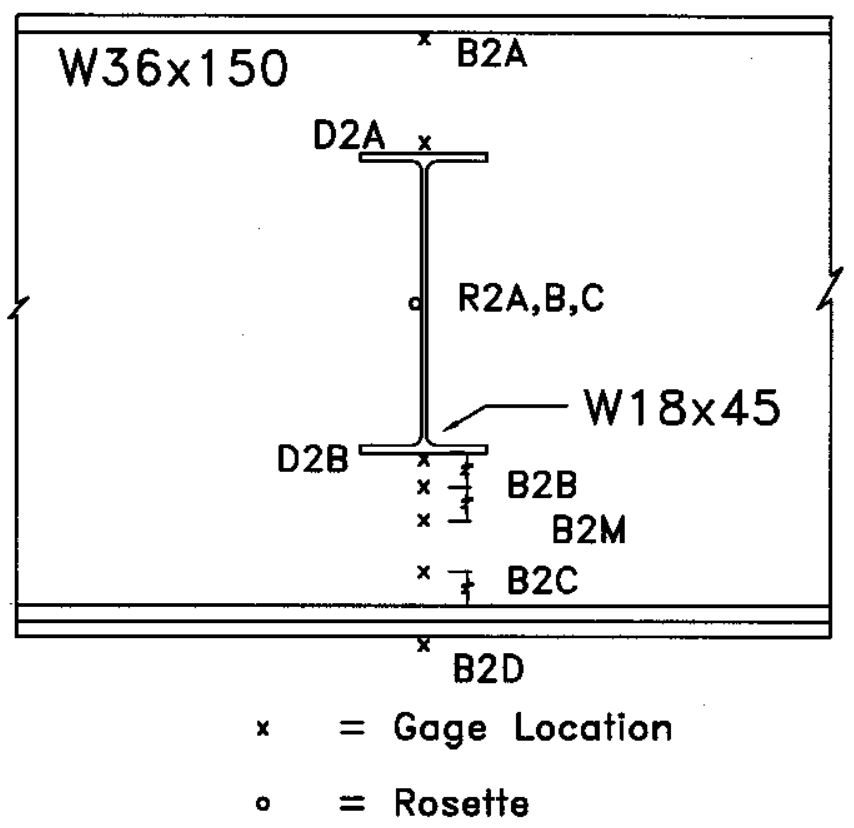

Figure 3.3.1.2 - I 65 - Strain Gage Placement - Diaphragm 


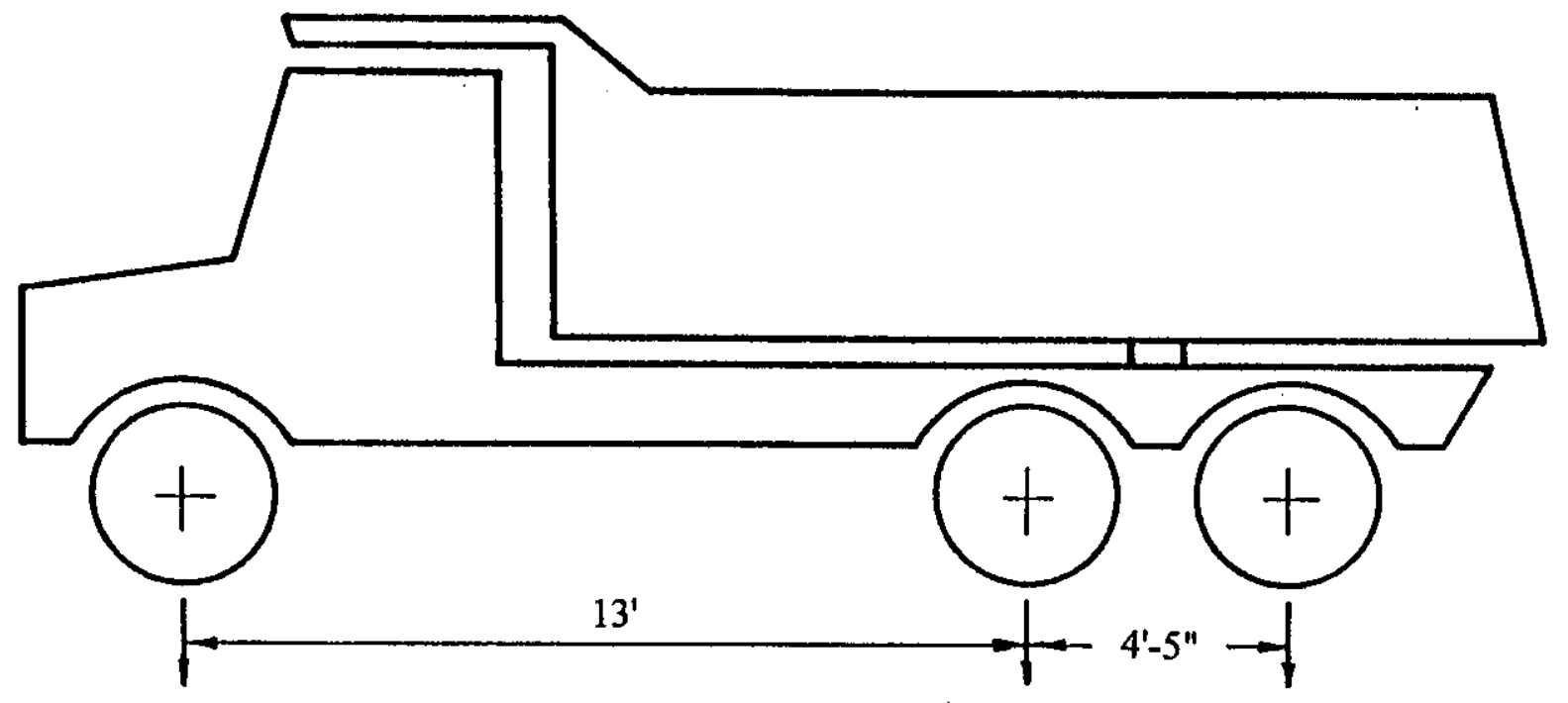

$14,380 \mathrm{lbs}$.

$19,980 \mathrm{lbs} . \quad 19,460 \mathrm{lbs}$.
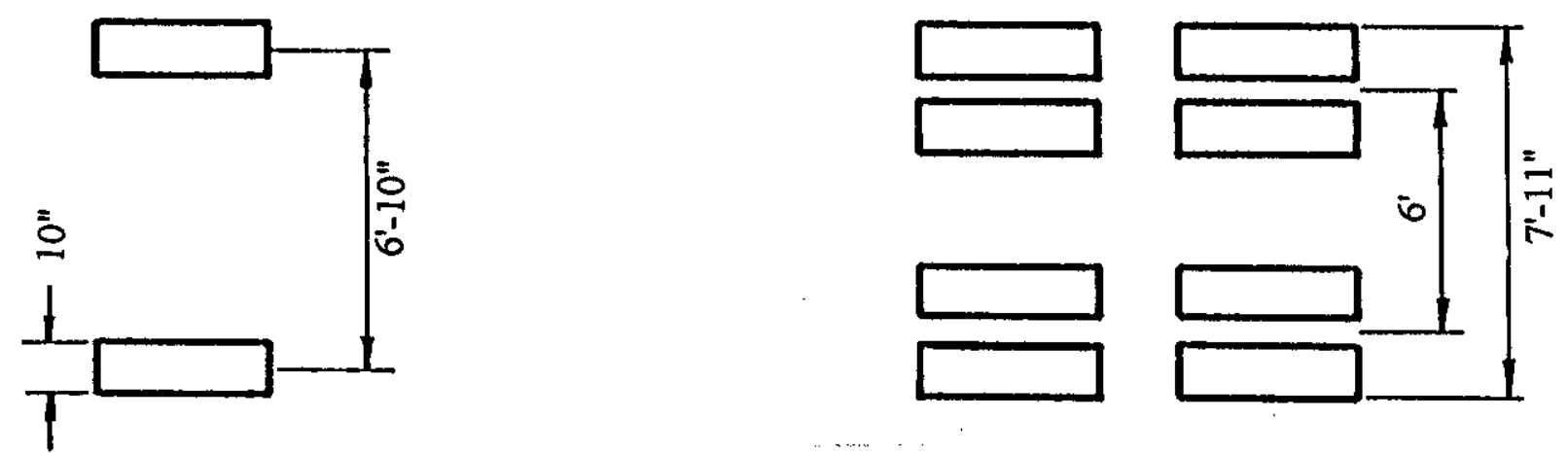

Figure 3.3.2.1 - I 65 - Tandem Axle Dump Truck 


\section{Longitudinal Static Loading Condition \#1}

(Rear Axles Centered Over Diaphragm \#2)

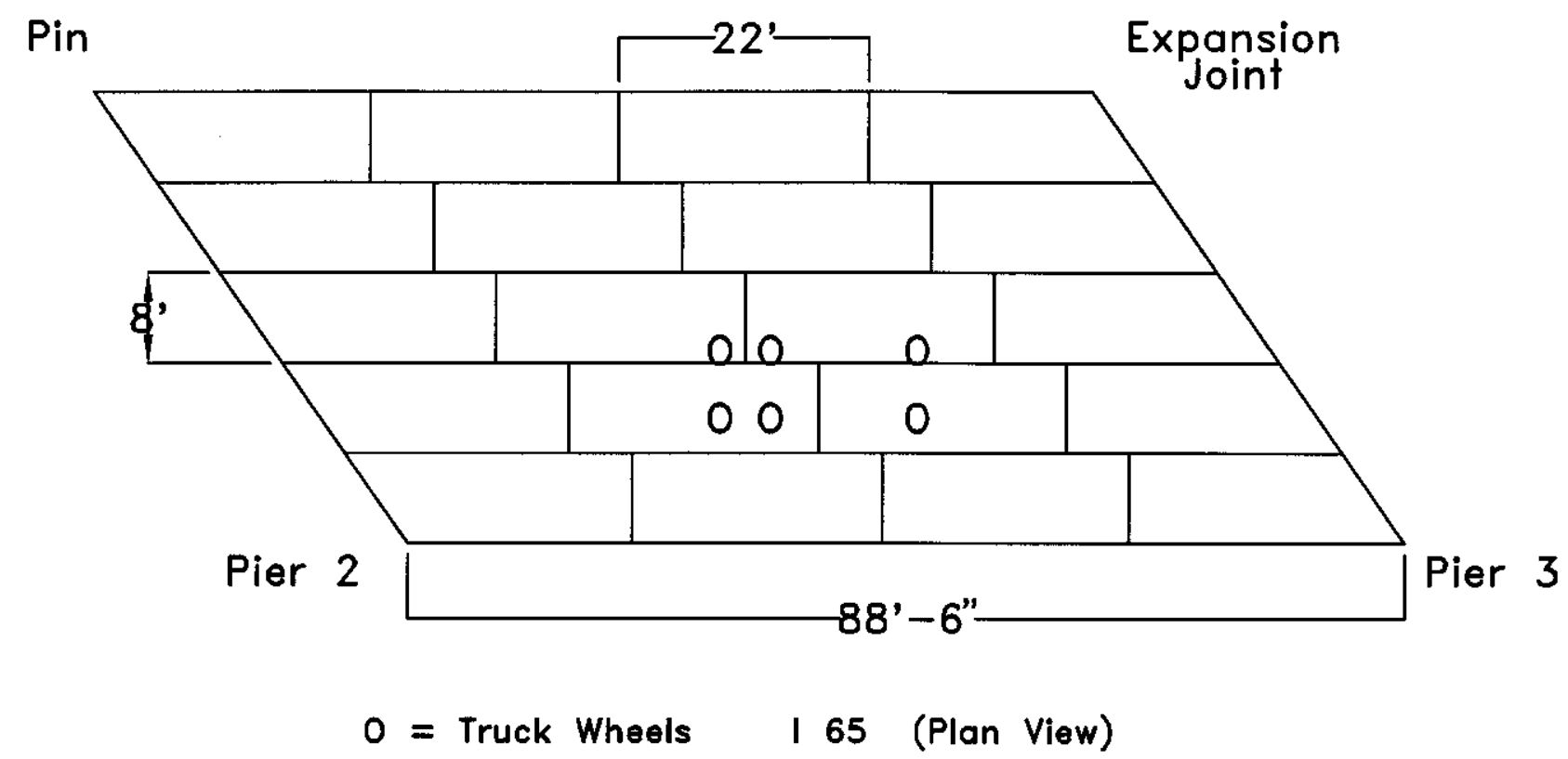

Figure 3.3.2.2 - I 65 - Static Loading Condition \#1 (LC \#1) 


\section{Longitudinal Static Loading Condition \#2}

(Rear Axles Centered Between Instrumented Diaphragms)

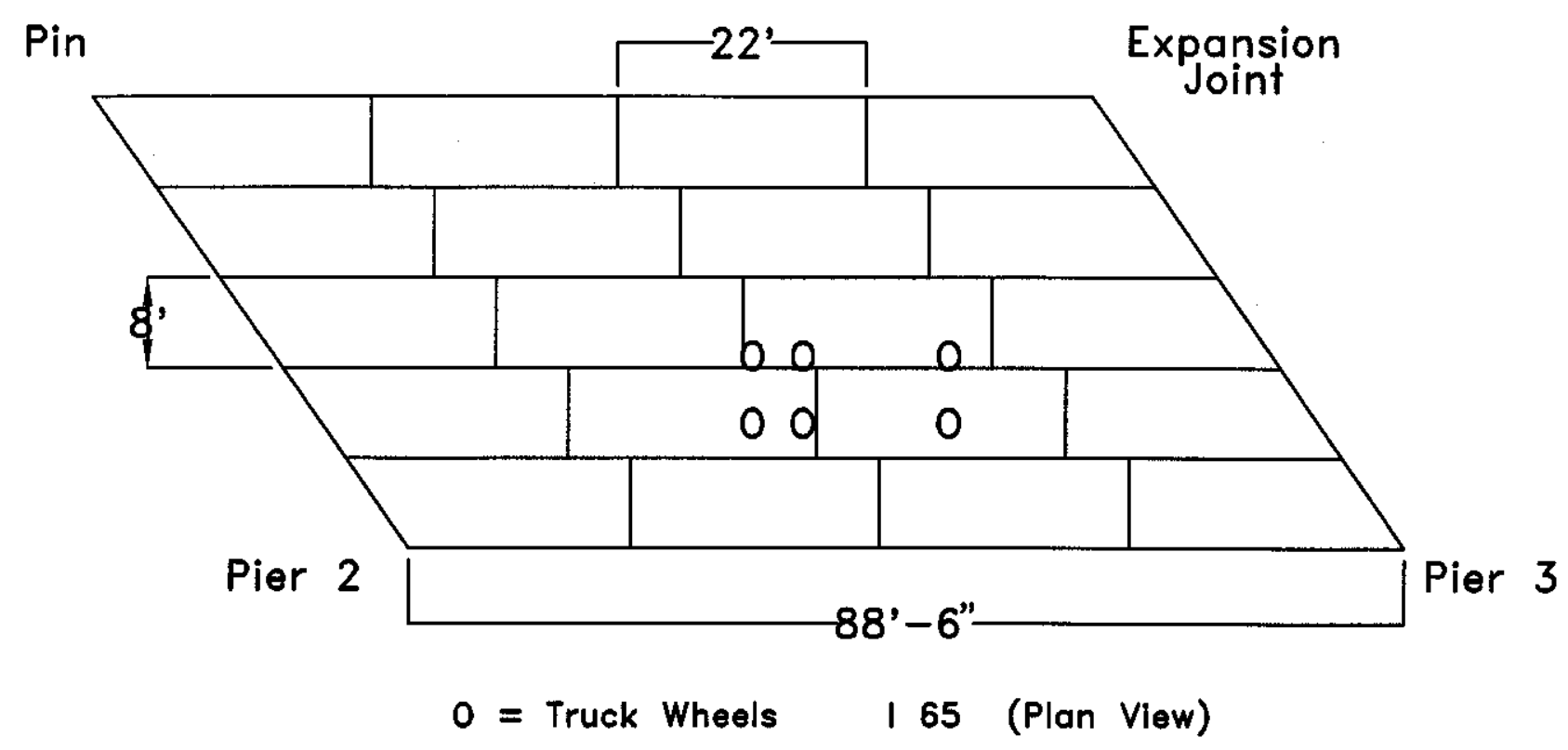

Figure 3.3.2.3 - I 65 - Static Loading Condition \#2 (LC \#2) 


\section{Longitudinal Static Loading Condition \#3}

(Rear Axles Centered Over Diaphragm \#1)

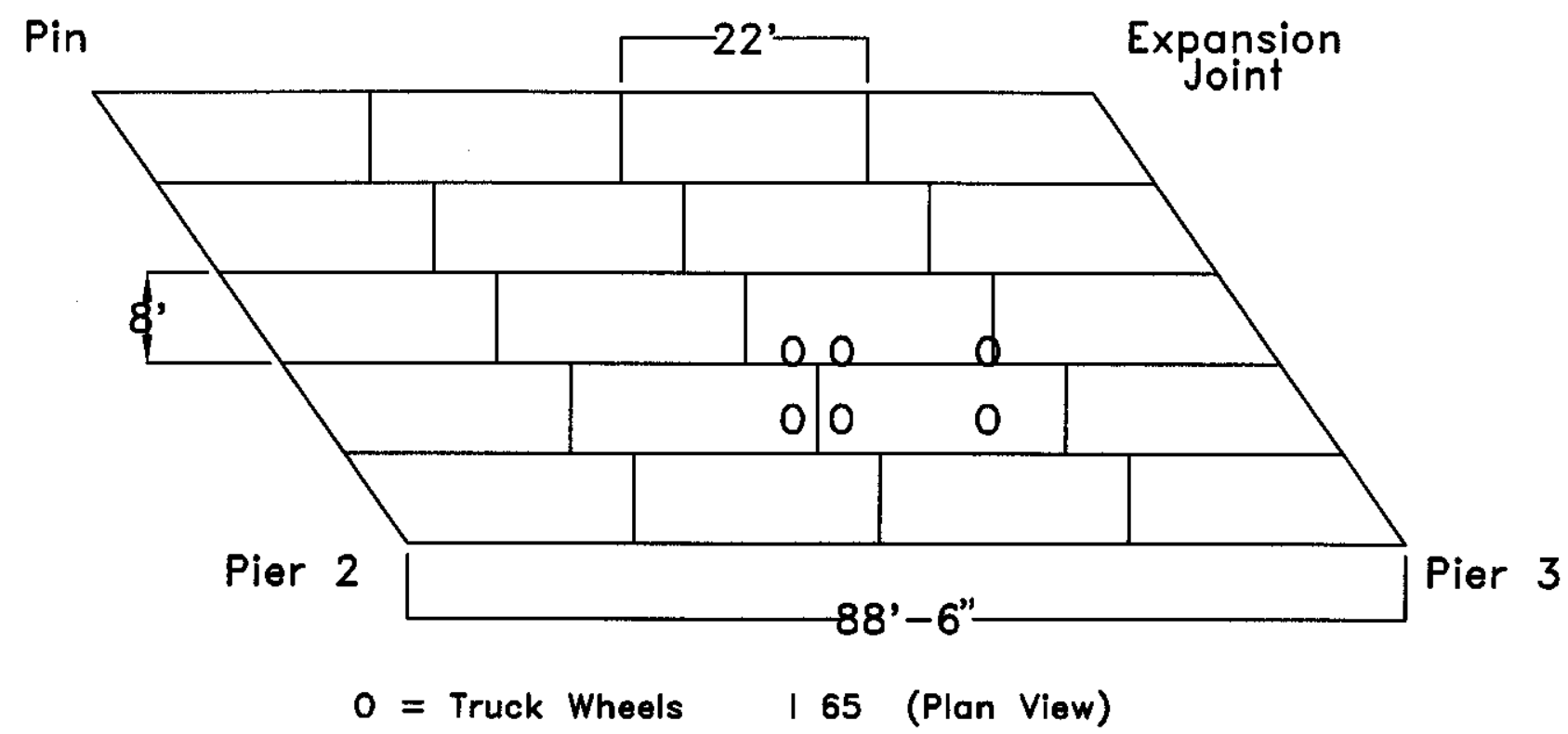

Figure 3.3.2.4 - I 65 - Static Loading Condition \#3 (LC \#3) 


\section{Transverse Loading Condition A \\ (Truck Centered in Right Lane) \\ I 65 Bridge}

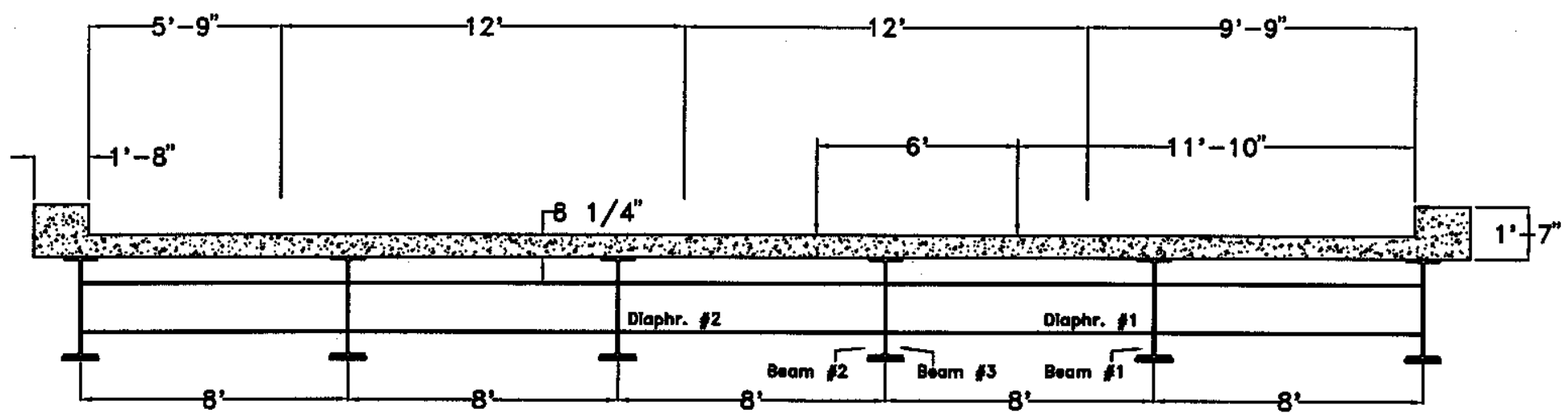

Figure 3.3.2.5 - I 65 - Static Loading Condition A 


\section{Transverse Loading Condition B \\ (Right Rear Wheels Along Shoulder Line) \\ I 65 Bridge}

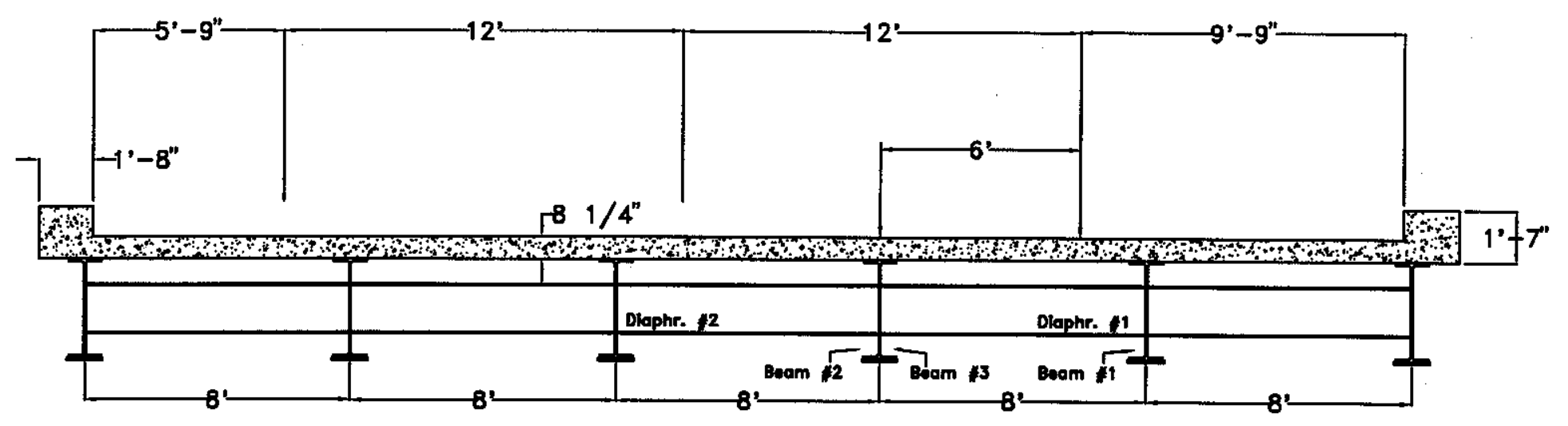

Figure 3.3.2.6 - I 65 - Static Loading Condition B 


\section{CHAPTER 4 \\ EXPERIMENTAL RESULTS}

This chapter presents the results of the previously described experimental program for both the US 52 bridge and the I 65 bridge. An evaluation and comparison of static and dynamic loadings and member behavior are also discussed.

\subsection{Assumptions Used in Data Analysis}

The actual strain value for each gage was determined by subtracting the strain measurement for the no loading case from the strain measurement with the load applied. Strain values for the static loading conditions are the result of taking the average of the gage readings recorded over a brief time interval utilizing a low sampling rate. A nearly linear strain distribution was observed using strain measurements in the three longitudinal strain gages on the diaphragms. Because longitudinal strain was measured at only two locations on the beam cross section, a linear strain distribution was assumed. Figure 4.1.1 shows typical strain distributions, based on actual strain measurements, in a diaphragm and a beam member, respectively. Member stresses were calculated using an elastic modulus of steel $\left(\mathrm{E}_{\mathrm{s}}\right)$ of $200,000 \mathrm{MPa}(29,000 \mathrm{ksi})$ and Poisson's ratio equal to 0.3 and strains in the transverse direction where appropriate. 
Experimental results indicate that diaphragm members are experiencing axial force as well as shear and bending forces. Tensile strains in the diaphragms were detected by strain gages located at mid-depth. Axial force in diaphragm members was calculated by multiplying the axial stress at mid-depth by the cross sectional area. In order to determine the moments in diaphragms due to pure bending, strains recorded at mid-depth were subtracted from those recorded on the top and bottom flanges for each member. Multiplying these corrected strains by the elastic modulus of steel yields the bending stresses. Bending moment was then determined for each diaphragm by multiplying the respective bending stress by the moment of inertia and dividing by half of the member's depth. The shear force in each diaphragm was calculated using strains recorded in the rosette strain gages (Figure 4.1.2). Shear strains, $\gamma_{x y}$, were computed using the following equations:

$$
\begin{aligned}
& \varepsilon_{A}=\varepsilon_{x x} \cos ^{2} \theta_{A}+\varepsilon_{y Y} \sin ^{2} \theta_{A}+\gamma_{x y} \sin \theta_{A} \cos \theta_{A} \\
& \varepsilon_{B}=\varepsilon_{x x} \cos ^{2} \theta_{B}+\varepsilon_{y Y} \sin ^{2} \theta_{B}+\gamma_{x y} \sin \theta_{B} \cos \theta_{B} \\
& \varepsilon_{C}=\varepsilon_{x x} \cos ^{2} \theta_{C}+\varepsilon_{y y} \sin ^{2} \theta_{C}+\gamma_{x y} \sin \theta_{C} \cos \theta_{C} .
\end{aligned}
$$

Shear stress was then calculated by multiplying shear strain by the shear modulus for steel $[\mathrm{G}=77,200 \mathrm{MPa}(\mathrm{G}=11,200 \mathrm{ksi})]$. Finally, shear force was calculated using the elastic shear stress formula:

$$
V=\left(I_{x} t_{w} \tau_{x y}\right) / Q
$$

\subsection{US 52 Analysis and Behavior}

While checking strain gages and connecting the wires to the data acquisition system, 
it was discovered that the strain gage mounted on the bottom of Beam \#1 read $364 \mathrm{ohm}$ and, consequently, would not provide reliable information. Another problem occurred while setting up the level to be used in deflection measurements. To operate the instrument properly, it must be level with the rulers on which it is to site. Because the bridge has a crown, the ruler attached to the bottom flange of Beam $\# 2$ was hidden by the two exterior beams. Therefore, only the deflections of Beam \#1 were able to be recorded for the static loading conditions.

\subsubsection{Beams}

Maximum beam strains and stresses resulting from the static loading conditions are listed in Table 4.2.1.1 along with their corresponding loading conditions (LC). Looking at Table 4.2.1.2, the maximum vertical deflection recorded for Beam \#1 was $6.71 \mathrm{~mm}(0.264$ in.) during static loading conditions \#2B and \#3B. These data indicate that the loading condition which produces the highest beam strains is LC \#3; when the truck's rear axles are straddling the instrumented diaphragm row. It was not surprising to find that strain generally increased as the rear axles of the truck moved over each instrumented member. The highest static strain reading in the beams was 91 microstrain on the bottom of Beam \#2 during LC \#3A. Figure 4.2.1.1 shows the strain measured on the bottom of Beam \#2 for each longitudinal location with the truck positioned in the center of the right lane.

For the dynamic loading conditions, maximum beam strains and strain ranges for each strain gage are presented in Table 4.2.1.3. As the dump truck crossed the span at a speed of about $40 \mathrm{~km} / \mathrm{h}(25 \mathrm{mph})$, the bottom of Beam \#2 yielded the highest beam strain 
range at 114 microstrain with a corresponding maximum strain reading of 94 microstrain. The speed of the dump truck did not noticeably influence strain measurements. Figures 4.2.1.2 through 4.2.1.4 depict strains on the bottom of Beam \#2 as the truck traversed the span in the center of the right lane at approximate speeds of 8,27 , and $40 \mathrm{~km} / \mathrm{h}(5,17$, and $25 \mathrm{mph})$, respectively.

Upon completion of the static and dynamic load testing with the dump truck of known load, regular traffic was monitored and forty-five truck events were recorded. A few events captured two trucks side-by-side or back-to-back. Although strain gage placement was concentrated under the right lane, larger trucks traveling in the left lane did trigger the data acquisition system to record these events. Average maximum beam strains and corresponding strain ranges are reported for several different common truck types in Table 4.2.1.4. The highest beam strain range reading for a single loading event was 146 microstrain and occurred at the bottom of Beam $\# 2$ during the simultaneous crossing of a dump truck and an eighteen-wheeler. When looking at Figure 4.2.1.5, note that the initial peak coincides with the strains due to the crossing of the dump truck and the second and third smaller peaks correspond to those caused by the front and rear axles of the ensuing eighteen-wheeler. The lower strain levels seen in the second and third peaks, may include the effects of supplemental compressive strains induced in the instrumented span when the dump truck was located on the adjacent span. The passing of a single eighteen-wheeler also produced high beam strains. Strains at the bottom of Beam \#2 are presented in Figure 4.2.1.6 for this event. The two peaks in this figure correspond to the passage of the front and rear axles of the truck over the gaged member. 
Strain measurements were collected for three different loading cases: static and dynamic loading conditions of known truck weight and regular traffic sampling. Maximum strain readings were detected at the bottom of Beam $\# 2$ for each loading condition. The maximum strain range for the dynamic loading was at a speed of $40 \mathrm{~km} / \mathrm{h}(25 \mathrm{mph})$, and the corresponding maximum strain reading is about 3 microstrain larger than the maximum strain value for the static loading. Therefore, the impact of the dynamic effect is minimal when comparing the strain measurements for the two loading conditions. During the monitoring of regular traffic, a maximum beam strain range of 146 microstrain was recorded at the bottom of Beam \#2. This value is about $22 \%$ greater than the comparable dynamic reading for the known load. The increase in strain is probably due to the heavier weight of regular truck traffic. Figure 4.2.1.7 compares the average strain found at the bottom of Beam \#2 for the static loading conditions to the maximum strain and strain range for each recorded traffic event.

Out-of-plane bending in the beam webs was also observed. The web strain gages on Beam \#1, indicate that both gages detect compressive strains, inferring single-curvature, outof-plane bending in the beam web between the bottom of the diaphragm and the bottom beam flange. However, web strain gage readings of opposite signs from Beam \#2 indicate double-curvature, out-of-plane bending in the beam's web. This behavior is consistent for all loading conditions.

\subsubsection{Diaphragms}

Maximum diaphragm strains and stresses and the corresponding loading conditions 
are listed in Table 4.2.2.1 for the static loading conditions at both transverse truck positions. Note that Diaphragm \#1 exhibits slightly larger strains when the truck is located along the shoulder line of the right lane than when the truck is centered in the same lane. The opposite case is true for Diaphragm \#3. Large strain values were recorded for Diaphragm \#2 regardless of the transverse truck position. In each diaphragm, the highest strain was registered in the strain gage mounted on the bottom of the member. The maximum static strain reading in the diaphragms was 99 microstrain on the bottom of Diaphragm \#2 for LC \#3A. Figure 4.2.2.1 presents the strain recorded on the bottom of Diaphragm \#2 for each longitudinal position with the truck located in the center of the right lane. In general, the static loading condition causing the largest diaphragm strains was LC \#3 - when the truck's rear axles are centered over the instrumented diaphragm row. Recall that this is the same loading condition which produced high beam strains as well.

Table 4.2.2.2 presents the maximum diaphragm forces for the static loading conditions at both transverse truck positions. The data show that greater shear forces occur in the first and third diaphragms and that Diaphragm \#2 developed a larger axial force and minimal shear force. Shear forces occurring in the diaphragms can be explained by the differential deflection of adjacent longitudinal beams. Because the wheels are situated closest to Beams \#1 and \#2, these beams are assumed to carry the majority of the load and have the larger deflections when compared to neighboring beams. Therefore, the differential deflection of the beams connected by Diaphragms \#1 and \#3 will be larger than that of the beams connected by Diaphragm \#2. Axial force in the diaphragms is also believed to be associated with beam deflection. When a concentrated load is applied to a member where 
relative lateral movement between the compression and tension flanges is not restrained, there is a tendency for the tension flange to rotate. This phenomenon is termed sidesway web buckling by the American Institute of Steel Construction, Inc. in the 1994 design manual. The presence of diaphragms between the beams resists rotation of the tension flanges thereby inducing axial forces in the diaphragms. Because Beams \#1 and \#2 deflect more than other adjacent beams, Diaphragm \#2 experiences the largest axial forces when compared to the other instrumented diaphragms. Also, note the difference in each diaphragm between shear forces for the " $\mathrm{A}$ " loading condition and those for the " $\mathrm{B}$ " loading condition. In the " $\mathrm{A}$ " loading condition, the truck is centered in the right lane which locates the wheels closer to Diaphragm \#3 and further from Diaphragm \#1. On the other hand, loading condition "B" positions the wheels almost directly over Beams \#1 and \#2 causing them to experience approximately equal deflections. If Beams \#1 and \#2 deflect almost evenly, the differential deflection of the two beams is small resulting in a small shear force in Diaphragm \#2. However, the differential deflection of the beams connecting Diaphragms \#1 and \#3 increases causing larger shear forces in Diaphragms \#1 and \#3 for the "B" position than for the " $\mathrm{A}$ " position. The highest calculated diaphragm shear force for the static loading conditions is $-11.6 \mathrm{kN}(-2.6 \mathrm{k})$ attained in Diaphragm \#3 during LC \#3B.

For each dynamic loading condition, Table 4.2.2.3 lists the maximum diaphragm strains and strain ranges at all gage locations. A maximum diaphragm strain range of 127 microstrain was recorded for the bottom of Diaphragm \#2 at a truck speed of $40 \mathrm{~km} / \mathrm{h}$ ( 25 $\mathrm{mph}$ ). Strain measurements indicate only a slight increase in strain range as the speed of the truck increased. Figures 4.2.2.2 through 4.2.2.4 present strains at the bottom of 
Diaphragm\#2 as the truck crossed the span in the center of the right lane at speeds of approximately 8,27 , and $40 \mathrm{~km} / \mathrm{h}(5,17$, and $25 \mathrm{mph})$, respectively. Maximum diaphragm shear forces and ranges are listed in Table 4.2.2.4 for the dynamic loading conditions. Similar trends as seen in the results from the static loading conditions are seen here. Diaphragms \#1 and \#3 experience larger shear forces than Diaphragm \#2 with the highest shear force range calculated in Diaphragm \#3 at $13.8 \mathrm{kN}$ (3.1 k). The speed of the truck had little effect on the magnitude of the shear force occurring in the diaphragms.

Table 4.2.2.5 is an account of the average maximum diaphragm strains and strain ranges for several typically monitored truck types. A maximum diaphragm strain range of 156 microstrain was measured in the strain gage on the bottom of Diaphragm \#2. This strain reading corresponds to the crossing of the same eighteen-wheeler that induced the maximum beam strain. Strains measured in the bottom of Diaphragm \#2 as the eighteen-wheeler passed over the instrumented span are presented in Figure 4.2.2.5. The simultaneous crossing of a dump truck and an eighteen-wheeler also caused significant diaphragm strains. Figure 4.2.2.6 is a plot of strains measured in the bottom of Diaphragm \#2 as the two vehicles traverse the span. Note the two peaks representing the passage of each truck over the gaged member. Average maximum shear forces determined for the different truck types are listed in Table 4.2.2.6. For a single loading event, the maximum calculated shear force was $-19.1 \mathrm{kN}(-4.3 \mathrm{k})$ in Diaphragm \#3 which corresponds to the crossing of a dump truck. Diaphragm behavior was similar to the conditions of known load with Diaphragms \#2 and \#3 exhibiting the larger shear forces. However, the direction of the shear force calculated for Diaphragm \#3 changed if the truck was traveling in the left lane. 
When comparing all loading conditions, diaphragm behavior is similar. The maximum strain reading in each diaphragm was generally detected on the bottom of the diaphragm. Moreover, the largest readings occurred in Diaphragm \#2. Dynamic known loading produced a maximum diaphragm strain about 9 microstrain larger than the maximum strain measured for the static known loading condition. The maximum diaphragm strain range for the regular traffic was about 30 microstrain higher than that for the dynamic known loading condition. As previously observed, dynamic effects had little influence on strain measurements for the US 52 bridge. Figure 4.2.2.7 presents a comparison between the average strain at the bottom of Diaphragm $\# 2$ for the static loading conditions and the maximum strain and strain range for each recorded traffic event.

The maximum diaphragm shear forces occurred in Diaphragm \#3 regardless of the loading condition. Shear forces resulting from the regular truck traffic usually have a slightly larger magnitude than those produced by the dynamic loadings using the truck of known load. Overall, both loading conditions yielded somewhat larger shear forces in the diaphragms than those from the static loading conditions. Figures 4.2.2.8 through 4.2.2.10 present a comparison between the average shear force for the static loading conditions and the maximum shear force for each traffic event in Diaphragm \#1 through Diaphragm \#3, respectively. In Figure 4.2.2.10, notice that the traffic shear forces are both positive and negative values which correspond to trucks traveling in the left and right lanes.

Because the longitudinal beams are designed as the main gravity load carrying members of a bridge, they are expected to undergo larger strains. However, measurements reinforce that the diaphragms also participate in supporting the weight of the truck. In fact, 
strains on the bottom of Diaphragm \#2 registered higher than those on the bottom of the beams. Figure 4.2.2.11 presents a comparison between strains on the bottom of Beam \#2 and Diaphragm \#2 for the static loading conditions.

\subsection{Analysis and Behavior}

After connecting the strain gage wires to the data acquisition system, it was discovered that the top strain gage located on the web of Beam \#1 was out of range. All other gages functioned properly. Longer rulers mounted to the bottom of the beams simplified deflection measurements.

\subsubsection{Beams}

Table 4.3.1.1 presents the maximum beam strains and stresses produced by the static loading conditions. In Beams \#1 and \#3, maximum strains were measured on the bottom of the member. Although high strains were observed also on the bottom of Beam \#2, the largest strain on this beam was recorded for the bottom strain gage on the beam web. In fact, high strains were measured in the bottom web gage of all beams. The highest strain reading in the beams was 75 microstrain on the bottom of Beam \#3 corresponding to LC \#3B. The maximum beam web strain of -75 microstrain was recorded in the bottom web gage on Beam $\# 2$. Notice that in both Beams \#2 and \#3 the top web gage shows a tensile strain, while the bottom web gage shows a compressive strain. These readings of opposite sign indicate double-curvature, out-of-plane bending of the beam's web between the diaphragm and the bottom flange of the beam.

Deflections measured for the static loading conditions are presented in Table 4.3.1.2. 
For the " $\mathrm{A}$ " loading conditions, where the dump truck is centered in the right lane, the wheels straddle Beam \#2 resulting in a greater deflection in Beam \#2 than Beam \#1. This differential deflection between the two beams is calculated as positive. In the "B" loading conditions, the vehicle's rear wheels are located along the shoulder line and more of the load is distributed to Beam \#1. Looking first at the deflections for the " $\mathrm{A}$ " loading conditions and then at those for the " $\mathrm{B}$ " loading conditions, note the general increase in the deflection of Beam \#1 and the decrease in deflection of Beam \#2.

Maximum beam strains and strain ranges for the dynamic loading conditions are listed in Table 4.3.1.3. Overall, beam strains increased slightly with increasing truck speed. The highest beam strain range, equaling 99 microstrain, was measured at the bottom of Beam \#2 corresponding to a vehicle speed of approximately $89 \mathrm{~km} / \mathrm{h}(55 \mathrm{mph})$. Figures 4.3.1.1 through 4.3.1.3 show strains on the bottom of Beam \#2 as the dump truck traversed the span in the center of the right lane at speeds of about 8,40 , and $89 \mathrm{~km} / \mathrm{h}(5,25$, and $55 \mathrm{mph})$, respectively. Initial negative strain readings in the signals are due to compressive strains induced in the instrumented span when the dump truck was located on the preceding span. Notice the sharp peak between 8 and 10 seconds in Figure 4.3.1.1. This inconsistency in the data record is possibly the result of an unexpected heavy vehicle traveling in the left lane during the dynamic load test at $8 \mathrm{~km} / \mathrm{h}(5 \mathrm{mph})$. Double-curvature, out-of-plane bending of the beam webs was observed for dynamic loading conditions as well. The maximum beam web strain range of 89 microstrain was detected in the bottom web gage on Beam \#2 coinciding with a truck speed of about $89 \mathrm{~km} / \mathrm{h}(55 \mathrm{mph})$.

Before monitoring regular traffic, strains were recorded for two final loadings using 
the dump truck of known load. With the dump truck in the right lane and positioned over the instrumented diaphragms, two readings were taken as large trucks passed in the left lane. Strain measurements indicate that beam behavior is similar to that observed in the previous static and dynamic known loading conditions in that maximum strain readings were recorded in the same gages. With two trucks located side-by-side, some strain gages produced slightly higher maximum strain readings than the loading conditions using the dump truck solely. However, because recording began with the dump truck already positioned over the instrumented members, strain ranges were lower.

After both lanes were returned to normal traffic flow, regular traffic was monitored. A total of eighty-seven truck events were recorded. Some events captured two trucks traveling back-to-back or side-by-side or heavier single trucks traveling in the left lane. Average maximum beam strains and corresponding strain ranges are reported for several different common truck types in Table 4.3.1.4. The strain record for a single eighteenwheeler crossing the span is presented in Figure 4.3.1.4 for strains measured at the bottom of Beam \#2 during a single event. Seven different beam strain gages detected strain ranges above 100 microstrain for this event with the maximum being 117 microstrain. In Figure 4.3.1.4, the two large peaks correspond to the passage of the front and rear axles, respectively, of the truck over the gaged member. The crossing of two eighteen-wheelers, side-by-side, also produced high beam strains. Figure 4.3.1.5 shows the strains at the bottom of Beam $\# 2$ for this event. The maximum peaks in the strain record are believed to correspond to the passing of the truck axles over the instrumented beams.

In general, beam behavior was similar for each of the three different loading 
conditions. The higher strain values were recorded in strain gages located on the web and bottom of the beams during all loading conditions. The maximum beam strain range for the dynamic known loading condition at $89 \mathrm{~km} / \mathrm{h}(55 \mathrm{mph})$ was approximately $25 \%$ higher than the maximum beam strain reading for the static loading condition. Regular traffic produced strain ranges that are only slightly higher than those for the dynamic known loading conditions. Although this comparison seems to indicate that increasing truck speed results in increased strain readings, this conclusion is not so. A similar comparison between maximum beam strains shows that the actual discrepancy between these values is small. While conducting dynamic and regular traffic loadings, one second worth of data prior to the beginning of recording was saved as part of the signal. This portion of the data set coincides with the vehicle located on the preceding span which, in turn, induced compressive strains at certain locations in the beams. Negative strain readings at the beginning of a data set and larger strain ranges can be explained by these compressive strains. Figure 4.3.1.6 presents a comparison between the average strain at the bottom of Beam \#3 for the static loading conditions and the maximum strain and strain range for each recorded traffic event. Doublecurvature, out-of-plane bending was observed in both Beams \#2 and \#3 for all loading conditions. However, the strains in the web of Beam \#2 were slightly larger than those found in Beam \#3.

\subsubsection{Diaphragms}

Maximum diaphragm strains and stresses and the corresponding loading conditions are listed in Table 4.3.2.1 for the static loading conditions at both transverse truck positions. 
Note that all strain gage readings were less than 10 microstrain. Because of low strain readings and inherent fluctuations that exist in the signal, few behavioral conclusions can be made. However, most of the higher strains are the result of the rear axles of the truck centered over either of the instrumented diaphragms. The maximum static strain reading in the diaphragms was 9.8 microstrain on the top of Diaphragm \#1 for LC \#1B. Table 4.3.2.2 presents the maximum diaphragm forces for the static loading conditions at both transverse truck positions. Because strains in the diaphragms were small, shear forces calculated from these strain readings are low. However, shear forces in the diaphragms are slightly higher for the " $\mathrm{B}$ " loading conditions than for the " $\mathrm{A}$ " loading conditions. The maximum shear force calculated for the diaphragms is $1.8 \mathrm{KN}(0.4 \mathrm{k})$ in Diaphragm \#2. Axial strains were also detected in the diaphragms. The maximum axial force was calculated to be about $13 \mathrm{kN}$ (3 k) in Diaphragm \#1. Axial force in the diaphragms is believed to be the result of the connecting beams attempting to rotate away from one another as they deflect.

For each dynamic loading condition, Table 4.3.2.3 lists the maximum diaphragm strains and strain ranges at all strain gage locations. A maximum diaphragm strain range of 13 microstrain was recorded for the top of Diaphragm \#1 with a corresponding truck speed of about $40 \mathrm{~km} / \mathrm{h}(25 \mathrm{mph})$. The speed of the truck did not noticeably influence strain measurements. Maximum diaphragm shear forces and ranges are presented in Table 4.3.2.4 for the dynamic loading conditions. The highest shear force range was calculated to be 2.7 $\mathrm{kN}(0.6 \mathrm{k})$ in Diaphragm \#2. Computed shear forces indicate only a small increase in shear force range as the speed of the truck increased. 
Table 4.3.2.5 is an account of the average maximum diaphragm strains and strain ranges for several typically monitored truck types. A maximum diaphragm strain range of 14 microstrain was measured on the top of Diaphragm \#1. This strain reading corresponds to the crossing of two eighteen-wheelers side-by-side, which is the same event previously discussed. Average maximum shear forces computed for representative truck types are listed in Table 4.3.2.6. The maximum calculated shear force for a single loading event was $1.3 \mathrm{kN}$ (0.3 k) in Diaphragm \#2 which corresponds to the passage of the single eighteen-wheeler referred to earlier.

When comparing all loading conditions, diaphragm behavior is similar. The maximum strain reading was consistently detected at the top of Diaphragm \#1 equaling about 10 to 15 microstrain. Increasing speeds did not influence strain readings. The maximum diaphragm shear force was always determined to be in Diaphragm \#2. Interestingly, calculated shear forces for the static and dynamic known loading conditions were usually larger than those calculated for most regular traffic events. This discrepancy may be because the loading is more concentrated for a dump truck than for the traffic monitored in this study. Figures 4.3.2.1 and 4.3.2.2 present a comparison between the average shear force for the static loading conditions and the maximum shear force for each traffic event in Diaphragms $\# 1$ and \#2, respectively.

Strains recorded in the beams were significantly higher than those recorded in the diaphragms. Figure 4.3.2.3 depicts a comparison between strain on the bottom of Beam \#3 and Diaphragm \#1 for the static loading conditions. 


\subsubsection{Traffic Events During Rain Storm}

Traffic strain measurements were collected during a hot July day in rural Indiana. Toward the end of monitoring regular traffic, a thunder storm approached. During the storm, eighteen unidentified truck events were captured. As a result of the drop in temperature and saturation of the concrete deck, the beams and diaphragms experienced thermal strains. A shift in the zero strain reading was also encountered. For example, Figure 4.3.3.1 shows an increase in maximum compressive strain in the top of the beams as the number of traffic samples, and therefore duration of the storm, increased. However, Figure 4.3.3.2 demonstrates no particular trend in the strain range in the top of the beams. Diaphragm behavior during the storm is similar to that of the beams in that the maximum strain increased slightly but the strain range showed no distinct trend. Figure 4.3.3.3 is an account of the axial strain range in the diaphragms over the course of the storm.

When compared to the strain ranges recorded prior to the storm, those recorded after the storm are just slightly higher. Any variation in strain range between traffic samples is principally due to the difference in weight between the trucks. Thermal strains endured by the members may explain any increase in strain range during the storm. Figure 4.3.3.4 presents the strain record for strains measured at the bottom of Beam $\# 2$ during the storm caused by an unidentified vehicle which induced high strains in many of the instrumented members. 
Table 4.2.1.1 US 52 - Maximum Beam Strains and Stresses for Static Loading Conditions

\begin{tabular}{|c|c|c|c|c|}
\hline Member & Gage & Strain $(\mu \varepsilon)$ & Stress (ksi) & LC\# \\
\hline \hline \multirow{3}{*}{ Beam \#1 } & B1A & -11.5 & -0.33 & 3A \\
\cline { 2 - 5 } & B1B & -27.2 & $-0.79^{*}$ & 3B \\
\cline { 2 - 5 } & B1C & -38.3 & $-1.11^{*}$ & 3B \\
\hline \multirow{3}{*}{ Beam \#2 } & B2A & -5.1 & -0.15 & 3A \\
\cline { 2 - 5 } & B2B & 15.1 & 0.89 & 4A \\
\cline { 2 - 5 } & B2C & -28.5 & -0.10 & 3B \\
\cline { 2 - 5 } & B2D & 90.6 & 2.63 & 3A \\
\hline
\end{tabular}

* Does not include the effect of strain in the transverse direction. 
Table 4.2.1.2 US 52 - Static Loading Conditions - Deflections

\begin{tabular}{|c|c|}
\hline Loading Condition & Deflection of Beam \#1 (in.) \\
\hline \hline LC \#1A & 0.213 \\
\hline LC \#2A & 0.224 \\
\hline LC \#3A & 0.213 \\
\hline LC \#4A & 0.201 \\
\hline LC \#1B & 0.228 \\
\hline LC \#2B & 0.264 \\
\hline LC \#3B & 0.264 \\
\hline LC \#4B & 0.193 \\
\hline
\end{tabular}


Table 4.2.1.3 US 52 - Maximum Beam Strains and Strain Ranges for Dynamic Loading Conditions

\begin{tabular}{|c|c|c|c|c|}
\hline Speed (mph) & Member & Gage & $\begin{array}{c}\text { Maximum Strain } \\
(\mu \varepsilon) \\
\end{array}$ & $\begin{array}{c}\text { Maximum Strain Range } \\
(\mu \varepsilon)\end{array}$ \\
\hline \multirow[t]{7}{*}{$\sim 5$} & \multirow[t]{3}{*}{ Beam \#1 } & $\mathrm{B} 1 \mathrm{~A}$ & -16.2 & 17.1 \\
\hline & & B1B & -37.7 & 36.6 \\
\hline & & $\mathrm{B} 1 \mathrm{C}$ & -44.0 & 47.2 \\
\hline & \multirow[t]{4}{*}{ Beam\#2 } & $\mathrm{B} 2 \mathrm{~A}$ & -11.5 & 11.8 \\
\hline & & B2B & 23.1 & 34.3 \\
\hline & & $\mathrm{B} 2 \mathrm{C}$ & -32.5 & 36.6 \\
\hline & & $\mathrm{B} 2 \mathrm{D}$ & 94.9 & 106.9 \\
\hline \multirow[t]{7}{*}{$\sim 15-20$} & \multirow[t]{3}{*}{ Beam \#1 } & $\mathrm{B} 1 \mathrm{~A}$ & -15.6 & 20.1 \\
\hline & & $\mathrm{B} 1 \mathrm{~B}$ & -38.9 & 50.2 \\
\hline & & $\mathrm{B} 1 \mathrm{C}$ & -41.6 & 50.2 \\
\hline & \multirow[t]{4}{*}{ Beam\#2 } & $\mathrm{B} 2 \mathrm{~A}$ & -10.3 & 11.8 \\
\hline & & $\mathrm{B} 2 \mathrm{~B}$ & 21.3 & 34.8 \\
\hline & & $\mathrm{B} 2 \mathrm{C}$ & -32.5 & 39.0 \\
\hline & & $\mathrm{B} 2 \mathrm{D}$ & 91.3 & 112.8 \\
\hline \multirow[t]{7}{*}{$\sim 25-30$} & \multirow[t]{3}{*}{ Beam \#1 } & $\mathrm{B} 1 \mathrm{~A}$ & -17.4 & 17.7 \\
\hline & & $\mathrm{B} 1 \mathrm{~B}$ & -43.6 & 42.5 \\
\hline & & $\mathrm{B} 1 \mathrm{C}$ & -43.4 & 49.6 \\
\hline & \multirow[t]{4}{*}{ Beam\#2 } & $\mathrm{B} 2 \mathrm{~A}$ & -9.1 & 11.2 \\
\hline & & $\mathrm{B} 2 \mathrm{~B}$ & 20.8 & 27.2 \\
\hline & & $\mathrm{B} 2 \mathrm{C}$ & -33.1 & 37.8 \\
\hline & & $\mathrm{B} 2 \mathrm{D}$ & 93.7 & 114.0 \\
\hline
\end{tabular}


Table 4.2.1.4 US 52 - Average Maximum Beam Strains and Strain Ranges for Regular Traffic

\begin{tabular}{|c|c|c|c|c|}
\hline Truck Type & Member & Gage & Maximum Strain $(\mu \varepsilon)$ & Strain Range $(\mu \varepsilon)$ \\
\hline \multirow[t]{7}{*}{ Flat Bed } & \multirow[t]{3}{*}{ Beam \#1 } & $\mathrm{B} 1 \mathrm{~A}$ & -12.8 & 15.2 \\
\hline & & $\mathrm{B} 1 \mathrm{~B}$ & -20.5 & 29.3 \\
\hline & & $\mathrm{B} 1 \mathrm{C}$ & -34.1 & 39.8 \\
\hline & \multirow[t]{4}{*}{ Beam \#2 } & $\mathrm{B} 2 \mathrm{~A}$ & -6.5 & 10.0 \\
\hline & & B2B & 21.7 & 25.4 \\
\hline & & $\mathrm{B} 2 \mathrm{C}$ & -24.6 & 31.5 \\
\hline & & $\mathrm{B} 2 \mathrm{D}$ & 82.3 & 100.4 \\
\hline \multirow{7}{*}{$\begin{array}{c}\text { Ready-Mix } \\
\text { Truck }\end{array}$} & \multirow[t]{3}{*}{ Beam \#1 } & $\mathrm{B} 1 \mathrm{~A}$ & -10.0 & 11.5 \\
\hline & & $\mathrm{B} 1 \mathrm{~B}$ & -26.3 & 28.3 \\
\hline & & $\mathrm{B} 1 \mathrm{C}$ & -28.1 & 31.6 \\
\hline & \multirow[t]{4}{*}{ Beam \#2 } & B2A & -3.5 & 8.3 \\
\hline & & B2B & 16.3 & 26.6 \\
\hline & & $\mathrm{B} 2 \mathrm{C}$ & -19.8 & 26.6 \\
\hline & & B2D & 63.5 & 79.4 \\
\hline \multirow{7}{*}{$\begin{array}{l}\text { Eighteen- } \\
\text { Wheeler(s) }\end{array}$} & \multirow[t]{3}{*}{ Beam \#1 } & $\mathrm{B} 1 \mathrm{~A}$ & -13.3 & 16.2 \\
\hline & & $\mathrm{B} 1 \mathrm{~B}$ & -29.2 & 39.7 \\
\hline & & $\mathrm{B} 1 \mathrm{C}$ & -35.6 & 43.3 \\
\hline & \multirow[t]{4}{*}{ Beam \#2 } & $\mathrm{B} 2 \mathrm{~A}$ & -5.9 & 12.0 \\
\hline & & B2B & 21.9 & 34.9 \\
\hline & & $\mathrm{B} 2 \mathrm{C}$ & -27.4 & 36.2 \\
\hline & & B2D & 82.0 & 104.0 \\
\hline \multirow[t]{7}{*}{ Dump Truck } & \multirow[t]{3}{*}{ Beam \#1 } & $\mathrm{B} 1 \mathrm{~A}$ & -12.9 & 15.8 \\
\hline & & $\mathrm{B} 1 \mathrm{~B}$ & -26.6 & 34.1 \\
\hline & & $\mathrm{B} 1 \mathrm{C}$ & -32.2 & 37.5 \\
\hline & \multirow[t]{4}{*}{ Beam \#2 } & $\mathrm{B} 2 \mathrm{~A}$ & -6.5 & 13.0 \\
\hline & & B2B & 18.0 & 34.0 \\
\hline & & $\mathrm{B} 2 \mathrm{C}$ & -26.0 & 33.9 \\
\hline & & $\mathrm{B} 2 \mathrm{D}$ & 82.1 & 96.8 \\
\hline
\end{tabular}


Table 4.2.2.1 US 52 - Maximum Diaphragm Strains and Stresses for Static Loading Conditions

\begin{tabular}{|c|c|c|c|c|}
\hline Member & Gage & Strain ( $\mu \varepsilon)$ & Stress (ksi) & $\mathrm{LC} \#$ \\
\hline \multirow[t]{5}{*}{ Diaphragm \#1 } & D1A & $2.6 /-5.5$ & $0.08 /-0.16$ & $2 \mathrm{~A} / 2 \mathrm{~B}$ \\
\hline & D1B & $37.5 / 48.1$ & $1.09 / 1.40$ & $3 \mathrm{~A} / 2 \mathrm{~B}$ \\
\hline & $\mathrm{R} 1 \mathrm{~A}$ & $-13.5 /-13.4$ & $-0.39 /-0.39$ & $2 \mathrm{~A} / 3 \mathrm{~B}$ \\
\hline & $\mathrm{R} 1 \mathrm{~B}$ & $19.4 / 20.4$ & $0.56 / 0.59$ & $3 \mathrm{~A} / 2 \mathrm{~B}$ \\
\hline & $\mathrm{R} 1 \mathrm{C}$ & $27.3 / 27.9$ & $0.79 / 0.81$ & $3 \mathrm{~A} / 3 \mathrm{~B}$ \\
\hline \multirow[t]{5}{*}{ Diaphragm \#2 } & $\mathrm{D} 2 \mathrm{~A}$ & $-44.4 /-44.1$ & $-1.29 /-1.28$ & $3 \mathrm{~A} / 3 \mathrm{~B}$ \\
\hline & D2B & $99.0 / 95.8$ & $2.87 / 2.78$ & $3 \mathrm{~A} / 3 \mathrm{~B}$ \\
\hline & $\mathrm{R} 2 \mathrm{~A}$ & $2.8 / 8.6$ & $0.08 / 0.25$ & $1 \mathrm{~A} / 3 \mathrm{~B}$ \\
\hline & $\mathrm{R} 2 \mathrm{~B}$ & $29.2 / 27.4$ & $0.85 / 0.80$ & $2 \mathrm{~A} / 3 \mathrm{~B}$ \\
\hline & $\mathrm{R} 2 \mathrm{C}$ & $18.2 / 10.9$ & $0.53 / 0.32$ & $3 \mathrm{~A} / 3 \mathrm{~B}$ \\
\hline \multirow[t]{5}{*}{ Diaphragm \#3 } & D3A & $-29.3 /-18.7$ & $-0.85 /-0.54$ & $2 \mathrm{~A} / 3 \mathrm{~B}$ \\
\hline & D3B & $81.7 / 63.1$ & $2.37 / 1.83$ & $3 \mathrm{~A} / 2 \mathrm{~B}$ \\
\hline & R3A & $-12.6 /-15.3$ & $-0.36 /-0.44$ & $3 \mathrm{~A} / 3 \mathrm{~B}$ \\
\hline & $\mathrm{R} 3 \mathrm{~B}$ & $25.5 / 21.7$ & $0.74 / 0.63$ & $3 \mathrm{~A} / 2 \mathrm{~B}$ \\
\hline & $\mathrm{R} 3 \mathrm{C}$ & $29.6 / 29.6$ & $0.86 / 0.86$ & $3 \mathrm{~A} / 3 \mathrm{~B}$ \\
\hline
\end{tabular}


Table 4.2.2.2 US 52 - Maximum Diaphragm Forces for Static Loading Conditions

\begin{tabular}{|c|c|c|c|c|}
\hline Member & $\begin{array}{c}\text { Maximum Shear } \\
\text { Force (k) }\end{array}$ & LC \# & $\begin{array}{c}\text { Maximum Axial } \\
\text { Force (k) }\end{array}$ & LC \# \\
\hline \hline \multirow{2}{*}{ Diaphragm \#1 } & 2.35 & $2 \mathrm{~A}$ & 7.45 & 3A \\
\cline { 2 - 5 } & 2.39 & $3 \mathrm{~B}$ & 7.84 & $2 \mathrm{~B}$ \\
\hline \multirow{2}{*}{ Diaphragm \#2 } & 0.93 & $3 \mathrm{~A}$ & 11.23 & $2 \mathrm{~A}$ \\
\cline { 2 - 5 } & 0.16 & $4 \mathrm{~B}$ & 10.53 & $3 \mathrm{~B}$ \\
\hline \multirow{2}{*}{ Diaphragm \#3 } & -2.44 & $3 \mathrm{~A}$ & 9.78 & $3 \mathrm{~A}$ \\
\cline { 2 - 5 } & -2.59 & $3 \mathrm{~B}$ & 8.34 & $2 \mathrm{~B}$ \\
\hline
\end{tabular}


Table 4.2.2.3 US 52 - Maximum Diaphragm Strains and Strain Ranges for Dynamic Loading Conditions

\begin{tabular}{|c|c|c|c|c|}
\hline $\begin{array}{l}\text { Speed } \\
(\mathrm{mph}) \\
\end{array}$ & Member & Gage & $\begin{array}{c}\text { Maximum Strain } \\
(\mu \varepsilon)\end{array}$ & $\begin{array}{c}\text { Maximum Strain Range } \\
(\mu \varepsilon)\end{array}$ \\
\hline \multirow[t]{15}{*}{$\sim 5$} & \multirow[t]{5}{*}{ Diaphragm \#1 } & D1A & 8.0 & 13.0 \\
\hline & & D1B & 54.0 & 54.0 \\
\hline & & R1A & -16.1 & 22.2 \\
\hline & & R1B & 22.5 & 25.7 \\
\hline & & $\mathrm{R} 1 \mathrm{C}$ & 30.9 & 32.2 \\
\hline & \multirow[t]{5}{*}{ Diaphragm \#2 } & $\mathrm{D} 2 \mathrm{~A}$ & -52.0 & 51.4 \\
\hline & & $\mathrm{D} 2 \mathrm{~B}$ & 108.2 & 111.6 \\
\hline & & $\mathrm{R} 2 \mathrm{~A}$ & 8.6 & 10.5 \\
\hline & & R2B & 33.1 & 38.0 \\
\hline & & $\mathrm{R} 2 \mathrm{C}$ & 20.3 & 24.6 \\
\hline & \multirow[t]{5}{*}{ Diaphragm \#3 } & D3A & -32.8 & 36.6 \\
\hline & & D3B & 86.9 & 97.4 \\
\hline & & R3A & -21.1 & 22.2 \\
\hline & & $\mathrm{R} 3 \mathrm{~B}$ & 28.6 & 33.3 \\
\hline & & $\mathrm{R} 3 \mathrm{C}$ & 35.6 & 38.0 \\
\hline
\end{tabular}


Table 4.2.2.3 (cont.) US 52 - Maximum Diaphragm Strains and Strain Ranges for Dynamic Loading Conditions

\begin{tabular}{|c|c|c|c|c|}
\hline $\begin{array}{l}\text { Speed } \\
\text { (mph) } \\
\end{array}$ & Member & Gage & $\begin{array}{c}\text { Maximum Strain } \\
(\mu \varepsilon) \\
\end{array}$ & $\begin{array}{c}\text { Maximum Strain Range } \\
(\mu \varepsilon)\end{array}$ \\
\hline \multirow[t]{15}{*}{$\sim 15-20$} & \multirow[t]{5}{*}{ Diaphragm \#1 } & D1A & 18.6 & 23.6 \\
\hline & & D1B & 56.4 & 61.4 \\
\hline & & R1A & 24.9 & 40.9 \\
\hline & & R1B & 22.5 & 27.5 \\
\hline & & $\mathrm{R} 1 \mathrm{C}$ & 32.1 & 35.1 \\
\hline & \multirow[t]{5}{*}{ Diaphragm \#2 } & D2A & -49.6 & 50.2 \\
\hline & & $\mathrm{D} 2 \mathrm{~B}$ & 108.2 & 118.7 \\
\hline & & $\mathrm{R} 2 \mathrm{~A}$ & 11.5 & 14.0 \\
\hline & & $\mathrm{R} 2 \mathrm{~B}$ & 33.7 & 40.9 \\
\hline & & $\mathrm{R} 2 \mathrm{C}$ & 19.7 & 23.4 \\
\hline & \multirow[t]{5}{*}{ Diaphragm \#3 } & D3A & -33.4 & 38.4 \\
\hline & & D3B & 90.4 & 107.5 \\
\hline & & R3A & -20.5 & 24.0 \\
\hline & & R3B & 29.8 & 36.9 \\
\hline & & $\mathrm{R} 3 \mathrm{C}$ & 34.4 & 38.6 \\
\hline
\end{tabular}


Table 4.2.2.3 (cont.) US 52 - Maximum Diaphragm Strains and Strain Ranges for Dynamic Loading Conditions

\begin{tabular}{|c|c|c|c|c|}
\hline $\begin{array}{l}\text { Speed } \\
(\mathrm{mph}) \\
\end{array}$ & Member & Gage & $\begin{array}{c}\text { Maximum Strain } \\
(\mu \varepsilon) \\
\end{array}$ & $\begin{array}{l}\text { Maximum Strain Range } \\
(\mu \varepsilon)\end{array}$ \\
\hline \multirow[t]{15}{*}{$\sim 25-30$} & \multirow[t]{5}{*}{ Diaphragm \#1 } & D1A & 8.0 & 11.8 \\
\hline & & D1B & 58.7 & 60.2 \\
\hline & & $\mathrm{R} 1 \mathrm{~A}$ & -18.4 & 28.7 \\
\hline & & $\mathrm{R} 1 \mathrm{~B}$ & 21.9 & 29.8 \\
\hline & & $\mathrm{R} 1 \mathrm{C}$ & 29.7 & 35.1 \\
\hline & \multirow[t]{5}{*}{ Diaphragm \#2 } & $\mathrm{D} 2 \mathrm{~A}$ & -49.6 & 54.9 \\
\hline & & D2B & 107.1 & 127.0 \\
\hline & & $\mathrm{R} 2 \mathrm{~A}$ & 12.8 & 13.5 \\
\hline & & $\mathrm{R} 2 \mathrm{~B}$ & 32.5 & 43.9 \\
\hline & & $\mathrm{R} 2 \mathrm{C}$ & 20.3 & 25.2 \\
\hline & \multirow[t]{5}{*}{ Diaphragm \#3 } & D3A & -34.6 & 39.0 \\
\hline & & D3B & 89.8 & 112.8 \\
\hline & & R3A & -21.7 & 22.8 \\
\hline & & $\mathrm{R} 3 \mathrm{~B}$ & 28.6 & 38.0 \\
\hline & & $\mathrm{R} 3 \mathrm{C}$ & 33.2 & 40.4 \\
\hline
\end{tabular}


Table 4.2.2.4 US 52 - Maximum Diaphragm Shear Forces and Ranges for Dynamic Loading Conditions

\begin{tabular}{|c|c|c|c|c|}
\hline $\begin{array}{l}\text { Speed } \\
\text { (mph) }\end{array}$ & Position & Member & $\begin{array}{c}\text { Maximum Shear } \\
(\mathrm{k})\end{array}$ & $\begin{array}{l}\text { Maximum Range } \\
(\mathrm{k})\end{array}$ \\
\hline \multirow[t]{6}{*}{$\sim 5$} & \multirow[t]{3}{*}{ A } & Diaphragm \#1 & 2.6 & 2.7 \\
\hline & & Diaphragm \#2 & 1.1 & 1.3 \\
\hline & & Diaphragm \#3 & -2.8 & 2.8 \\
\hline & \multirow[t]{3}{*}{ B } & Diaphragm \#1 & 2.7 & 2.7 \\
\hline & & Diaphragm \#2 & 0.6 & 0.8 \\
\hline & & Diaphragm \#3 & -3.0 & 2.9 \\
\hline \multirow[t]{6}{*}{$\sim 15-20$} & \multirow[t]{3}{*}{ A } & Diaphragm \#1 & 2.6 & 2.7 \\
\hline & & Diaphragm \#2 & 1.1 & 1.3 \\
\hline & & Diaphragm \#3 & -2.9 & 3.0 \\
\hline & \multirow[t]{3}{*}{ B } & Diaphragm \#1 & 2.5 & 2.7 \\
\hline & & Diaphragm \#2 & 0.3 & 0.6 \\
\hline & & Diaphragm \#3 & -2.9 & 3.1 \\
\hline \multirow[t]{6}{*}{$\sim 25-30$} & \multirow[t]{3}{*}{ A } & Diaphragm \#1 & 2.6 & 2.8 \\
\hline & & Diaphragm \#2 & 1.1 & 1.3 \\
\hline & & Diaphragm \#3 & -2.6 & 3.1 \\
\hline & \multirow[t]{3}{*}{ B } & Diaphragm \#1 & 2.5 & 2.6 \\
\hline & & Diaphragm \#2 & -0.4 & 0.5 \\
\hline & & Diaphragm \#3 & -2.9 & 3.0 \\
\hline
\end{tabular}


Table 4.2.2.5 US 52 - Average Maximum Diaphragm Strains and Strain Ranges for Regular Traffic

\begin{tabular}{|c|c|c|c|c|}
\hline Truck Type & Member & Gage & $\begin{array}{c}\text { Maximum Strain } \\
(\mu \varepsilon) \\
\end{array}$ & $\begin{array}{c}\text { Maximum Strain } \\
\text { Range ( } \mu \varepsilon) \\
\end{array}$ \\
\hline \multirow[t]{15}{*}{ Flat Bed } & \multirow[t]{5}{*}{ Diaphragm \#1 } & D1A & 4.5 & 7.9 \\
\hline & & $\mathrm{D} 1 \mathrm{~B}$ & 38.8 & 43.1 \\
\hline & & $\mathrm{R} 1 \mathrm{~A}$ & -10.9 & 12.9 \\
\hline & & $\mathrm{R} 1 \mathrm{~B}$ & 21.1 & 24.4 \\
\hline & & $\mathrm{R} 1 \mathrm{C}$ & 22.2 & 27.3 \\
\hline & \multirow[t]{5}{*}{ Diaphragm \#2 } & $\mathrm{D} 2 \mathrm{~A}$ & -38.0 & 41.9 \\
\hline & & $\mathrm{D} 2 \mathrm{~B}$ & 93.3 & 103.0 \\
\hline & & $\mathrm{R} 2 \mathrm{~A}$ & 4.9 & 7.8 \\
\hline & & R2B & 30.4 & 36.5 \\
\hline & & $\mathrm{R} 2 \mathrm{C}$ & 21.3 & 23.6 \\
\hline & \multirow[t]{5}{*}{ Diaphragm \#3 } & $\mathrm{D} 3 \mathrm{~A}$ & -32.7 & 37.8 \\
\hline & & D3B & 88.2 & 99.6 \\
\hline & & R3A & -12.3 & 16.0 \\
\hline & & R3B & 29.8 & 35.3 \\
\hline & & $\mathrm{R} 3 \mathrm{C}$ & 30.0 & 34.9 \\
\hline
\end{tabular}


Table 4.2.2.5 (cont.) US 52 - Average Maximum Diaphragm Strains and Strain Ranges for Regular Traffic

\begin{tabular}{|c|c|c|c|c|}
\hline Truck Type & Member & Gage & $\begin{array}{c}\text { Maximum Strain } \\
(\mu \varepsilon)\end{array}$ & $\begin{array}{c}\text { Maximum Strain } \\
\text { Range }(\mu \varepsilon) \\
\end{array}$ \\
\hline \multirow{15}{*}{$\begin{array}{c}\text { Ready-Mix } \\
\text { Truck }\end{array}$} & \multirow[t]{5}{*}{ Diaphragm \#1 } & D1A & -4.7 & 6.5 \\
\hline & & D1B & 28.9 & 32.8 \\
\hline & & R1A & -9.4 & 11.1 \\
\hline & & R1B & 12.9 & 17.3 \\
\hline & & $\mathrm{R} 1 \mathrm{C}$ & 17.3 & 21.6 \\
\hline & \multirow[t]{5}{*}{ Diaphragm \#2 } & $\mathrm{D} 2 \mathrm{~A}$ & -28.3 & 32.5 \\
\hline & & $\mathrm{D} 2 \mathrm{~B}$ & 68.8 & 75.6 \\
\hline & & $\mathrm{R} 2 \mathrm{~A}$ & 4.4 & 7.0 \\
\hline & & R2B & 21.4 & 26.3 \\
\hline & & $\mathrm{R} 2 \mathrm{C}$ & 20.2 & 17.6 \\
\hline & \multirow[t]{5}{*}{ Diaphragm \#3 } & $\mathrm{D} 3 \mathrm{~A}$ & -22.1 & 28.9 \\
\hline & & D3B & 66.1 & 71.2 \\
\hline & & R3A & -9.4 & 15.2 \\
\hline & & R3B & 23.4 & 27.2 \\
\hline & & $\mathrm{R} 3 \mathrm{C}$ & 26.6 & 33.1 \\
\hline
\end{tabular}


Table 4.2.2.5 (cont.) US 52 - Average Maximum Diaphragm Strains and Strain Ranges for Regular Traffic

\begin{tabular}{|c|c|c|c|c|}
\hline Truck Type & Member & Gage & $\begin{array}{l}\text { Maximum Strain } \\
(\mu \varepsilon)\end{array}$ & $\begin{array}{c}\text { Maximum Strain } \\
\text { Range ( } \mu \varepsilon)\end{array}$ \\
\hline \multirow{15}{*}{$\begin{array}{l}\text { Eighteen - } \\
\text { Wheeler(s) }\end{array}$} & \multirow[t]{5}{*}{ Diaphragm \#1 } & D1A & 5.5 & 11.0 \\
\hline & & D1B & 42.7 & 50.7 \\
\hline & & R1A & -11.7 & 13.4 \\
\hline & & $\mathrm{R} 1 \mathrm{~B}$ & 18.2 & 24.7 \\
\hline & & $\mathrm{R} 1 \mathrm{C}$ & 23.5 & 28.1 \\
\hline & \multirow[t]{5}{*}{ Diaphragm \#2 } & $\mathrm{D} 2 \mathrm{~A}$ & -38.1 & 44.7 \\
\hline & & $\mathrm{D} 2 \mathrm{~B}$ & 91.4 & 104.7 \\
\hline & & $\mathrm{R} 2 \mathrm{~A}$ & 6.8 & 9.9 \\
\hline & & R2B & 28.3 & 36.3 \\
\hline & & $\mathrm{R} 2 \mathrm{C}$ & 24.8 & 22.6 \\
\hline & \multirow[t]{5}{*}{ Diaphragm \#3 } & $\mathrm{D} 3 \mathrm{~A}$ & -26.9 & 34.2 \\
\hline & & D3B & 85.9 & 96.3 \\
\hline & & $\mathrm{R} 3 \mathrm{~A}$ & -13.7 & 22.1 \\
\hline & & R3B & 30.9 & 36.6 \\
\hline & & $\mathrm{R} 3 \mathrm{C}$ & 33.8 & 40.9 \\
\hline
\end{tabular}


Table 4.2.2.5 (cont.) US 52 - Average Maximum Diaphragm Strains and Strain Ranges for Regular Traffic

\begin{tabular}{|c|c|c|c|c|}
\hline Truck Type & Member & Gage & $\begin{array}{c}\text { Maximum Strain } \\
(\mu \varepsilon)\end{array}$ & $\begin{array}{c}\text { Maximum Strain } \\
\text { Range }(\mu \varepsilon) \\
\end{array}$ \\
\hline \multirow{15}{*}{$\begin{array}{l}\text { Dump } \\
\text { Truck }\end{array}$} & \multirow[t]{5}{*}{ Diaphragm \#1 } & D1A & 6.5 & 10.4 \\
\hline & & D1B & 34.4 & 41.6 \\
\hline & & $\mathrm{R} 1 \mathrm{~A}$ & -10.3 & 12.9 \\
\hline & & R1B & 14.7 & 20.8 \\
\hline & & $\mathrm{R} 1 \mathrm{C}$ & 20.8 & 24.6 \\
\hline & \multirow[t]{5}{*}{ Diaphragm \#2 } & D2A & -33.3 & 44.7 \\
\hline & & D2B & 80.5 & 89.6 \\
\hline & & $\mathrm{R} 2 \mathrm{~A}$ & 6.2 & 8.4 \\
\hline & & $\mathrm{R} 2 \mathrm{~B}$ & 26.2 & 31.6 \\
\hline & & $\mathrm{R} 2 \mathrm{C}$ & 27.2 & 20.4 \\
\hline & \multirow[t]{5}{*}{ Diaphragm \#3 } & D3A & -21.7 & 30.8 \\
\hline & & D3B & 80.1 & 84.1 \\
\hline & & $\mathrm{R} 3 \mathrm{~A}$ & 13.8 & 26.3 \\
\hline & & $\mathrm{R} 3 \mathrm{~B}$ & 31.6 & 34.6 \\
\hline & & $\mathrm{R} 3 \mathrm{C}$ & 34.0 & 42.4 \\
\hline
\end{tabular}


Table 4.2.2.6 US 52 - Average Maximum Diaphragm Shear Forces for Regular Traffic

\begin{tabular}{|c|c|c|}
\hline Truck Type & Member & Maximum Avg. Shear (k) \\
\hline \hline \multirow{5}{*}{ Flat Bed } & Diaphragm \#1 & 1.9 \\
\cline { 2 - 3 } & Diaphragm \#2 & 0.94 \\
\cline { 2 - 3 } & Diaphragm \#3 & -2.4 \\
\hline \multirow{5}{*}{ Ready-Mix Truck } & Diaphragm \#1 & 2.3 \\
\cline { 2 - 3 } & Diaphragm \#2 & 0.91 \\
\cline { 2 - 3 } & Diaphragm \#3 & -2.1 \\
\hline \multirow{5}{*}{ Eighteen-Wheeler(s) } & Diaphragm \#1 & 2.0 \\
\cline { 2 - 3 } & Diaphragm \#2 & 1.2 \\
\cline { 2 - 3 } & Diaphragm \#3 & -2.8 \\
\hline \multirow{3}{*}{ Dump Truck } & Diaphragm \#1 & 1.8 \\
\cline { 2 - 4 } & Diaphragm \#2 & 1.3 \\
\cline { 2 - 3 } & Diaphragm \#3 & -2.9 \\
\hline
\end{tabular}


Table 4.3.1.1 I 65 - Maximum Beam Strains and Stresses for Static Loading Conditions

\begin{tabular}{|c|c|c|c|c|}
\hline Member & Gage & Strain $(\mu \varepsilon)$ & Stress (ksi) & LC\# \\
\hline \multirow[t]{3}{*}{ Beam \#1 } & $\mathrm{B} 1 \mathrm{~A}$ & -3.7 & -0.11 & $1 \mathrm{~A}$ \\
\hline & $\mathrm{B} 1 \mathrm{C}$ & -53.1 & -1.16 & $1 \mathrm{~B}$ \\
\hline & B1D & 68.4 & 1.98 & $3 \mathrm{~B}$ \\
\hline \multirow[t]{5}{*}{ Beam \#2 } & $\mathrm{B} 2 \mathrm{~A}$ & -2.7 & -0.08 & $3 \mathrm{~B}$ \\
\hline & $\mathrm{B} 2 \mathrm{~B}$ & 67.3 & 2.60 & $3 \mathrm{~A}$ \\
\hline & $\mathrm{B} 2 \mathrm{M}$ & 74.7 & 2.17 & $1 \mathrm{~A}$ \\
\hline & $\mathrm{B} 2 \mathrm{C}$ & -75.0 & -1.76 & $2 \mathrm{~A}$ \\
\hline & B2D & 71.0 & 2.06 & $1 \mathrm{~A}$ \\
\hline \multirow[t]{5}{*}{ Beam \#3 } & $\mathrm{B} 3 \mathrm{~A}$ & -2.9 & -0.08 & $1 \mathrm{~B}$ \\
\hline & $\mathrm{B} 3 \mathrm{~B}$ & 33.5 & 1.63 & $1 \mathrm{~A}$ \\
\hline & $\mathrm{B} 3 \mathrm{M}$ & 69.2 & 2.01 & $2 \mathrm{~A}$ \\
\hline & $\mathrm{B} 3 \mathrm{C}$ & -65.7 & -1.45 & $2 \mathrm{~A}$ \\
\hline & B3D & 75.3 & 2.18 & $3 \mathrm{~B}$ \\
\hline
\end{tabular}


Table 4.3.1.2 I 65 - Static Loading Conditions - Deflections

\begin{tabular}{|c|c|c|c|}
\hline \multirow{2}{*}{$\begin{array}{c}\text { Loading } \\
\text { Condition }\end{array}$} & \multicolumn{3}{|c|}{ Deflection (in.) } \\
\cline { 2 - 4 } & Beam\#1 & Beam \#2 & Differential \\
\hline \hline LC \#1A & 0.156 & 0.176 & 0.020 \\
\hline LC \#2A & 0.173 & 0.189 & 0.016 \\
\hline LC \#3A & 0.157 & 0.169 & 0.012 \\
\hline LC \#1B & 0.169 & 0.170 & 0.001 \\
\hline LC \#2B & 0.168 & 0.165 & -0.003 \\
\hline LC \#3B & 0.176 & 0.175 & -0.001 \\
\hline
\end{tabular}


Table 4.3.1.3 I 65 - Maximum Beam Strains and Strain Ranges for Dynamic Loading Conditions

\begin{tabular}{|c|c|c|c|c|}
\hline Speed (mph) & Member & Gage & $\begin{array}{c}\text { Maximum Strain } \\
(\mu \varepsilon) \\
\end{array}$ & $\begin{array}{c}\text { Maximum Strain } \\
\text { Range ( } \mu \varepsilon)\end{array}$ \\
\hline \multirow[t]{13}{*}{$\sim 5$} & \multirow[t]{3}{*}{ Beam \#1 } & $\mathrm{B} 1 \mathrm{~A}$ & -9.0 & 9.4 \\
\hline & & $\mathrm{B} 1 \mathrm{C}$ & -62.8 & 40.2 \\
\hline & & BID & 75.6 & 60.2 \\
\hline & \multirow[t]{5}{*}{ Beam\#2 } & $\mathrm{B} 2 \mathrm{~A}$ & -7.3 & 11.2 \\
\hline & & $\mathrm{B} 2 \mathrm{~B}$ & 80.4 & 56.1 \\
\hline & & $\mathrm{B} 2 \mathrm{M}$ & 100.3 & 77.4 \\
\hline & & $\mathrm{B} 2 \mathrm{C}$ & -91.2 & 65.0 \\
\hline & & $\mathrm{B} 2 \mathrm{D}$ & 107.3 & 87.4 \\
\hline & \multirow[t]{5}{*}{ Beam\#3 } & $\mathrm{B} 3 \mathrm{~A}$ & -7.5 & 9.4 \\
\hline & & $\mathrm{B} 3 \mathrm{~B}$ & 60.3 & 42.5 \\
\hline & & B3M & 94.3 & 76.2 \\
\hline & & $\mathrm{B} 3 \mathrm{C}$ & -79.5 & 60.8 \\
\hline & & $\mathrm{B} 3 \mathrm{D}$ & 95.8 & 85.0 \\
\hline \multirow[t]{13}{*}{$\sim 25$} & \multirow[t]{3}{*}{ Beam \#1 } & $\mathrm{BlA}$ & -5.5 & 8.9 \\
\hline & & $\mathrm{B} 1 \mathrm{C}$ & -62.2 & 68.5 \\
\hline & & B1D & 69.6 & 86.8 \\
\hline & \multirow[t]{5}{*}{ Beam\#2 } & $\mathrm{B} 2 \mathrm{~A}$ & 8.6 & 8.3 \\
\hline & & $\mathrm{B} 2 \mathrm{~B}$ & 72.8 & 86.8 \\
\hline & & $\mathrm{B} 2 \mathrm{M}$ & 72.6 & 87.4 \\
\hline & & $\mathrm{B} 2 \mathrm{C}$ & -69.9 & 83.3 \\
\hline & & $\mathrm{B} 2 \mathrm{D}$ & 78.4 & 92.1 \\
\hline & \multirow[t]{5}{*}{ Beam\#3 } & $\mathrm{B} 3 \mathrm{~A}$ & 7.3 & 6.5 \\
\hline & & $\mathrm{B} 3 \mathrm{~B}$ & 42.9 & 50.8 \\
\hline & & $\mathrm{B} 3 \mathrm{M}$ & 63.9 & 83.3 \\
\hline & & $\mathrm{B} 3 \mathrm{C}$ & -65.7 & 77.4 \\
\hline & & B3D & 71.3 & 92.1 \\
\hline
\end{tabular}


Table 4.3.1.3 (cont.) I 65 - Maximum Beam Strains and Strain Ranges for Dynamic Loading Conditions

\begin{tabular}{|c|c|c|c|c|}
\hline Speed (mph) & Member & Gage & $\begin{array}{c}\text { Maximum Strain } \\
(\mu \varepsilon)\end{array}$ & $\begin{array}{c}\text { Maximum Strain } \\
\text { Range }(\mu \varepsilon)\end{array}$ \\
\hline \hline \multirow{5}{*}{$\sim 55$} & \multirow{3}{*}{ Beam \#1 } & B1A & -7.2 & 7.1 \\
\hline & & B1C & -59.8 & 69.7 \\
\hline & B1D & 63.3 & 88.0 \\
\hline \multirow{5}{*}{ Beam\#2 } & B2A & -10.3 & 10.0 \\
\hline & B2B & 72.7 & 85.0 \\
\hline & B2M & 76.4 & 94.5 \\
\hline & B2C & -74.4 & 89.2 \\
\hline & B2D & 71.7 & 98.6 \\
\hline & \multirow{5}{*}{ Beam\#3 } & B3A & 7.3 & 6.5 \\
\hline & & B3B & 42.9 & 50.8 \\
\hline & B3M & 63.7 & 83.3 \\
\hline & B3C & -65.7 & 77.4 \\
\hline & B3D & 71.3 & 92.1 \\
\hline
\end{tabular}


Table 4.3.1.4 I 65 - Average Maximum Beam Strains and Strain Ranges for Regular Traffic

\begin{tabular}{|c|c|c|c|c|}
\hline Truck Type & Member & Gage & Maximum Strain $(\mu \varepsilon)$ & Strain Range $(\mu \varepsilon)$ \\
\hline \multirow{13}{*}{$\begin{array}{l}\text { Eighteen - } \\
\text { Wheeler(s) }\end{array}$} & \multirow[t]{3}{*}{ Beam \#1 } & B1A & 6.6 & 10.1 \\
\hline & & $\mathrm{BlC}$ & -49.4 & 62.1 \\
\hline & & B1D & 51.4 & 74.4 \\
\hline & \multirow[t]{5}{*}{ Beam \#2 } & $\mathrm{B} 2 \mathrm{~A}$ & 4.9 & 7.3 \\
\hline & & B2B & 79.8 & 94.3 \\
\hline & & $\mathrm{B} 2 \mathrm{M}$ & 67.6 & 84.5 \\
\hline & & $\mathrm{B} 2 \mathrm{C}$ & -72.1 & 86.5 \\
\hline & & $\mathrm{B} 2 \mathrm{D}$ & 67.0 & 88.1 \\
\hline & \multirow[t]{5}{*}{ Beam \#3 } & $\mathrm{B} 3 \mathrm{~A}$ & 3.3 & 6.5 \\
\hline & & B3B & 49.0 & 60.2 \\
\hline & & $\mathrm{B} 3 \mathrm{M}$ & 60.8 & 78.3 \\
\hline & & B3C & -62.5 & 74.8 \\
\hline & & B3D & 65.2 & 85.8 \\
\hline \multirow[t]{13}{*}{ Flat Bed } & \multirow[t]{3}{*}{ Beam \#1 } & $\mathrm{B} 1 \mathrm{~A}$ & 32.0 & 34.5 \\
\hline & & $\mathrm{BlC}$ & -46.7 & 61.7 \\
\hline & & B1D & 49.5 & 69.9 \\
\hline & \multirow[t]{5}{*}{ Beam \#2 } & $\mathrm{B} 2 \mathrm{~A}$ & 6.8 & 9.1 \\
\hline & & $\mathrm{B} 2 \mathrm{~B}$ & 80.4 & 96.1 \\
\hline & & $\mathrm{B} 2 \mathrm{M}$ & 67.5 & 83.6 \\
\hline & & $\mathrm{B} 2 \mathrm{C}$ & -73.1 & 88.6 \\
\hline & & B2D & 67.3 & 86.6 \\
\hline & \multirow[t]{5}{*}{ Beam \#3 } & $\mathrm{B} 3 \mathrm{~A}$ & 7.2 & 8.9 \\
\hline & & $\mathrm{B} 3 \mathrm{~B}$ & 48.2 & 60.2 \\
\hline & & B3M & 61.6 & 78.3 \\
\hline & & $\mathrm{B} 3 \mathrm{C}$ & -62.5 & 74.8 \\
\hline & & B3D & 65.2 & 85.8 \\
\hline
\end{tabular}


Table 4.3.1.4 (cont.) I 65 - Average Maximum Beam Strains and Strain Ranges for Regular Traffic

\begin{tabular}{|c|c|c|c|c|}
\hline Truck Type & Member & Gage & Maximum Strain $(\mu \varepsilon)$ & Strain Range $(\mu \varepsilon)$ \\
\hline \multirow[t]{13}{*}{ Twin Trailers } & \multirow{3}{*}{ Beam \#1 } & $\mathrm{BlA}$ & 30.6 & 31.0 \\
\hline & & $\mathrm{B} 1 \mathrm{C}$ & -45.6 & 63.2 \\
\hline & & B1D & 54.8 & 77.2 \\
\hline & \multirow[t]{5}{*}{ Beam \#2 } & $\mathrm{B} 2 \mathrm{~A}$ & 7.1 & 11.1 \\
\hline & & $\mathrm{B} 2 \mathrm{~B}$ & 79.6 & 96.3 \\
\hline & & $\mathrm{B} 2 \mathrm{M}$ & 62.0 & 82.7 \\
\hline & & $\mathrm{B} 2 \mathrm{C}$ & -72.5 & 88.6 \\
\hline & & B2D & 61.7 & 83.1 \\
\hline & \multirow[t]{5}{*}{ Beam \#3 } & $\mathrm{B} 3 \mathrm{~A}$ & 6.9 & 8.6 \\
\hline & & B3B & 48.1 & 62.7 \\
\hline & & $\mathrm{B} 3 \mathrm{M}$ & 58.2 & 77.5 \\
\hline & & $\mathrm{B} 3 \mathrm{C}$ & -62.3 & 77.7 \\
\hline & & B3D & 63.5 & 84.0 \\
\hline \multirow[t]{13}{*}{ Tanker Truck } & \multirow[t]{3}{*}{ Beam \#1 } & BlA & 3.9 & 7.3 \\
\hline & & $\mathrm{B} 1 \mathrm{C}$ & -52.1 & 63.3 \\
\hline & & B1D & 52.7 & 78.5 \\
\hline & \multirow[t]{5}{*}{ Beam \#2 } & $\mathrm{B} 2 \mathrm{~A}$ & 4.0 & 6.1 \\
\hline & & $\mathrm{B} 2 \mathrm{~B}$ & 88.8 & 100.6 \\
\hline & & $\mathrm{B} 2 \mathrm{M}$ & 71.3 & 89.2 \\
\hline & & $\mathrm{B} 2 \mathrm{C}$ & -80.0 & 92.5 \\
\hline & & $\mathrm{B} 2 \mathrm{D}$ & 68.6 & 92.4 \\
\hline & \multirow[t]{5}{*}{ Beam \#3 } & $\mathrm{B} 3 \mathrm{~A}$ & 3.2 & 6.3 \\
\hline & & B3B & 52.8 & 63.2 \\
\hline & & B3M & 65.2 & 84.2 \\
\hline & & $\mathrm{B} 3 \mathrm{C}$ & -68.9 & 80.0 \\
\hline & & B3D & 69.5 & 92.6 \\
\hline
\end{tabular}


Table 4.3.2.1 I 65 - Maximum Diaphragm Strains and Stresses for Static Loading Conditions

\begin{tabular}{|c|c|c|c|c|}
\hline Member & Gage & Strain (uE) & Stress (ksi) & LC \# \\
\hline \hline Diaphragm \#1 & D1A & $8.6 / 9.8$ & $0.25 / 0.28$ & $2 \mathrm{~A} / 1 \mathrm{~B}$ \\
\cline { 2 - 5 } & $\mathrm{D} 1 \mathrm{~B}$ & $7.2 / 5.7$ & $0.21 / 0.17$ & $1 \mathrm{~A} / 1 \mathrm{~B}$ \\
\cline { 2 - 5 } & $\mathrm{R} 1 \mathrm{~A}$ & $2.7 / 6.5$ & $0.08 / 0.19$ & $3 \mathrm{~A} / 3 \mathrm{~B}$ \\
\cline { 2 - 5 } & $\mathrm{R} 1 \mathrm{~B}$ & $5.6 / 7.7$ & $0.16 / 0.22$ & $3 \mathrm{~A} / 3 \mathrm{~B}$ \\
\cline { 2 - 5 } & $\mathrm{R} 1 \mathrm{C}$ & $3.3 / 1.6$ & $0.10 / 0.05$ & $1 \mathrm{~A} / 1 \mathrm{~B}$ \\
\hline \multirow{5}{*}{ Diaphragm \#2 } & $\mathrm{D} 2 \mathrm{~A}$ & $3.3 / 2.5$ & $0.10 / 0.07$ & $3 \mathrm{~A} / 2 \mathrm{~B}$ \\
\cline { 2 - 5 } & $\mathrm{D} 2 \mathrm{~B}$ & $7.1 / 5.4$ & $0.21 / 0.16$ & $3 \mathrm{~A} / 1 \mathrm{~B}$ \\
\cline { 2 - 5 } & $\mathrm{R} 2 \mathrm{~A}$ & $1.3 /-3.6$ & $0.04 /-0.10$ & $1 \mathrm{~A} / 3 \mathrm{~B}$ \\
\cline { 2 - 5 } & $\mathrm{R} 2 \mathrm{~B}$ & $5.3 / 3.8$ & $0.15 / 0.11$ & $3 \mathrm{~A} / 1 \mathrm{~B}$ \\
\cline { 2 - 5 } & $\mathrm{R} 2 \mathrm{C}$ & $6.4 / 5.1$ & $0.19 / 0.15$ & $3 \mathrm{~A} / 1 \mathrm{~B}$ \\
\hline
\end{tabular}


Table 4.3.2.2 I 65 - Maximum Diaphragm Forces for Static Loading Conditions

\begin{tabular}{|c|c|c|c|c|}
\hline Member & $\begin{array}{c}\text { Maximum Shear } \\
\text { Force }(\mathrm{k})\end{array}$ & LC \# & $\begin{array}{c}\text { Maximum Axial Force } \\
(\mathrm{k})\end{array}$ & LC \# \\
\hline \hline \multirow{2}{*}{ Diaphragm \#1 } & -0.11 & 3A & 2.15 & 3A \\
\cline { 2 - 5 } & -0.34 & 3B & 2.95 & 3B \\
\hline \multirow{2}{*}{ Diaphragm \#2 } & 0.40 & $3 \mathrm{~A}$ & 2.05 & $3 \mathrm{~A}$ \\
\cline { 2 - 5 } & 0.41 & 2B & 1.46 & 2B \\
\hline
\end{tabular}


Table 4.3.2.3 I 65 - Maximum Diaphragm Strains and Strain Ranges for Dynamic Loading Conditions

\begin{tabular}{|c|c|c|c|c|}
\hline Speed (mph) & Member & Gage & $\begin{array}{c}\text { Maximum Strain } \\
(\mu \varepsilon)\end{array}$ & $\begin{array}{c}\text { Maximum Strain } \\
\text { Range }(\mu \varepsilon) \\
\end{array}$ \\
\hline \multirow[t]{10}{*}{$\sim 5$} & \multirow[t]{5}{*}{ Diaphragm \#1 } & D1A & 12.7 & 10.0 \\
\hline & & D1B & 9.7 & 8.3 \\
\hline & & R1A & 9.8 & 7.0 \\
\hline & & R1B & 11.1 & 9.9 \\
\hline & & $\mathrm{R} 1 \mathrm{C}$ & 4.6 & 5.3 \\
\hline & \multirow[t]{5}{*}{ Diaphragm \#2 } & D2A & 6.1 & 5.9 \\
\hline & & D2B & 11.1 & 10.6 \\
\hline & & $\mathrm{R} 2 \mathrm{~A}$ & 4.3 & 6.4 \\
\hline & & R2B & 8.0 & 8.8 \\
\hline & & $\mathrm{R} 2 \mathrm{C}$ & 9.3 & 6.4 \\
\hline \multirow[t]{10}{*}{$\sim 25$} & \multirow[t]{5}{*}{ Diaphragm \#1 } & D1A & 10.9 & 13.0 \\
\hline & & D1B & 7.4 & 10.6 \\
\hline & & R1A & 9.8 & 8.2 \\
\hline & & $\mathrm{R} 1 \mathrm{~B}$ & 9.9 & 11.1 \\
\hline & & $\mathrm{R} 1 \mathrm{C}$ & 2.8 & 4.7 \\
\hline & \multirow[t]{5}{*}{ Diaphragm \#2 } & D2A & 4.3 & 5.9 \\
\hline & & D2B & 9.9 & 9.4 \\
\hline & & $\mathrm{R} 2 \mathrm{~A}$ & -4.5 & 4.7 \\
\hline & & R2B & 6.3 & 7.6 \\
\hline & & $\mathrm{R} 2 \mathrm{C}$ & 8.8 & 7.6 \\
\hline
\end{tabular}


Table 4.3.2.3 (cont.) I 65 - Maximum Diaphragm Strains and Strain Ranges for Dynamic Loading Conditions

\begin{tabular}{|c|c|c|c|c|}
\hline Speed (mph) & Member & Gage & $\begin{array}{c}\text { Maximum Strain } \\
(\mu \varepsilon) \\
\end{array}$ & $\begin{array}{l}\text { Maximum Strain Range } \\
(\mu \varepsilon)\end{array}$ \\
\hline \multirow[t]{10}{*}{$\sim 55$} & \multirow[t]{5}{*}{ Diaphragm \#1 } & D1A & 9.2 & 11.8 \\
\hline & & D1B & 10.0 & 10.0 \\
\hline & & R1A & -7.0 & 8.2 \\
\hline & & $\mathrm{R} 1 \mathrm{~B}$ & 9.5 & 11.1 \\
\hline & & $\mathrm{R} 1 \mathrm{C}$ & 4.7 & 5.3 \\
\hline & \multirow[t]{5}{*}{ Diaphragm \#2 } & D2A & -5.5 & 6.5 \\
\hline & & D2B & -11.2 & 10.6 \\
\hline & & $\mathrm{R} 2 \mathrm{~A}$ & 7.3 & 5.3 \\
\hline & & $\mathrm{R} 2 \mathrm{~B}$ & 6.9 & 8.2 \\
\hline & & $\mathrm{R} 2 \mathrm{C}$ & -7.6 & 8.8 \\
\hline
\end{tabular}


Table 4.3.2.4 I 65 - Maximum Diaphragm Shear Forces and Ranges for Dynamic Loading Conditions

\begin{tabular}{|c|c|c|c|c|}
\hline Speed (mph) & Position & Member & $\begin{array}{c}\text { Maximum Shear } \\
(\mathrm{k}) \\
\end{array}$ & $\begin{array}{c}\text { Maximum Range } \\
(\mathbf{k}) \\
\end{array}$ \\
\hline \multirow[t]{4}{*}{$\sim 5$} & \multirow[t]{2}{*}{ A } & Diaphragm \#1 & 0.50 & 0.44 \\
\hline & & Diaphragm \#2 & -0.56 & 0.54 \\
\hline & \multirow[t]{2}{*}{ B } & Diaphragm \#1 & 0.47 & 0.51 \\
\hline & & Diaphragm \#2 & -0.70 & 0.51 \\
\hline \multirow[t]{4}{*}{$\sim 25$} & \multirow[t]{2}{*}{ A } & Diaphragm \#1 & 0.54 & 0.47 \\
\hline & & Diaphragm \#2 & -0.56 & 0.57 \\
\hline & \multirow[t]{2}{*}{ B } & Diaphragm \#1 & 0.64 & 0.47 \\
\hline & & Diaphragm \#2 & -0.70 & 0.57 \\
\hline \multirow[t]{4}{*}{$\sim 55$} & \multirow[t]{2}{*}{ A } & Diaphragm \#1 & -0.41 & 0.44 \\
\hline & & Diaphragm \#2 & 0.39 & 0.61 \\
\hline & \multirow[t]{2}{*}{ B } & Diaphragm \#1 & -0.34 & 0.51 \\
\hline & & Diaphragm \#2 & 0.35 & 0.54 \\
\hline
\end{tabular}


Table 4.3.2.5 I 65 - Average Maximum Diaphragm Strains and Strain Ranges for Regular Traffic

\begin{tabular}{|c|c|c|c|c|}
\hline Truck Type & Member & Gage & $\begin{array}{c}\text { Maximum Strain } \\
(\mu \varepsilon)\end{array}$ & $\begin{array}{c}\text { Maximum Strain } \\
\text { Range ( } \mu \varepsilon) \\
\end{array}$ \\
\hline \multirow{10}{*}{$\begin{array}{l}\text { Eighteen - } \\
\text { Wheeler(s) }\end{array}$} & \multirow[t]{5}{*}{ Diaphragm \#1 } & D1A & 8.6 & 11.5 \\
\hline & & D1B & 6.9 & 10.4 \\
\hline & & R1A & -4.4 & 8.3 \\
\hline & & $\mathrm{R} 1 \mathrm{~B}$ & 7.3 & 10.5 \\
\hline & & $\mathrm{R} 1 \mathrm{C}$ & 3.0 & 5.0 \\
\hline & \multirow[t]{5}{*}{ Diaphragm \#2 } & D2A & 5.7 & 6.7 \\
\hline & & $\mathrm{D} 2 \mathrm{~B}$ & 8.7 & 11.1 \\
\hline & & $\mathrm{R} 2 \mathrm{~A}$ & -2.9 & 5.2 \\
\hline & & R2B & 6.0 & 8.7 \\
\hline & & $\mathrm{R} 2 \mathrm{C}$ & 4.7 & 8.7 \\
\hline \multirow[t]{10}{*}{ Flat Bed } & \multirow[t]{5}{*}{ Diaphragm \#1 } & D1A & 13.1 & 15.5 \\
\hline & & D1B & 8.1 & 11.2 \\
\hline & & $\mathrm{R} 1 \mathrm{~A}$ & 7.2 & 10.9 \\
\hline & & $\mathrm{R} 1 \mathrm{~B}$ & 9.5 & 12.5 \\
\hline & & $\mathrm{R} 1 \mathrm{C}$ & 7.4 & 9.0 \\
\hline & \multirow[t]{5}{*}{ Diaphragm \#2 } & D2A & 6.8 & 7.2 \\
\hline & & D2B & 10.0 & 12.2 \\
\hline & & $\mathrm{R} 2 \mathrm{~A}$ & -2.6 & 5.0 \\
\hline & & R2B & 7.0 & 9.4 \\
\hline & & $\mathrm{R} 2 \mathrm{C}$ & 5.0 & 8.8 \\
\hline
\end{tabular}


Table 4.3.2.5 (cont.) I 65 - Average Maximum Diaphragm Strains and Strain Ranges for Regular Traffic

\begin{tabular}{|c|c|c|c|c|}
\hline Truck Type & Member & Gage & $\begin{array}{c}\text { Maximum Strain } \\
(\mu \varepsilon)\end{array}$ & $\begin{array}{c}\text { Maximum Strain } \\
\text { Range }(\mu \varepsilon)\end{array}$ \\
\hline \multirow[t]{10}{*}{ Twin Trailers } & \multirow[t]{5}{*}{ Diaphragm \#1 } & $\mathrm{D} 1 \mathrm{~A}$ & 11.2 & 14.3 \\
\hline & & D1B & 6.5 & 10.5 \\
\hline & & $\mathrm{R} 1 \mathrm{~A}$ & 5.0 & 9.5 \\
\hline & & $\mathrm{R} 1 \mathrm{~B}$ & 6.7 & 11.4 \\
\hline & & $\mathrm{R} 1 \mathrm{C}$ & 5.4 & 8.2 \\
\hline & \multirow[t]{5}{*}{ Diaphragm \#2 } & D2A & 5.8 & 6.4 \\
\hline & & D2B & 8.6 & 11.7 \\
\hline & & $\mathrm{R} 2 \mathrm{~A}$ & -3.7 & 6.0 \\
\hline & & R2B & 5.3 & 8.8 \\
\hline & & $\mathrm{R} 2 \mathrm{C}$ & 5.0 & 9.2 \\
\hline \multirow[t]{10}{*}{ Tanker Truck } & \multirow[t]{5}{*}{ Diaphragm \#1 } & D1A & 9.0 & 11.5 \\
\hline & & D1B & 7.6 & 10.8 \\
\hline & & R1A & -4.3 & 8.5 \\
\hline & & $\mathrm{R} 1 \mathrm{~B}$ & 8.0 & 10.9 \\
\hline & & $\mathrm{R} 1 \mathrm{C}$ & 2.9 & 4.5 \\
\hline & \multirow[t]{5}{*}{ Diaphragm \#2 } & D2A & 6.3 & 7.6 \\
\hline & & D2B & 9.8 & 11.6 \\
\hline & & $\mathrm{R} 2 \mathrm{~A}$ & 2.7 & 5.3 \\
\hline & & $\mathrm{R} 2 \mathrm{~B}$ & 7.0 & 9.4 \\
\hline & & $\mathrm{R} 2 \mathrm{C}$ & 5.2 & 8.9 \\
\hline
\end{tabular}


Table 4.3.2.6 I 65 - Average Maximum Diaphragm Shear Forces for Regular Traffic

\begin{tabular}{|c|c|c|}
\hline Truck Tvpe & Member & Maximum Avg. Shear $(\mathrm{k})$ \\
\hline \hline \multirow{2}{*}{ Eighteen - Wheeler(s) } & Diaphragm \#1 & -0.05 \\
\cline { 2 - 3 } & Diaphragm \#2 & 0.14 \\
\hline \multirow{2}{*}{ Flat Bed } & Diaphragm \#1 & -0.12 \\
\cline { 2 - 3 } & Diaphragm \#2 & 0.14 \\
\hline \multirow{2}{*}{ Twin Trailers } & Diaphragm \#1 & -0.09 \\
\cline { 2 - 3 } & Diaphragm \#2 & 0.15 \\
\hline \multirow{2}{*}{ Tanker Truck } & Diaphragm \#1 & -0.07 \\
\cline { 2 - 3 } & Diaphragm \#2 & 0.14 \\
\hline
\end{tabular}




\section{Strain Distributions for US 52}

Static Loading Condition \#3A

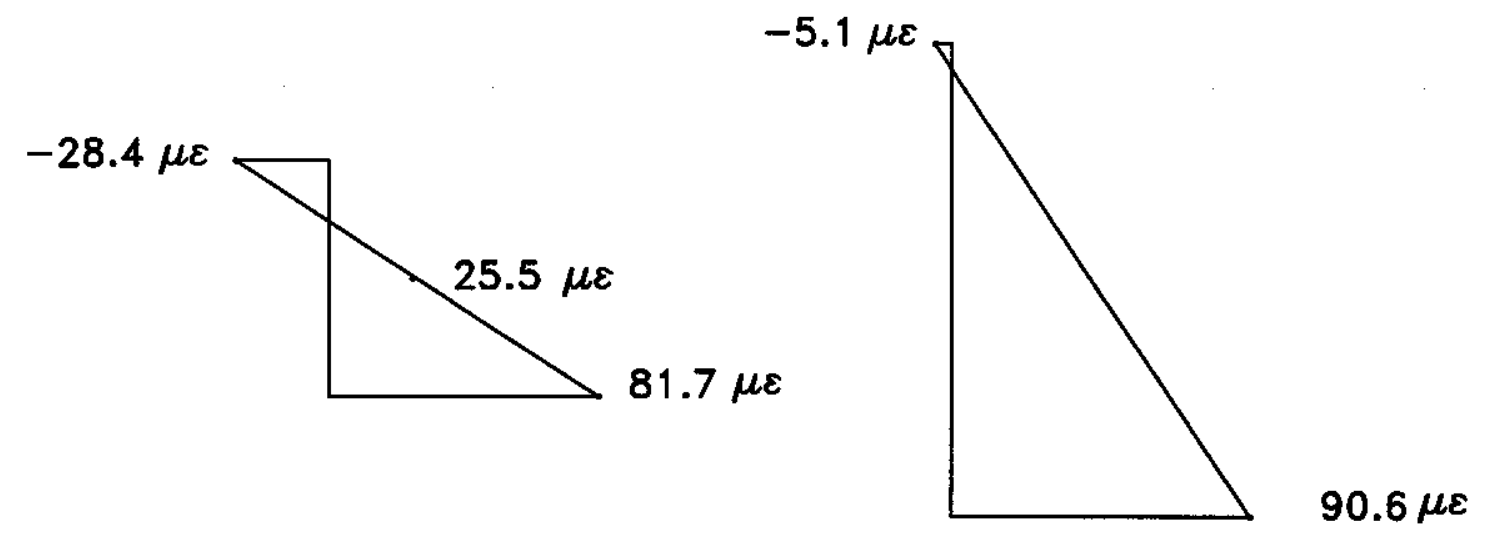

(a) Diaphragm \#3 (b) Beam \#2 


\section{Typical Rosette Strain Gage Orientation}

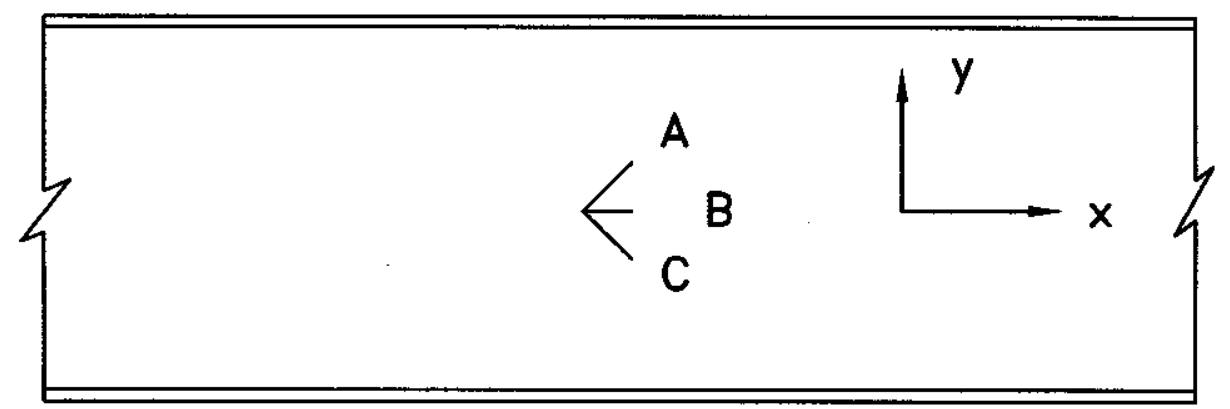

Figure 4.1.2 - Rosette Strain Gage on Diaphragm 


\section{US 52}

\section{Static Loading Conditions (Center)}

\section{Bottom of Beam \#2}

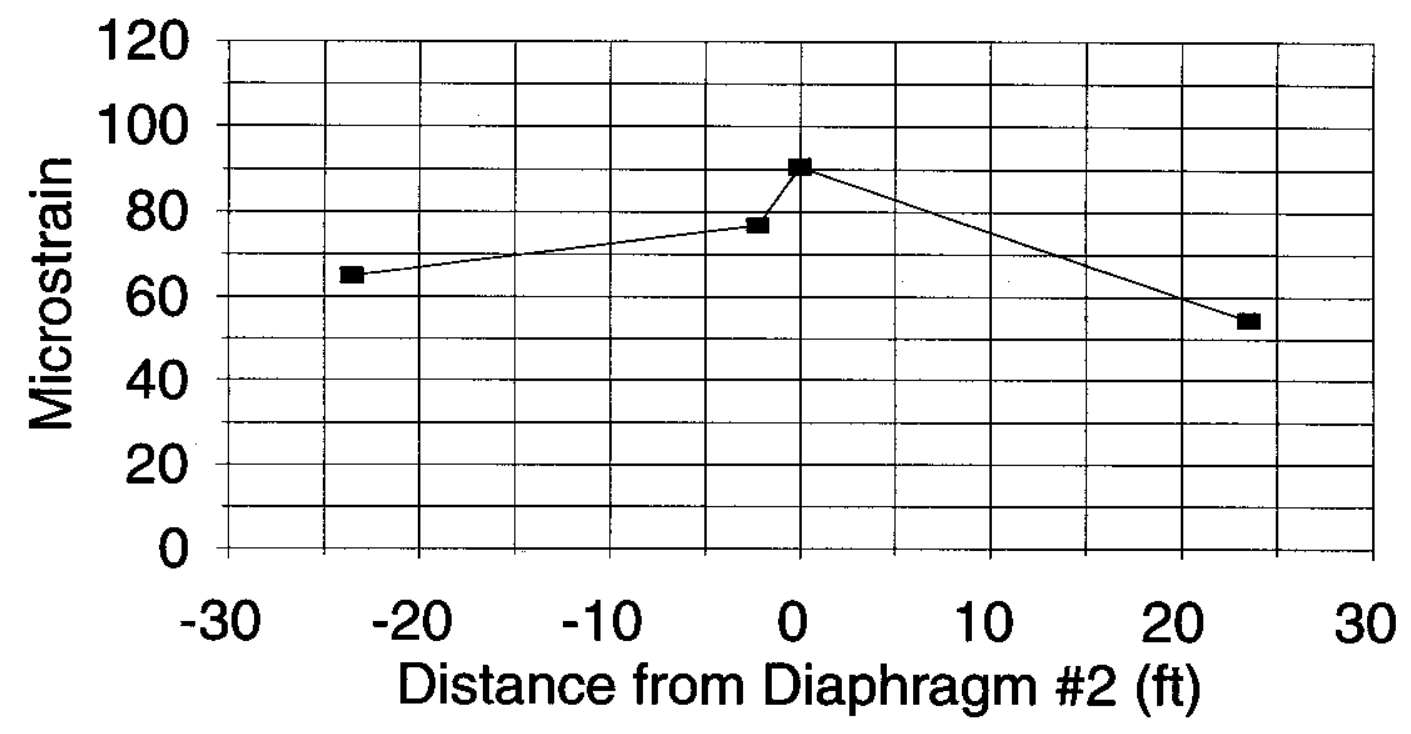

\section{Max - 91 microstrain}

Figure 4.2.1.1 - US 52 - Strains at Bottom of Beam \#2 - Loading Condition A 


\section{US 52}

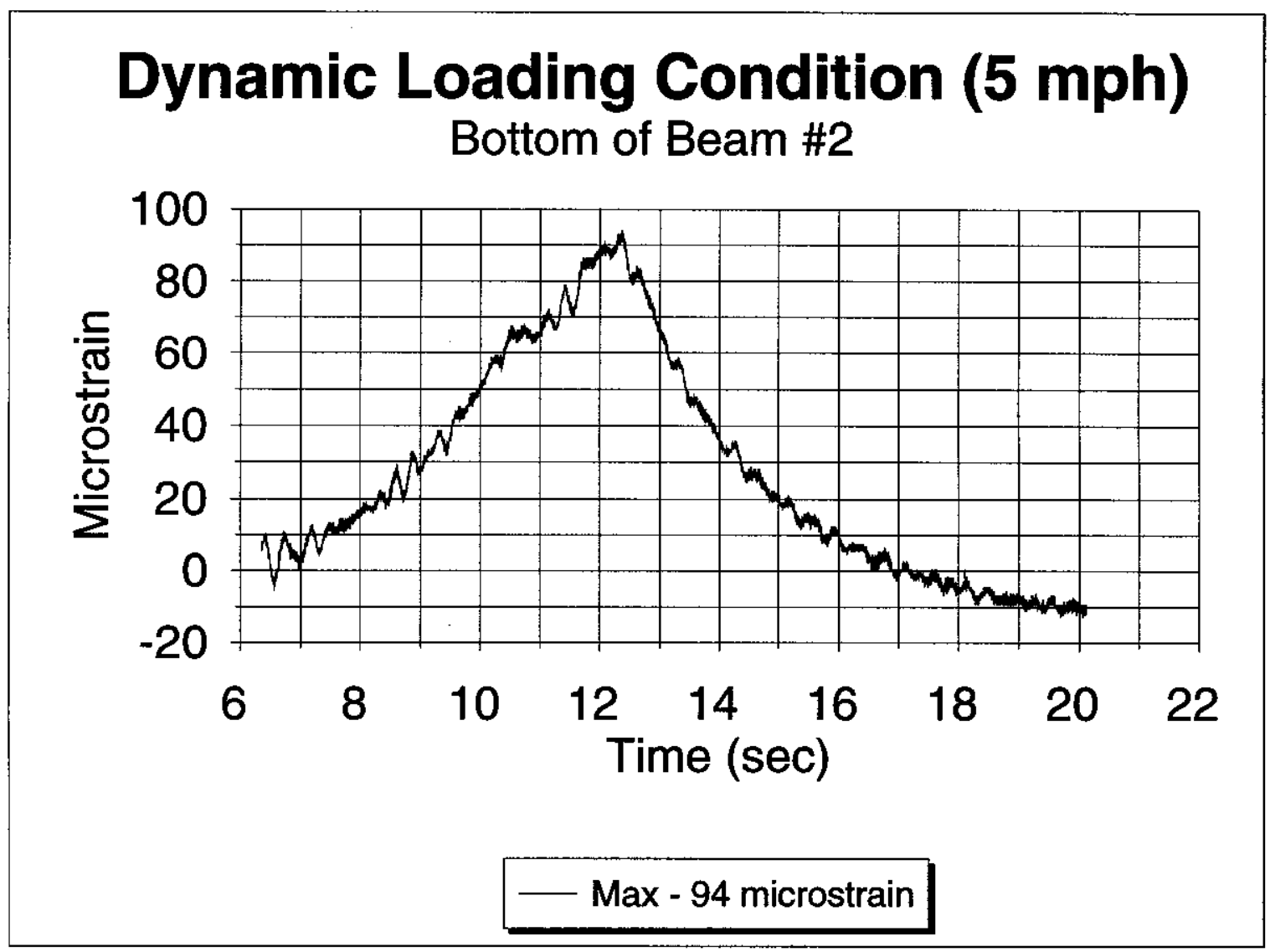

Figure 4.2.1.2 - US 52 - Strains at Bottom of Beam \#2 - $5 \mathrm{mph}$ 


\section{US 52}

\section{Dynamic Loading Condition (17 mph) Bottom of Beam \#2}

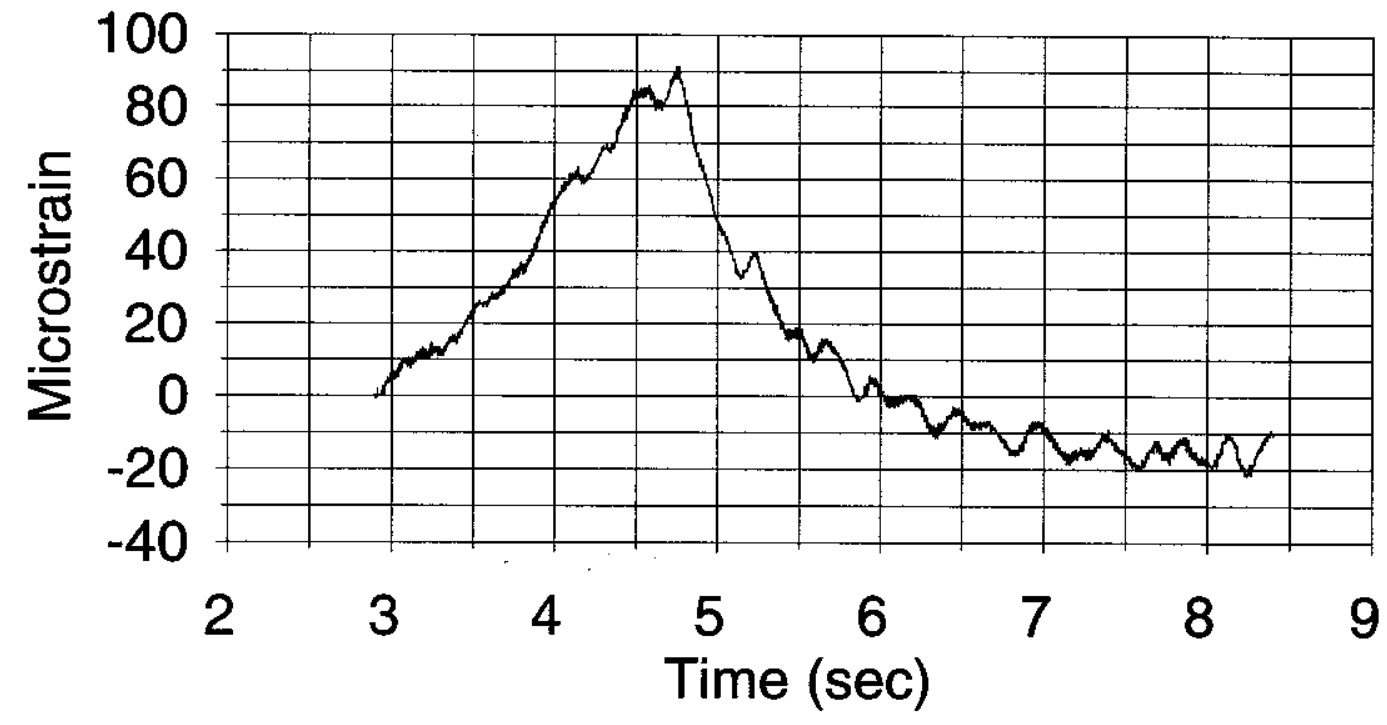

\section{Max - 91 microstrain}

Figure 4.2.1.3 - US 52 - Strains at Bottom of Beam \#2 - $17 \mathrm{mph}$ 


\section{US 52}

\section{Dynamic Loading Condition (25 mph)}

\section{Bottom of Beam \#2}

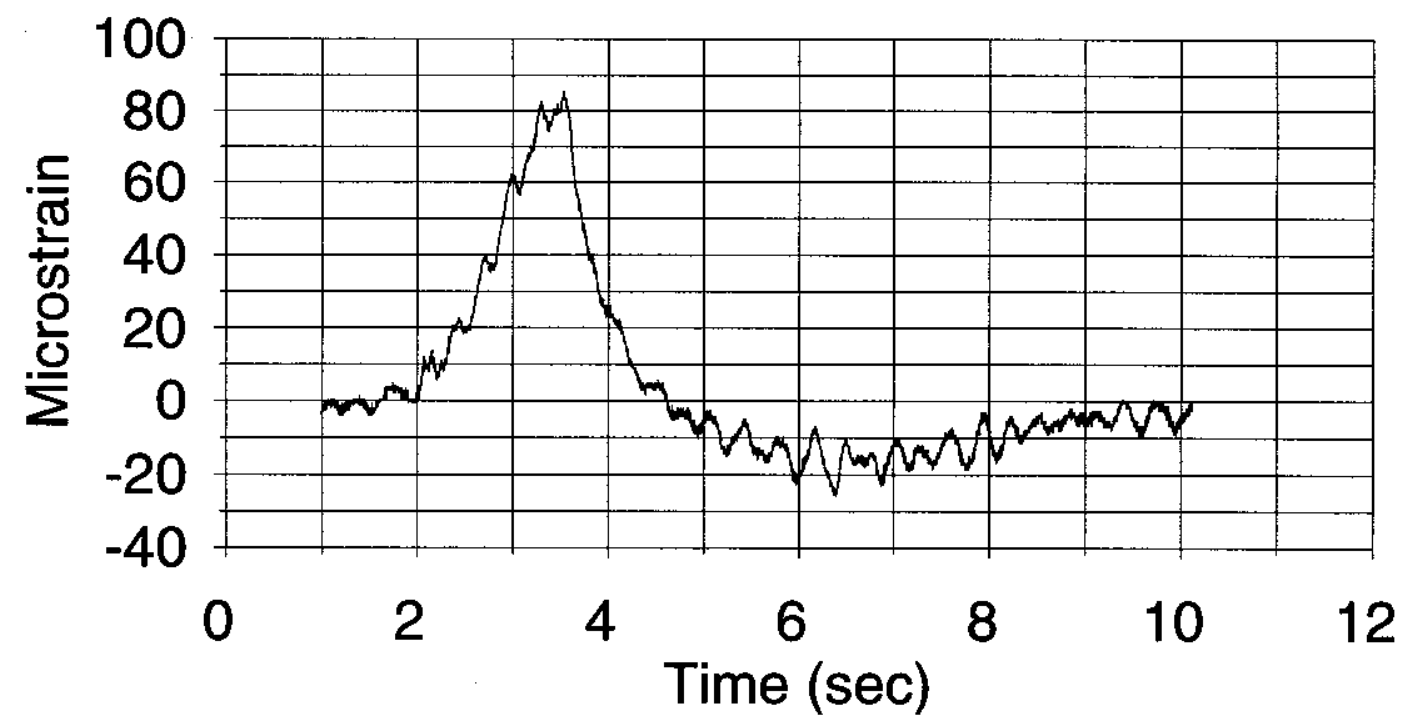

\section{Max - 85 microstrain}

Figure 4.2.1.4 - US 52 - Strains at Bottom of Beam \#2 - $25 \mathrm{mph}$ 


\section{US 52}

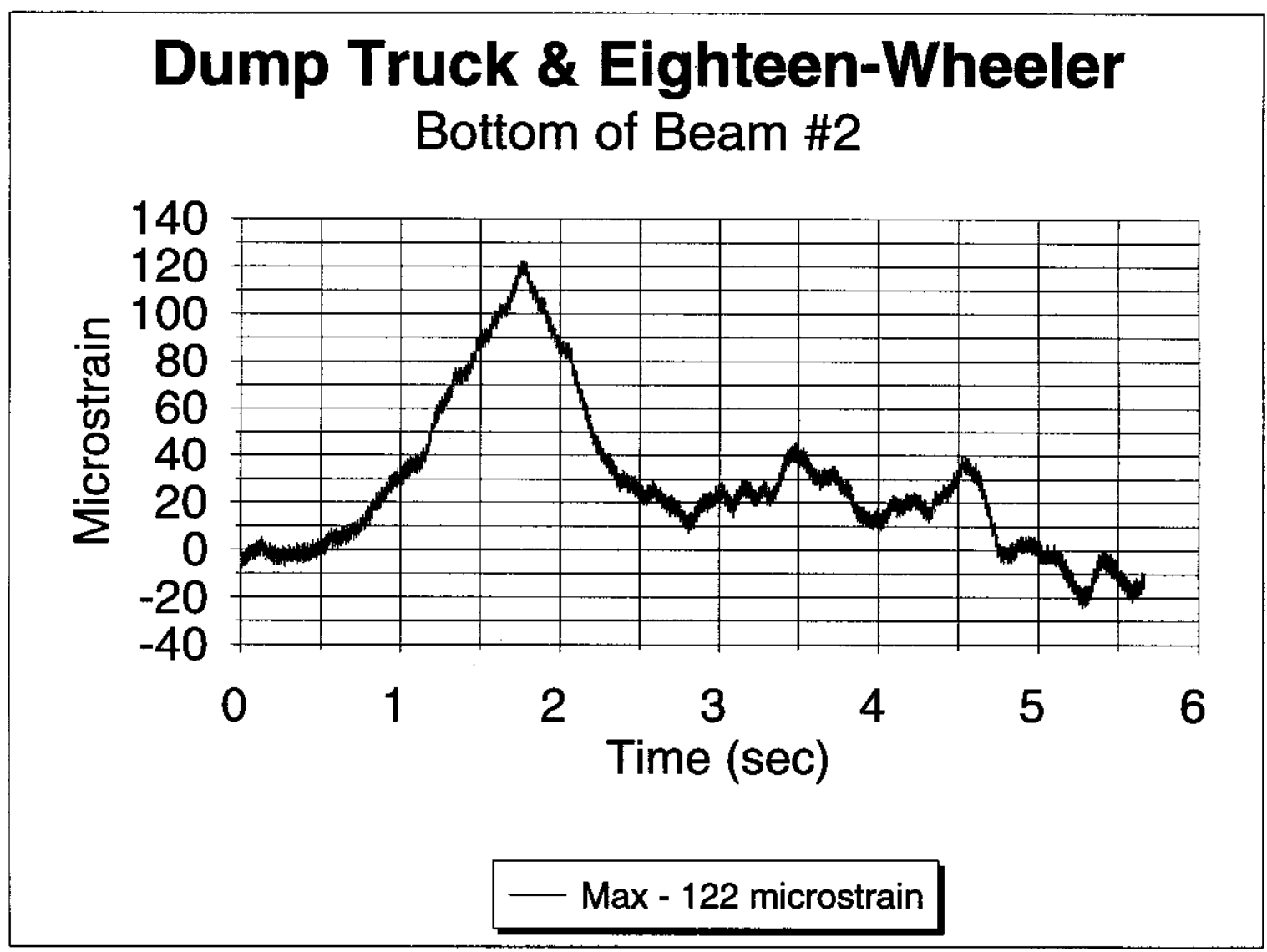

Figure 4.2.1.5 - US 52 - Strains at Bottom of Beam \#2 - Dump Truck and Eighteen-Wheeler 


\section{US 52}

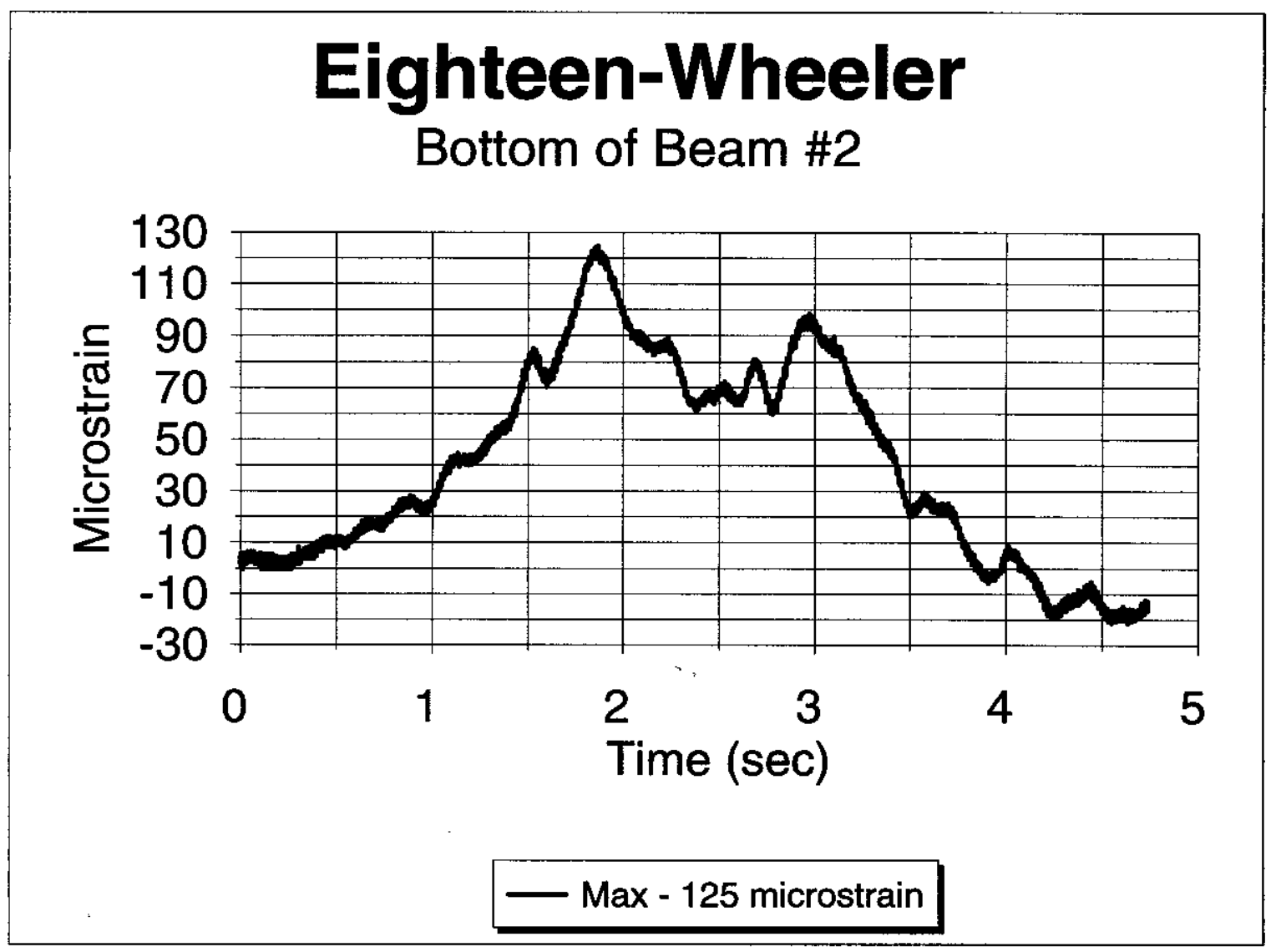

Figure 4.2.1.6 - US 52 - Strains at Bottom of Beam \#2 - Eighteen-Wheeler 


\section{US 52}

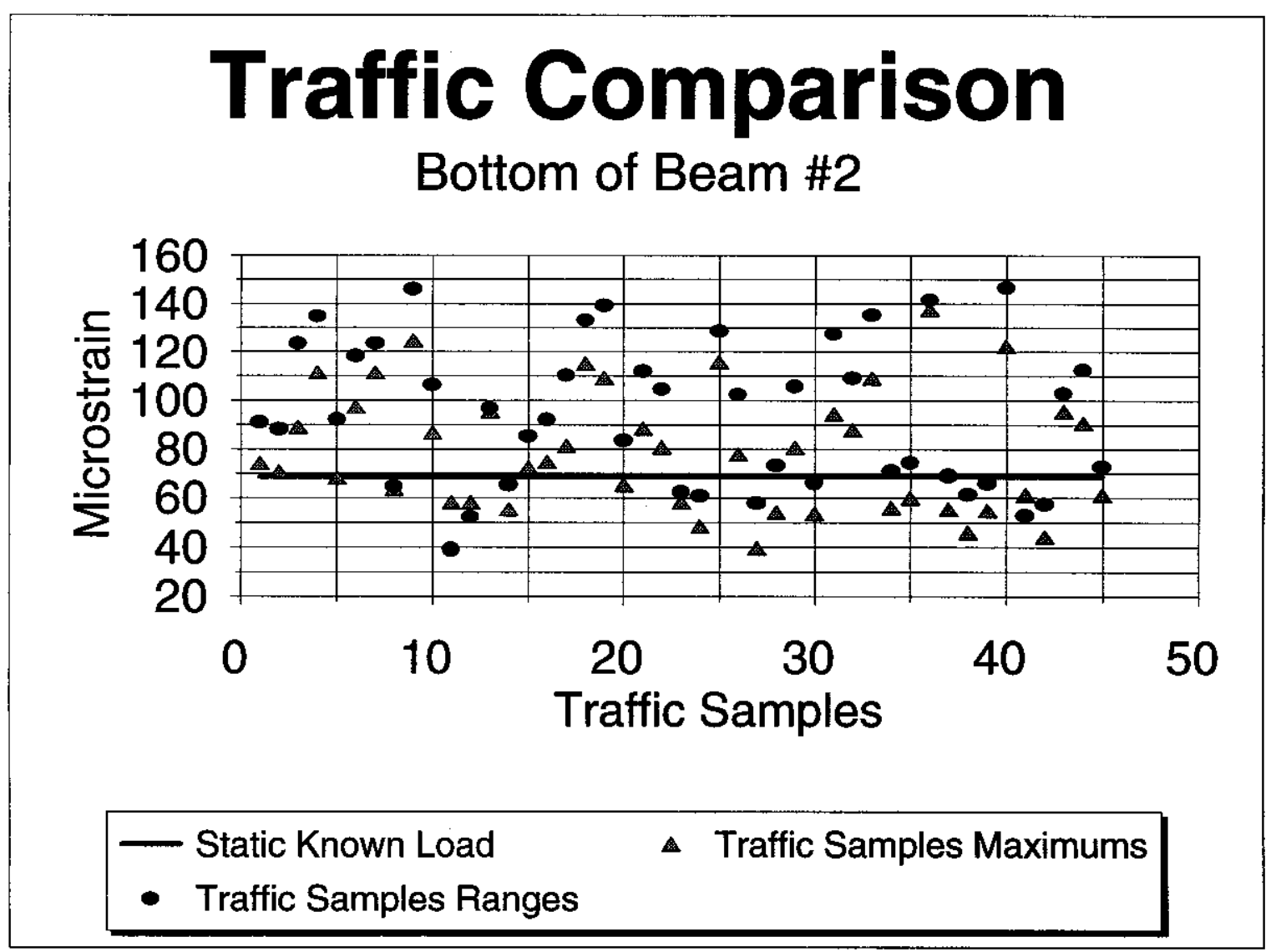

Figure 4.2.1.7 - US 52 - Strains at Bottom of Beam \#2 - Comparison Between Static and Traffic Loadings 


\section{US 52}

\section{Static Loading Conditions (Center)}

\section{Bottom of Diaphragm \#2}

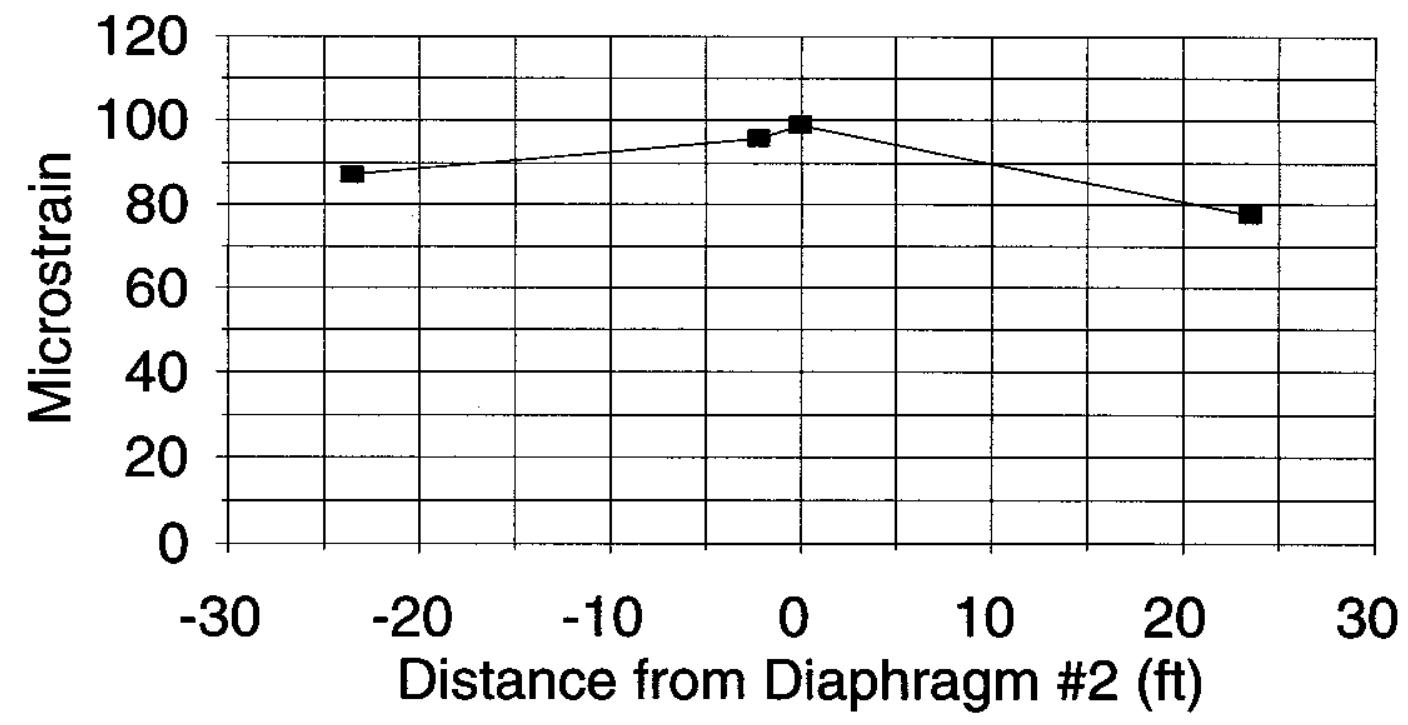

Figure 4.2.2.1 - US 52 - Strains at Bottom of Diaphragm \#2 - Static Loading Condition A 


\section{US 52}

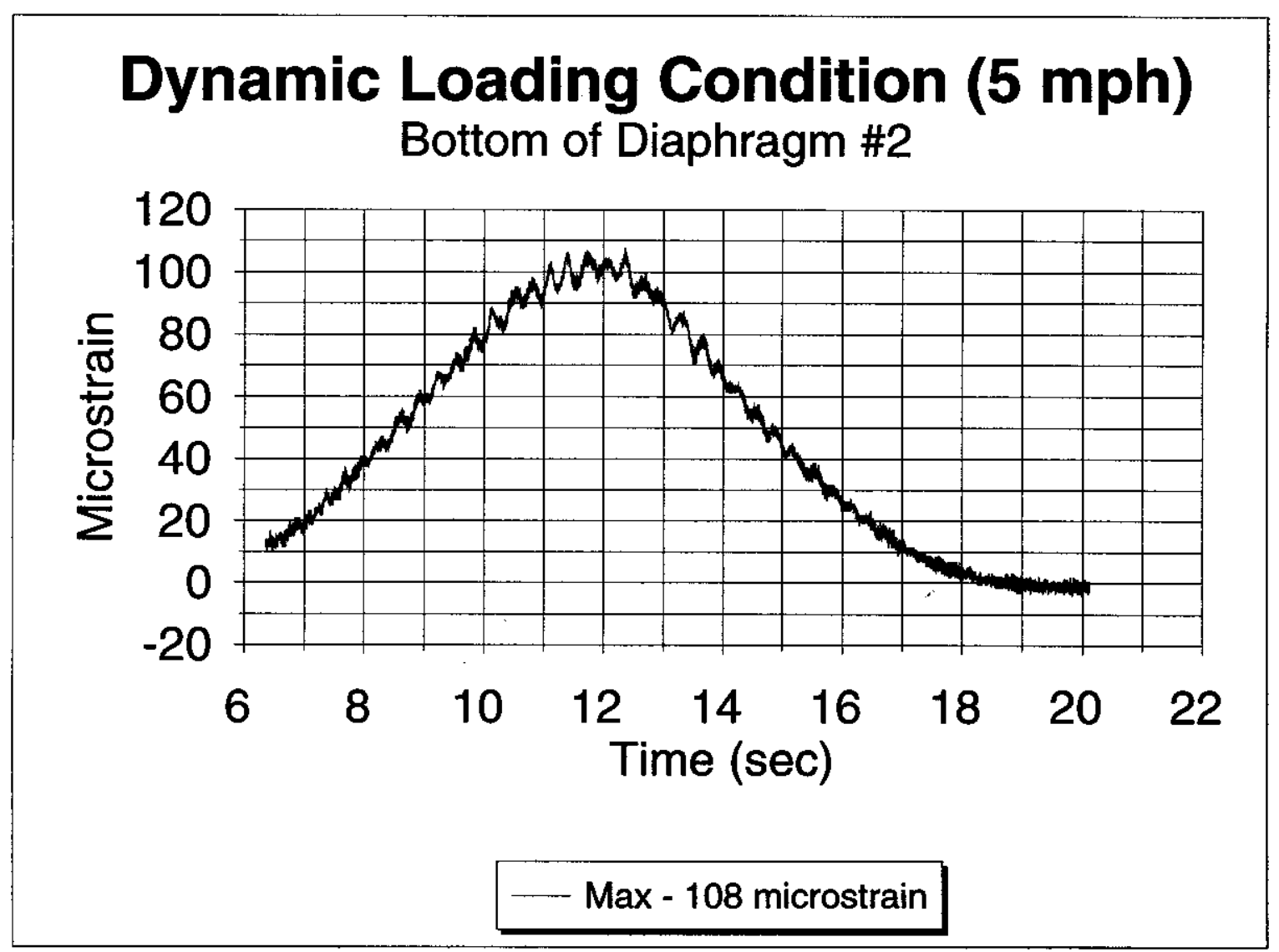

Figure 4.2.2.2 - US 52 - Strains at Bottom of Diaphragm \#2 - $5 \mathrm{mph}$ 


\section{US 52}

Dynamic Loading Condition (17 mph) Bottom of Diaphragm \#2

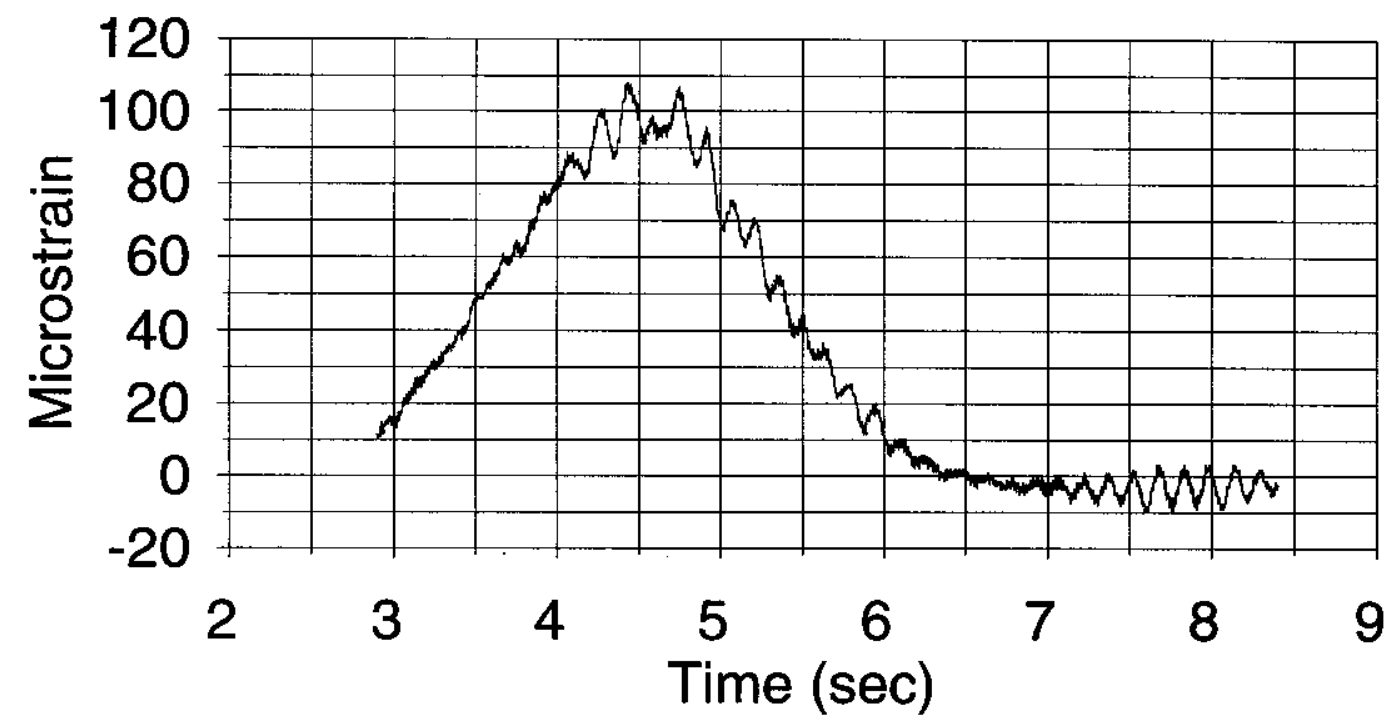

\section{Max - 108 microstrain}

Figure 4.2.2.3 - US 52 -Strains at Bottom of Diaphragm \#2 - $17 \mathrm{mph}$ 


\section{US 52}

\section{Dynamic Loading Condition (25 mph) Bottom of Diaphragm \#2}

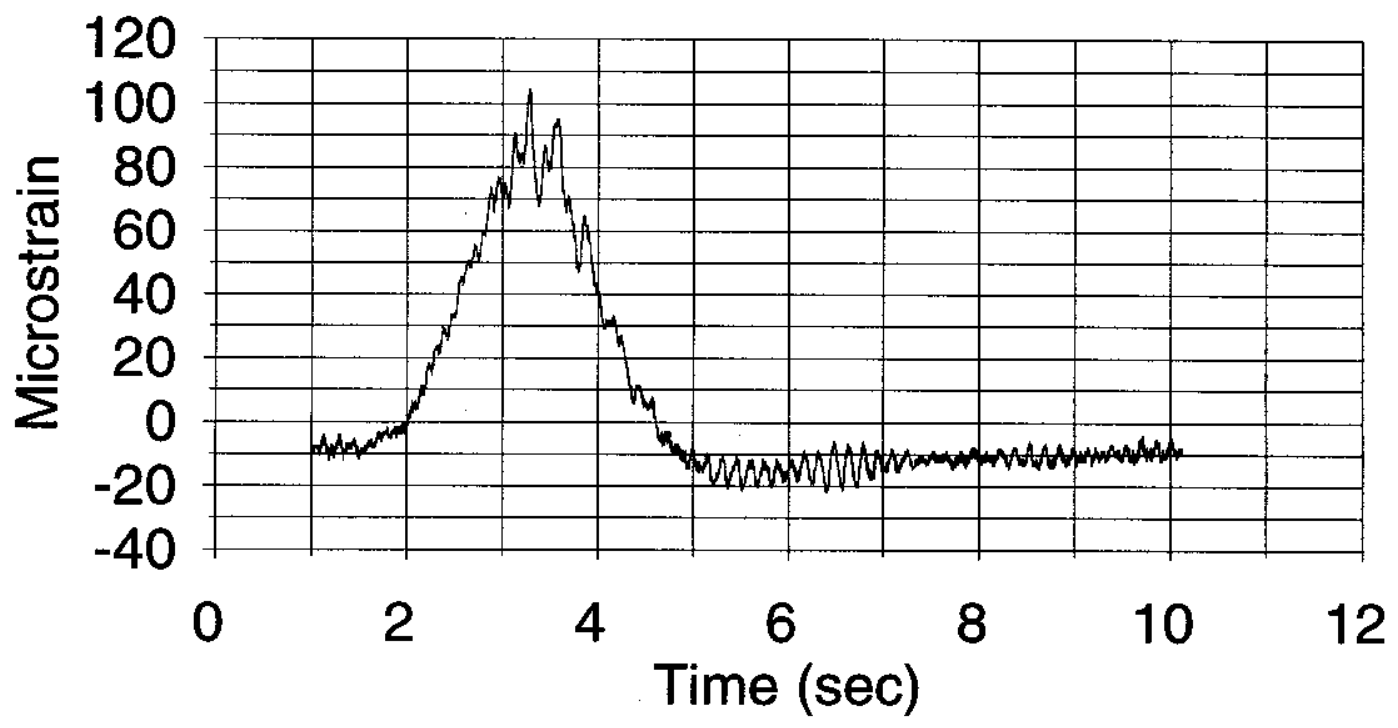

Figure 4.2.2.4 - US 52 - Strains at Bottom of Diaphragm \#2 - $25 \mathrm{mph}$ 


\section{US 52}

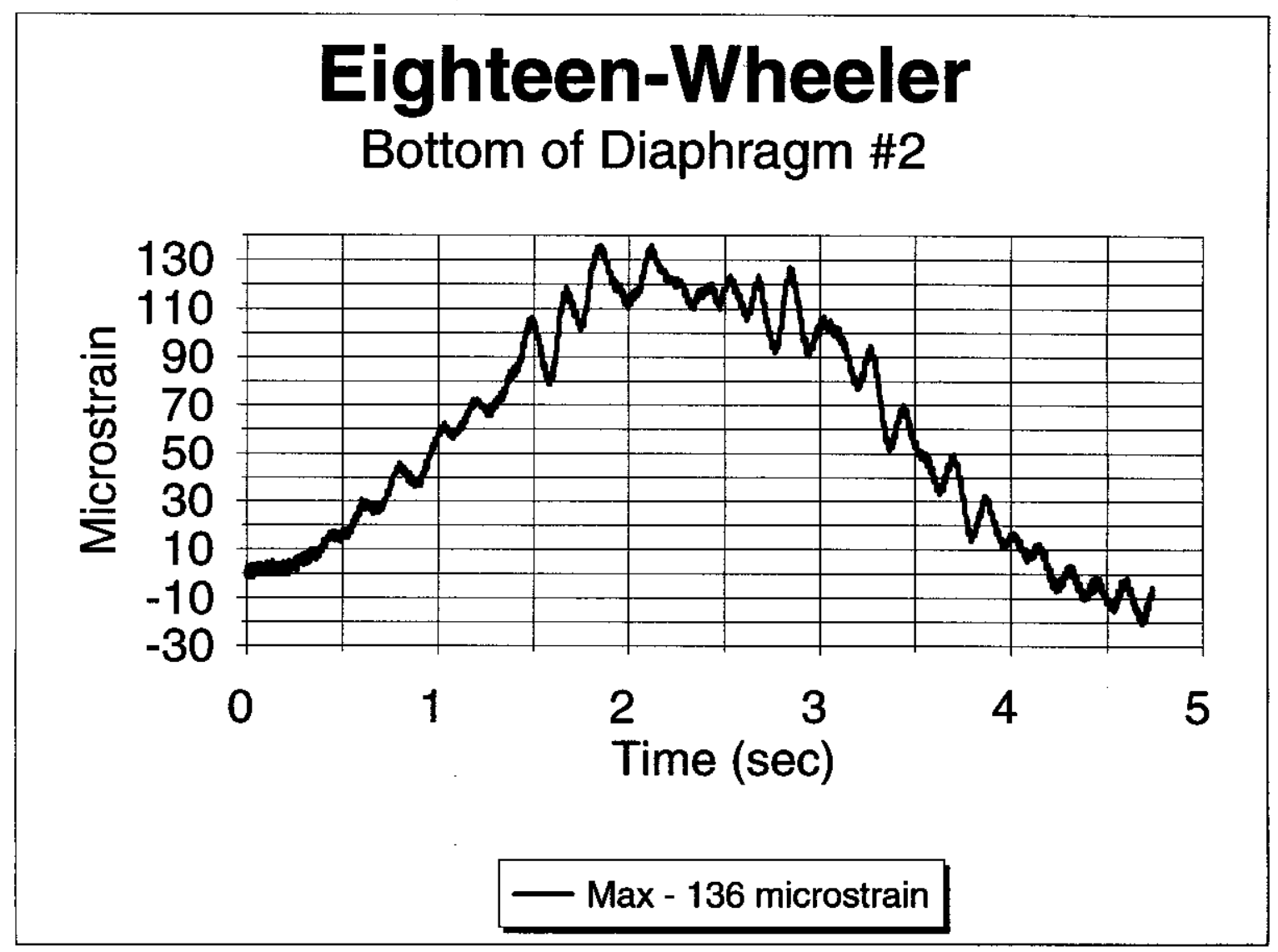

Figure 4.2.2.5 -US 52 - Strains at Bottom of Diaphragm \#2 - Eighteen-Wheeler 


\section{US 52}

\section{Dump Truck \& Eighteen-Wheeler Bottom of Diaphragm \#2}

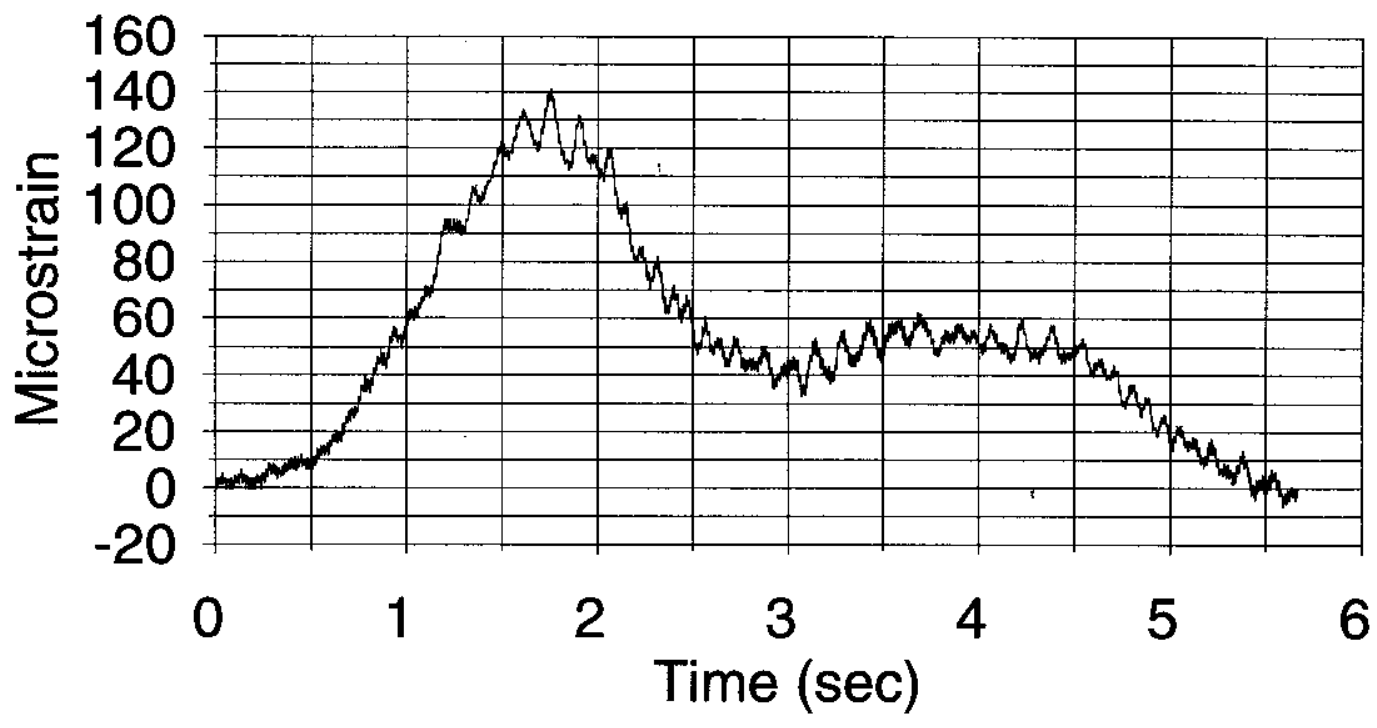

\section{Max - 141 microstrain}

Figure 4.2.2.6 - US 52 - Strains at Bottom of Diaphragm \#2 - Dump Truck and Eighteen-Wheeler 


\section{US 52}

\section{Traffic Comparison Bottom of Diaphragm \#2}

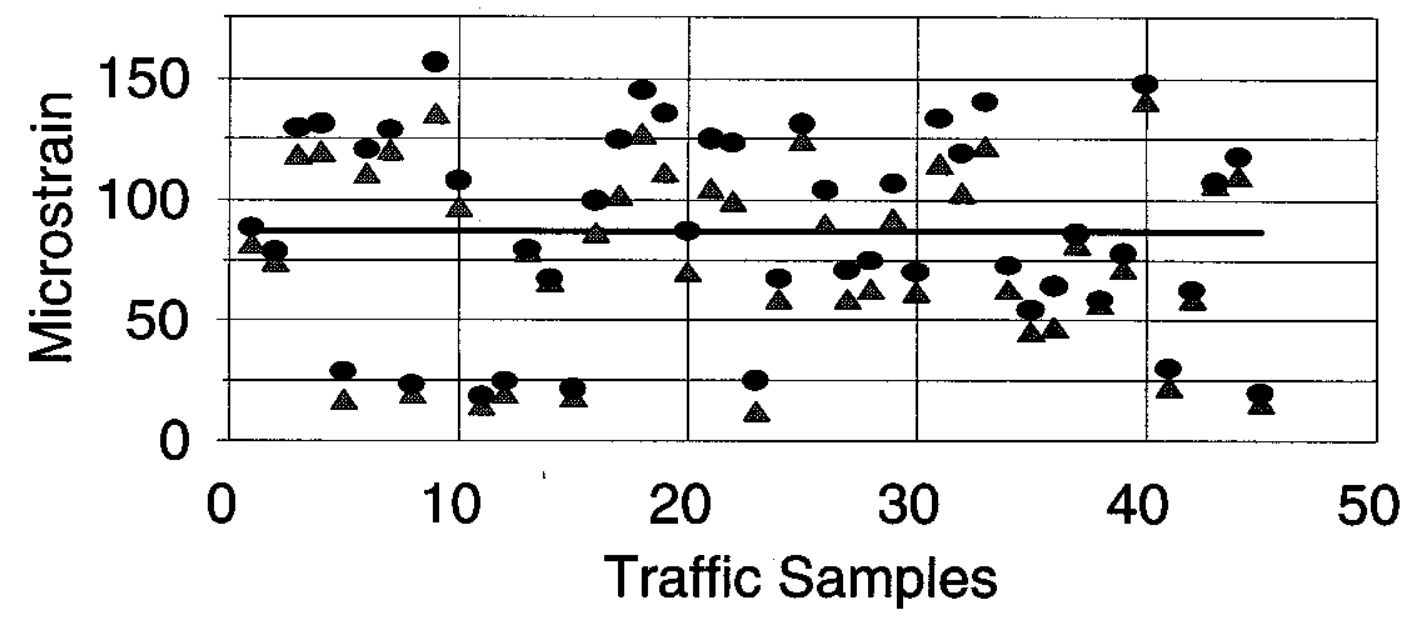

Figure 4.2.2.7 - US 52 - Strains at Bottom of Diaphragm \#2 - Comparison Between Static and Traffic Loadings 


\section{US 52}

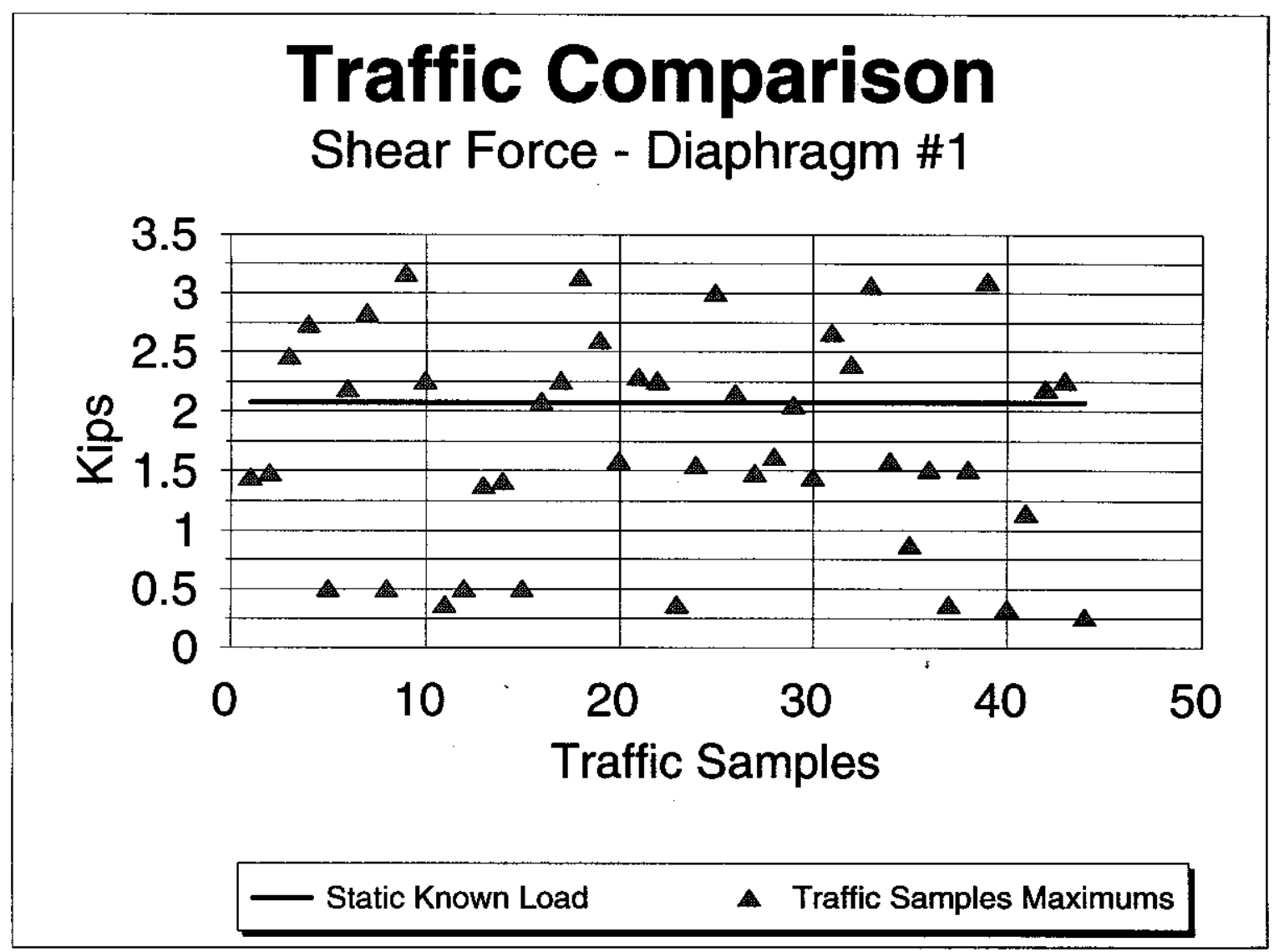

Figure 4.2.2.8 - US 52 - Shear Force in Diaphragm \#1 - Comparison Between Static and Traffic Loadings 


\section{US 52}

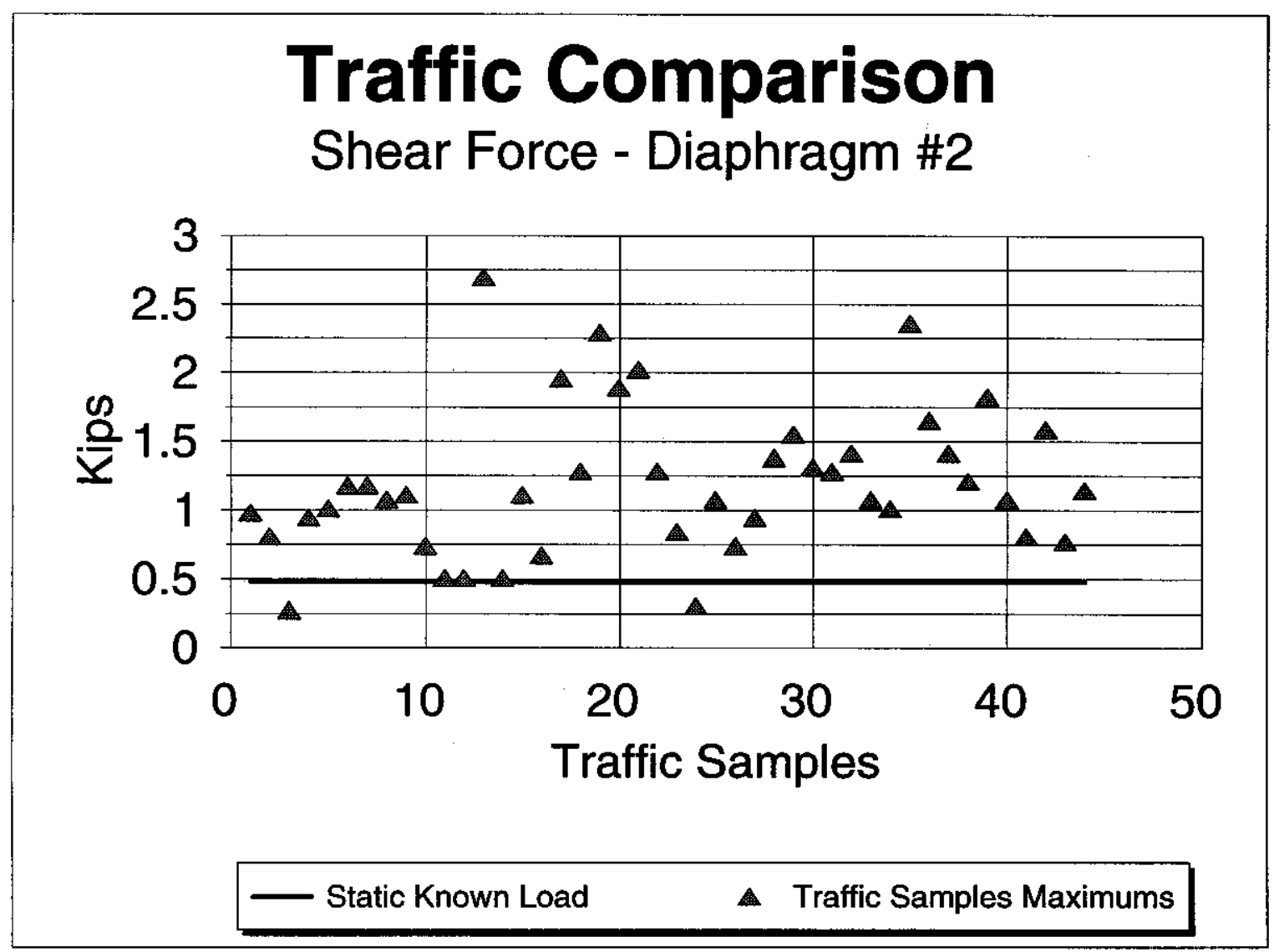

Figure 4.2.2.9 - US 52 - Shear Force in Diaphragm \#2 - Comparison Between Static and Traffic Loadings 


\section{US 52}

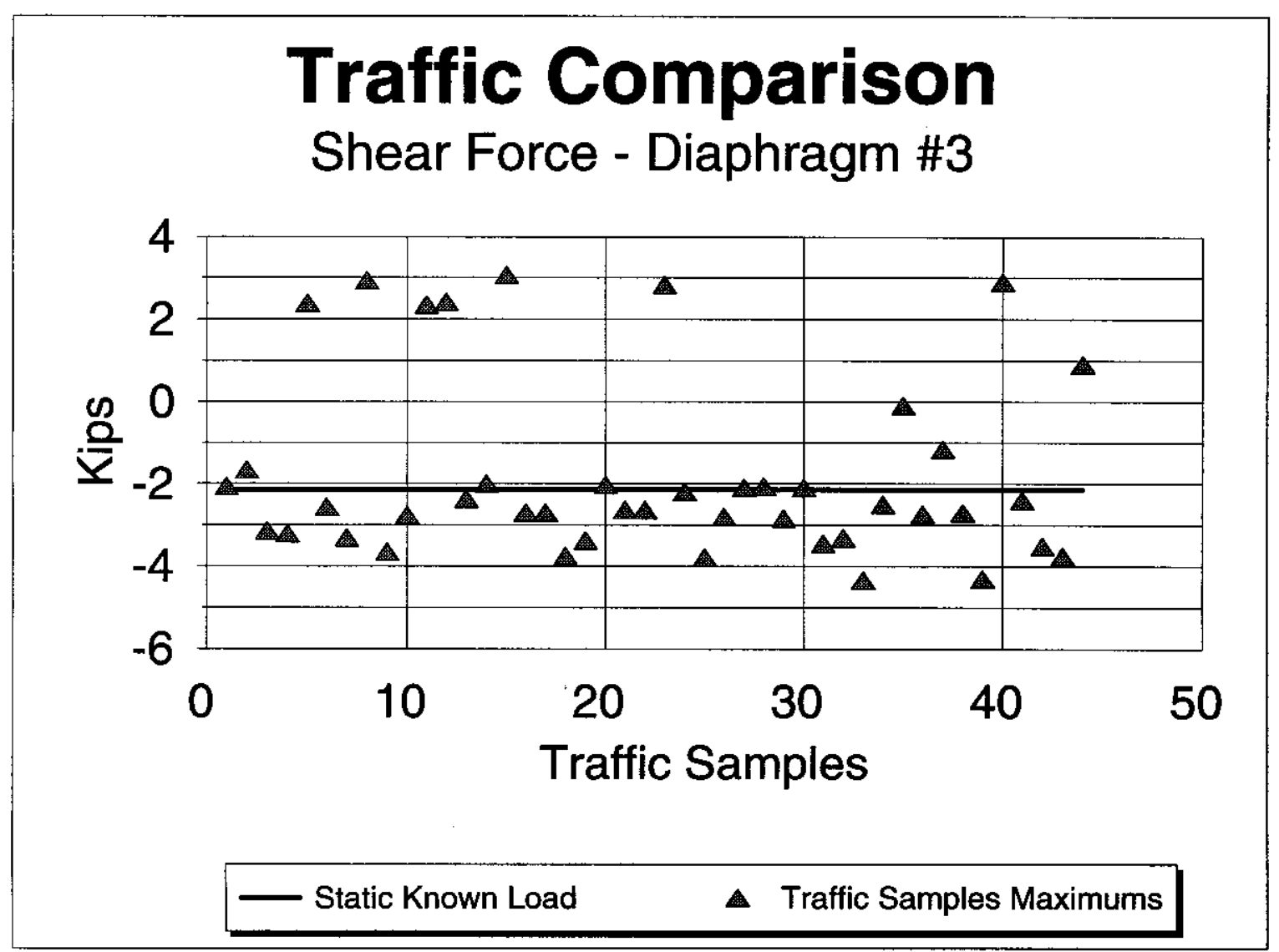

Figure 4.2.2.10 - US 52 - Shear Force in Diaphragm \#3 - Comparison Between Static and Traffic Loadings 


\section{US 52}

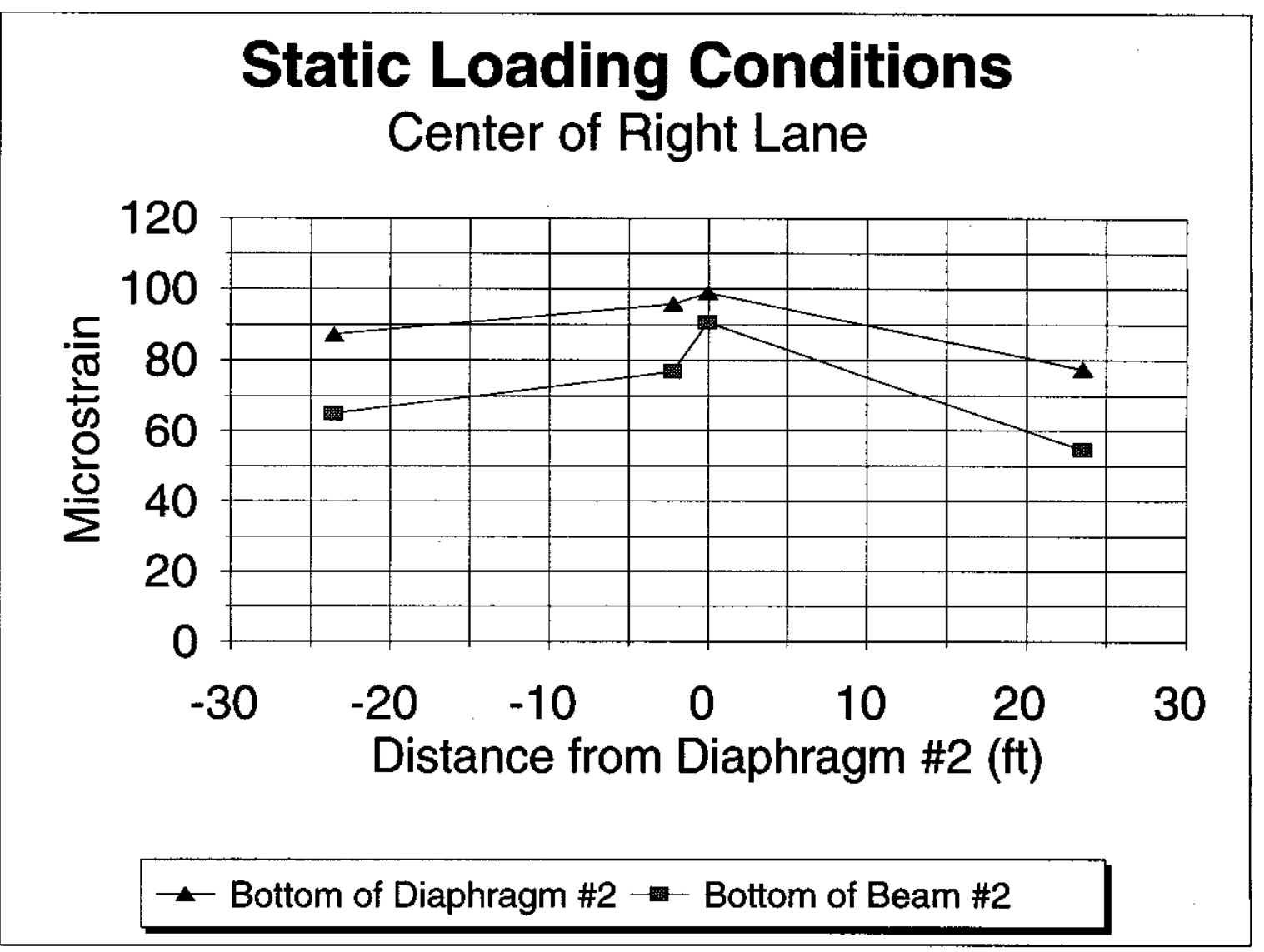

Figure 4.2.2.11 - US 52 - Behavioral Comparison of Beams to Diaphragms 
165

\section{Dynamic Loading Condition (5 mph) Bottom of Beam \#2}

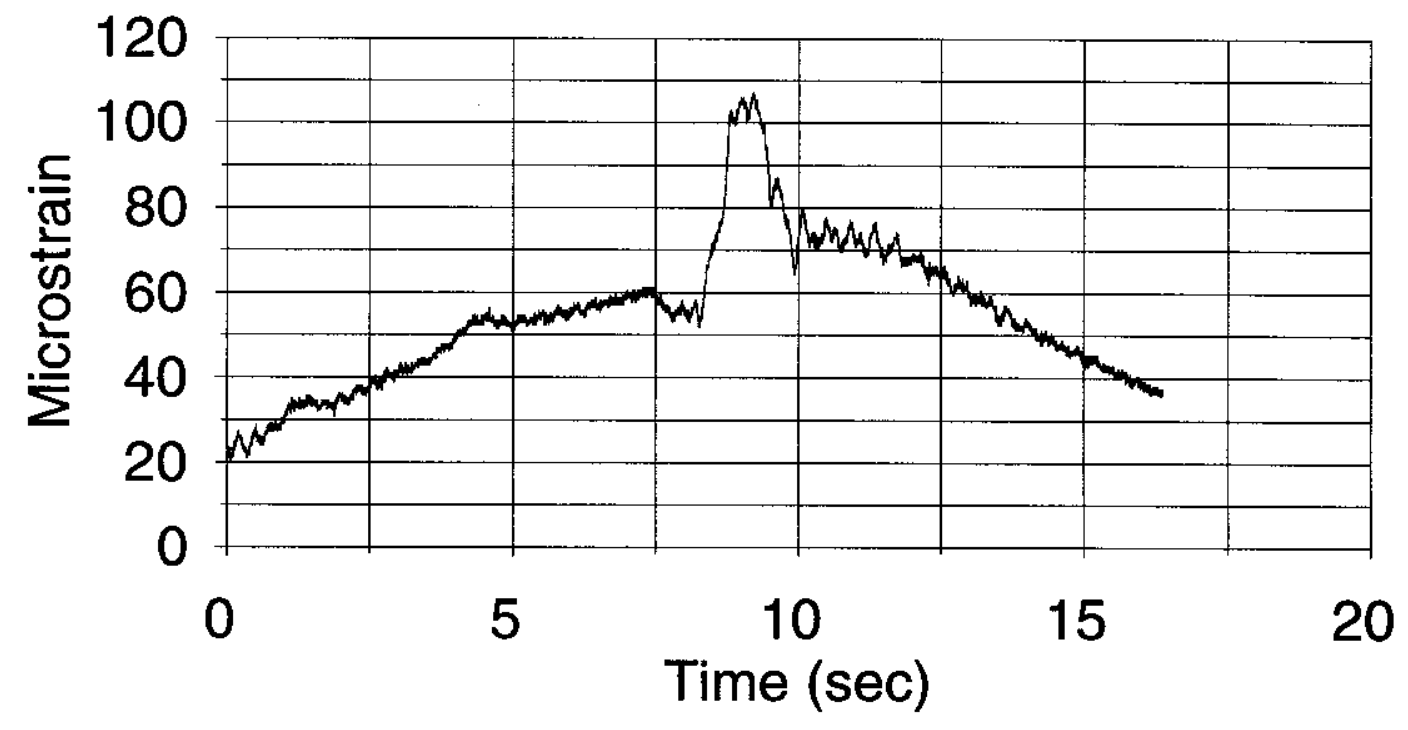

\section{Max - 107 microstrain}

Figure 4.3.1.1 - I 65 - Strains at Bottom of Beam \#2 - $5 \mathrm{mph}$ 
165

\section{Dynamic Loading Condition (25 mph)}

\section{Bottom of Beam \#2}

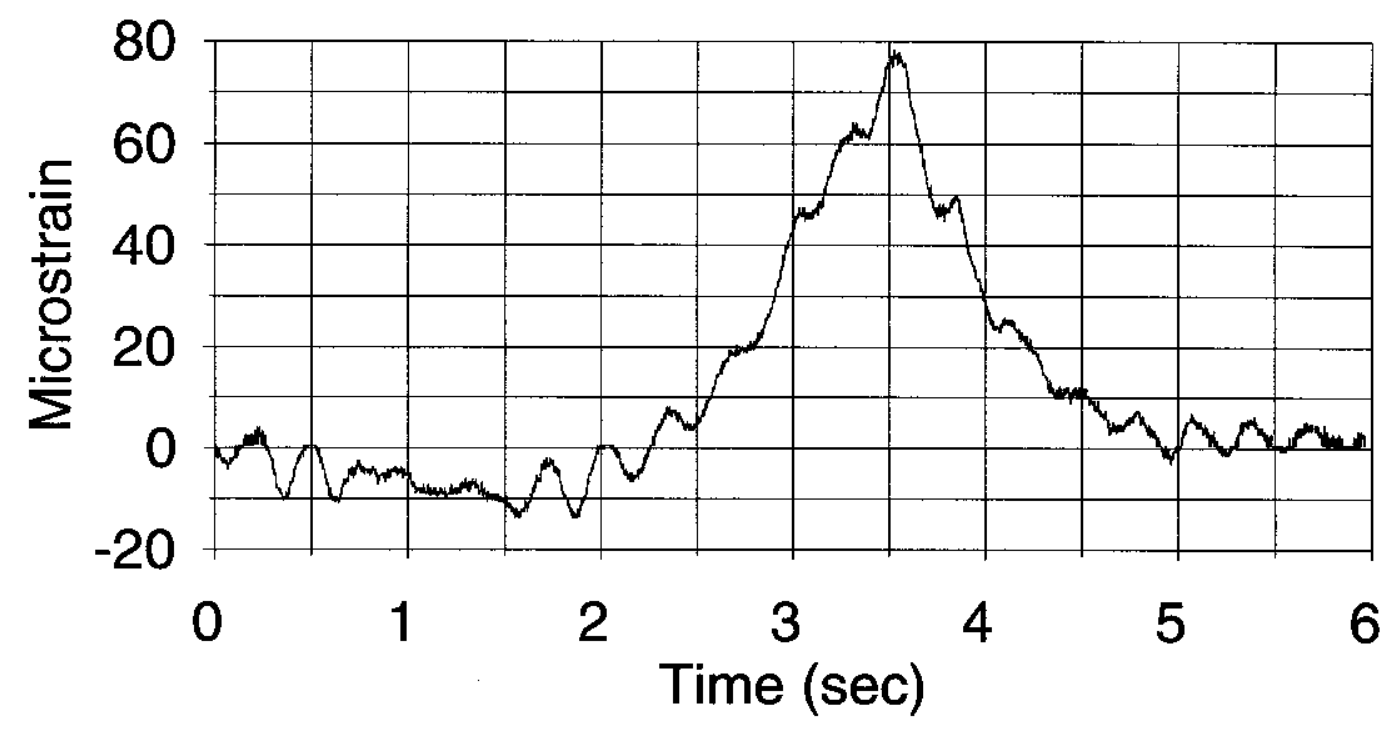

\section{Max - 78 microstrain}

Figure 4.3.1.2 - I 65 - Strains at Bottom of Beam \#2 - $25 \mathrm{mph}$ 
165

\section{Dynamic Loading Condition (55 mph)}

\section{Bottom of Beam \#2}

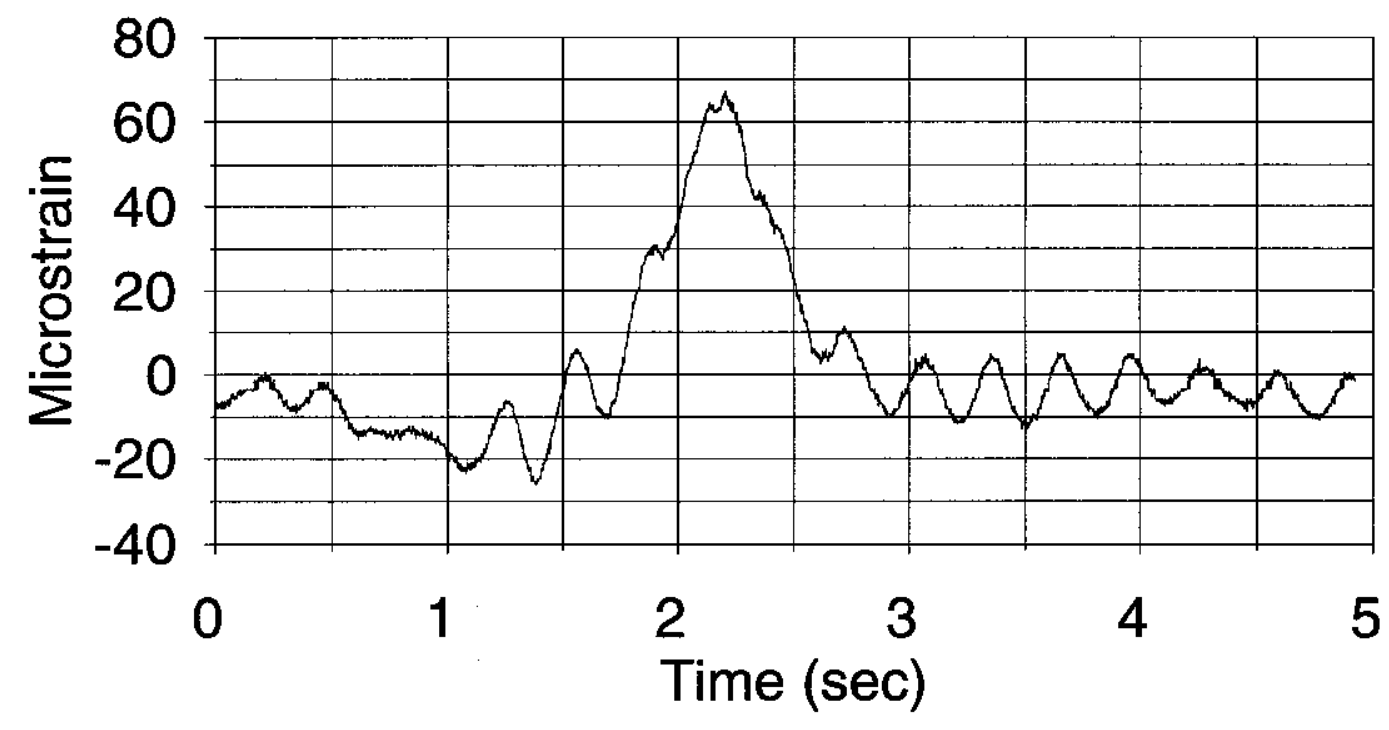

Max - 67 microstrain

Figure 4.3.1.3 - I 65 - Strains at Bottom of Beam \#2 - $55 \mathrm{mph}$ 


\section{65}

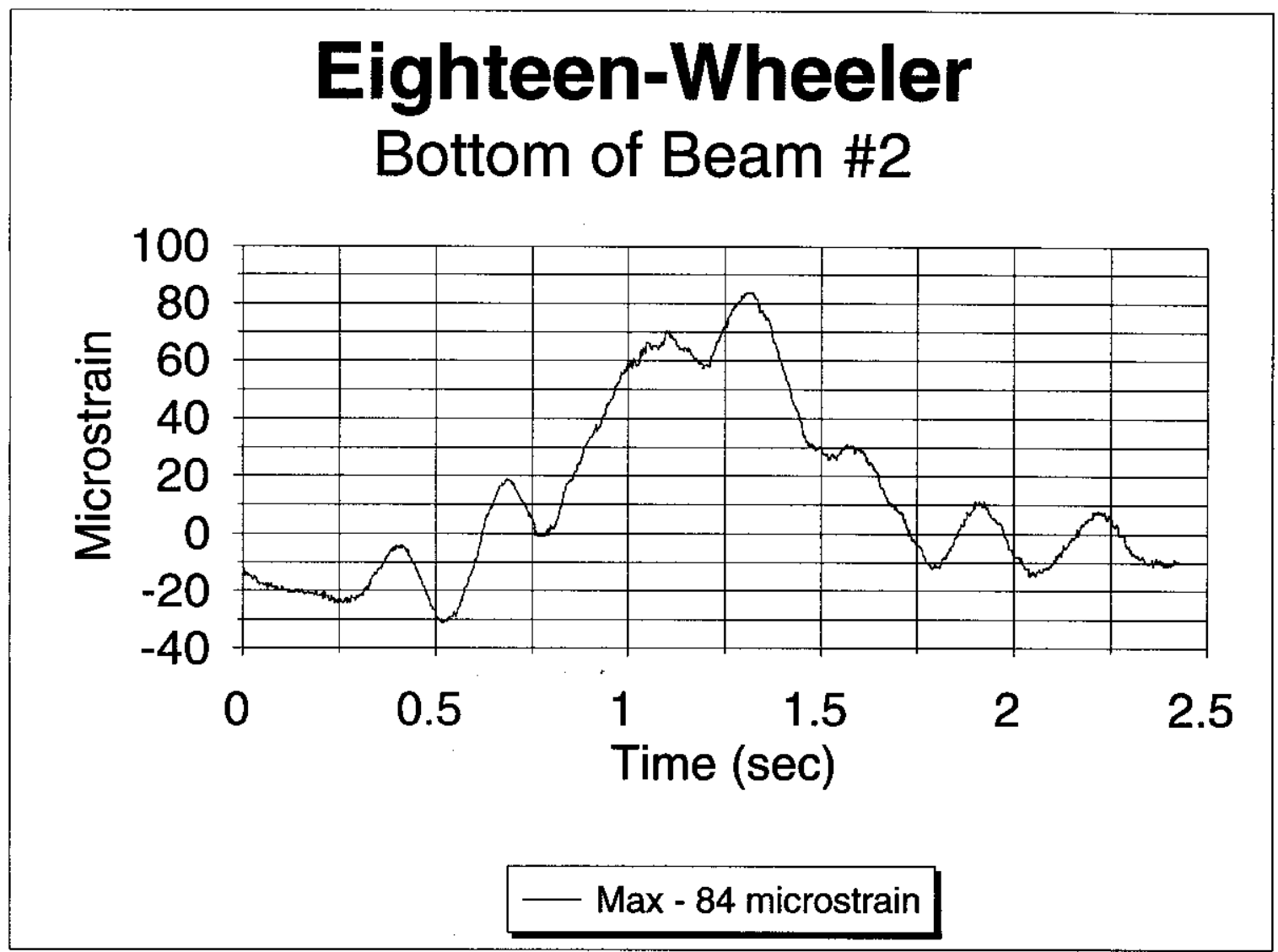

Figure 4.3.1.4 - I 65 - Strains at Bottom of Beam \#2 - Eighteen-Wheeler 


\section{5}

\section{Two Eighteen-Wheelers (Both Lanes) Bottom of Beam \#2}

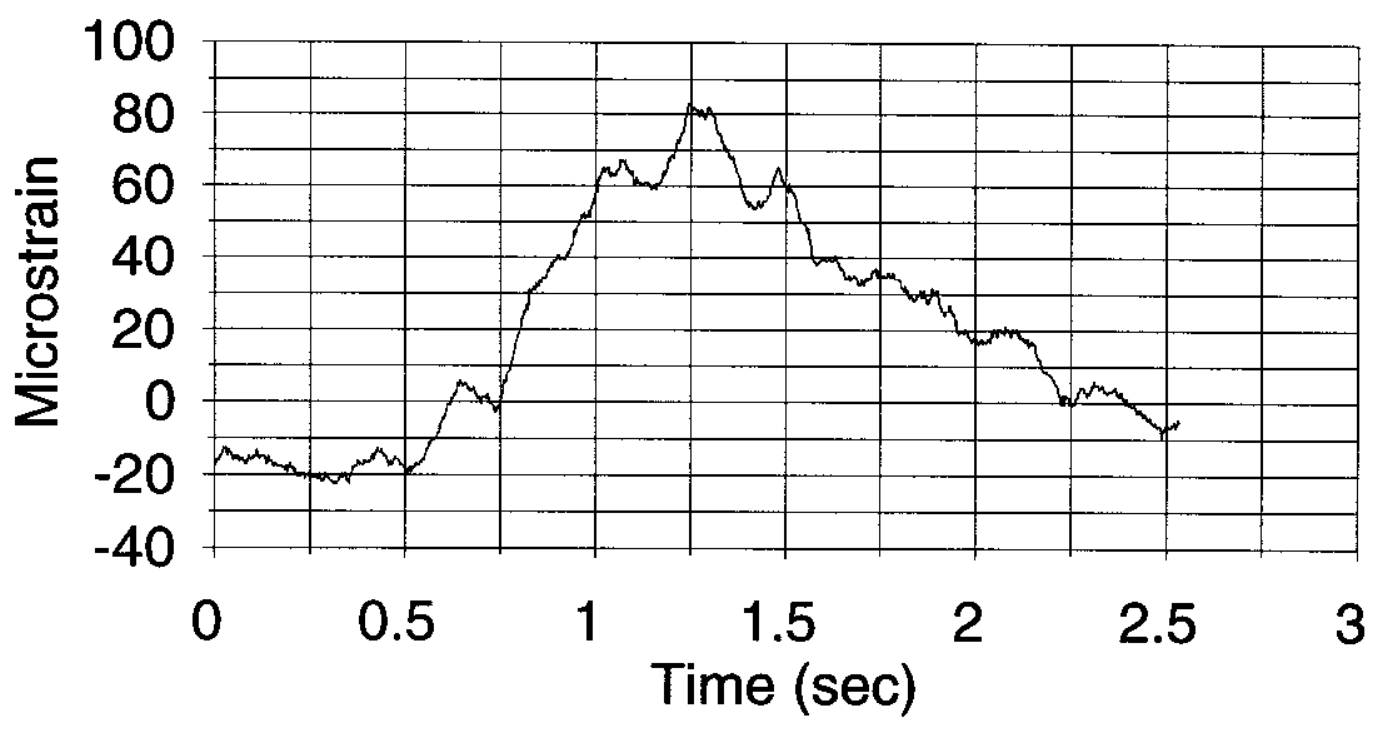

\section{Max - 83 microstrain}

Figure 4.3.1.5 - I 65 - Strains at Bottom of Beam \#2 - Two Eighteen-Wheelers (Side-by-Side) 


\section{65}

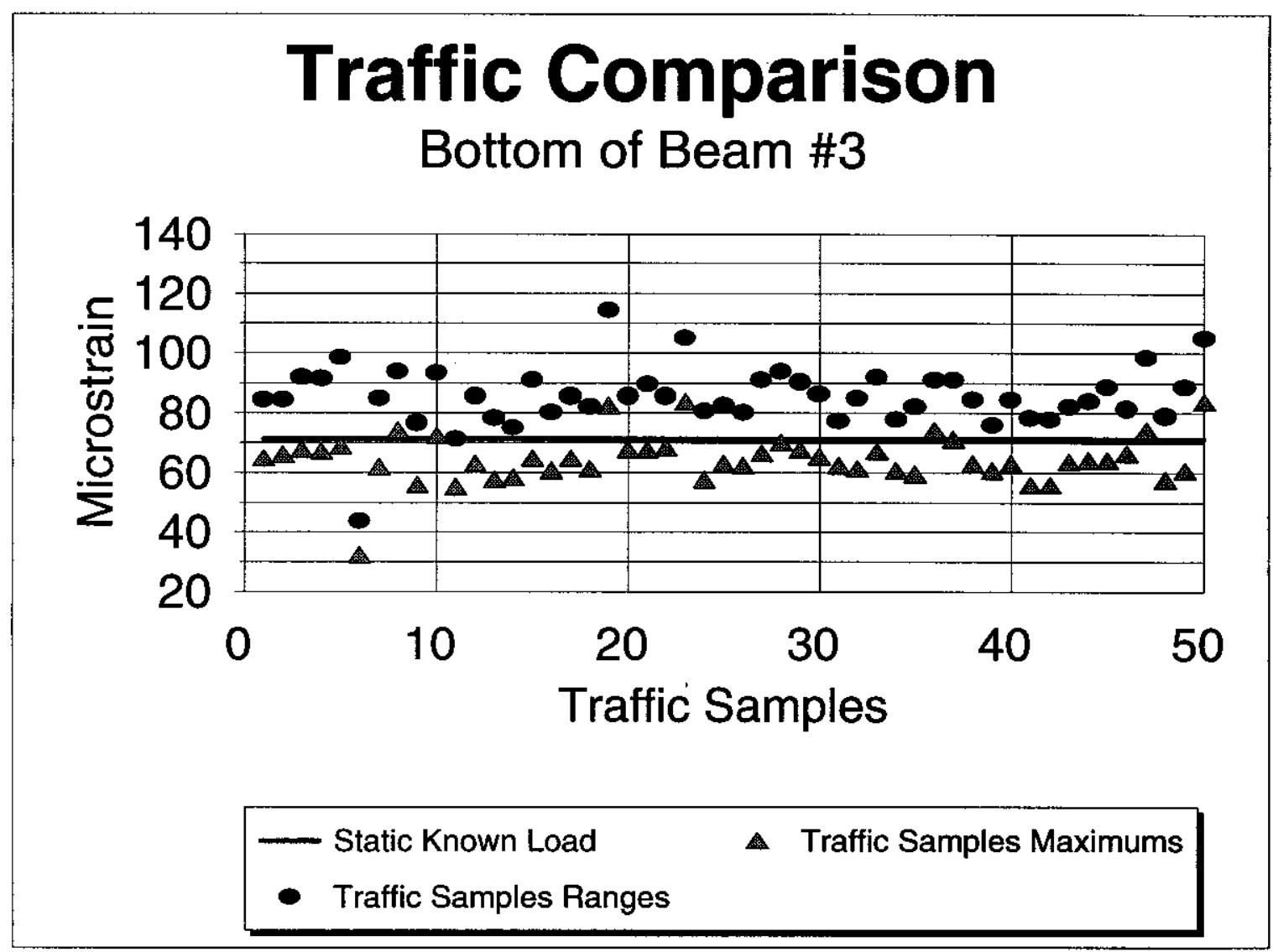

Figure 4.3.1.6 - I 65 - Strain Comparison Between Static and Traffic Loadings 


\section{65}

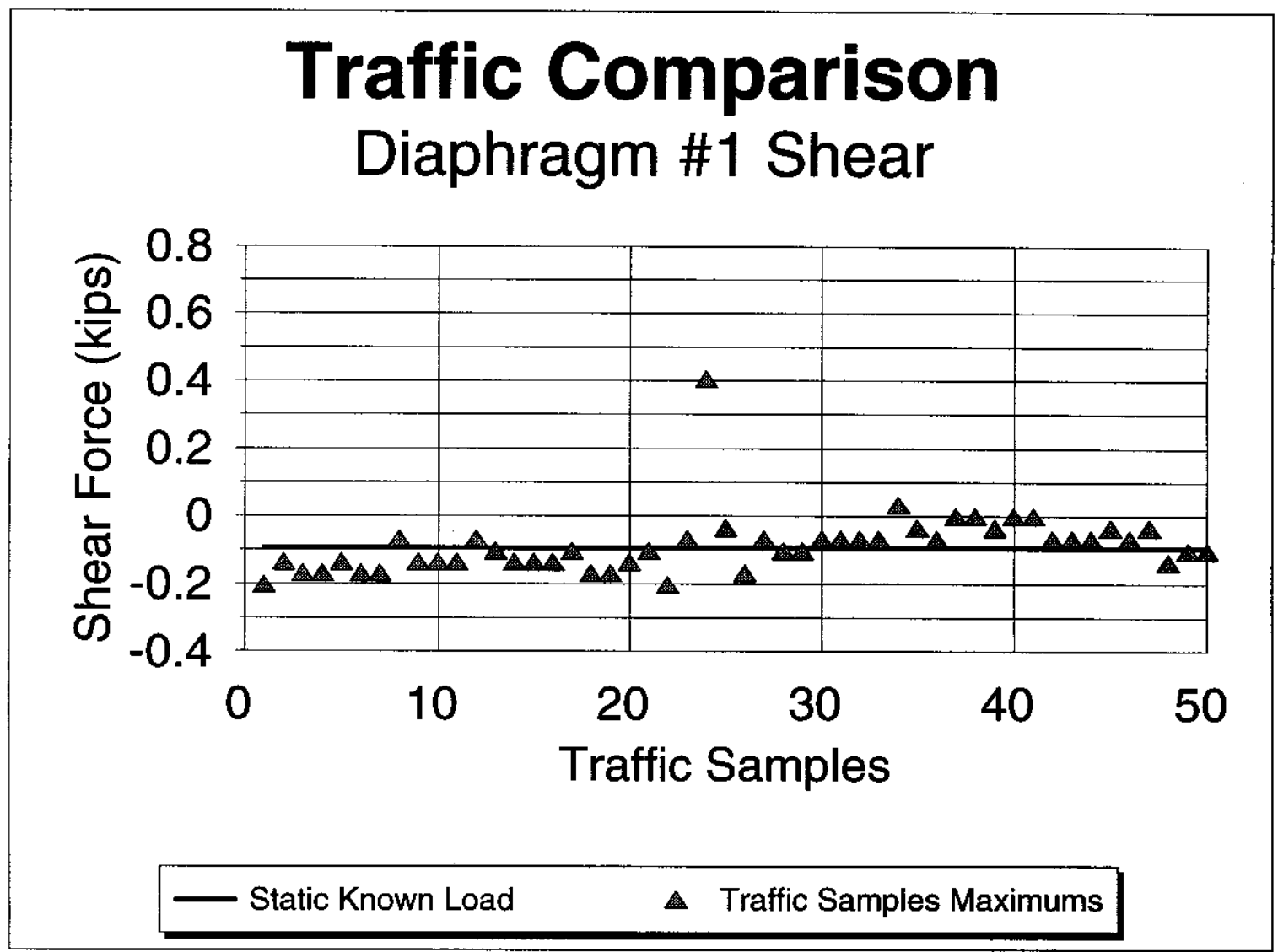

Figure 4.3.2.1 - I 65 - Shear Force in Diaphragm \#1 - Comparison Between Static and Traffic Loadings 
165

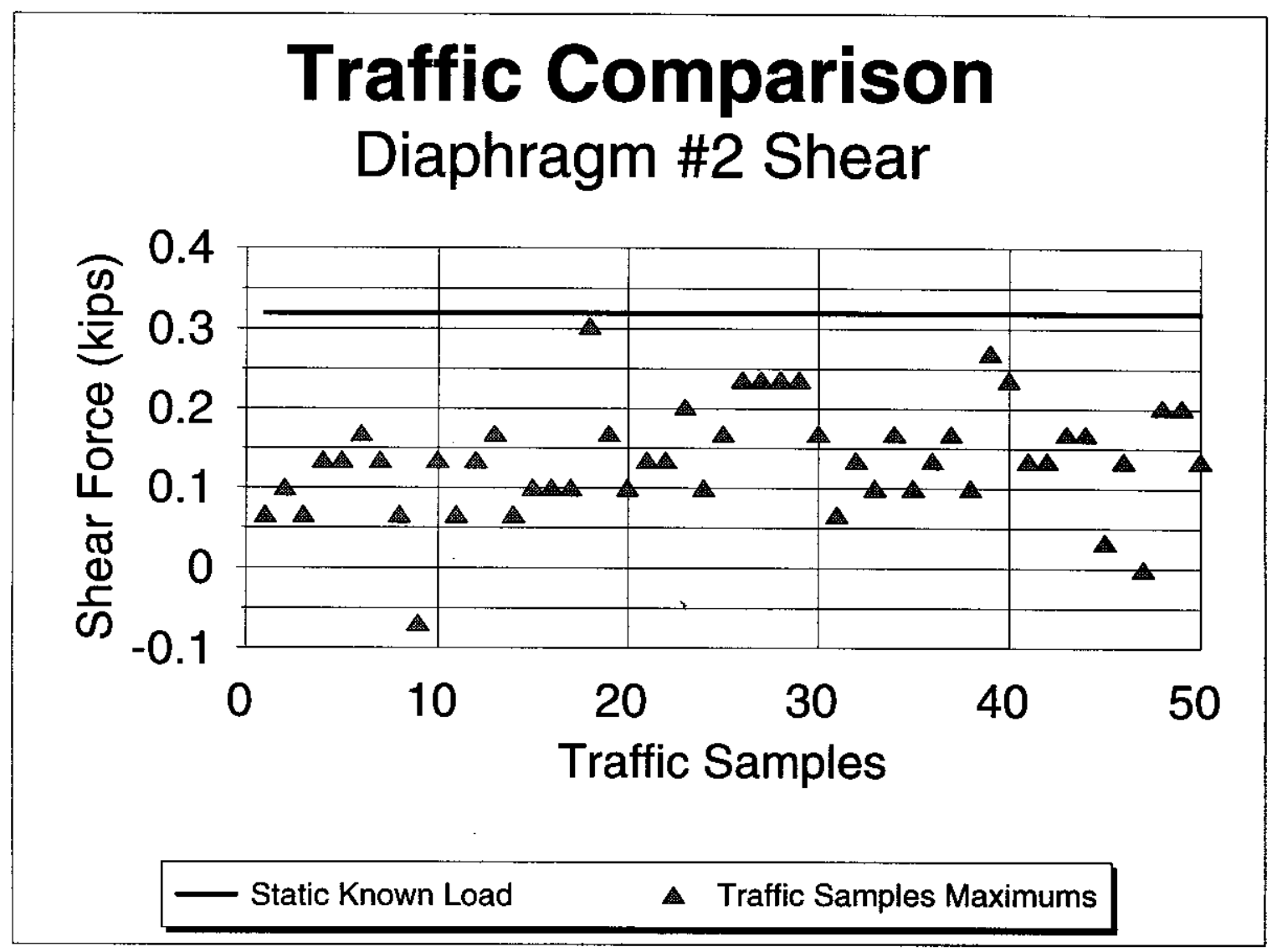

Figure 4.3.2.2 - I 65 - Shear Force in Diaphragm \#2 - Comparison Between Static and Traffic Loadings 
165

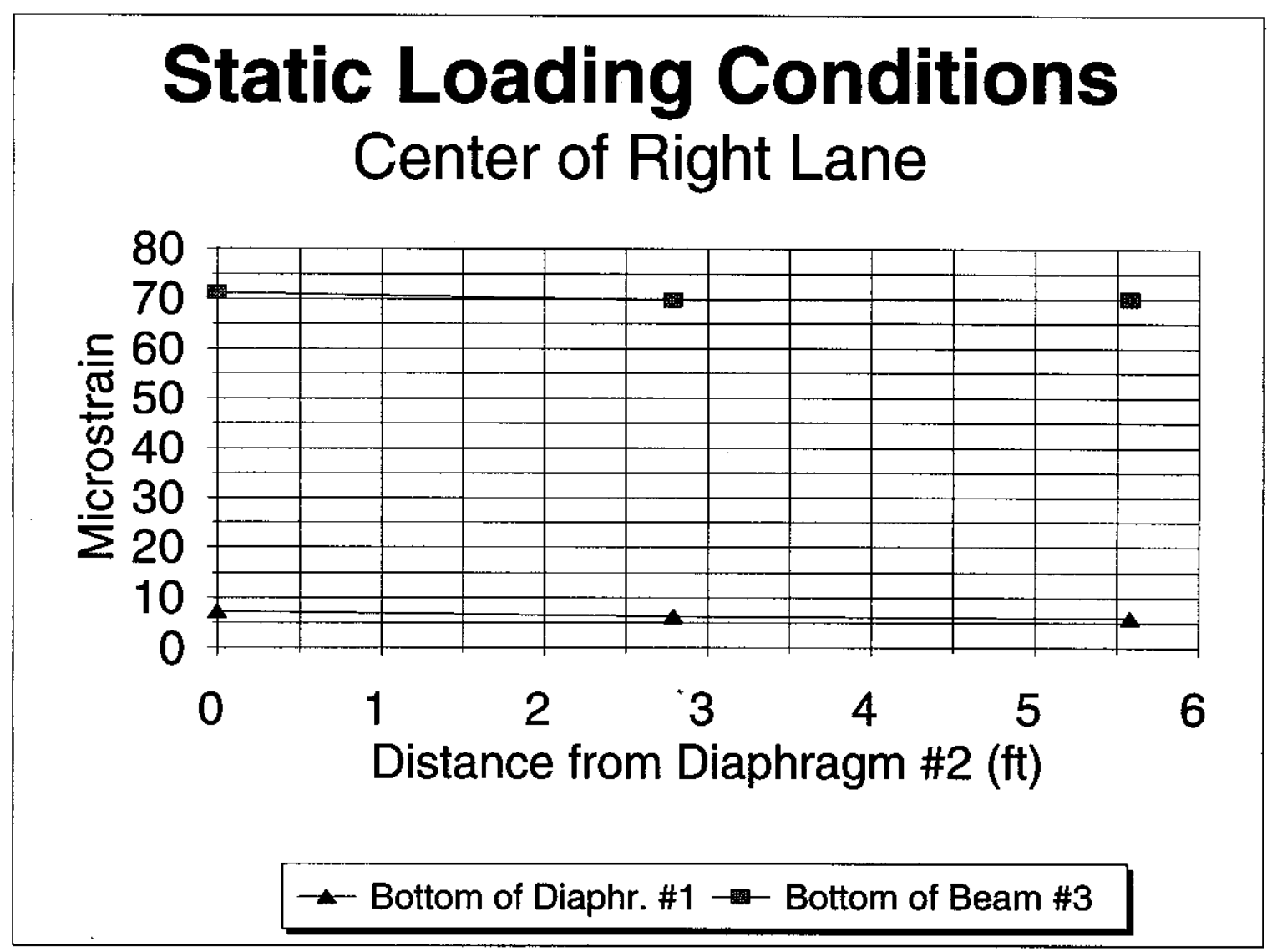

Figure 4.3.2.3 - I 65 - Behavioral Comparison of Beams to Diaphragms 


\section{5}

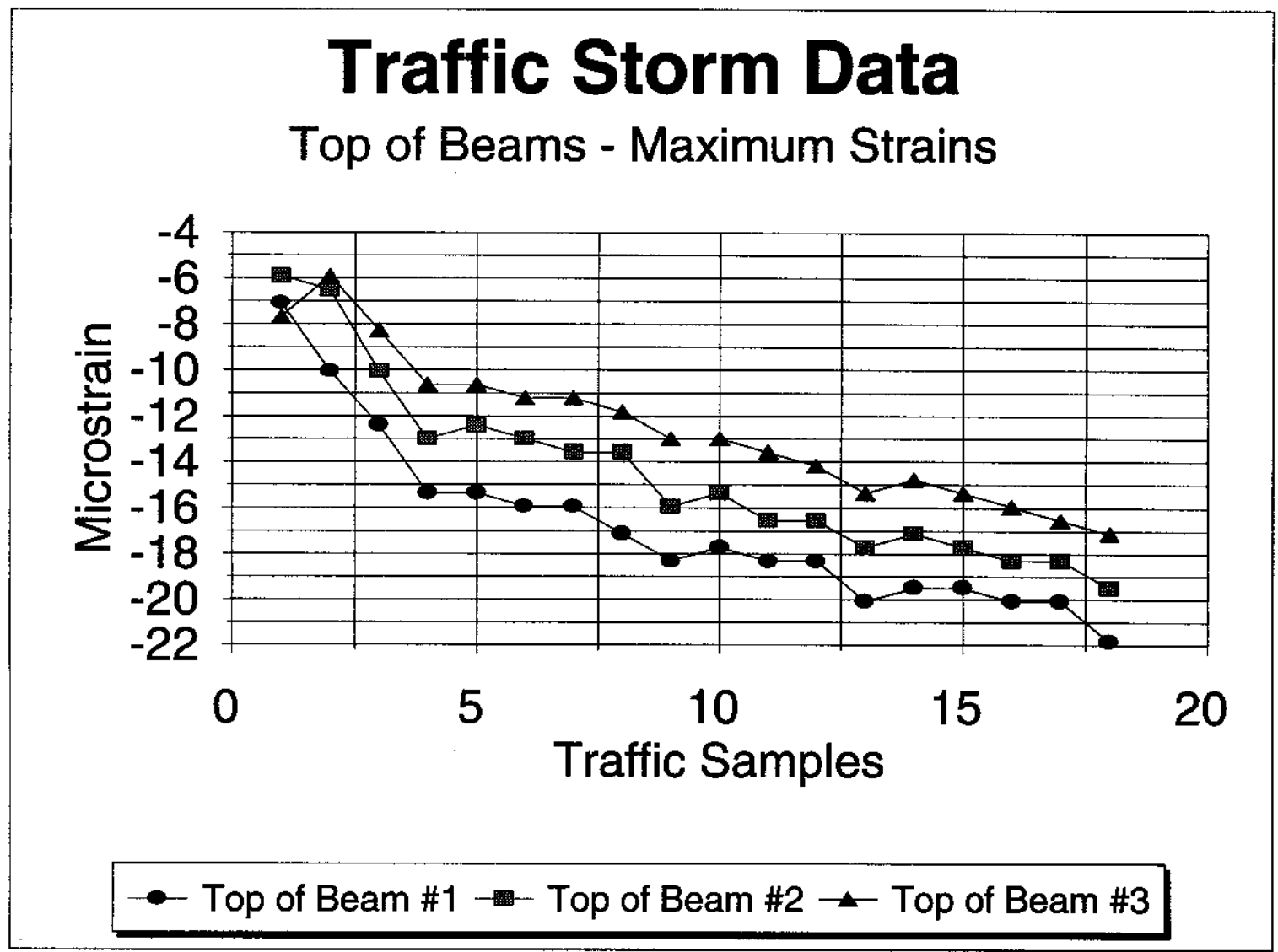

Figure 4.3.3.1 - I 65 - Traffic Storm Data - Maximum Strains in Top of Beams 


\section{5}

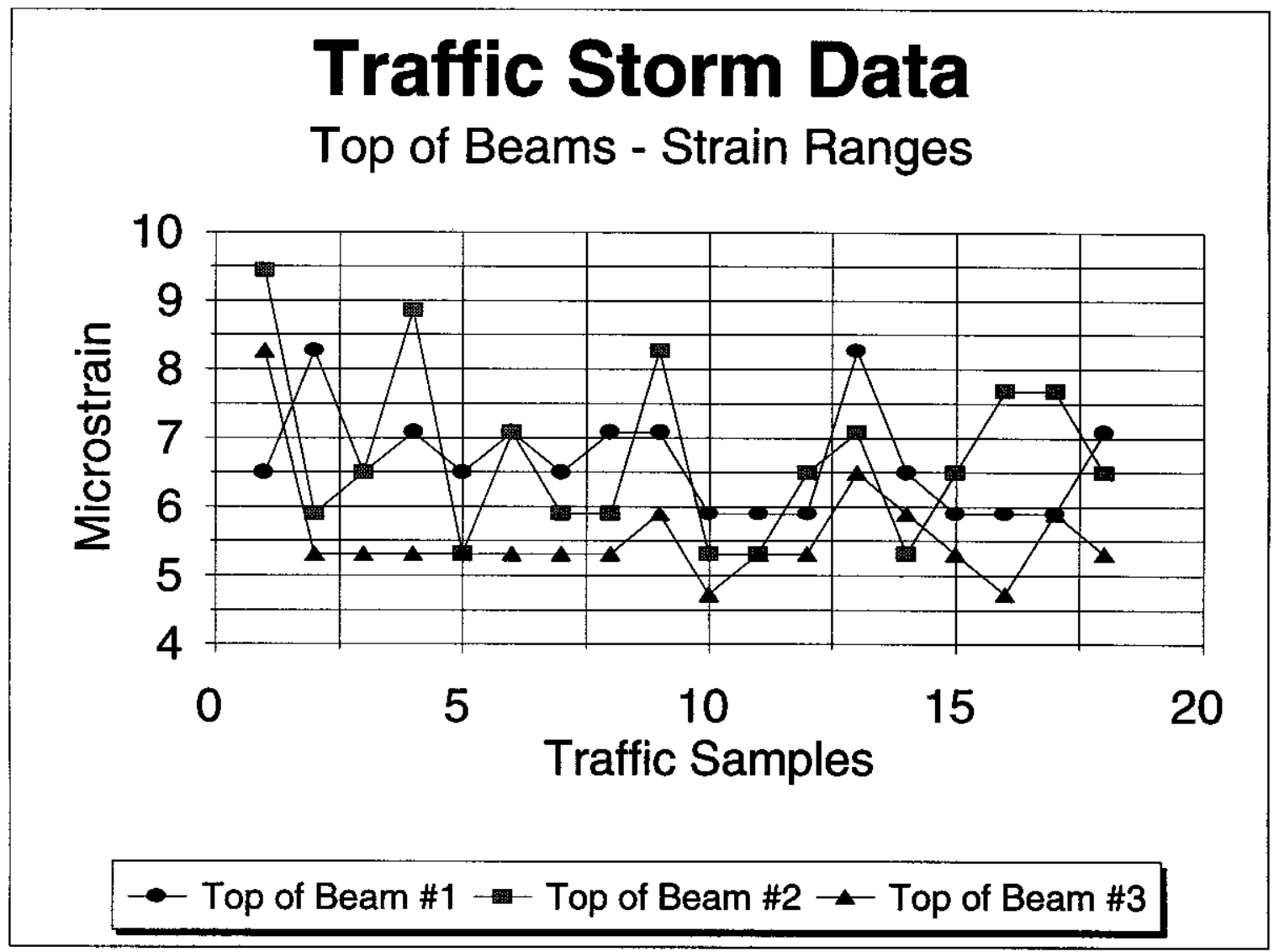

Figure 4.3.3.2 - I 65 - Traffic Storm Data - Strain Ranges in Top of Beams 


\section{5}

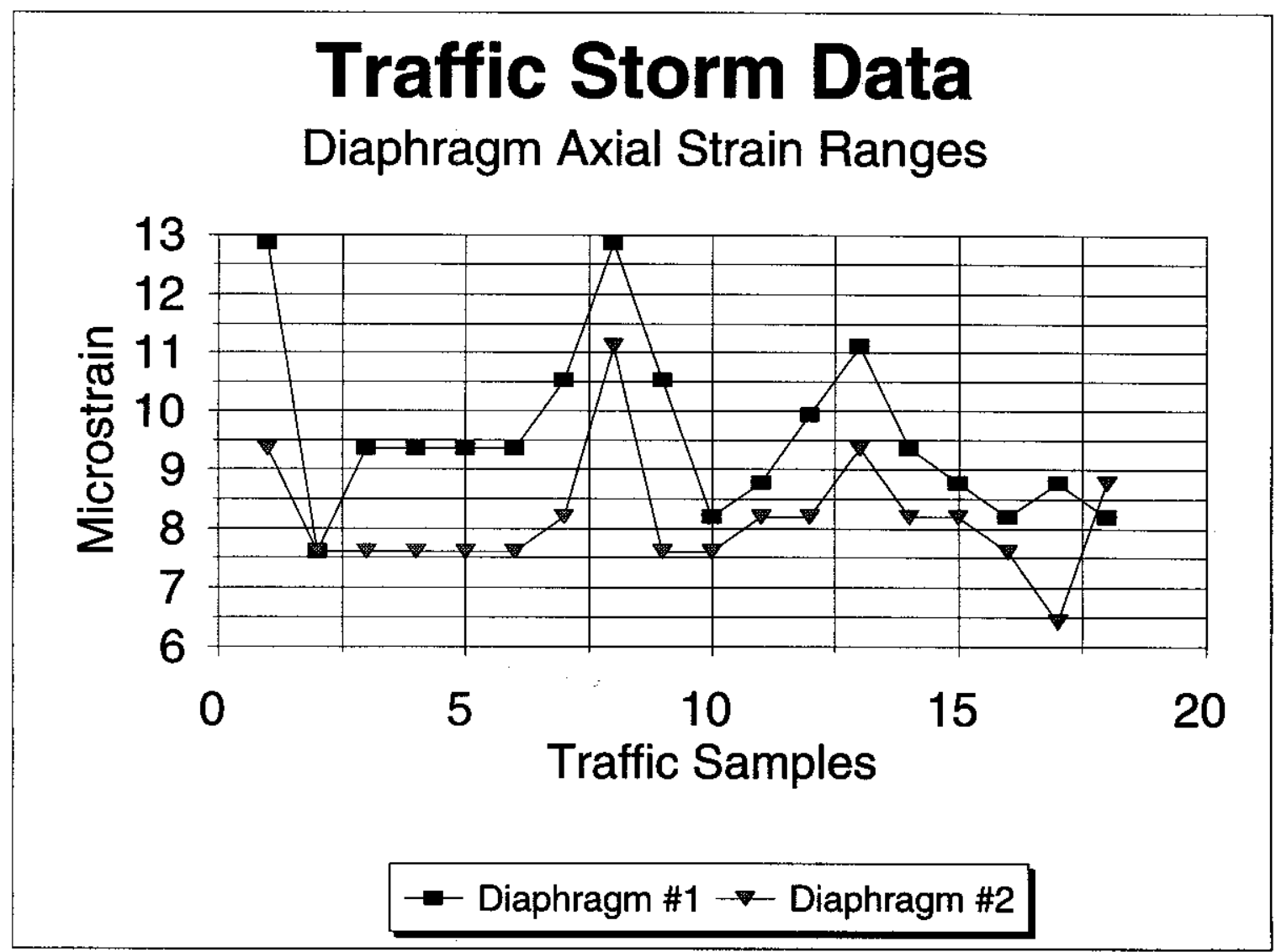

Figure 4.3.3.3 - I 65 - Traffic Storm Data - Axial Strain Ranges in Diaphragms 
I 65

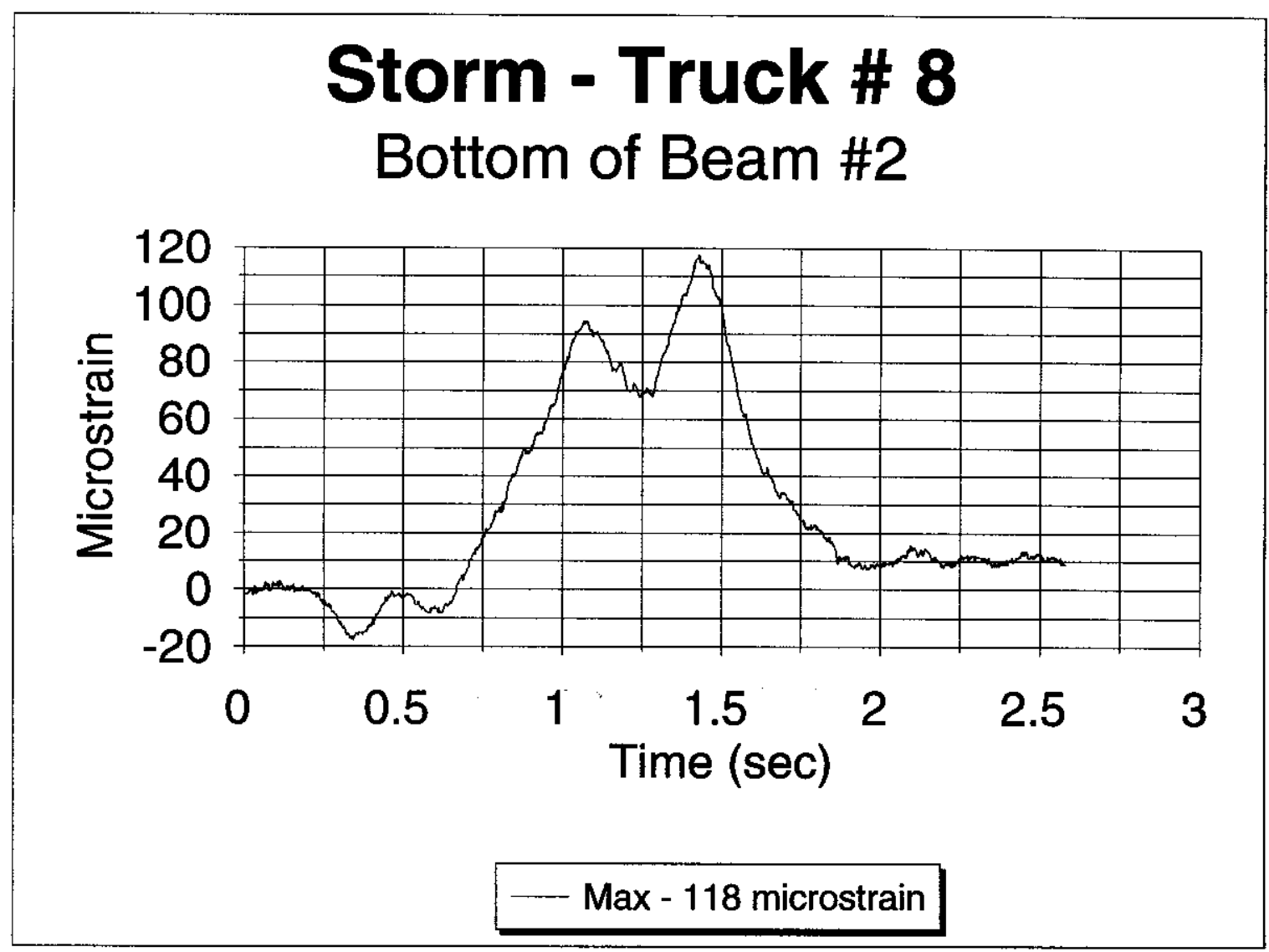

Figure 4.3.3.4 - I 65 - Strains at Bottom of Beam \#2 - Truck Event During Storm 


\section{CHAPTER 5}

\section{EXPERIMENTAL COMPARISON BETWEEN BRIDGES}

Despite the similarities of the welded diaphragm-to-beam connection and the use of similar rolled shapes, there are many differences between the US 52 and I 65 bridges. One of the more relevant disparities is the staggering of the diaphragms in the skewed I 65 bridge. Diaphragms in the US 52 bridge are situated back-to-back. Diaphragm orientation within a structure appears to have a significant effect on their behavior. This chapter discusses the similarities and differences between the US 52 and I 65 bridges.

\subsection{Beam Comparison}

Although the longitudinal members in the instrumented region of both bridges are composed of composite $\mathrm{W} 36 \mathrm{X} 150$ rolled shapes, cover plates are welded to the bottom of the longitudinal members of the I 65 bridge. In the US 52 bridge, eight beams are spaced at $1520 \mathrm{~mm}$ and $1830 \mathrm{~mm}$ ( $5 \mathrm{ft}$. and $6 \mathrm{ft}$.) on center for both the exterior and interior beams, respectively. The six beams in the $\mathrm{I} 65$ bridge are spaced at $2,440 \mathrm{~mm}(8 \mathrm{ft}$.) on center. The $210 \mathrm{~mm}\left(8 \frac{1}{4} \mathrm{in}\right.$.) concrete deck of the 165 bridge is thicker than the $190 \mathrm{~mm}(7 \mathrm{1} / 2 \mathrm{in})$. concrete deck of the US 52 bridge. Even though the beam spacing in the I 65 bridge is larger, longitudinal strains measured in the beams were comparatively smaller than those in the US 52 bridge. Two apparent reasons for this 
observation are the increased moment of inertia in the beams with the welded cover plates and the thicker concrete deck of the I 65 bridge.

For the static loading conditions, a maximum beam strain of 91 microstrain was recorded for the US 52 bridge, while a maximum beam strain of 75 microstrain was recorded for the $\mathrm{I} 65$ bridge. Both maximum readings were measured on the bottom of the beams at a location near the diaphragms. Figure 5.1.1 presents a comparison between strains measured at the bottom of Beam \#2 in the US 52 bridge and those observed on the bottom of Beam \#3 in the $\mathrm{I} 65$ bridge. The strain readings shown correspond to the distance from the center of the truck's rear axles to Diaphragm \#2. A comparison of the maximum beam strain ranges between the two bridges shows an almost identical difference in readings for the dynamic loading conditions. Strains detected on the bottom of Beam \#2 are plotted in Figure 5.1.2 for each bridge under dynamic loading. The difference in the duration of the signals reflects the higher truck speeds on the I 65 bridge than on the US 52 bridge.

Out-of-plane bending strains were measured in the webs of all instrumented beams between the diaphragm and the bottom flange for both bridges. Beam \#1 in the US 52 bridge exhibited single-curvature web bending. All remaining beams experienced double-curvature bending in the beam web region. Figure 5.1.3 is a record of measured beam web strains for Beam \#2 in each bridge. Notice that the webs of both beams undergo double-curvature, outof-plane bending and that the magnitude of the strains in the beam web of the I 65 bridge are significantly higher.

Although the tandem axle dump truck used in the I 65 load test was slightly heavier 
than the one used in the US 52 load test, deflections measured in the US 52 bridge were larger than those in the 165 bridge. The maximum deflection measured in the US 52 bridge was $6.71 \mathrm{~mm}$ ( $0.264 \mathrm{in}$.) whereas the maximum deflection measured in the $\mathrm{I} 65$ bridge was $4.80 \mathrm{~mm}(0.189 \mathrm{in}$.$) . The larger deflections in the US 52$ bridge are believed to be the result of a longer span, a thinner concrete deck, and the absence of beam of cover plates.

\subsection{Diaphragm Comparison}

Diaphragms in both bridges consist of rolled W18X45 members. In the US 52 bridge, diaphragms are oriented back-to-back. However, diaphragms in the skewed I 65 bridge are arranged with a stagger of approximately $1700 \mathrm{~mm}(5 \mathrm{ft} .-7 \mathrm{in}$.$) . The diaphragms$ in the I 65 bridge are longer in length than those in the US 52 bridge because the distance between exterior beams is $12,190 \mathrm{~mm}$ ( $40 \mathrm{ft}$.) for both bridges, and the 165 bridge has fewer beams.

When comparing the diaphragms of the US 52 bridge to those of the I 65 bridge, Diaphragms \#2 and \#3 of the US 52 bridge are matched up with Diaphragms \#1 and \#2 of the I 65 bridge, respectively. Correlations between the diaphragms in the two bridges were determined by examining their location with respect to the beams and the load placement.

Looking at the strain readings for both the static and dynamic known loading conditions, there is a large discrepancy in the strains measured in the diaphragms between the two bridges. Strains measured in the diaphragms of the US 52 bridge are significantly larger than those evaluated in the I 65 bridge. Some diaphragm strain readings in the US 52 bridge were even larger than strains measured in the beams. However, diaphragm strain 
values from the I 65 bridge are minimal. For the static loading conditions, a maximum diaphragm strain of 99 microstrain was recorded for the US 52 bridge, and a maximum diaphragm strain of 9.8 microstrain was measured for the I 65 bridge - an order of magnitude difference. Figure 5.2.1 presents a comparison between maximum strains detected at the bottom of Diaphragm \#2 in the US 52 bridge and those measured on the bottom of Diaphragm \#1 in the I 65 bridge. Dynamic loading conditions show an equally large disparity between diaphragm strain readings for each bridge (Figure 5.2.2).

Comparing forces in the diaphragms that were computed from the measured diaphragm strain values reinforces the trend in behavior discussed in the preceding paragraph. Maximum diaphragm axial and shear forces for static loading conditions for each bridge are listed in Table 5.2.1. Both axial and shear forces in the diaphragms of the US 52 bridge are substantially larger than those in the $\mathrm{I} 65$ bridge. For dynamic loading conditions at comparable speeds, calculated shear force ranges are presented in Table 5.2.2. These computed values also indicate that the US 52 diaphragms are experiencing considerably larger forces than the diaphragms in the $\mathrm{I} 65$ bridge.

The arrangement of the diaphragms within the bridge is believed to greatly influence the behavior of the diaphragms and the amount in which they participate in load distribution. Diaphragms that are situated back-to-back, as in the US 52 bridge, act as one continuous member running perpendicular to the flow of traffic. This "continuous" diaphragm provides significant stiffness between differentially deflecting adjacent beams, causing sizable diaphragm strains and forces as described in Chapter 4. When the diaphragms are staggered, as in the I 65 bridge, individual diaphragms are not stiffened as much by adjacent 
diaphragms, resulting in considerably lower diaphragm strains and forces. Because neighboring diaphragms do not provide as much lateral stiffness, the beam web between the diaphragm and the bottom flange of the beam is subjected to larger out-of-plane bending strains, consistent with observations in the I 65 bridge and in the US 52 bridge.

\subsection{Monitored Traffic Comparison}

Although fewer traffic events were recorded for the US 52 bridge, more time was spent monitoring regular traffic; indicating a greater frequency of large truck traffic on the I 65 bridge than the US 52 bridge. Because average vehicle speeds are faster on I 65 than on US 52 , traffic records for the US 52 bridge are longer than those for the $\mathrm{I} 65$ bridge. Beam and diaphragm behavior during traffic loadings is similar to that observed for the known loading conditions. Higher strain readings can be explained by the larger weight of the recorded regular traffic loadings as compared to the dump truck test vehicle of known load.

As seen in previous sections, beam strains recorded for regular truck traffic in the US 52 bridge are larger than those recorded in the beams of the I 65 bridge. Figure 5.3 .1 shows a comparison between beam strains in both bridges for the crossing of a single eighteenwheeler which produced maximum strain readings for each bridge. Compared to the I 65 bridge, larger beam strains were also detected in the US 52 bridge for a sizable loading by two trucks (Figure 5.3.2). The two trucks inducing maximum strains in the US 52 bridge were a dump truck and an eighteen-wheeler. Those corresponding to the maximum strains in the I 65 bridge were two eighteen-wheelers traveling side-by-side. 
Diaphragm comparisons between the two bridges for monitored traffic events correlate well with diaphragm comparisons corresponding to the known loading conditions. Maximum diaphragm strains measured in the US 52 bridge were significantly higher than those measured in the I 65 bridge. Figure 5.3.3 presents a comparison between diaphragms from each bridge which experienced the maximum strains during the crossing of a single eighteen-wheeler. A similarly large difference in measured strain values between the diaphragms of the two bridges was observed for the passing of two trucks over the instrumented span (Figure 5.3.4).

When examining all traffic samples for both bridges, shear forces in the diaphragms of the US 52 bridge were also much larger than those in the diaphragms of the I 65 bridge. Figure 5.3.5 illustrates the shear force in Diaphragm \#2 in the US 52 bridge and Diaphragm $\# 1$ in the $\mathrm{I} 65$ bridge for all traffic loadings. Figure 5.3.6 compares the shear force in Diaphragm \#3 in the US 52 bridge and Diaphragm \#2 in the 165 bridge. 
Table 5.2.1 Bridge Comparison - Maximum Diaphragm Forces for Static Loading Conditions

\begin{tabular}{|c|c|c|c|c|}
\hline & \multicolumn{2}{|c|}{ Maximum Shear Force (k) } & \multicolumn{2}{c|}{ Maximum Axial Force (k) } \\
\hline Member & US 52 & I 65 & US 52 & I65 \\
\hline \hline Diaphragm \#1 & 2.39 & & 7.84 & \\
\hline Diaphragm \#2 & & & & 2.03 \\
\hline Diaphragm \#3 & -259 & NA & & NA \\
\hline
\end{tabular}

Note: (a) Shaded boxes represent diaphragms which can be compared.

(b) NA = Not Applicable 
Table 5.2.2 Bridge Comparison - Maximum Diaphragm Shear Force Ranges for Dynamic Loading Conditions

\begin{tabular}{|c|c|c|}
\hline Speed (mph) & Member & $\begin{array}{l}\text { Maximum Shear Force Range (k) } \\
\text { US } 52\end{array}$ \\
\hline \multirow[t]{3}{*}{$\sim 5$} & Diaphragm \#1 & 2.7 \\
\hline & Diaphragm \#2 & (j) \\
\hline & Diaphragm \#3 & NA \\
\hline \multirow[t]{3}{*}{$\sim 25$} & Diaphragm \#1 & 2.8 \\
\hline & Diaphragm \#2 & \\
\hline & Diaphragm \#3 & NA \\
\hline
\end{tabular}

Note: (a) Shaded boxes represent diaphragms which can be compared.

(b) NA = Not Applicable 


\section{Bridge Comparison Static LC - Beams}

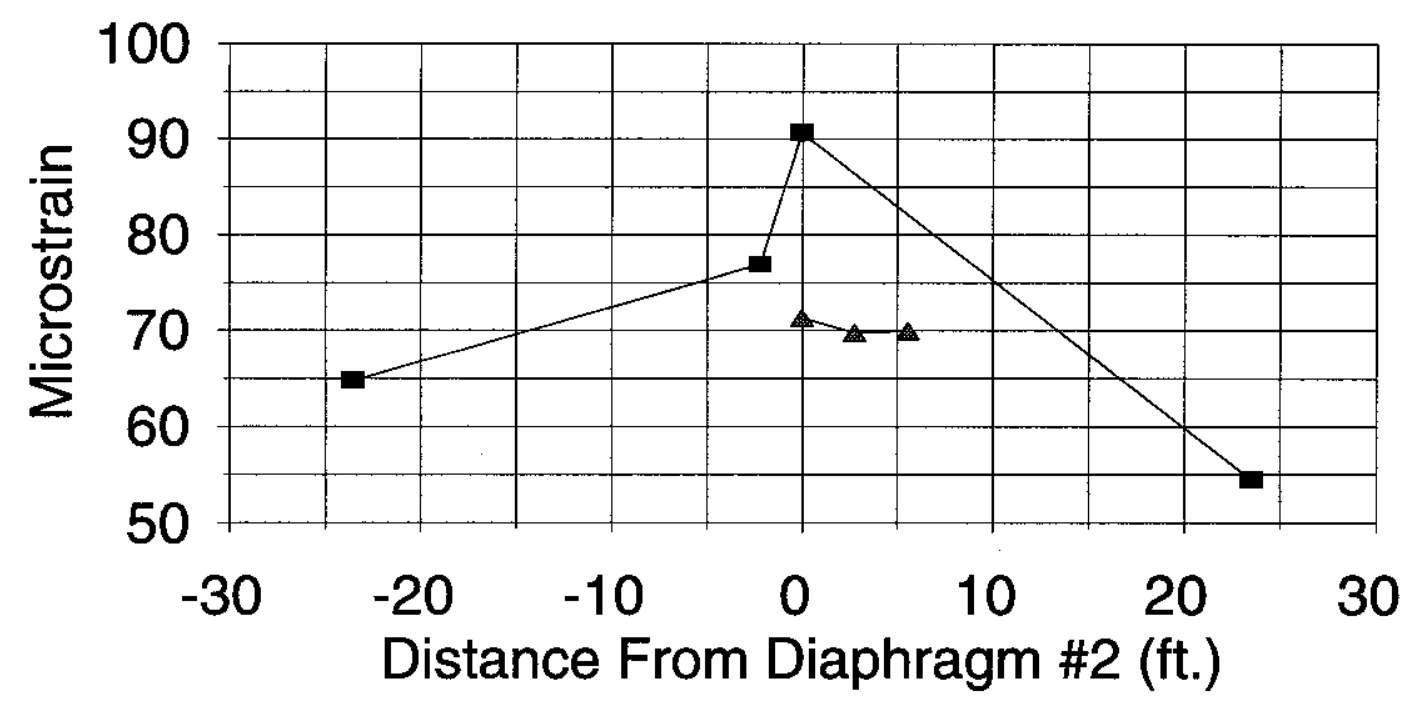

-- US 52 - Bottom of Beam \#2 $\_$I 65 - Bottom of Beam \#3

Figure 5.1.1 - Bridge Comparison - Strains at Bottom of Beams for Static Loading Conditions 


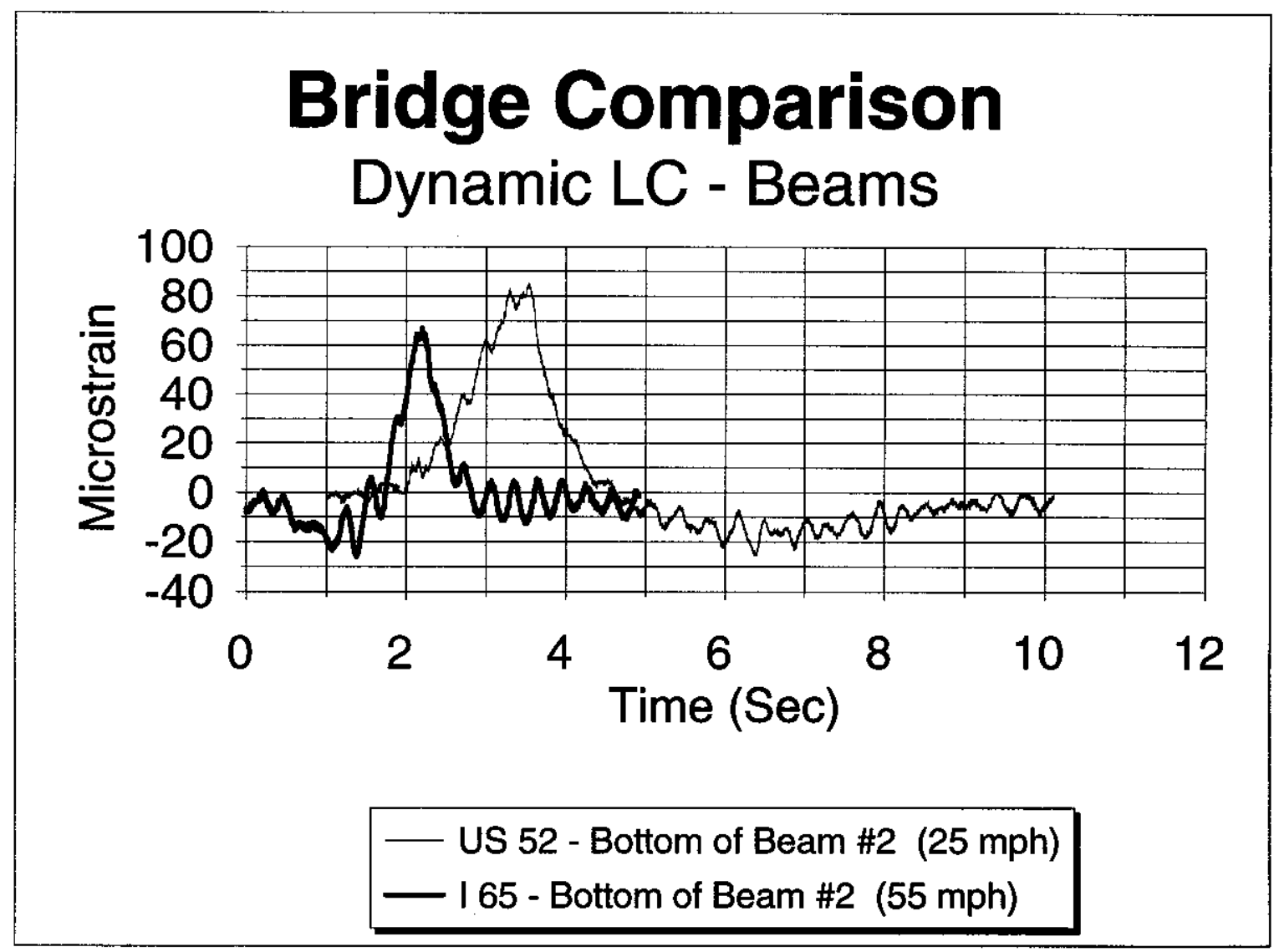

Figure 5.1.2 - Bridge Comparison - Strains at Bottom of Beams for Dynamic Loading Conditions 


\section{Bridge Comparison Static LC - Beam Webs}

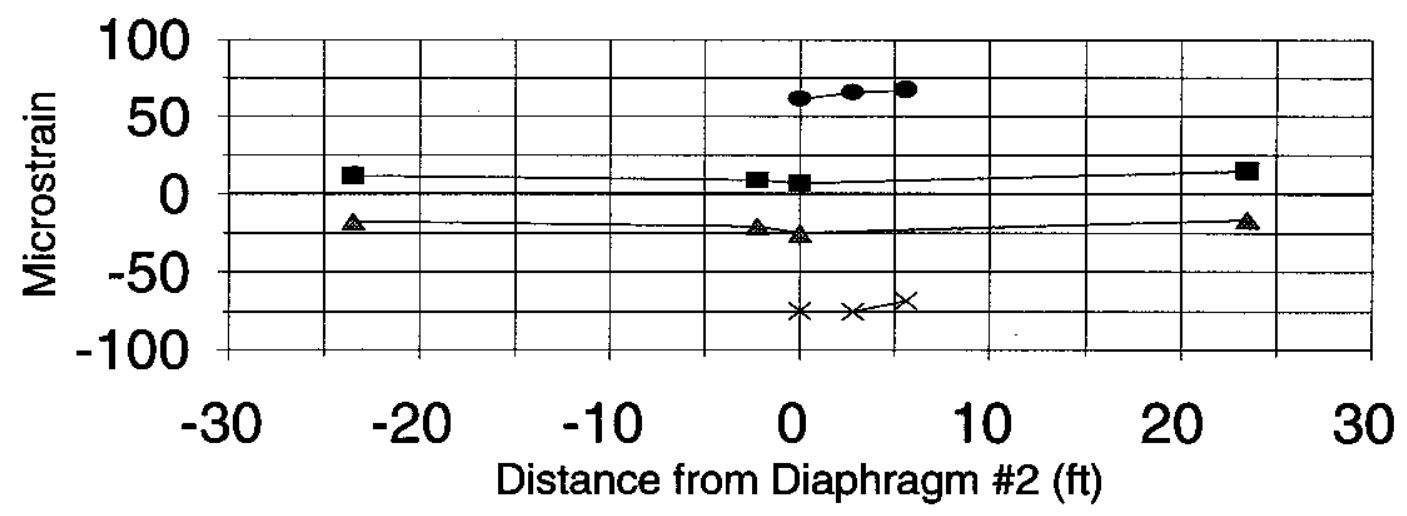

-- US 52 - Top Web Gage of Beam \#2

- US 52 - Bottom Web Gage of Beam \#2

- I 65 - Top Web Gage of Beam \#2

$\star$ I 65 - Bottom Web Gage of Beam \#2

Figure 5.1.3 - Bridge Comparison - Beam Web Strains for Static Loading Conditions 


\section{Bridge Comparison Static LC - Diaphragms}

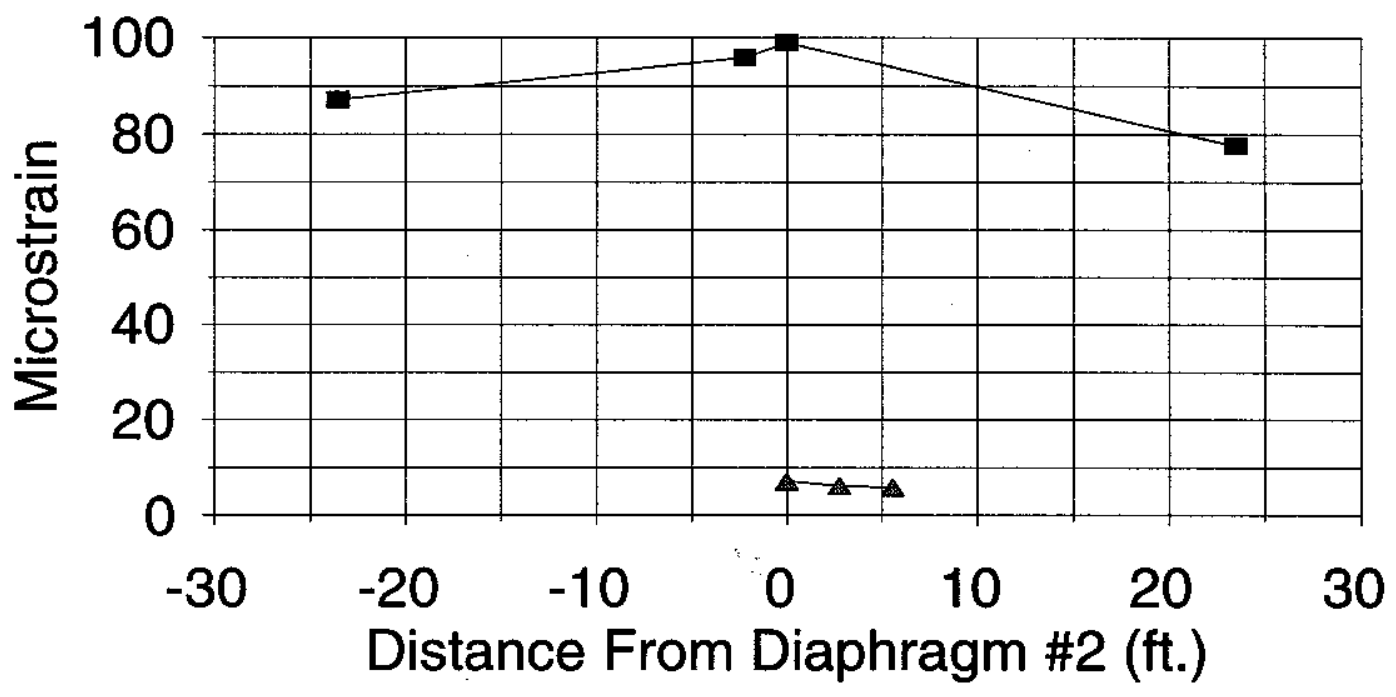

- US 52 - Bottom of Diaphragm \#2 - 165 - Bottom of Diaphragm \#1

Figure 5.2.1 - Bridge Comparison - Diaphragm Strains for Static Loading Conditions 


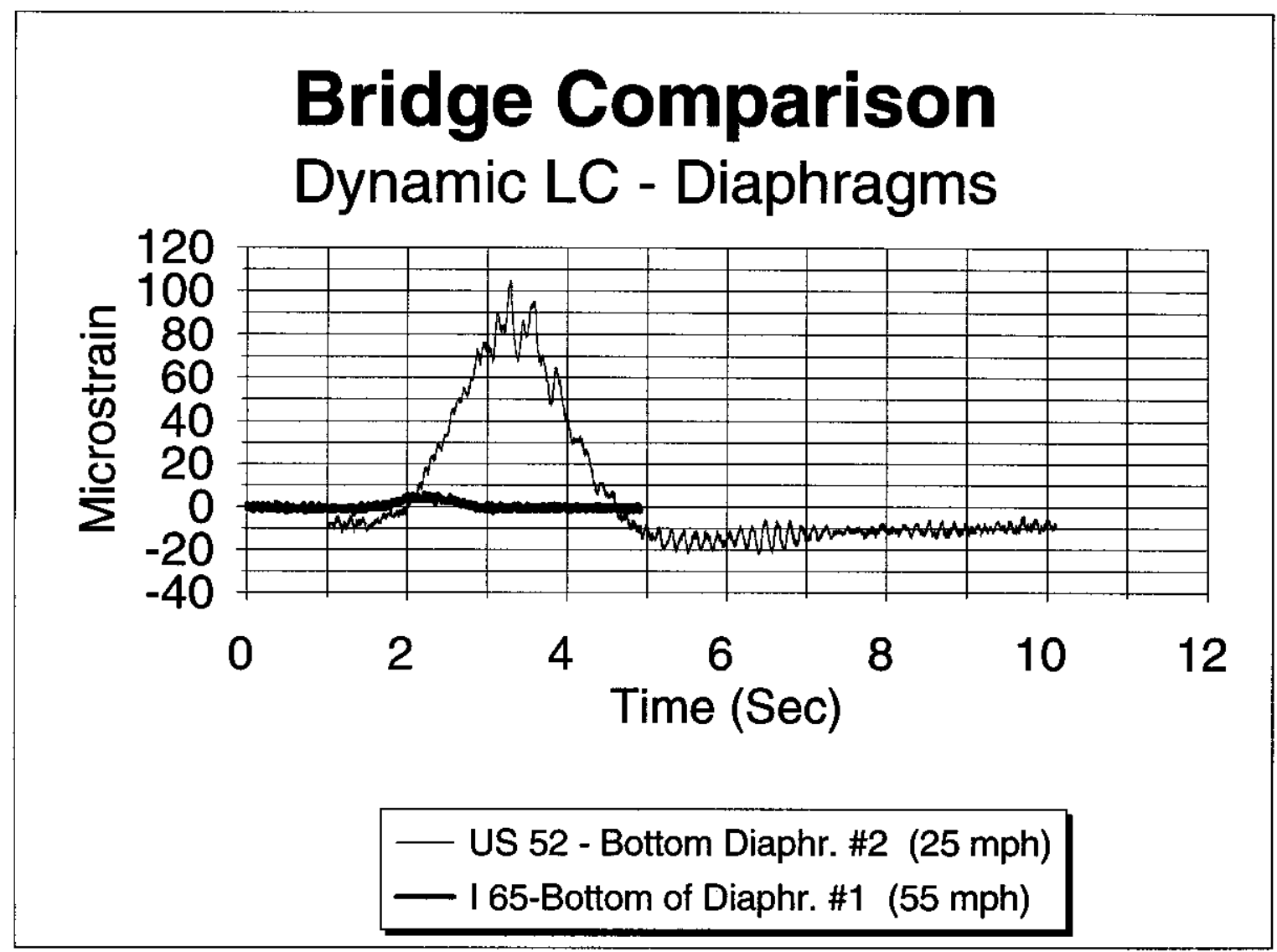

Figure 5.2.2 - Bridge Comparison - Diaphragm Strains for Dynamic Loading Conditions 


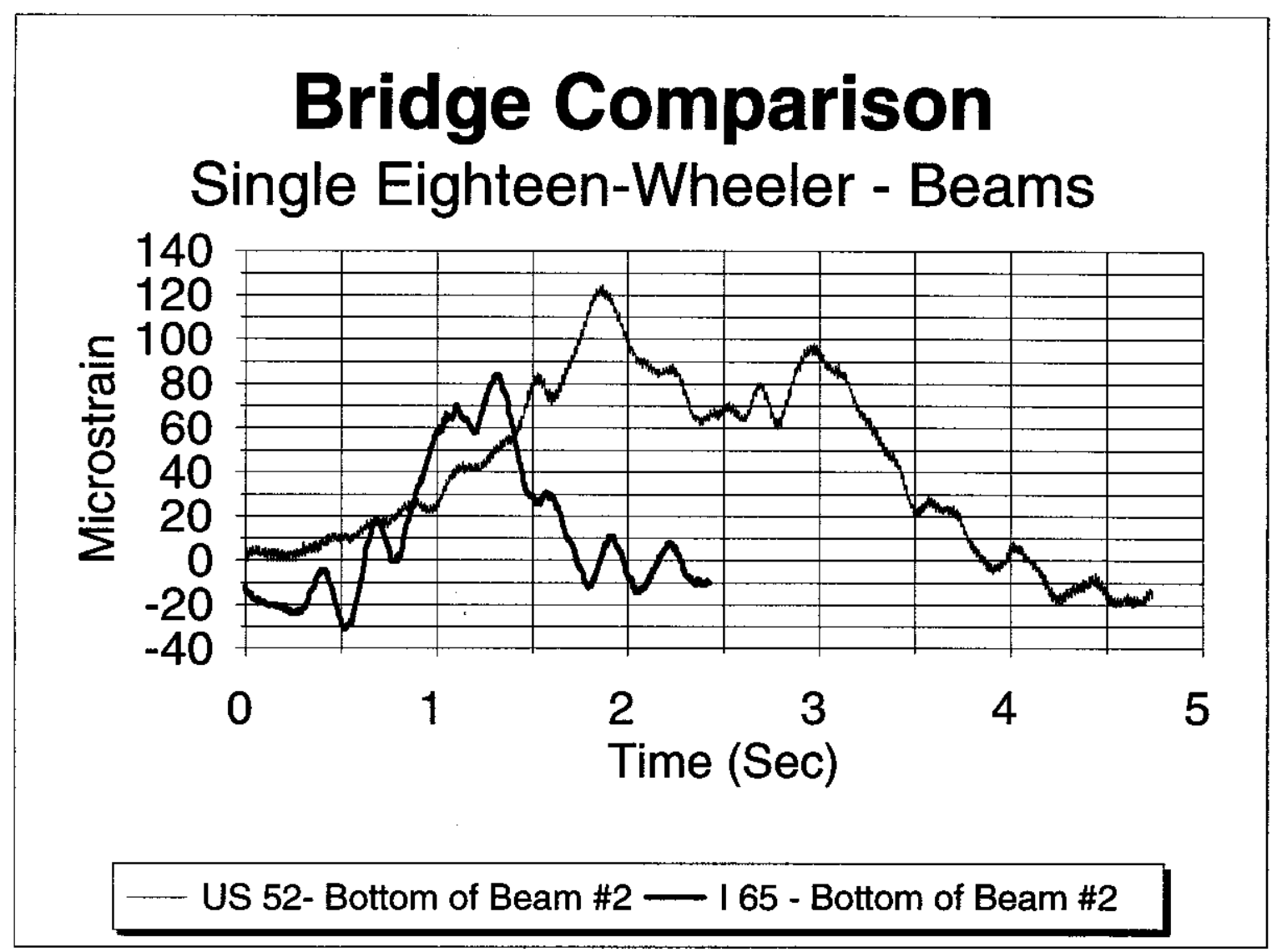

Figure 5.3.1 - Bridge Comparison - Strains at Bottom of Beams for a Single Eighteen-Wheeler 


\section{Bridge Comparison Two Trucks - Beams}

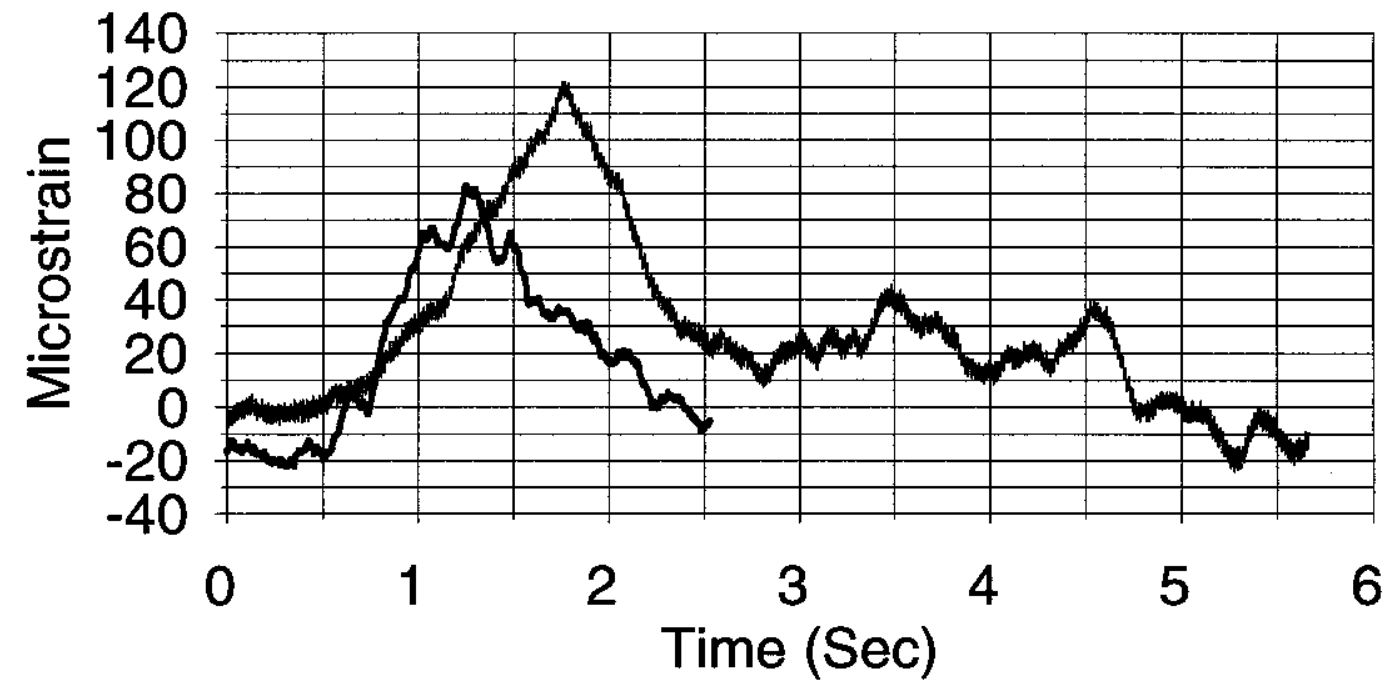

US 52 - Bottom of Beam \#2 - 165 - Bottom of Beam \#2

Figure 5.3.2 - Bridge Comparison - Strains at Bottom of Beams for Two Trucks 


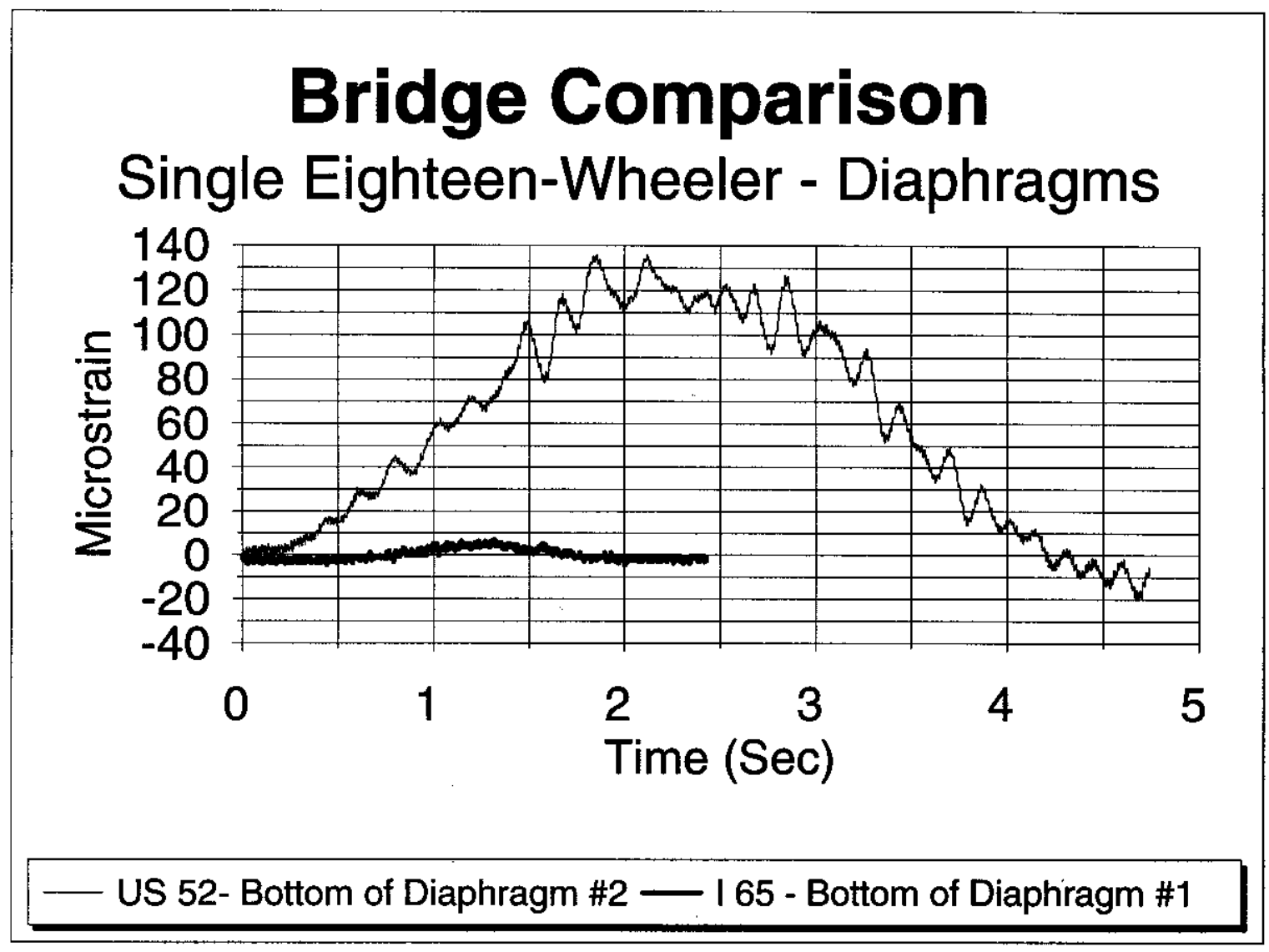

Figure 5.3.3 - Bridge Comparison - Diaphragm Strains for a Single Eighteen-Wheeler 


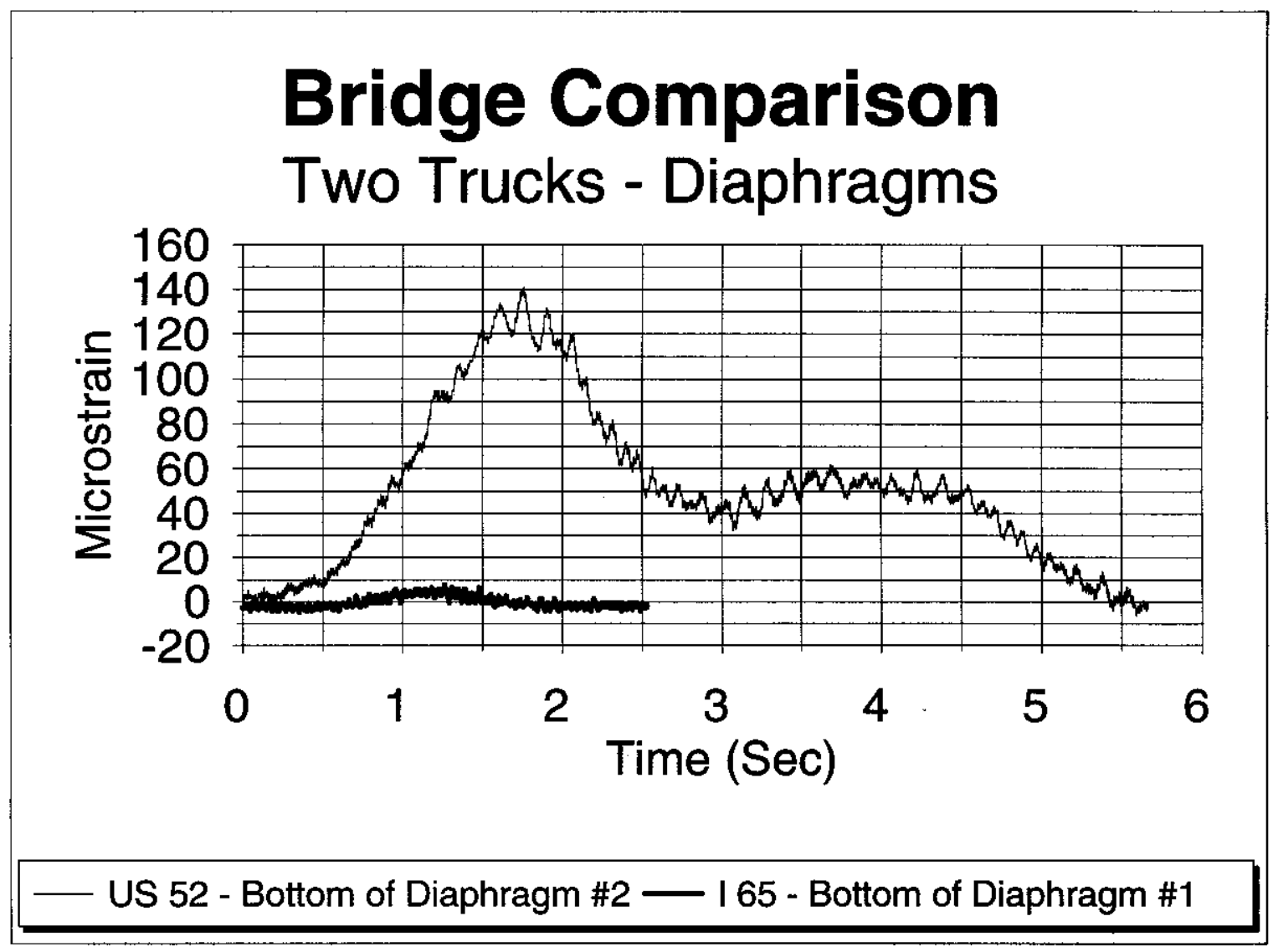

Figure 5.3.4 - Bridge Comparison - Diaphragm Strains for Two Trucks 


\section{Bridge Comparison Shear Force Comparison}

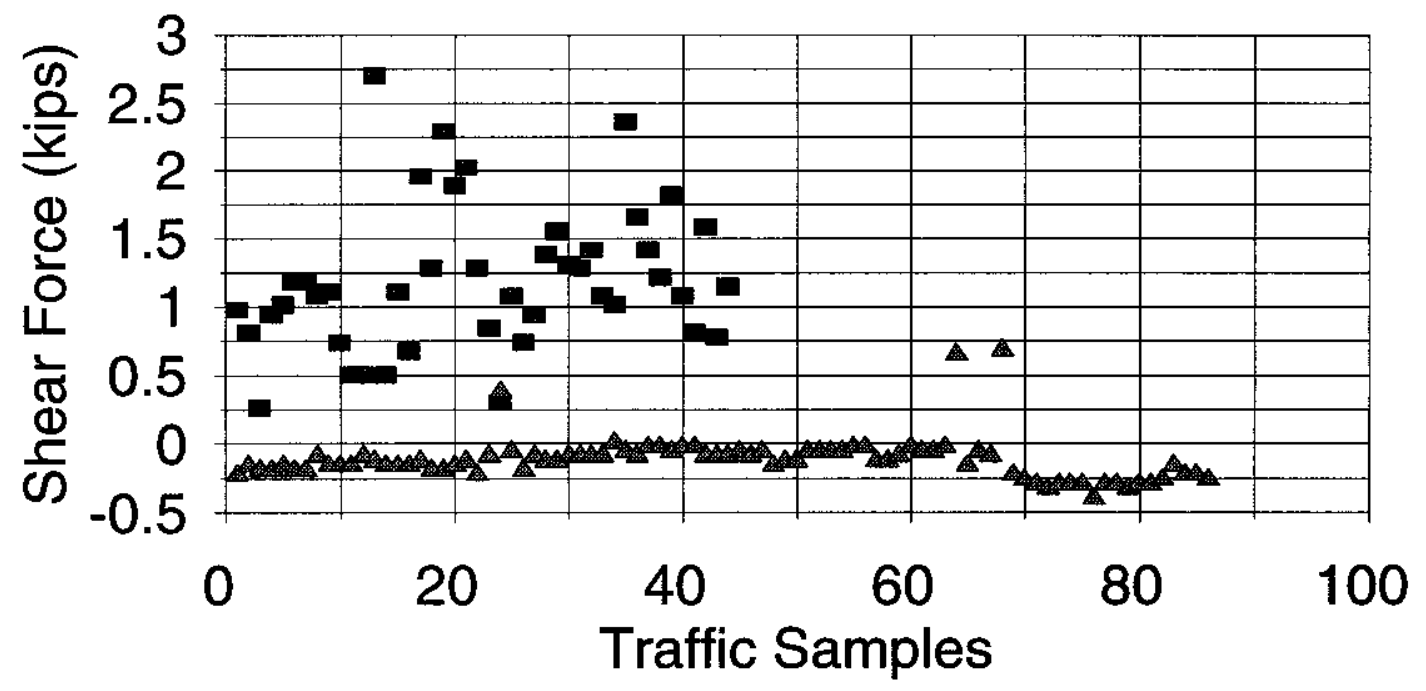

- US 52 - Diaphragm \#2 $\Delta$ I 65 - Diaphragm \#1

Figure 5.3.5 - Bridge Comparison - Shear Force in Diaphragm \#2 of the US 52 Bridge and Diaphragm \#1 of the I 65 Bridge for Traffic Samples 


\section{Bridge Comparison Shear Force Comparison}

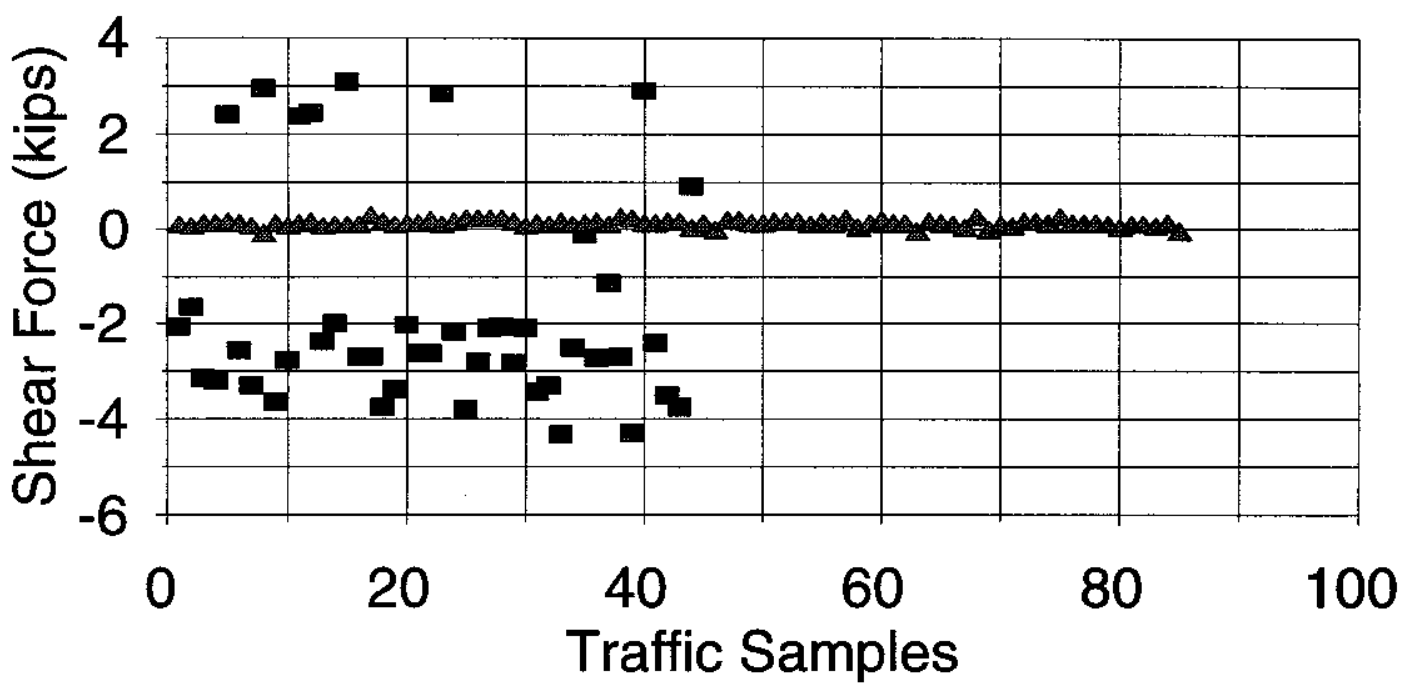

- US 52 - Diaphragm \#3 $\Delta 165$ - Diaphragm \#2

Figure 5.3.6 - Bridge Comparison - Shear Force in Diaphragm \#3 of the US 52 Bridge and Diaphragm \#2 of the I 65 Bridge for Traffic Samples 


\section{CHAPTER 6}

\section{ANALYTICAL TO EXPERIMENTAL COMPARISON}

An attempt was made to reciprocate the experimental results using an analytical program. The development of each bridge model used in the analyses is discussed in this chapter. Results of these analyses are also presented and compared with the experimental data.

\subsection{SAP90 Description and Limitations}

A two-span, three-dimensional model of each bridge was created and tested using the analysis program SAP90 (CSI, 1991). Rolled shapes were modeled as frame elements using either members from the available menu or user defined members created with manually input member properties. To represent continuous members and welded joints, beam-tobeam and diaphragm-to-beam connections were defined as rigid attachments. Fixed supports were modeled by restraining movement in the $\mathrm{x}, \mathrm{y}$, and $\mathrm{z}$ directions at appropriate nodes. Expansion joints were defined by restricting displacement in the $\mathrm{y}$ and $\mathrm{z}$ directions. Loads totaling the measured axle weights were distributed to the beams; load distribution methods will be discussed in the next section. Figures 6.1.1 and 6.1.2 present plan views of each bridge model. 
While creating and testing the computer models, several program limitations were encountered. The available version of SAP90 provides the user with only 100 nodes in which to create a model. It was decided to omit the concrete deck from the bridge models for this reason. To accurately represent the distribution of the truck weight, three loading nodes per beam were needed. So as not to exceed the limit of 100 nodes, a row of diaphragms was removed in the non-loaded span. Under identical loadings, the discrepancy between the forces in the members of interest before and after the diaphragm row removal was insignificant.

Frame elements are modeled using the appropriate member properties specified, such as area and moment of inertia. A linear element implies that the only member dimension utilized in the analyses was length and that the difference in the member depths at the diaphragm-to-beam connections was not recognized. Because the beam web gaps between the diaphragm and the beam flanges were not accounted for, the models were analyzed incorporating diaphragm-to-beam connections that were more rigid than actually exist in the field.

To compare analytical results with experimentally measured data, strains were computed using member forces from the analysis output. In the process, several assumptions were made. When computing beam strains, the concrete deck was assumed to be composite with the longitudinal beams. The use of composite properties is justified because shear studs were placed on the beams in the positive moment region. The following material properties were also assumed: $f_{c}{ }^{\prime}=28 \mathrm{MPa}(4 \mathrm{ksi}), E_{\mathrm{c}}=25,300 \mathrm{MPa}(3670 \mathrm{ksi})$, and $E_{\mathrm{s}}=200,000 \mathrm{MPa}$ $(29,000 \mathrm{ksi})$. 


\subsection{Methods of Load Distribution}

When attempting to model the static loading conditions on each bridge, the question of how to distribute the wheel loads to individual beam members had to be addressed. Initially, each set of axles was placed on a continuous member supported by the appropriate number of beams. Wheel loads were applied to correspond to transverse loading positions, and each beam was represented by a rigid support. This load distribution model was rejected for several reasons. First, it is believed that the stiffness provided by the concrete deck tends to spread the load out to nearby beams more than this initial model represents. Also, denoting the beams as rigidly supporting the concrete deck is unrealistic as deflection of the beams was observed.

Therefore, a load distribution model incorporating beam deflection and the properties of the concrete deck was needed. The following load distribution model will be referred to as load distribution \#1 throughout this report. This model includes a $300 \mathrm{~mm}(1 \mathrm{ft}$.) wide, continuous concrete deck with a thickness corresponding to the bridge being examined. The beams supporting the concrete slab were represented by linear springs; each having a stiffness approximately equal to that of the longitudinal member which it represents. Figure 6.2.1 depicts the load distribution \#1 model for the US 52 bridge. A similar model was used for the load distribution \#1 model for the I 65 bridge. For each bridge, each pair of wheel loads was applied to the appropriate load distribution model at locations correlating with the transverse loading conditions. Spring forces resulting from each loading were then used as the forces applied to the beams in the SAP90 bridge models. 
To provide a lower bound solution, an additional load distribution model was investigated and will be subsequently referred to as load distribution \#2. In this load distribution model, equal load was distributed to each of the beams in both bridge models.

Load distribution \#3 corresponds to the beams acting as rigid supports. This aforementioned model is compared with the other two load distribution models in Table 6.2.1 for the US 52 bridge and Table 6.2 .2 for the I 65 bridge.

\subsection{US 52-Analytical to Experimental Comparison}

Because static loading condition \#3A produced the largest member strains, it was selected as the loading condition to be modeled on SAP90 and then compared to experimental results. Recall that this loading condition locates the rear axles of the dump truck centered over the instrumented diaphragm row. The experimental strain value on the bottom of Beam \#2 was recorded as 91 microstrain. This strain reading is slightly less than a strain value of 99 microstrain predicted using load distribution \#1 but significantly higher than 57 microstrain which was the result when using load distribution \#2. Looking at similar comparisons for the other instrumented members listed in Table 6.3.1, notice that load distribution \#1 provides an upper bound estimate while load distribution \#2 provides a lower bound estimate for the experimental results. Also note that load distribution \#1 yields a more accurate estimate of the beam strain than the diaphragm strains or forces and that predicted diaphragm strains are larger than the predicted beam strain. 
The vertical deflection of Beam \#1 was measured to be $5.41 \mathrm{~mm}(0.213 \mathrm{in}$.). Analyses using load distributions \#1 and \#2 predicted deflections of $18.64 \mathrm{~mm}$ (0.734 in.) and $11.43 \mathrm{~mm}(0.45 \mathrm{in}$.$) , respectively. Because the bridge models did not include the$ concrete deck, the experimental beam deflection was significantly smaller than that predicted utilizing either load distribution in the SAP90 analyses.

When comparing current bridge specifications (AASHTO, 1992) to the load distribution methods used in the above analyses, the design requirements are even more conservative than the loads induced by load distribution \#1. The specifications state that each interior beam should be designed for a live load equaling $45 \%$ of the total weight of the test vehicle, whereas the maximum live load applied to a single beam using load distribution \#1 equals only $41 \%$ of the total weight of the test vehicle.

\subsection{I65 - Analytical to Experimental Comparison}

Although no one loading condition was responsible for a large majority of high strain readings, static loading condition \#1B was selected as the loading condition to be modeled and compared for the I 65 bridge. In loading condition \#1B, the rear axles of the dump truck are centered over Diaphragm \#2. During this loading condition, a strain equaling 71 microstrain was detected on the bottom of Beam \#2. When using load distribution \#1 in the SAP90 analysis, a higher strain of 119 microstrain was predicted at this location. The use of load distribution \#2 resulted in a lower value of 46 microstrain at the bottom of Beam \#2. Table 6.4.1 presents similar comparisons for other instrumented members. Again, load distribution \#1 appears to provide an upper bound estimate, and load distribution \#2 a lower 
bound estimate, for the experimental results. In general, experimental strain and shear values lie approximately half-way between the two load distribution predictions. Estimated diaphragm strains, using either load distribution, are significantly lower than estimated beam strains.

A comparison between beam deflections from the experimental data and the analyses is included in Table 6.4.1. Experimental beam deflections in the I 65 bridge were smaller than deflections predicted utilizing either load distribution model in the SAP90 analyses.

Current bridge design requirements were found to be conservative when looking at the I 65 bridge as well. Specifications state that the interior beams are to be designed for a live load equal to $73 \%$ of the total weight of the test vehicle, whereas the maximum live load applied to a single beam using load distribution \#1 equals only $51 \%$ of the test vehicle's total weight.

\subsection{Discussion of Discrepancies}

Much of the discrepancy between the analytical results and the experimental data can be explained by the analysis limitations discussed in the first section of this chapter. However, another cause for the disparity is the inaccurate way in which the loads were distributed to the beams. Although load distribution \#1 seems practical, the exact distribution of the loads to the beams is uncertain. This uncertainty is a source of error between beam strains predicted using load distribution \#1 and the experimentally recorded data.

When studying Tables 6.3.1 and 6.4.1, note the substantial difference between the 
experimental diaphragm values and those predicted using either load distribution. The majority of this discrepancy is believed to be the result of the inexact modeling of the diaphragm-to-beam connections. An attempt was made to more accurately model the stiffness of this connection by utilizing torsional springs; however, it was discovered that connections between members had to be defined as either hinged (released) or fully rigid (no release). Incorporating the torsional springs and assigning the release option in the SAP90 program resulted in zero force in the diaphragms, while using the no release option with the torsional springs was not practical. Another shortcoming of the analyses was the failure to detect axial force in the diaphragms. Recall that axial strains were measured in the diaphragms of both bridges during load testing.

Discovering discrepancy between experimental data and analytical results is not uncommon. Many researchers, such as Nowak et al. (1993), have been faced with this challenge. However, when using load distribution \#1, the analyses did predict higher diaphragm forces in the bridge with non-staggered diaphragms than those in the skewed bridge with staggered diaphragms. 
Table 6.2.1 Load Distribution Models for Beam Loadings on US 52

\begin{tabular}{|c|c|c|c|}
\hline \multirow{2}{*}{$\begin{array}{c}\text { Beam } \\
\text { Number }\end{array}$} & Model \#1 & Model \#2 & Model \#3 \\
\cline { 2 - 4 } & -0.012 & 0.125 & -0.001 \\
\hline 1 & -0.016 & 0.125 & 0.005 \\
\hline 2 & 0.023 & 0.125 & -0.017 \\
\hline 3 & 0.181 & 0.125 & 0.068 \\
\hline 4 & 0.381 & 0.125 & 0.560 \\
\hline 5 & 0.360 & 0.125 & 0.416 \\
\hline 6 & 0.120 & 0.125 & -0.038 \\
\hline 7 & -0.037 & 0.125 & 0.008 \\
\hline 8 & & & \\
\hline
\end{tabular}

Note: Loads given as a fraction of the total axle weight 
Table 6.2.2 Load Distribution Models for Beam Loadings on I 65

\begin{tabular}{|c|c|c|c|}
\hline \multirow{2}{*}{$\begin{array}{c}\text { Beam } \\
\text { Number }\end{array}$} & Model \#1 & Model \#2 & Model \#3 \\
\cline { 2 - 4 } & -0.017 & 0.167 & 0.0005 \\
\hline \hline 1 & -0.011 & 0.167 & -0.003 \\
\hline 2 & 0.169 & 0.167 & 0.012 \\
\hline 3 & 0.509 & 0.167 & 0.709 \\
\hline 4 & 0.365 & 0.167 & 0.314 \\
\hline 5 & -0.015 & 0.167 & -0.033 \\
\hline 6 & & & \\
\hline
\end{tabular}

Note: Loads given as a fraction of the total axle weight 
Table 6.3.1 US 52 - Analytical to Experimental Comparison

\begin{tabular}{|c|c|c|c|c|}
\hline Member & Strain / Force & Experimental & Load Distr. \#1 & Load Distr. \#2 \\
\hline \hline \multirow{2}{*}{ Diaphragm \#1 } & Strain at Bottom & $37.5 \mu \varepsilon$ & $172 \mu \varepsilon$ & $0 \mu \varepsilon$ \\
\cline { 2 - 5 } & Shear & $2.3 \mathrm{k}$ & $5 \mathrm{k}$ & $0 \mathrm{k}$ \\
\hline \multirow{2}{*}{ Diaphragm \#2 } & Strain at Bottom & $99 \mu \varepsilon$ & $261 \mu \varepsilon$ & $0 \mu \varepsilon$ \\
\cline { 2 - 5 } & Shear & $0.93 \mathrm{k}$ & $0.72 \mathrm{k}$ & $0 \mathrm{k}$ \\
\hline \multirow{2}{*}{ Diaphragm \#3 } & Strain at Bottom & $81.7 \mu \varepsilon$ & $210 \mu \varepsilon$ & $0 \mu \varepsilon$ \\
\cline { 2 - 5 } & Shear & $-2.4 \mathrm{k}$ & $-3.96 \mathrm{k}$ & $0 \mathrm{k}$ \\
\hline Beam \#2 & Strain at Bottom & $90.6 \mu \varepsilon$ & $99 \mu \varepsilon$ & $57 \mu \varepsilon$ \\
\hline
\end{tabular}


Table 6.4.1 I 65 - Analytical to Experimental Comparison

\begin{tabular}{|c|c|c|c|c|}
\hline Member & $\begin{array}{c}\text { Strain / Force / } \\
\text { Deflection }\end{array}$ & Experimental & Load Distr. \#1 & Load Distr. \#2 \\
\hline \hline \multirow{2}{*}{ Diaphragm \#1 } & Strain at Bottom & $5.7 \mu \varepsilon$ & $11.2 \mu \varepsilon$ & $0.27 \mu \varepsilon$ \\
\cline { 2 - 5 } & Shear & $-0.10 \mathrm{k}$ & $-0.04 \mathrm{k}$ & $0 \mathrm{k}$ \\
\hline \multirow{2}{*}{ Diaphragm \#2 } & Strain at Bottom & $5.4 \mu \varepsilon$ & $2.4 \mu \varepsilon$ & $0.32 \mu \varepsilon$ \\
\cline { 2 - 5 } & Shear & $0.40 \mathrm{k}$ & $-0.42 \mathrm{k}$ & $0 \mathrm{k}$ \\
\hline \multirow{2}{*}{ Beam \#1 } & Strain at Bottom & $61.9 \mu \varepsilon$ & $117 \mu \varepsilon$ & $44 \mu \varepsilon$ \\
\cline { 2 - 5 } & Deflection & $0.169 \mathrm{in}$. & $1.06 \mathrm{in}$. & $0.4 \mathrm{in}$. \\
\hline \multirow{2}{*}{ Beam \#2 } & Strain at Bottom & $70.8 \mu \varepsilon$ & $119 \mu \varepsilon$ & $46.1 \mu \varepsilon$ \\
\cline { 2 - 5 } & Deflection & $0.170 \mathrm{in}$. & $1.06 \mathrm{in}$. & $0.41 \mathrm{in}$. \\
\hline Beam \#3 & Strain at Bottom & $68.2 \mu \varepsilon$ & $120 \mu \varepsilon$ & $46.3 \mu \varepsilon$ \\
\hline
\end{tabular}




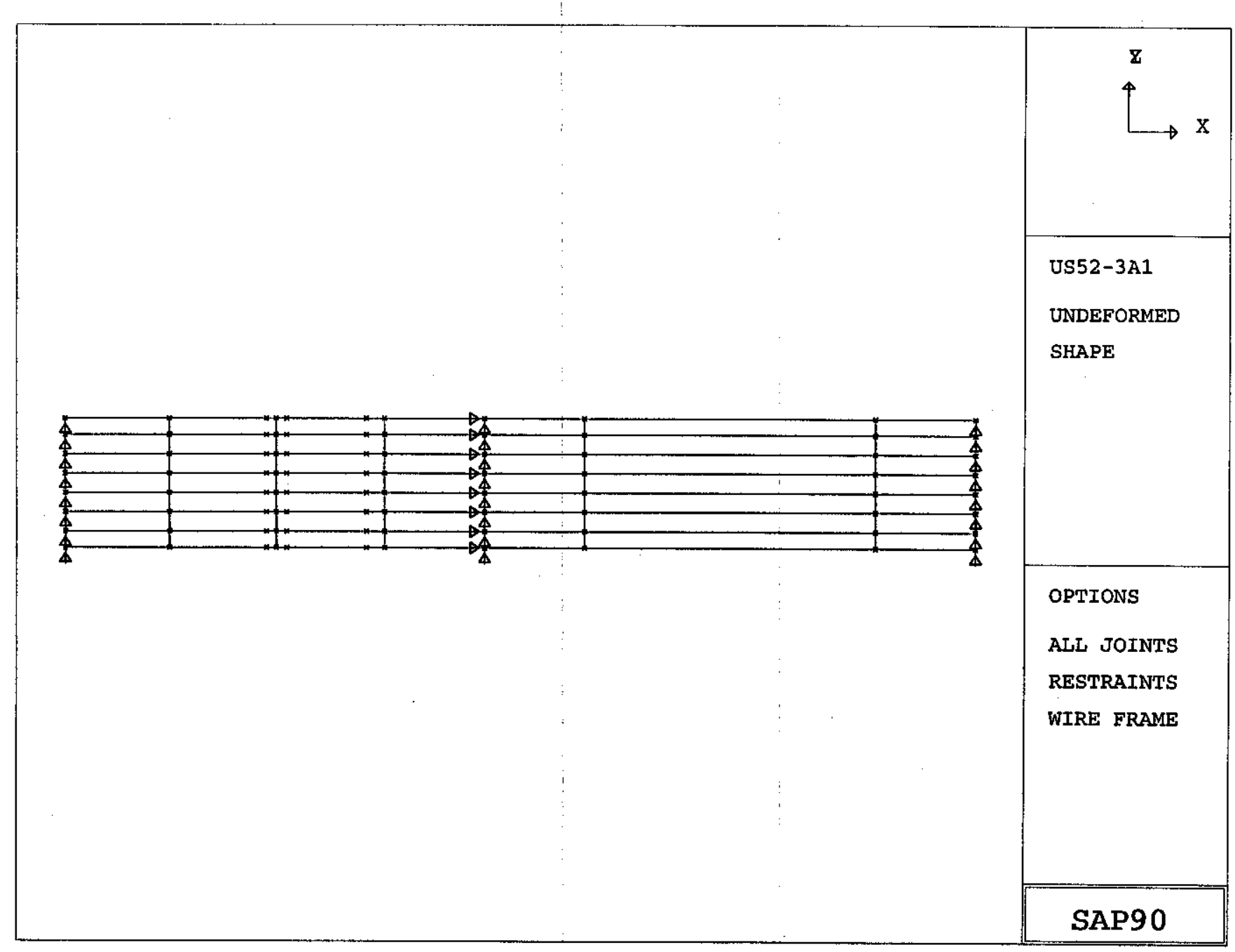

Figure 6.1.1 - US 52 - Plan View of Bridge Model 


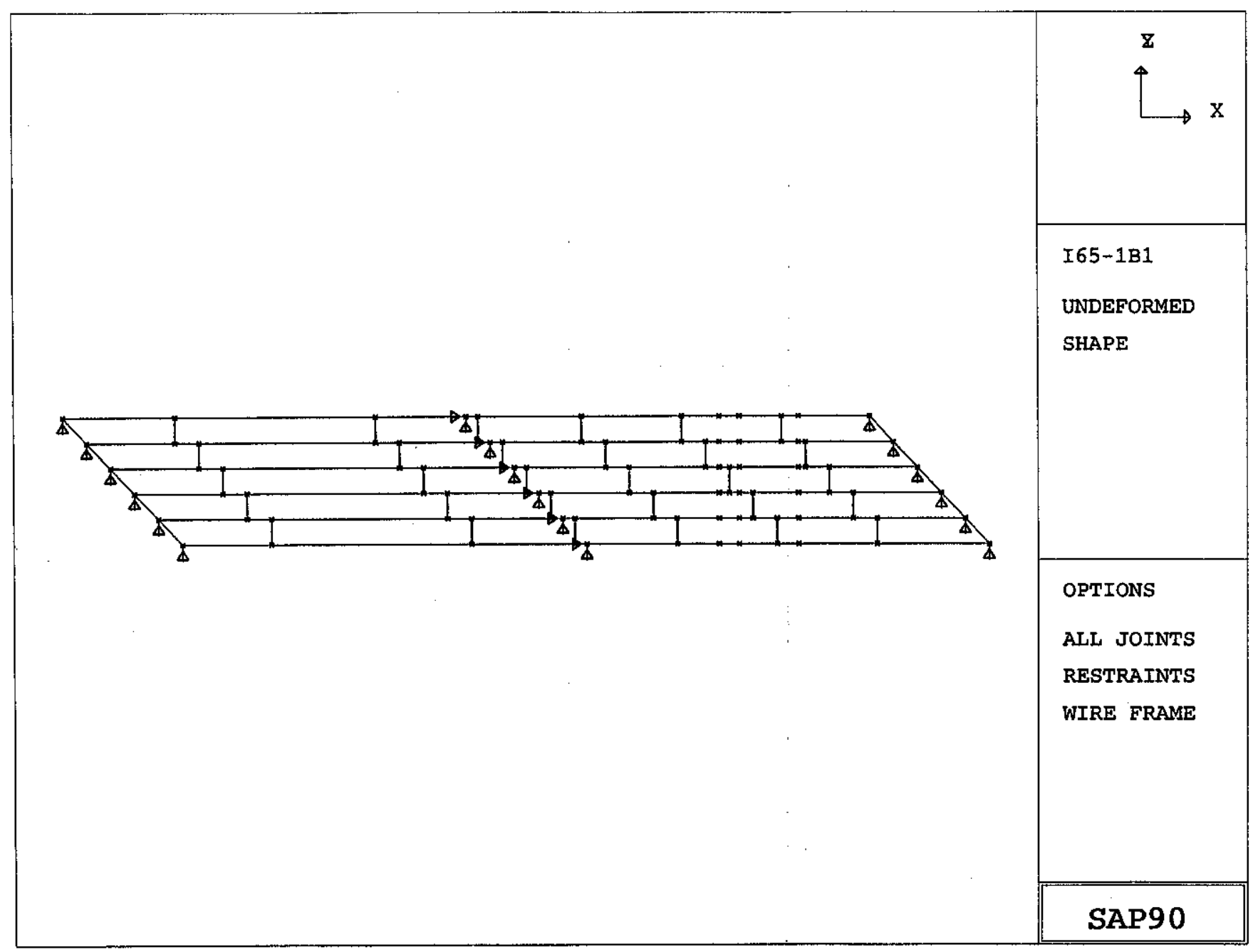

Figure 6.1.2 - I 65 - Plan View of Bridge Model 


\section{US 52 Bridge Load Distribution \#1}

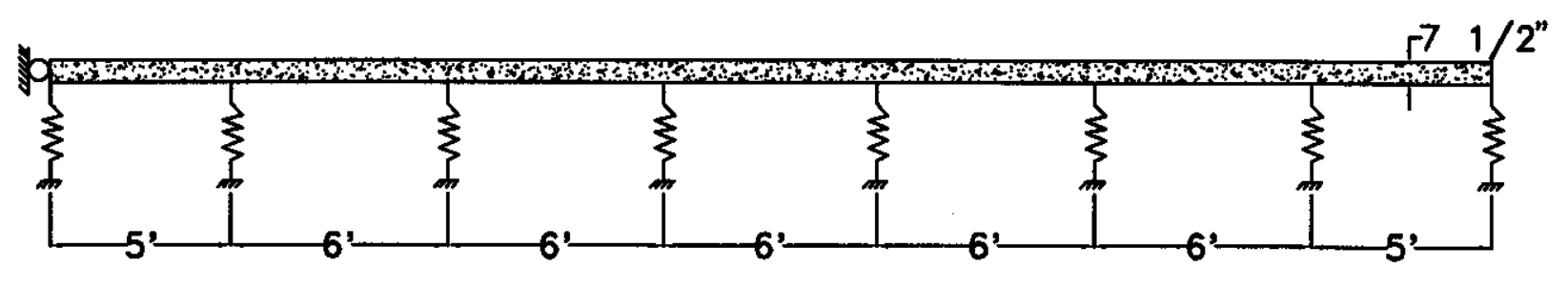

Figure 6.2.1 - US 52 - Load Distribution \#1 Model 


\section{CHAPTER 7}

\section{CONCLUSIONS, RECOMMENDATIONS, IMPLEMENTATION}

\subsection{Conclusions}

When comparing the US 52 bridge to the I 65 bridge, there is a clear difference in diaphragm behavior. Significantly higher strains were observed in the diaphragms of the US 52 bridge than in the $\mathrm{I} 65$ bridge. In the US 52 bridge, diaphragms are situated back-to-back. This orientation causes each diaphragm row to act as a continuous member spanning between exterior beams. The transverse stiffness provided by the "continuous diaphragm" explains the high strain readings in the instrumented diaphragms. Some recorded strain values in the bottom of the diaphragms were even larger than measured beam strains. Diaphragms in the US 52 bridge also experienced significant shear and axial forces. These diaphragm forces are caused by the differential deflection of adjacent longitudinal beams. For these reasons, it is believed that bridges with non-staggered diaphragms are more susceptible to the formation of initial weld cracks in the intermittent fillet welds along the web of the diaphragm than bridges with staggered diaphragms.

Diaphragms in the skewed I 65 bridge are staggered approximately $1700 \mathrm{~mm}(5 \mathrm{ft} .-7$ in.). Because they are staggered, diaphragms in skewed bridges do not have the added stiffness provided by an adjacent diaphragm located directly opposite the beam web. As a result, very low strain readings - bending, axial, and shear strain - were recorded in the 
instrumented diaphragms of the I 65 bridge. However, for the same reasons, staggered diaphragms are not restrained from pushing into the web of a beam as a vehicle passes over an adjacent beam. This behavior was confirmed by significant out-of-plane bending strains recorded in the beam web between the bottom of the diaphragm and the bottom flange of the beam. The large out-of-plane bending strains may cause fatigue cracks to form in the welded diaphragm-to-beam connection in skewed bridges at the fillet weld along the bottom flange of the diaphragm.

Despite the differences in the diaphragm strains, both instrumented bridges did share several behavioral trends:

(a) No significant increase in strain was observed when comparing the static to the dynamic strain measurements caused by the test vehicle of known load for either bridge.

(b) Strain readings corresponding to regular truck traffic were typically larger than the strains caused by the test vehicle and are believed to be due primarily to the increased weight of the vehicle and not a dynamic effect.

(c) Although forces in the US 52 bridge diaphragms were larger than those in the 165 bridge, diaphragms in both bridges experienced axial as well as shear forces.

(d) Out-of-plane bending strains in the beam web between the diaphragm and the bottom flange of the beam were observed in the instrumented beams of both bridges. However, those recorded in the I 65 bridge were larger than those measured in the US 52 bridge. 
(e) The maximum beam strain readings were detected in the strain gages located on the bottom of the beams in both bridges. The maximum strain readings, however, were rather low. When the diaphragm position is taken into account, then the stress range developed at the outermost portions of the beam-to-diaphragm connection would suggest a long fatigue life.

In general, results generated by the SAP90 analyses were representative of the experimental data. A transverse load distribution based upon the flexural stiffness of the beam members provided an upper bound estimate of the experimental data, whereas an equal distribution of the vehicle load to all supporting beam members provided a lower bound estimate. The primary source of discrepancy between the two is probably due to inadequate modeling of the diaphragm-to-beam connection. However, the analyses did predict that higher diaphragm forces would occur in diaphragms situated back-to-back than in those that are staggered in skewed bridges. This analytical prediction of diaphragm behavior correlates well with that obtained from field test results.

\subsection{Recommendations}

The work reported herein was conducted to determine the magnitude of the strains and stresses inferred therefrom - developed in bridges with staggered and non-staggered diaphragm details. The influence of dynamic loading was also examined, with strain data collected for both stationary and moving vehicles with known axle spacings and weight. Additional work, however, must address the influence of cyclic loads on welded diaphragm 
details.

The influence of repetitive loads on the cracking behavior of diaphragms with intermittent fillet welds is being evaluated in a companion effort of this research project (Part I, Vol. 2). The results of the fatigue study, including the behavior of repaired diaphragm details, will be reported separately.

\subsection{Implementation}

Only limited recommendations for implementation can be made until the fatigue damage portion of the study has been completed. However, based on the results of the field survey, it appears that the following recommendations can be suggested for inspection of welded diaphragm members:

(a) For beams with non-stagger diaphragm details, the intermittent welds connecting the diaphragm webs to the beam webs should be inspected to detect the onset of cracking.

(b) For beams with staggered diaphragm details, the diaphragm flange weld especially on the tension side - should be inspected to detect fatigue cracking. 


\section{LIST OF REFERENCES}




\section{LIST OF REFERENCES}

Albrecht, P., Brown, W.P., and Wright, W.J., Analysis of Fatigue Cracking in I-64 Bridges Qver Maury River and Kerr's Creek, Rockbridge County. Virginia, 1991.

Computers and Structures Inc. (CSI), SAP90, Berkeley, California, June, 1991.

Fisher, J.W., Yen, B.T., and Daniels, J.H., Fatigue Damage in the Lehigh Canal Bridge From Displacement-Induced Secondary Stresses, Transportation Research Record 607,1976 , pp. 56-62.

Kato, S., Yoshikawa, O., Terada, H., and Matsumato, Y., Studies on Fatigue Damages Based on Strain Measurements of a Highway Bridge, Proceedings of Japan Society of Civil Engineers, vol. 2, no. 2, October 1985, pp. 199-208.

Koob, M.J. and Walther, R.A., Fatigue Evaluation of the Gerald Desmond Bridge: Long Beach, California, WJE No. 900893, November 1993.

Laman, J.A. and Nowak, A.S., Load Model for Bridge System Reliability, Proceedings of the IFIP WG7.5 Fifth Working Conference on Reliability and Optimization of Structural Systems, Kagawa, Japan, March 24-26, 1993, pp. 149-156.

"Load and Resistance Factor Design", Volume I, Second Edition, American Institute of Steel Construction, Inc., 1994.

Nowak, A.S., Nassif, H., and Frank, K.H., Fatigue Load Spectra for a Steel Girder Bridge, Transportation Research Record n1393, 1993, pp. 154-161.

Rewerts, T.L. and Gaudette, P.E., Field Evaluation of Steel Bridges for Fatigue Damage Due to Secondary Structural Behavior, Official Proceedings of 5th Annual International Bridge Conference, Pittsburgh, PA, June 13-15, 1988, pp. 138-145.

"Standard Specifications for Highway Bridges," Fifteenth Edition, American Association of State Highway and Transportation Officials, 1992. 
Wright, W.J., Nelson, R., and Chase, S., I-64 Over Maury River; Analysis of Fatigue Retrofit Procedures, Turner Fairbank Highway Research Center, McLean, Virginia, 1991.

Zwerneman, F.J., West, A.B., and Lim, K.S., Fatigue Damage to Steel Bridge Diaphragms, ASCE Journal of Performance of Constructed Facilities, vol. 7, no. 4, November 1993, pp. 207-224.

Zwerneman, F.J., West, A.B., and Lim, K.S., "Fatigue Damage to Steel Bridge Diaphragms", Oklahoma State University, Final Report No. FHWA/OK 89(10), December, 1989. 


\section{APPENDIX A}




\section{APPENDIX A}

Appendix A contains dimensions of the fillet and intermittent welds located at the diaphragm-to-beam connections of the instrumented members for each bridge. Weld and leg lengths as well as spacing are included. All dimensions are presented in inches. Dimensions were measured using a $150 \mathrm{~mm}$ ( 6 in.) ruler and calipers. Values presented in decimal form were measured using the calipers, while values shown as a fraction were measured with the ruler. Some entries were omitted due to the inability to obtain precise measurements in awkward positions. 


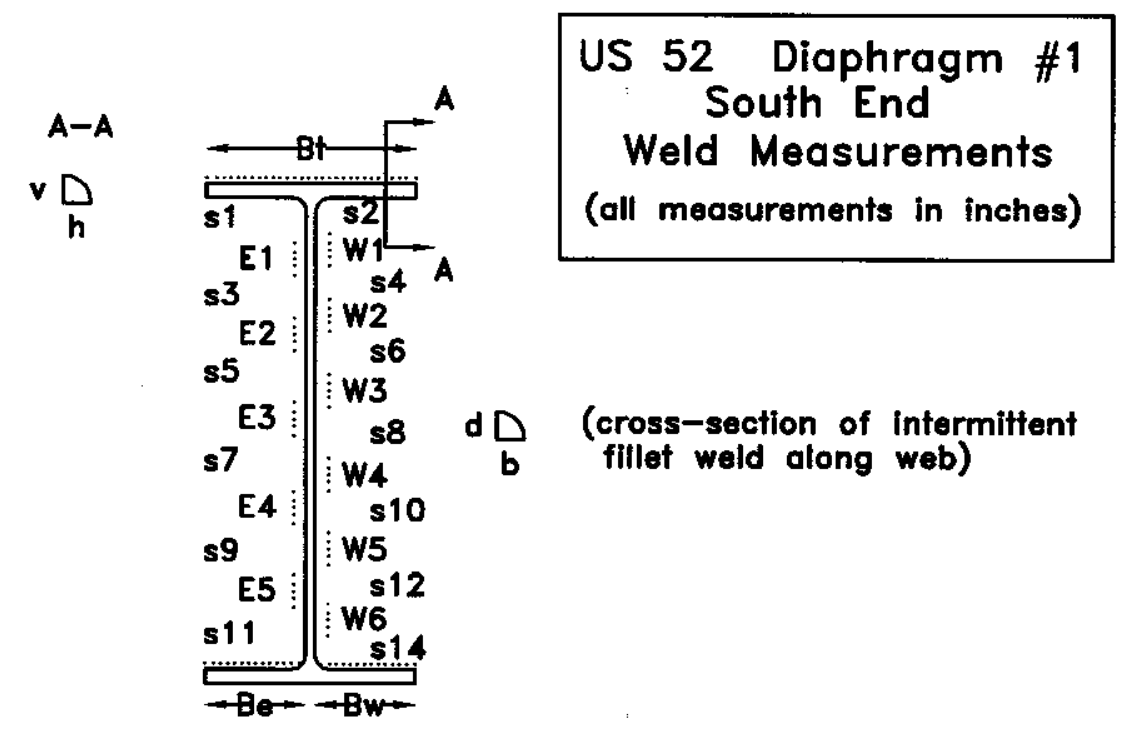

\begin{tabular}{|l|l|c|c||c|c|}
\hline Weld & Length & Leg $v$ or $d$ & Leg $h$ or $b$ & Spacing & Length \\
\hline Bt & $79 / 16$ & $26 / 64$ & $22 / 64$ & $s 1$ & 0.818 \\
\hline Bw & $318 / 64$ & $20 / 64$ & $22 / 64$ & $s 2$ & 0 \\
\hline Be & $334 / 64$ & $20 / 64$ & $20 / 64$ & $s 3$ & 1.898 \\
\hline W1 & 1.142 & $38 / 64$ & $30 / 64$ & $s 4$ & 1.336 \\
\hline W2 & 1.692 & $24 / 64$ & $20 / 64$ & $s 5$ & 1.465 \\
\hline W3 & 2.106 & $24 / 64$ & $30 / 64$ & $s 6$ & 1.324 \\
\hline W4 & 1.660 & $22 / 64$ & $30 / 64$ & $s 7$ & 1.544 \\
\hline W5 & 1.596 & $22 / 64$ & $22 / 64$ & $s 8$ & $18 / 64$ \\
\hline W6 & 1.212 & $28 / 64$ & $24 / 64$ & $s 9$ & 1.479 \\
\hline E1 & 1.992 & $14 / 64$ & $20 / 64$ & $s 10$ & 1.379 \\
\hline E2 & 1.383 & $22 / 64$ & $20 / 64$ & $s 11$ & 1.308 \\
\hline E3 & 1.515 & $18 / 64$ & $18 / 64$ & $s 12$ & 1.512 \\
\hline E4 & 1.796 & $16 / 64$ & $18 / 64$ & $s 13$ & NA \\
\hline E5 & 1.036 & $24 / 64$ & $22 / 64$ & $s 14$ & 0 \\
\hline
\end{tabular}

Figure A.1 - US 52 - South End of Diaphragm \#1 


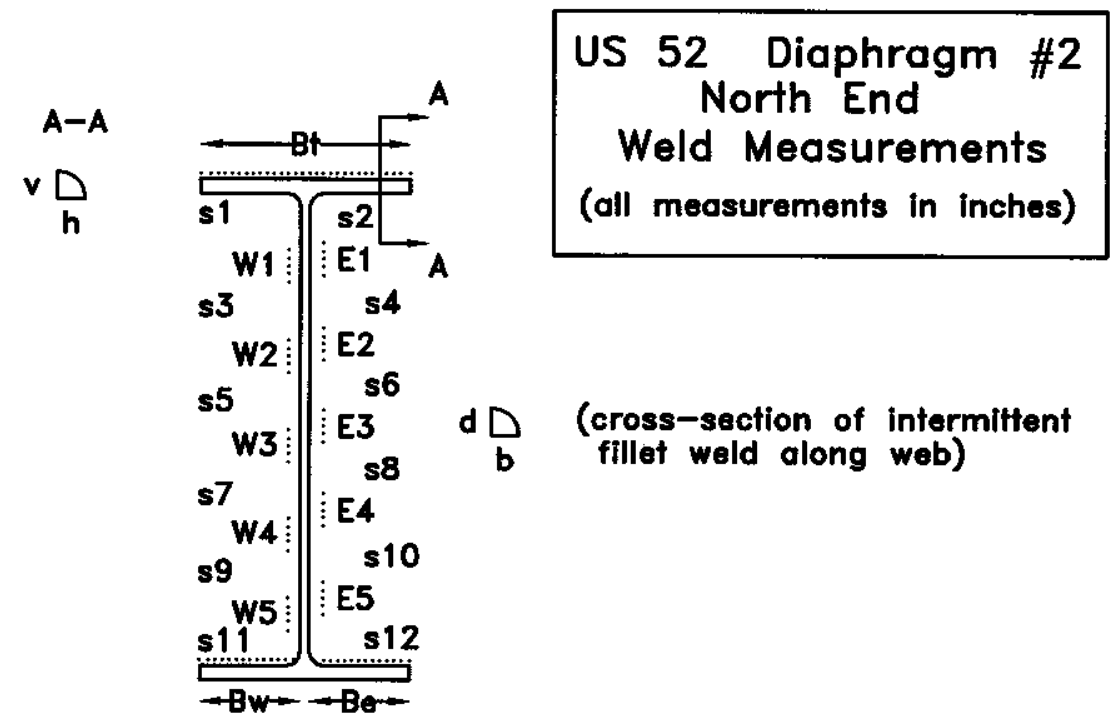

\begin{tabular}{|l|l|c|c||c|c|}
\hline Weld & Length & Leg $v$ or $d$ & Leg $h$ or $b$ & Spacing & Length \\
\hline Bt & 7.50 & $14 / 64$ & $16 / 64$ & $s 1$ & 0.698 \\
\hline Bw & $340 / 64$ & $16 / 64$ & $24 / 64$ & $s 2$ & 0 \\
\hline Be & $334 / 64$ & $22 / 64$ & $20 / 64$ & $s 3$ & 1.272 \\
\hline W1 & 1.975 & $24 / 64$ & $22 / 64$ & $s 4$ & 0.979 \\
\hline W2 & 1.975 & $22 / 64$ & $20 / 64$ & $s 5$ & 1.719 \\
\hline W3 & $224 / 64$ & $18 / 64$ & $18 / 64$ & $s 6$ & 1.828 \\
\hline W4 & 1.899 & $16 / 64$ & $18 / 64$ & $s 7$ & 1.242 \\
\hline W5 & 2.028 & $20 / 64$ & $18 / 64$ & $s 8$ & 1.279 \\
\hline E1 & 1.551 & $22 / 64$ & $22 / 64$ & $s 9$ & 1.021 \\
\hline E2 & 2.312 & $20 / 64$ & $24 / 64$ & $s 10$ & 1.332 \\
\hline E3 & 1.600 & $20 / 64$ & $22 / 64$ & $s 11$ & 0 \\
\hline E4 & 2.050 & $24 / 64$ & $20 / 64$ & $s 12$ & 1.263 \\
\hline E5 & 2.122 & $20 / 64$ & $18 / 64$ & & \\
\hline
\end{tabular}

Figure A.2 - US 52 - North End of Diaphragm \#2 


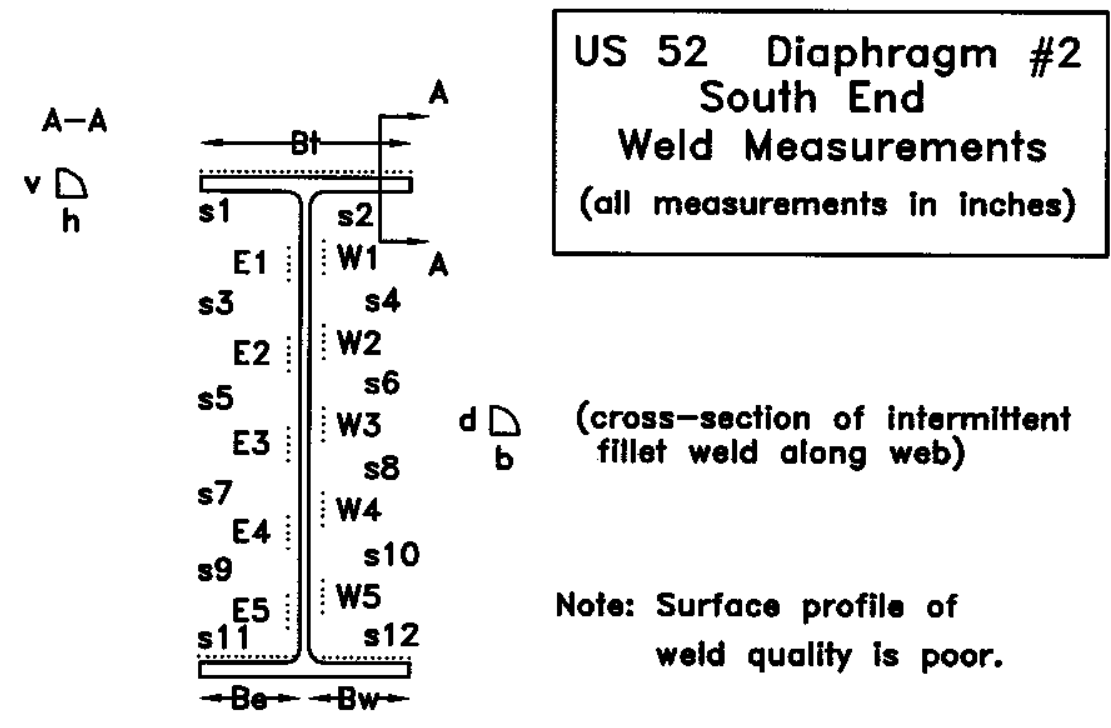

\begin{tabular}{|l|l|c|c||c|c|}
\hline Weld & Length & Leg $v$ or $d$ & Leg $h$ or $b$ & Spacing & Length \\
\hline Bt & $* * *$ & $22 / 64$ & & $s 1$ & 0 \\
\hline Bw & $334 / 64$ & $18 / 64$ & $12 / 64$ & $s 2$ & 0 \\
\hline Be & $324 / 64$ & $20 / 64$ & $22 / 64$ & $s 3$ & 1.094 \\
\hline W1 & $118 / 64$ & $22 / 64$ & $20 / 64$ & $s 4$ & 1.186 \\
\hline W2 & 2.078 & $20 / 64$ & $22 / 64$ & $s 5$ & 2.030 \\
\hline W3 & 2.240 & $22 / 64$ & $20 / 64$ & $s 6$ & 1.606 \\
\hline W4 & 1.953 & $20 / 64$ & $22 / 64$ & $s 7$ & 2.630 \\
\hline W5 & 1.504 & $26 / 64$ & $18 / 64$ & $s 8$ & 2.770 \\
\hline E1 & 1.318 & $22 / 64$ & & $s 9$ & 1.174 \\
\hline E2 & 2.348 & $22 / 64$ & $24 / 64$ & $s 10$ & 1.657 \\
\hline E3 & $24 / 64$ & $22 / 64$ & $22 / 64$ & $s 11$ & 0 \\
\hline E4 & 2.336 & $24 / 64$ & $22 / 64$ & $s 12$ & 0 \\
\hline E5 & 1.269 & $24 / 64$ & $22 / 64$ & & \\
\hline
\end{tabular}

*** $141 / 64$ in. on east and and $146 / 64$ in. over web

Figure A.3 - US 52 - South End of Diaphragm \#2 


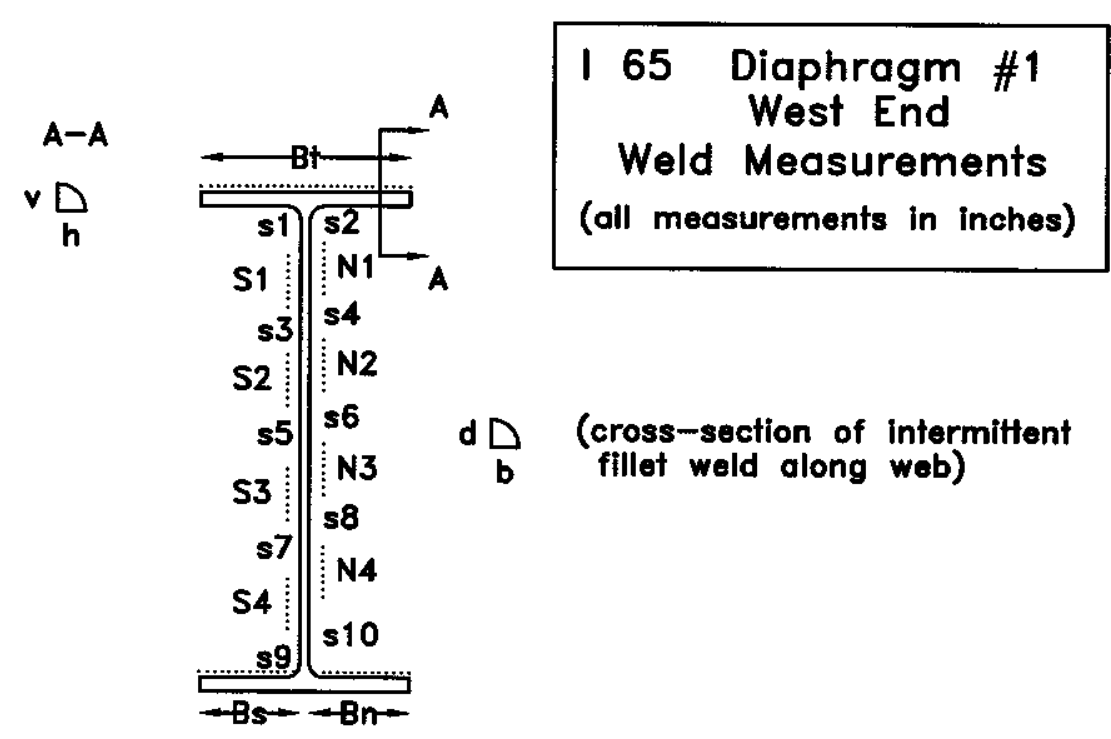

\begin{tabular}{|l|l|c|c||c|c|}
\hline Wold & Length & Leg $v$ or $d$ & Leg $h$ or $b$ & Spacing & Length \\
\hline B 1 & $710 / 16$ & $22 / 64$ & $20 / 64$ & $s 1$ & 0.423 \\
\hline Bn & 3.248 & $16 / 64$ & $14 / 64$ & $s 2$ & 1.532 \\
\hline Bs & $340 / 64$ & $24 / 64$ & $16 / 64$ & $s 3$ & 1.344 \\
\hline N1 & 1.918 & $16 / 64$ & $24 / 64$ & $s 4$ & 1.706 \\
\hline N2 & 2.057 & $16 / 64$ & $18 / 64$ & $s 5$ & 1.342 \\
\hline N3 & 2.056 & $20 / 64$ & $20 / 64$ & $s 6$ & 2.344 \\
\hline N4 & 1.827 & $14 / 64$ & $16 / 64$ & $s 7$ & 1.670 \\
\hline S1 & 1.426 & $18 / 64$ & $16 / 64$ & $s 8$ & 2.526 \\
\hline S2 & 1.980 & $20 / 64$ & $16 / 64$ & $s 9$ & 2.056 \\
\hline S3 & 2.234 & $18 / 64$ & $18 / 64$ & $s 10$ & 0 \\
\hline S4 & 2.924 & $18 / 64$ & $20 / 64$ & & \\
\hline
\end{tabular}

Figure A.4 - I 65 - West End of Diaphragm \#1 


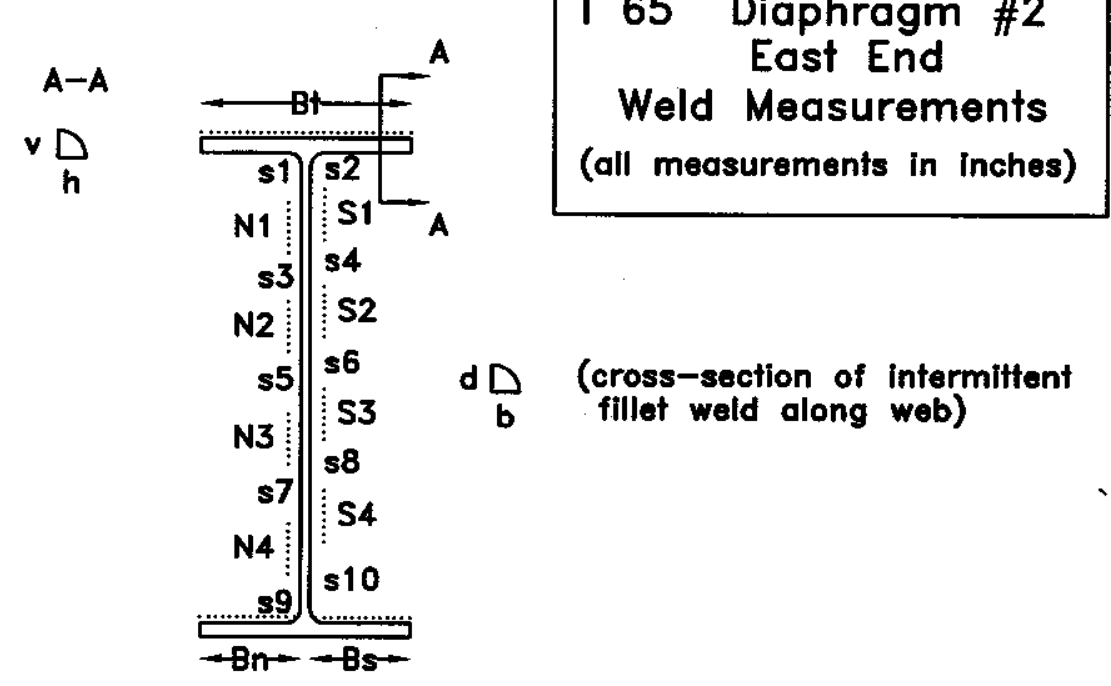

\begin{tabular}{|l|l|c|c||c|c|}
\hline Weld & Length & Leg $v$ or $d$ & Leg $h$ or $b$ & Spocing & Length \\
\hline Bt & & & & $s 1$ & 1.974 \\
\hline Bn & $332 / 64$ & $32 / 64$ & $14 / 64$ & $s 2$ & 0 \\
\hline Bs & $340 / 64$ & $28 / 64$ & $22 / 64$ & $s 3$ & 1.678 \\
\hline N1 & 1.859 & $18 / 64$ & $14 / 64$ & $s 4$ & 1.478 \\
\hline N2 & $238 / 64$ & $16 / 64$ & $16 / 64$ & $s 5$ & $48 / 64$ \\
\hline N3 & 2.875 & $14 / 64$ & $14 / 64$ & $s 6$ & 2.002 \\
\hline N4 & $240 / 64$ & $20 / 64$ & $22 / 64$ & $s 7$ & 2.118 \\
\hline S1 & 1.469 & & & $s 8$ & 2.155 \\
\hline S2 & 2.352 & & & $s 9$ & 0 \\
\hline S3 & $24 / 64$ & & & $s 10$ & 2.176 \\
\hline S4 & 2.540 & & & & \\
\hline
\end{tabular}

Figure A.5 - I 65 - East End of Diaphragm \#2 


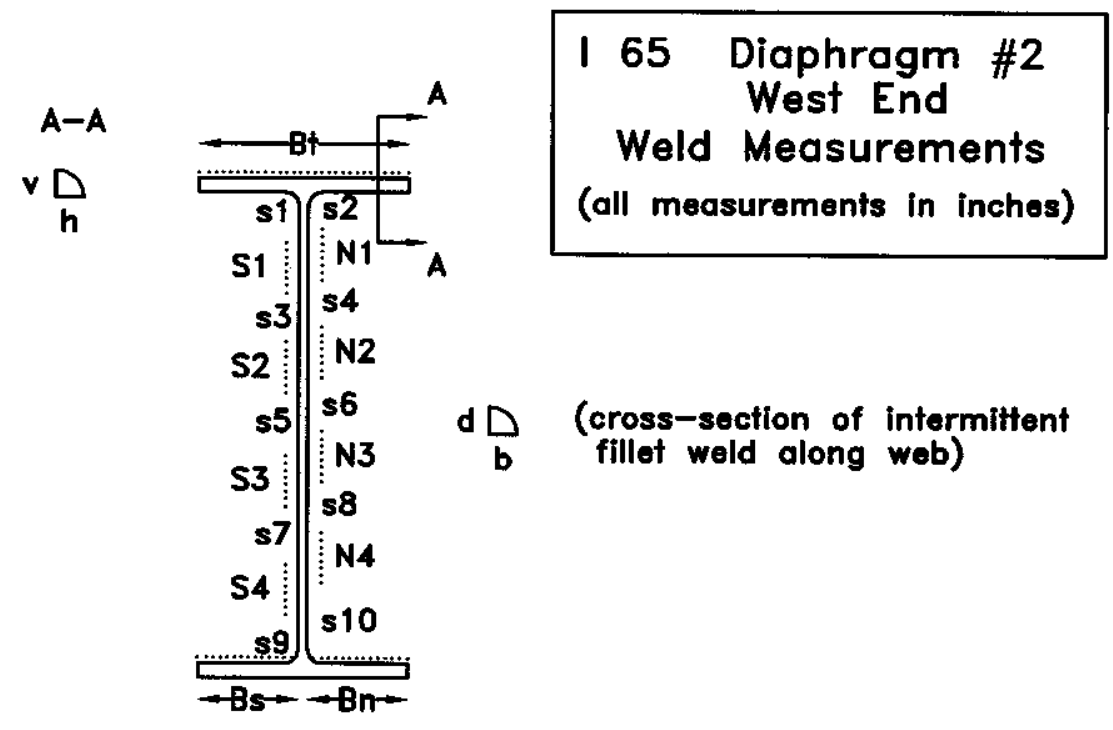

\begin{tabular}{|l|l|c|c||c|c|}
\hline Weld & Length & Leg $v$ or $d$ & Leg $h$ or $b$ & Spacing & Longth \\
\hline Bt & & $24 / 64$ & $24 / 64$ & $s 1$ & 0 \\
\hline Bn & $340 / 64$ & $22 / 64$ & $18 / 64$ & $s 2$ & 0.927 \\
\hline Bs & $340 / 64$ & $30 / 64$ & $16 / 64$ & $s 3$ & 1.066 \\
\hline N1 & 2.227 & $14 / 64$ & $18 / 64$ & $s 4$ & 1.657 \\
\hline N2 & 1.978 & $14 / 64$ & $20 / 64$ & $s 5$ & 2.188 \\
\hline N3 & 2.292 & $18 / 64$ & $18 / 64$ & $s 6$ & $216 / 64$ \\
\hline N4 & 2.332 & $18 / 64$ & $18 / 64$ & $s 7$ & 1.733 \\
\hline S1 & $140 / 64$ & $16 / 64$ & & $s 8$ & 2.438 \\
\hline S2 & 2.410 & $18 / 64$ & $20 / 64$ & $s 9$ & 2.665 \\
\hline S3 & $236 / 64$ & $14 / 64$ & $16 / 64$ & $s 10$ & 0 \\
\hline S4 & 2.486 & $18 / 64$ & $20 / 64$ & & \\
\hline
\end{tabular}

Figure A. 6 - I 65 - West End of Diaphragm \#2 
APPENDIX B 


\section{APPENDIX B}

Appendix B presents an elevation view of each bridge including the span lengths. The instrumented span is designated on both elevation views. Additional photographs taken at the bridge sites are included also. These figures depict actual beam strain gage locations and the typical set up during load testing. 


\section{US 52 Elevation}

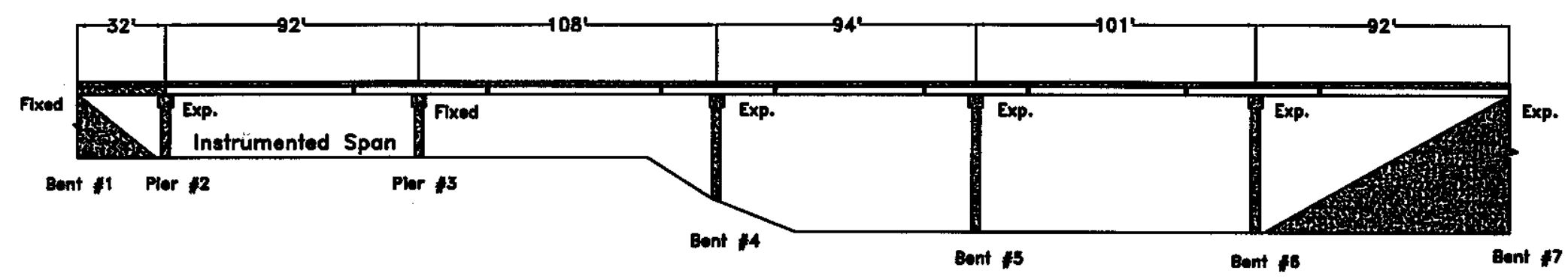

Figure B.1 - US 52 - Elevation View 


\section{65 Elevation}

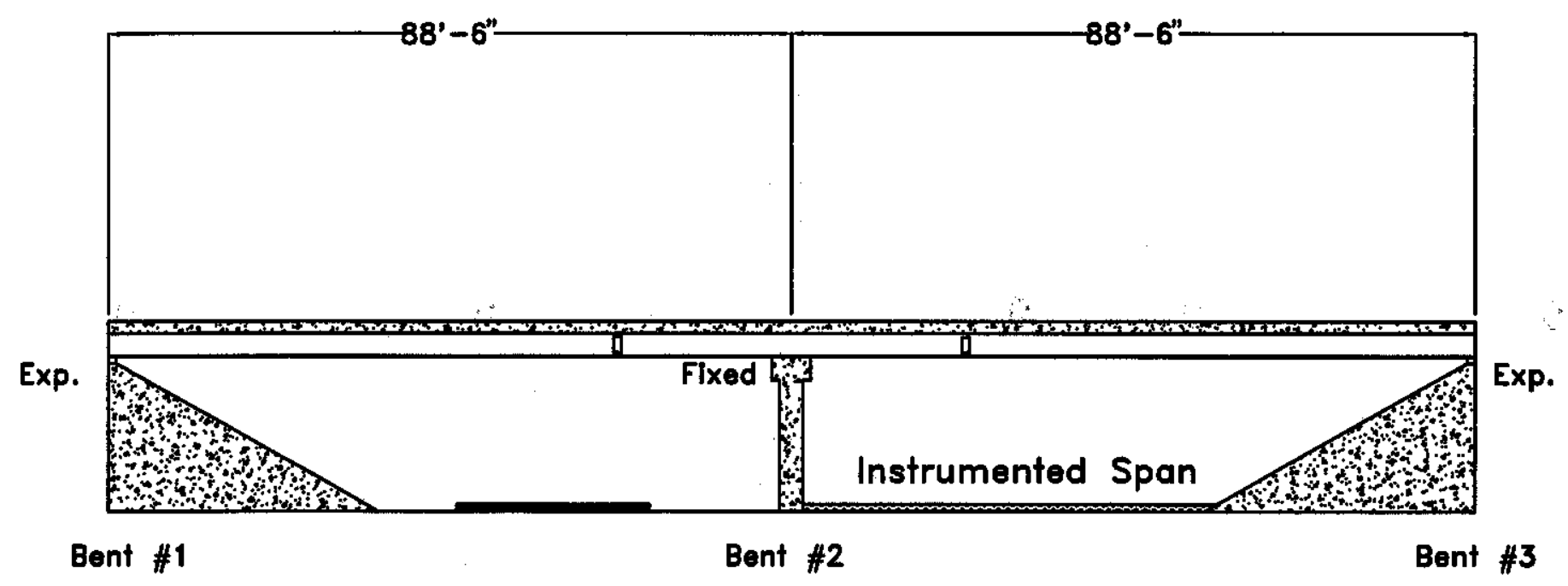

Figure B.2 - I 65 - Elevation View 


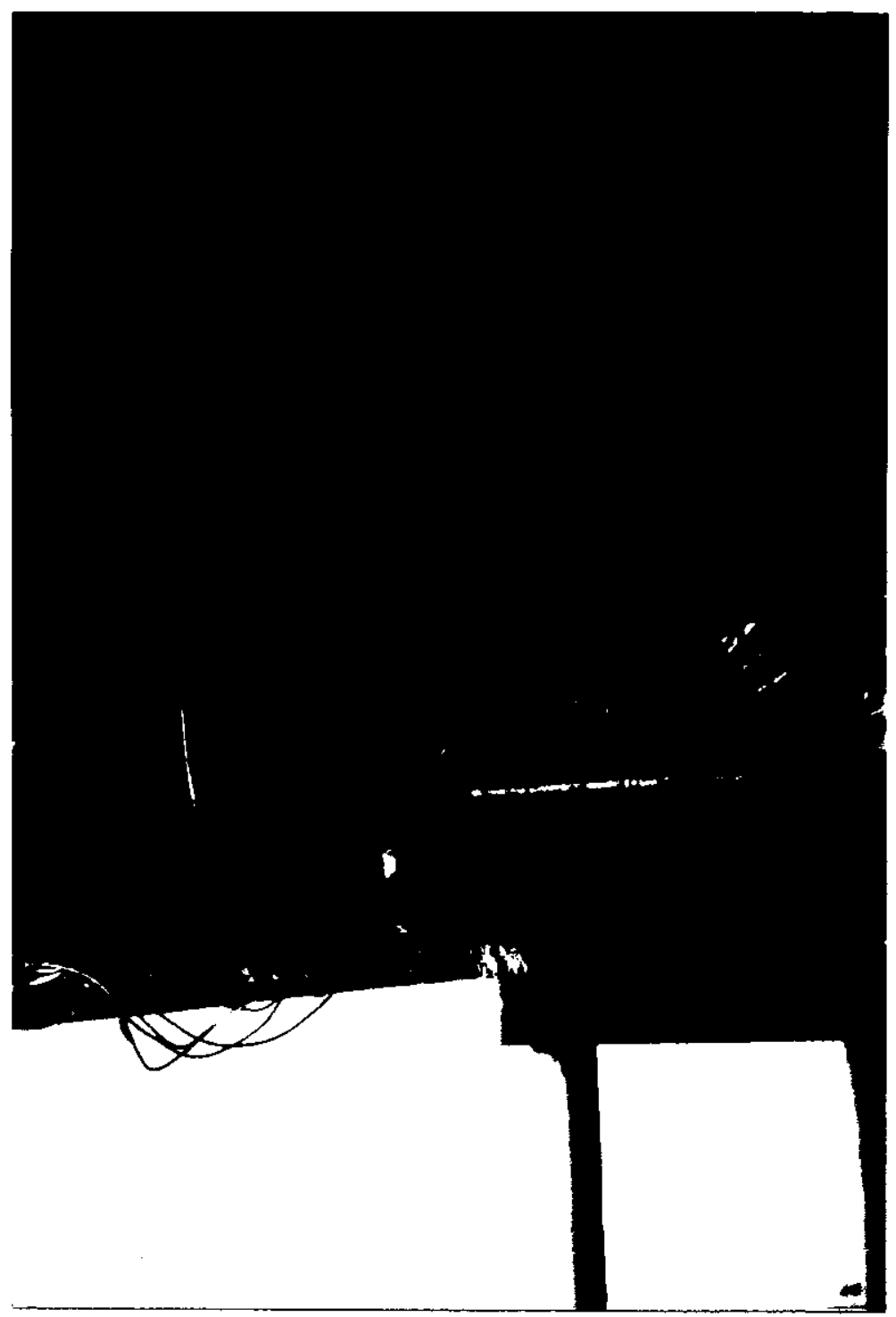

Figure B.3 - I 65 - Beam Strain Gages 


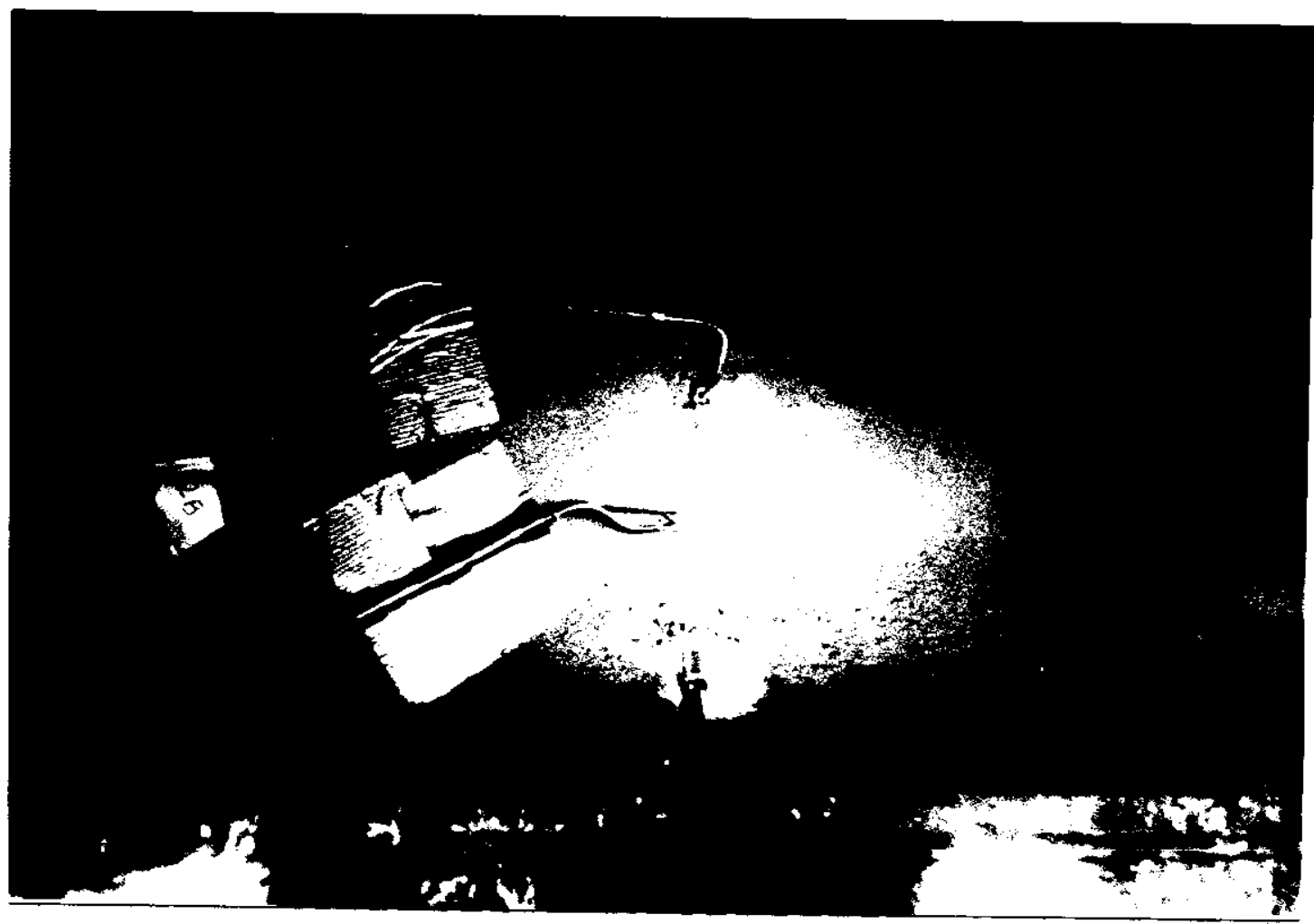

Figure B.4 - I 65 - Orientation of Beam Web Gages 


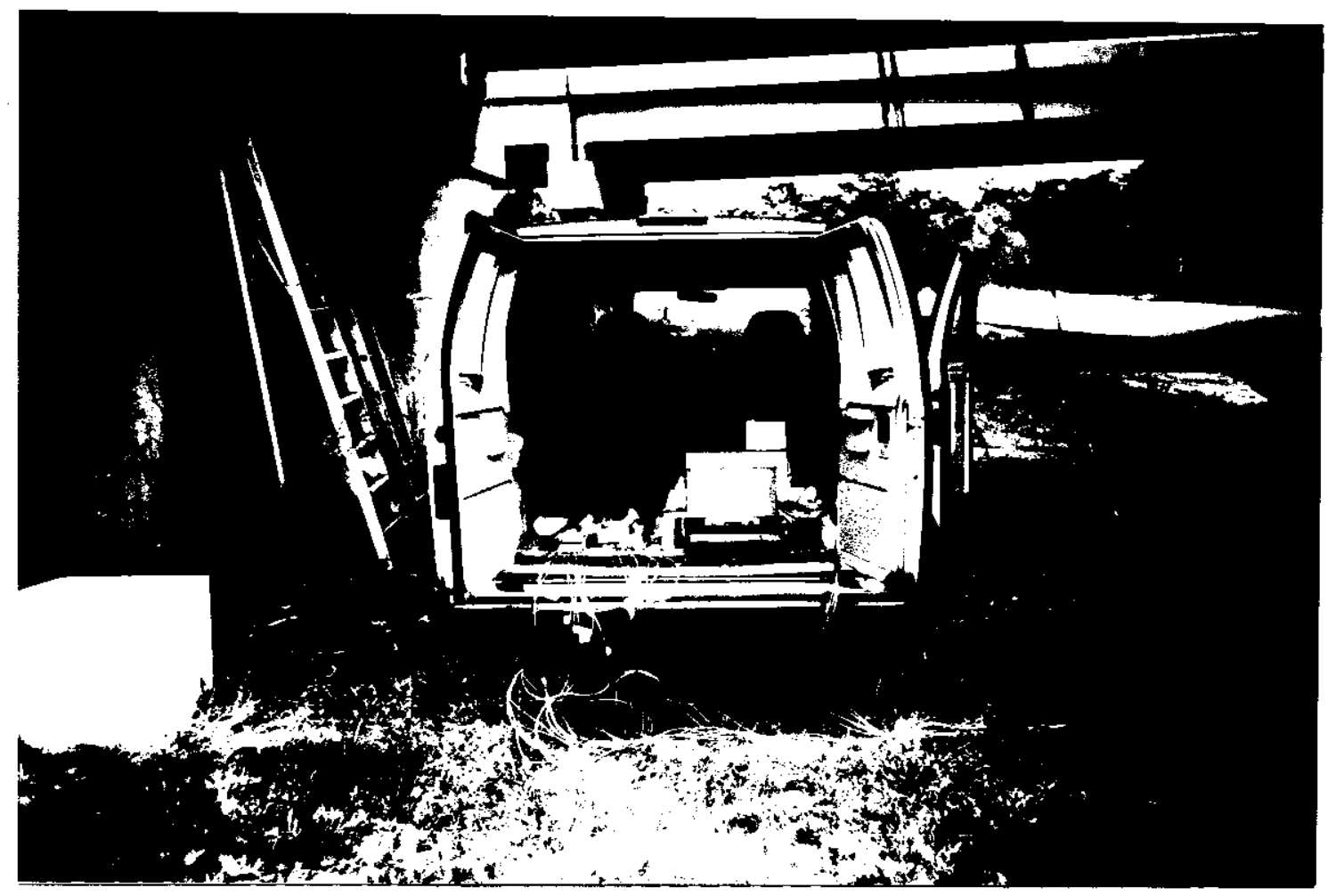

Figure B.5 - Data Acquisition System Set Up 


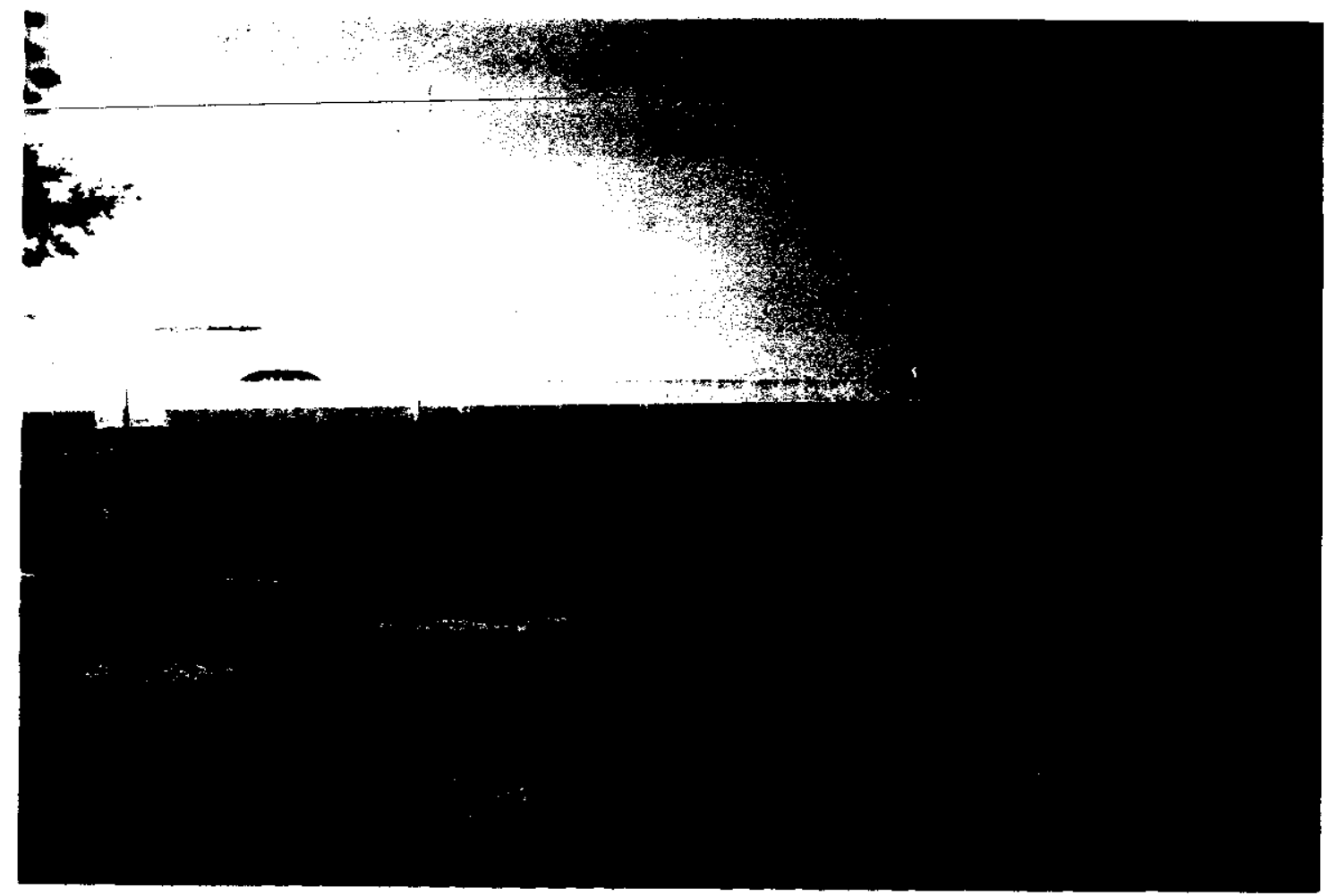

Figure B.6 - US 52 - Side View of Bridge 


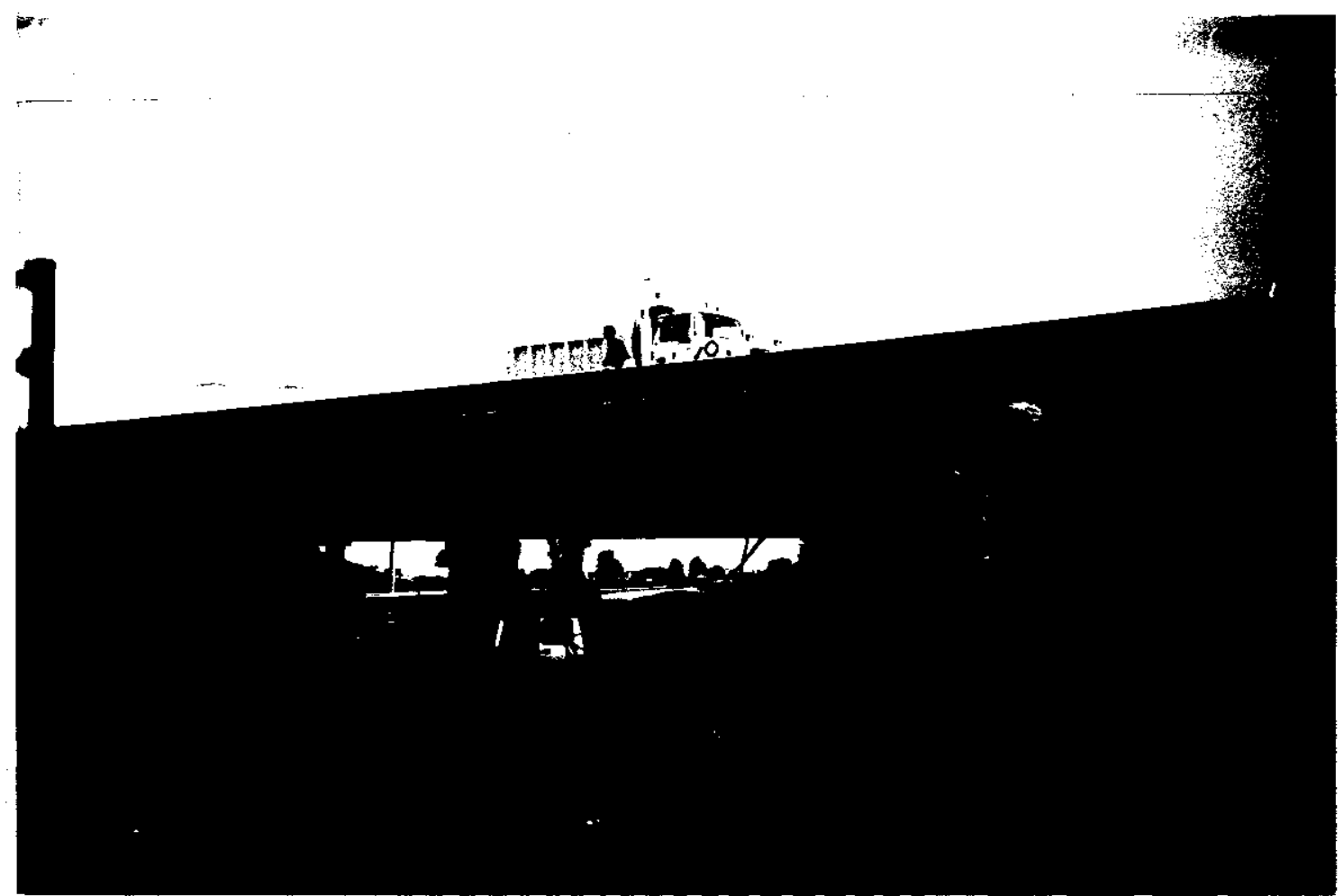

Figure B.7 - I 65 - Typical Set Up for a Static Loading Condition 
APPENDIX C 


\section{APPENDIX C}

Appendix $\mathrm{C}$ includes additional experimental data not presented in the main text.

The relationship between shear force and truck position for static loading conditions is presented here. 


\section{US 52}

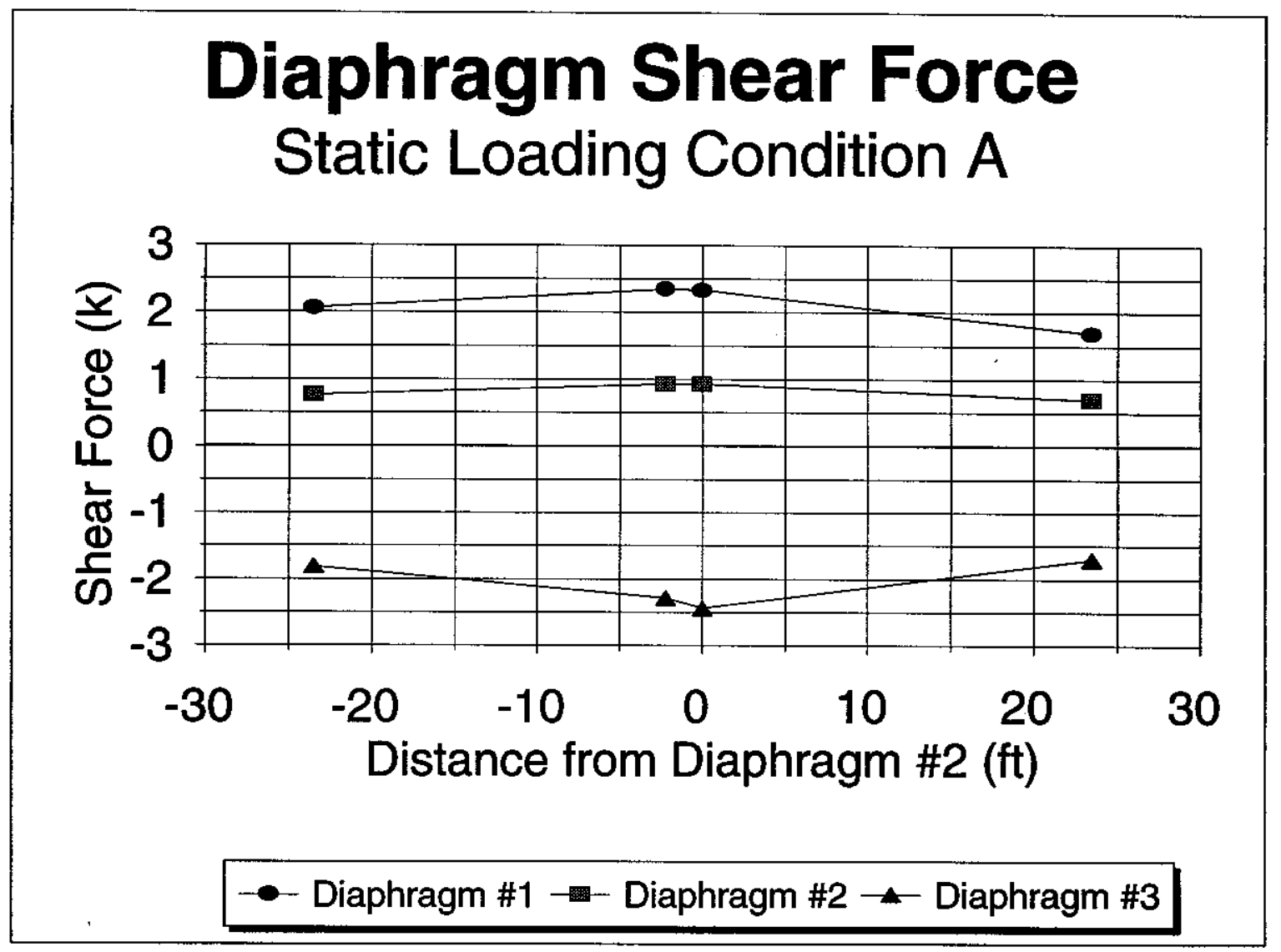

Figure C. 1 - US 52 - Diaphragm Shear Forces for Static Loading Condition A 


\section{US 52}

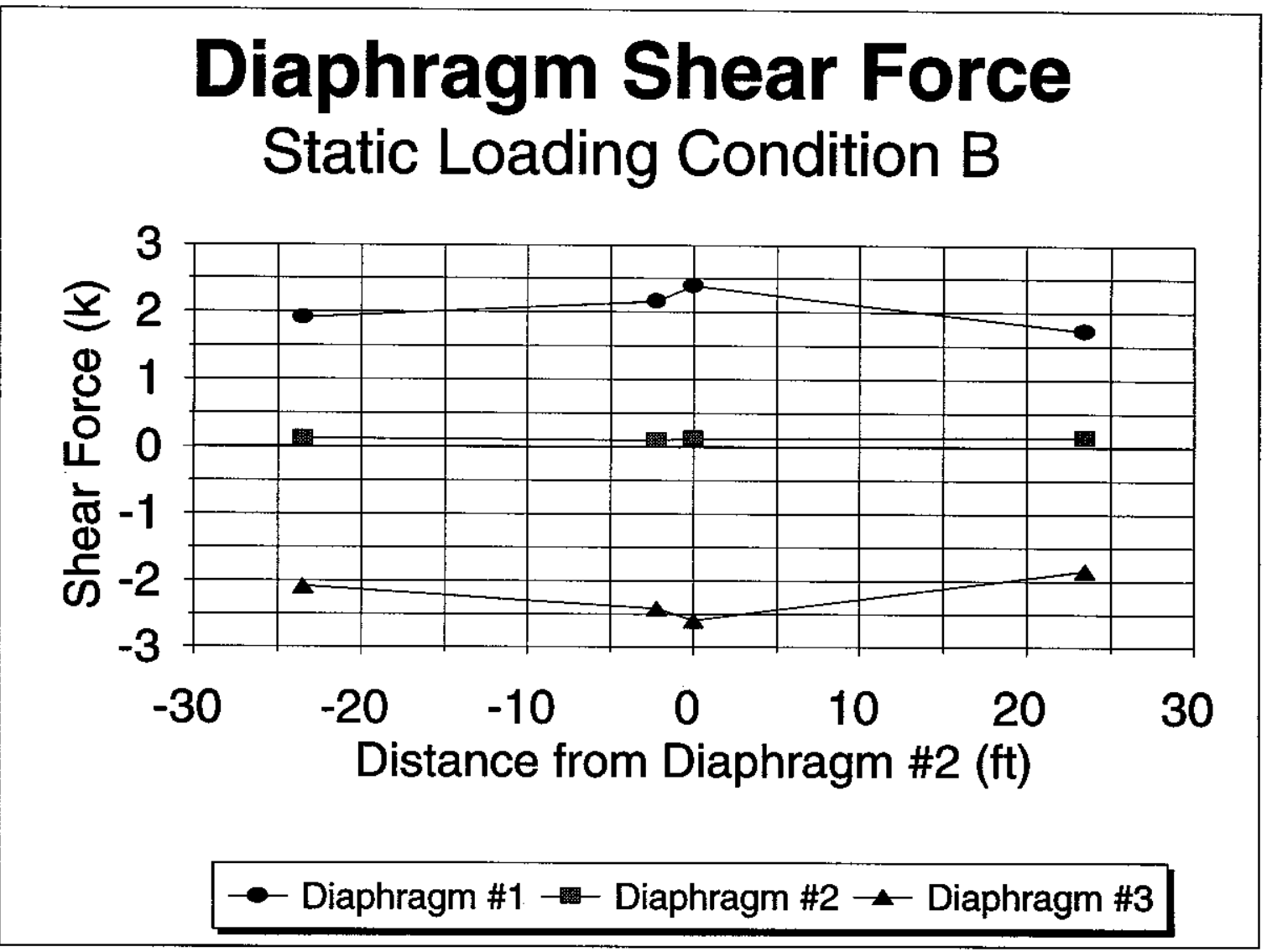

Figure C.2 - US 52 - Diaphragm Shear Forces for Static Loading Condition B 


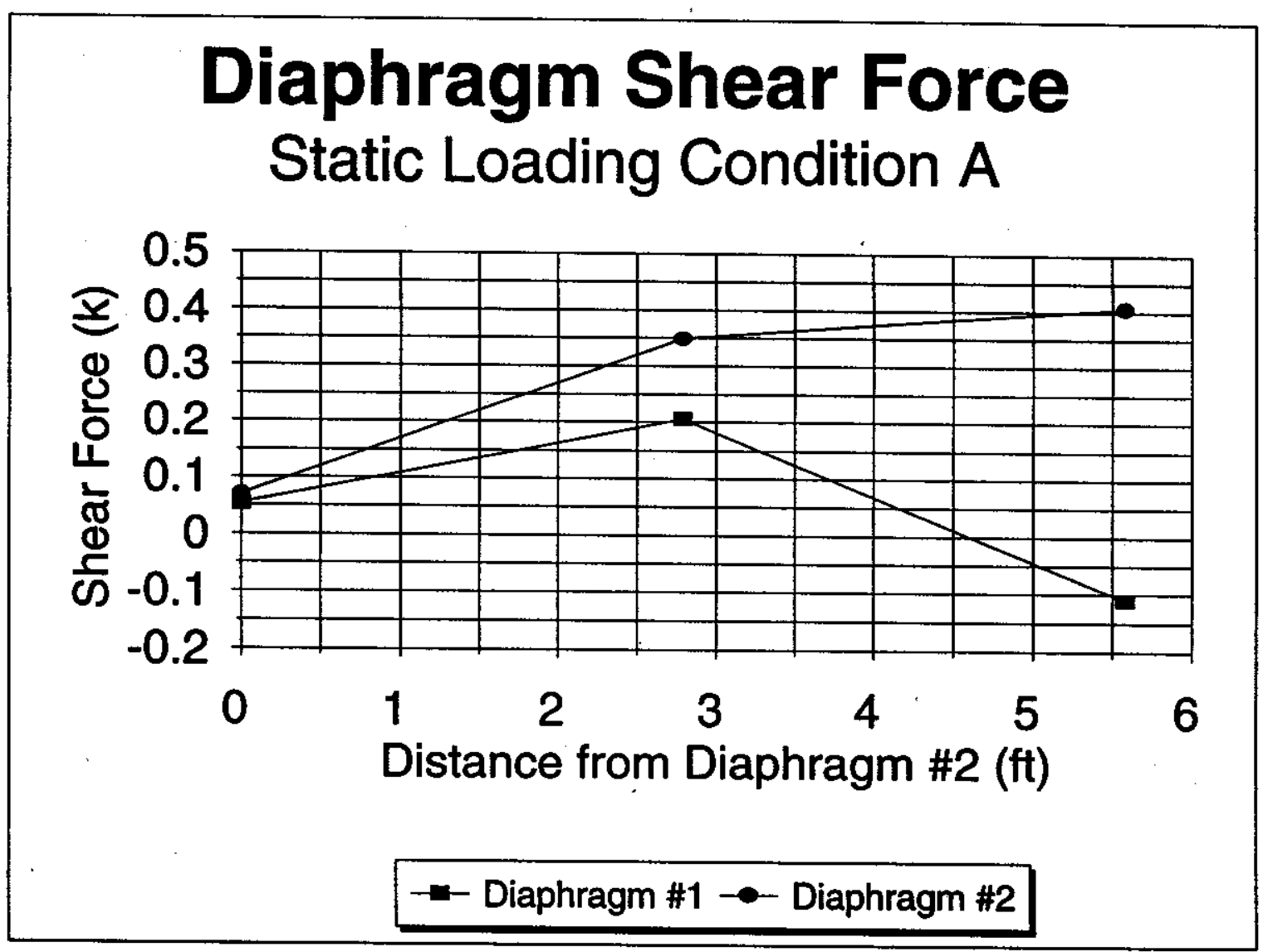

Figure C.3 - I 65 - Diaphragm Shear Forces for Static Loading Condition A 


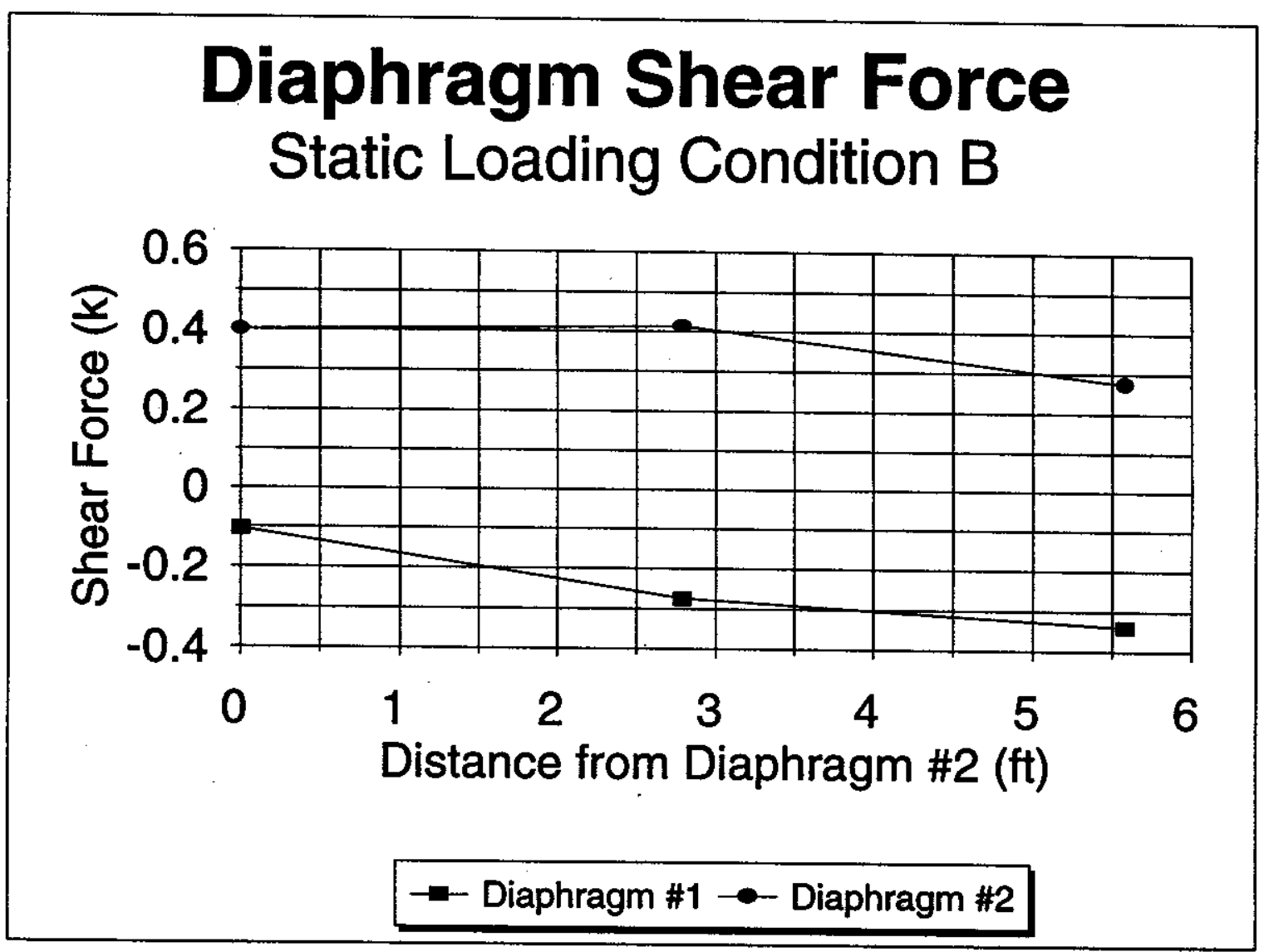

Figure C.4 - I 65 - Diaphragm Shear Forces for Static Loading Condition B 